University of Louisville

ThinkIR: The University of Louisville's Institutional Repository

$5-2015$

\title{
The effects of highly engaged field experiences and multi-faceted mentoring stategies on ameliorating pre-service teacher concerns.
}

Twyla Diane Harris

University of Louisville

Follow this and additional works at: https://ir.library.louisville.edu/etd

Part of the Curriculum and Instruction Commons

\section{Recommended Citation}

Harris, Twyla Diane, "The effects of highly engaged field experiences and multi-faceted mentoring stategies on ameliorating pre-service teacher concerns." (2015). Electronic Theses and Dissertations. Paper 2020.

https://doi.org/10.18297/etd/2020

This Doctoral Dissertation is brought to you for free and open access by ThinkIR: The University of Louisville's Institutional Repository. It has been accepted for inclusion in Electronic Theses and Dissertations by an authorized administrator of ThinkIR: The University of Louisville's Institutional Repository. This title appears here courtesy of the author, who has retained all other copyrights. For more information, please contact thinkir@louisville.edu. 
THE EFFECTS OF HIGHLY ENGAGED FIELD EXPERIENCES AND

MULTI-FACETED MENTORING STRATEGIES

ON AMELIORATING PRE-SERVICE TEACHER CONCERNS

By

Twyla Diane Harris

B. S., Belmont College, 1981

M. A., Western Kentucky University, 1983

Ed. S., Western Kentucky University, 2008

\author{
A Dissertation \\ Submitted to the Faculty of the \\ College of Education and Human Development \\ of the University of Louisville \\ in Partial Fulfillment \\ of the Requirements \\ for the Degree of \\ Doctor of Philosophy \\ in Curriculum and Instruction
}

Department of Middle and Secondary Education

University of Louisville

Louisville, Kentucky

May, 2015 
Copyright by

Twyla D. Harris

2015

All rights reserved 

THE EFFECTS OF HIGHLY ENGAGED FIELD EXPERIENCES AND

\author{
MULTI-FACETED MENTORING STRATEGIES
}

ON AMELIORATING PRE-SERVICE TEACHER CONCERNS

By

Twyla Diane Harris

B. S., Belmont College, 1981

M. A., Western Kentucky University, 1983

Ed. S., Western Kentucky University, 2008

A Dissertation Approved on

March 31, 2015

by the following Dissertation Committee

Dr. Thomas Tretter, co-chair

Dr. Samuel Stringfield, co-chair

Dr. Jennifer Bay-Williams

Dr. Vivian Moody 


\section{DEDICATION}

I dedicate this dissertation to my Lord and my family.

First, I wish to dedicate this dissertation to my Lord and Savior, for instilling in me a thirst for knowledge and the desire to share Your wonders to others. Without Your mercies, I couldn't have been able to endure the trials or to succeed in such marvelous ways.

I also want to dedicate this work to my parents, Alfred and Normalee Green, for supporting all my educational endeavors. Without your support, guidance, and prayers I would not be where I am today. I am proud to be your daughter.

Finally, I wish to dedicate this study to my wonderful husband, and my beautiful daughters. You three are my reason for living. Without your unfailing support, guidance, and counsel, I would not have been able to achieve so much. Thank you, Steven, for pushing me to do my best and for being so strong for both of us. I pray that you are proud of our hard work! To my children, Alicia and Jessica, I am grateful that I had your neverending encouragement. Thank you for becoming my friends and my sounding board. Thank you, both for sharing this time with me, as we venture into the unknown to follow our dreams. I hope I have been able show you that, even though the trip isn't always easy, becoming what we were born to be is definitely worth it.

God bless you all. 


\section{ACKNOWLEDGEMENTS}

With great respect, admiration and appreciation I would like to acknowledge the members of my dissertation committee. I would like to thank my co-chairmen, Dr.

Stringfield, Dr. Bush, and Dr. Tretter. Dr. Samuel Stringfield has supported me from the very beginning. With his encouragement, I was able to move from a rough idea to a completed study. I also wish to thank Dr. Bush for the outstanding job he did in editing my drafts and helping to become a better research writer. I offer up many thanks to Dr. Tretter for stepping in to help me see this dissertation to its completion. Dr. Jennifer BayWilliams was always my advocate. She embodied the idea of what a strong female leader should be. Dr. Vivian Moody offered her encouragement when the task seemed daunting. I also wish to thank Mr. Bob Cobb for providing invaluable statistical advice.

I am grateful for Rico Tyler, Dr. Kanita DuCloux and David Bell for supporting my efforts by allowing me to gather data during their class meetings. In addition, I wish to express my appreciation to all the pre-service teachers for being so honest about their personal concerns about teaching. Their insights will help future generations of teachers as they train for this worthy profession. I would also like to thank my colleagues in the WKU Mathematics department who were always there to direct my path and encourage me to reach new heights.

Finally I wish to express my appreciation to Mrs. Joy Curtis, for the many memories we shared during our doctoral classes and to her family for sharing their time and home with us during the summers. 


\begin{abstract}
THE EFFECTS OF HIGHLY ENGAGED FIELD EXPERIENCES AND MULTI-FACETED MENTORING STRATEGIES

ON AMELIORATING PRE-SERVICE TEACHER CONCERNS
\end{abstract}

Twyla D. Harris

March 31, 2015

Mathematics and science teachers leave education more than teachers in other fields (Alliance for Excellent Education, 2008). Job-related stress and burn-out can attribute to early attrition in veteran teachers and pre-service teachers (PSTs) (e.g. Fives, Hamman, \& Olivarez, 2007; Gold, 1985). A strategy for addressing attrition is to reduce self-preservation concerns in pre-service education programs.

This study used a mixed-methods quasi-experimental research design to examine two STEM teacher education programs, with the long-term goal of improving STEM teacher retention. The first, "SkyTeach", incorporated instructional experiences and an assortment of mentoring models prior to student teaching. The second program utilized primarily observational field experiences and academic advisors preceding student teaching. This study investigated how engaged field experiences and multi-faceted mentoring impacted pre-service teacher concerns.

Concerns measured included self-preservation, task-related, and impact concerns. Quantitative results showed no significant differences between Traditional and SKyTeach 
pre-service teachers (PST) on any concern before student teaching. Both programs possessed moderate levels of individual concerns. A qualitative investigation into self-preservation concerns revealed that Traditional PSTs recorded mainly content concerns; whereas SKyTeach PSTs primarily noted respect concerns before student teaching. Qualitative findings denoted a shift in Traditional PSTs' concerns from content to respect concerns, whereas SKyTeach self-preservation concerns essentially disappeared by end of student teaching.

Impacts of mentoring and field experiences on self-preservation concerns were investigated. Before student teaching, Traditional PSTs experienced primarily observational experiences; whereas, SKyTeach PSTs had instructional practice experiences. Those PSTs with more instructional practices concluded that they were not intimidated by the upcoming teaching experience. Traditional PSTs identified academic advisors as mentors and SKyTeach identified a variety of mentors prior to student teaching. During student teaching, both programs stated their primary mentors were their cooperating teachers and university supervisors. SKyTeach PSTs also relied on SKyTeach Master Teachers as a secondary source of counsel. This evidence indicated that the presence of a trained mentor reduced self-preservation concerns.

This study found having a mentor who provided a triad of support coupled with the focused observational and instructional field experiences helped reduce self-preservation concerns among PSTs before student teaching. 


\section{TABLE OF CONTENTS}

DEDICATION ........................................................................

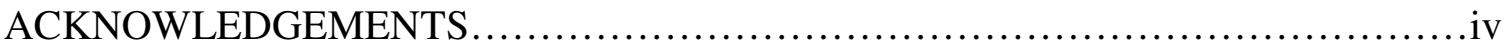

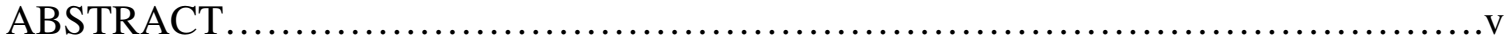

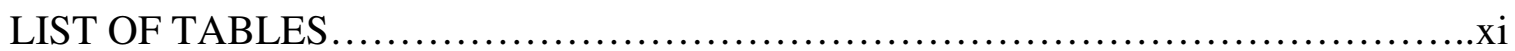

LIST OF FIGURES ..............................................................

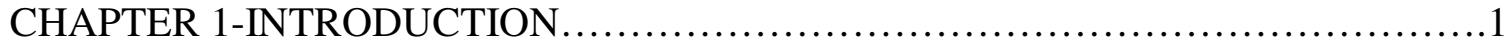

Background of the Study .......................................................

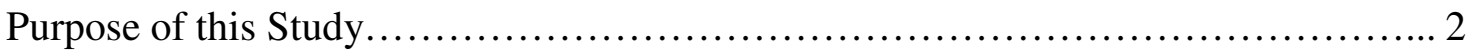

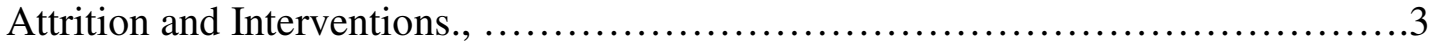

Teacher Concerns and Attrition Characteristics................................... 4

Two Programs of Study. ......................................................

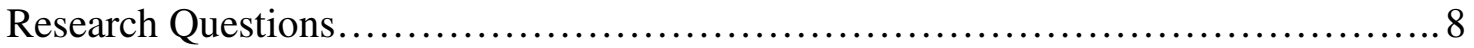

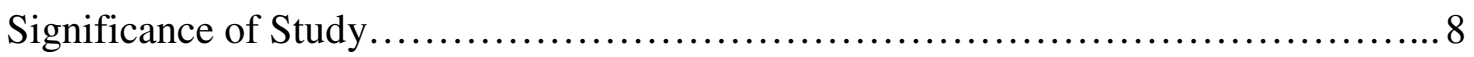

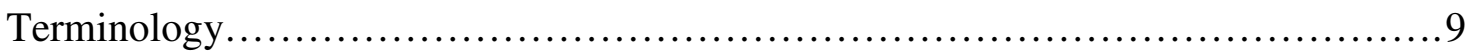

CHAPTER 2-REVIEW OF LITERATURE.......................................12

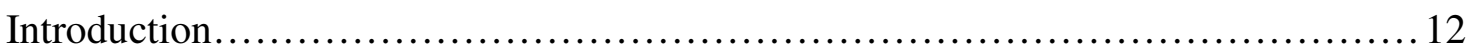

Conceptual Framework.................................................... 15

Teacher Career Trajectory ......................................................

Professional Teacher Career Trajectories. .......................................16

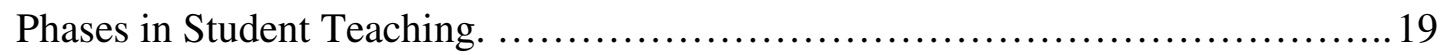

Attrition Rates and the Induction Programs....................................22

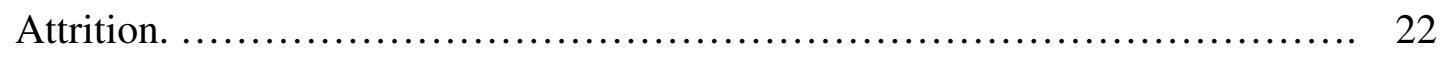

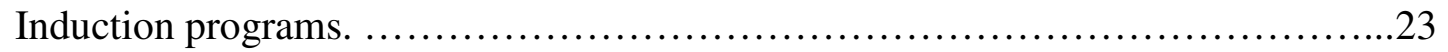

Teacher Concerns and Self-Efficacy Beliefs.................................... 25

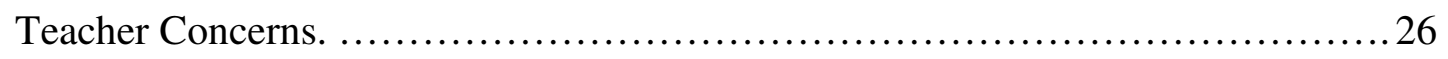

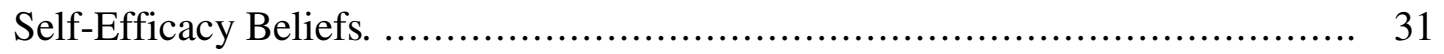


Studies integrating teacher concerns and efficacy beliefs....................... 33

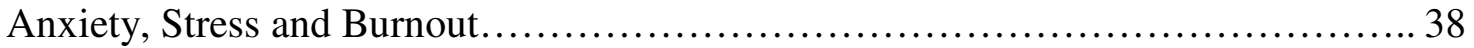

Affective Attrition Characteristics.......................................... 39

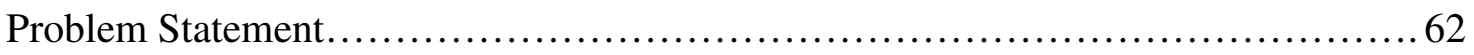

A New Vision of STEM Teacher Programs.................................... 63

Different Interpretations to Educational Program Structures....................6 64

Two Key Components: Field work and Educational Mentoring.................. 66

Early Field Experiences................................................. 66

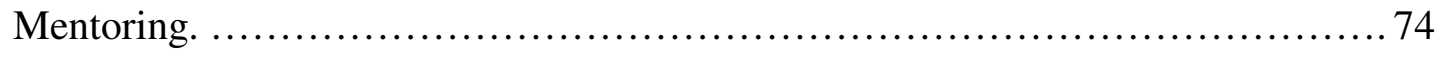

The UTeach Institute. ............................................... 88

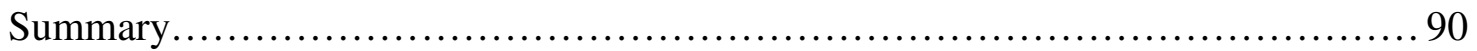

Characteristics of the two contrasting programs............................. 95

The Traditional Program................................................ 95

The SKyTeach Program...................................................... 98

CHAPTER 3-METHODOLOGY ........................................... 106

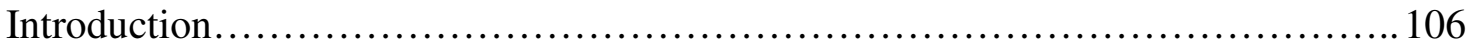

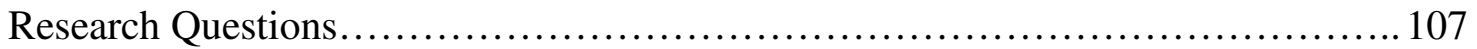

Research Design...................................................... 108

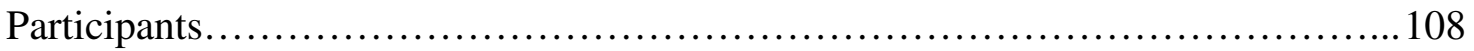

Instruments............................................................. 110

Interviews........................................................ 111

Developing the Semi-structured interviews. ............................ 111

Semi-structured Interviews Executed. .................................. 112

The Teacher Concern Survey............................................ 117

Validity and Reliability of the TCC Survey. ................................ 117

Reflective Journaling Using Blackboard. ................................ 120

Data Collection Procedures............................................. 120

Data-Analysis Procedure. ................................................ 125

CHAPTER 4-RESULTS OF TEACHER CONCERNS ............................. 127

Demographics of the Quantitative Study Participants.......................... 128

Teaching Concerns of Traditional and SKyTeach PSTs.........................129 
Quantitative Results of Teacher Concerns. ................................ 129

Qualitative Results of Teacher Concerns. ................................. 136

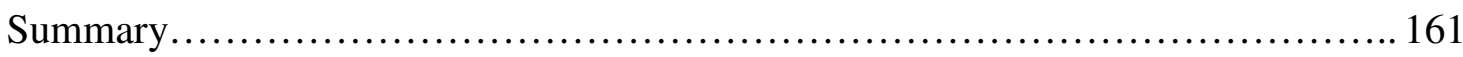

CHAPTER 5-RESULTS OF FIELD EXPERIENCES AND MENTORING............164

Field Experiences Perceived as Effective in Helping Reduce Self-Preservation

Concerns............................................................ 166

Instructional and Observational Field Experiences............................169

Beneficial Observational and Instructional Practices....................... 176

Summary of Early Field Experiences.................................... 181

Mentoring Experiences Perceived as Effective in Helping Reduce Self-Preservation

Concerns............................................................ 184

Summary of Mentoring Aspects of Each Program................................ 198

CHAPTER 6-DISCUSSION ................................................... 200

Concerns of Preservice Teachers........................................ 201

Self-Preservation Concerns...................................................205

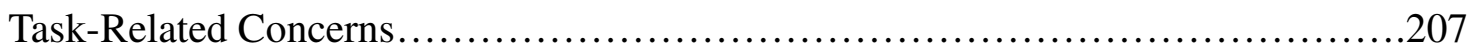

Student-Impact Concerns...............................................209

Summary of Teacher Concern Results...................................... 211

Reducing Self-Preservation Concerns before Student Teaching................... 214

Mentoring Effects on Self-Preservation Concerns before Student Teaching....... 216

Field Experiences Effects on Self-Preservation Concerns before Student Teaching.

Reducing Self-Preservation Concerns during Student teaching.................... 224

Mentoring Effects on Concerns after Student Teaching...................... 226

Field Experience Effects on Concerns after Student Teaching.................. 228

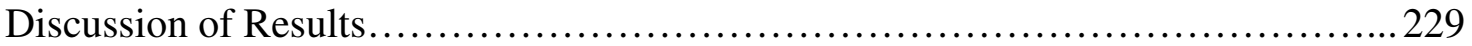

Self-Preservation Concerns were Different Between Programs.................... 229

The Importance of Trained, Effective Mentoring Practices.......................230

The Importance of Early and Engaged Field Experiences........................231

Generalization and Limitations of the Study................................232

Generalization...................................................... 232

Methodological Limitations.................................................. 234 
Implications for Future Research........................................ 236

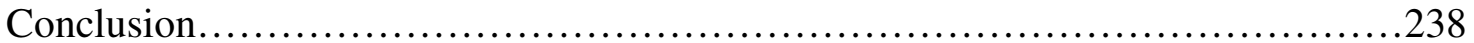

Components of PST Programs Which Do Not Show Evidence of Reducing Self-

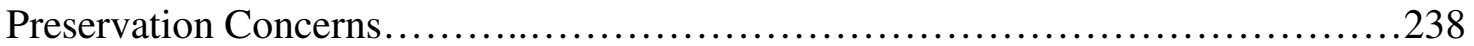

Necessary Components of PST Programs Which Show Evidence of Reducing Self-

Preservation Concerns........................................................239

REFERENCES............................................................ 242

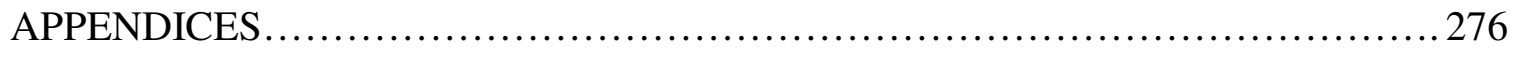

A. Initial Interview Questions............................................276

B. Final Interview Questions..............................................280

C. Qualitative Coding .................................................. 283

D. Teacher Concerns Checklist........................................... 287

E. Assorted Tables of Concern........................................... 298

CURRICULUM VITA.................................................... 300 


\section{LIST OF TABLES}

TABLE

PAGE

Table 1. Comparison of Characteristics of Programs ................................................. 105

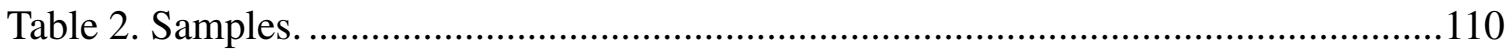

Table 3. Timeline to be used for Interviews (Spring 2011-Fall 2012)...........................114

Table 4. Timeline to be used for Data Gathering (Spring 2011-Fall 2012) .................... 121

Table 5. Mean (S.D.) Scores of Overall Concerns Before and After Student Teaching. 131

Table 6. Mean (S. D.) Scores of Self-, Task-, and Impact-related Concerns.............134

Table 7. Ratio of Responses related to Self-Preservation Concerns Throughout the Study

Table 8. Summary of Self-Preservation Sub-Themes Comments .141

Table 9. Reoccurring Sub-Themes Responses Relating to Self-Preservation Concerns 144

Table 10. Ratio of Responses related to Task-Related Concerns throughout the Study. 149

Table 11. Summary of Task-Related Sub-Themes Comments .....................150

Table 12. Reoccurring Sub-Themes Responses Relating to Task-Related Concerns ..... 152

Table 13. Ratio of Responses related to Student-Impact Related Concerns .............155

Table 14. Summary of Student-Impact Sub-Themes Comments................................ 157

Table 15. Sub-Themes Responses Relating to Student-Impact Related Concern.......158 
Table 16. Percentages of Different Types of Early Field Experiences 168

Table 17. Summary of Field-Experiences Type Comments ............................................170

Table 18. Perceived Beneficial Characteristics of Field Experiences ...................173

Table 19. Sub-Types of Beneficial Early Field Experiences. ...........................................178

Table 20.Statements which Identified Mentors of the Traditional and SKyTeach Programs 185

Table 21. Perceived Characteristics of WKU Mentors and University Sponsored Mentors 192

Table 22. Summary of Mentoring Comments 196 


\section{LIST OF FIGURES}

FIGURE

PAGE

Figure 1. Data collection procedure for interviews ...............................................116

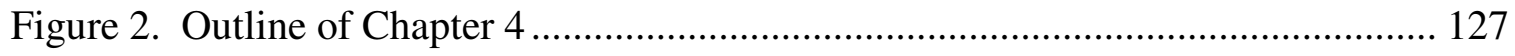

Figure 3. Quantitative measures of teacher concerns between \& within programs ...... 130

Figure 4. Qualitative measures of self-preservation teacher concerns ....................... 138

Figure 5. Outline of major topics of Chapter 5...................................................... 165

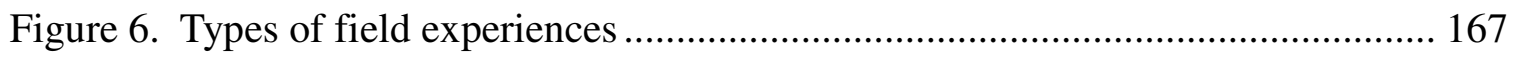

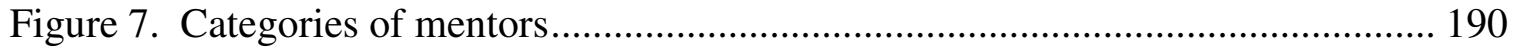




\section{CHAPTER 1}

\section{INTRODUCTION}

\section{Background of the Study}

According to the Business-Higher Education Forum (BHEF, 2006), the shortage

of middle and high school secondary mathematics and science teachers continues to be a major issue in the American school systems. This forum estimated that by the year 2015 a shortage of 283,000 secondary mathematics and science teachers will exist. Currently teachers in the science, technology, engineering, and mathematics (STEM) fields leave education after relatively short terms as teachers at an alarming rate.

In addition to other possible variables such as more lucrative non-teaching opportunities, overwhelming job anxiety, stress, and burn-out seem to also be some key sources of this pattern of early attrition. Together, these affective characteristics relate to a teacher's high levels of self-preservation concerns towards launching a teaching career. Teachers who have left the profession report early "burn-out" during their pre-service training or first years of teaching (Gold, 1985). Studies have shown that this early appearance of the "burn-out syndrome" can be attributed to: (a) unrealistic expectations, (b) lack of mentoring support, and/or (c) low content knowledge (Fives, Hamman, \& Olivarez, 2007; Murray-Harvey, Slee, Lawson, Silins, Banfield, \& Russell, 2000). Preservice secondary mathematics and science teacher education programs that concentrate on content knowledge, pedagogical knowledge, and pre-service teachers' concerns related to self-preservation are needed. 


\section{Purpose of this Study}

The purpose of this study was to identify the kinds of teacher concerns that pre-service teachers (PSTs) had and to what extent these concerns remained until the end of two different STEM middle and secondary pre-service education programs. Among these concerns, of particular interest was a focus on self-preservations concerns. Both programs studied in this dissertation were implemented simultaneously at a south-central state university.

One specific area of exploration focused on how these programs addressed retention issues of student teachers by providing support that may reduce teaching concerns as they progress into their professional teaching fields. In particular, this study examined whether the existence of a combination of two key components, highly engaged field experiences and multi-faceted mentoring strategies, minimized concerns and reduced beginning anxiety, stress, and burnout symptoms before the student teaching experience. Assessment of these key components took place both before and after the student-teaching experience in order to bracket these components within the teacher education programs. According to Smith and Ingersoll (2004), the presence of quality experiences, such as the combination of these two components, may increase the likelihood of PSTs remaining in the teaching profession beyond the national average.

In the following sections, an outline of the attrition of teachers will be provided. In particular STEM middle and high school teachers' attrition rates will be explored. Next, intervention programs at the professional and preservice levels will be described. Also attrition issues in recently designed teacher education curricula will be discussed. This will be followed by a summary of Fuller's (1969) teacher concerns model. The 
characteristics of teachers that leave the teaching profession due to "anxiety," "stress" and "burn-out" tendencies will be discussed. Interestingly, novice pre-service teachers (PST) can also possess some early signs of these tendencies. This section will continue by offering suggestions for reducing these tendencies in the curriculum for PSTs, in the hopes of decreasing future attrition rates. Finally, this portion will conclude with specific research questions, the significance of this study, and definition of terms that were used throughout this document.

Attrition and Interventions. The mathematics and science teacher shortage predicted in the BHEF (2006) can only be partially explained by retirement. According to recent data (Alliance for Excellent Education, 2008), only one-third of retiring teachers account for the attrition rates in education. The remaining two-thirds were teachers who transferred from teaching or left teaching primarily because of unsatisfactory working conditions. Approximately $14 \%$ of teachers left after their first year of teaching, and nearly 50\% left within five years (Henke, Chen, \& Geis, 2000; Ingersoll, 2003a; Rogusky, 2003: Steffy \& Wolfe, 2001).

Other studies reported that new teachers in the mathematics and science, especially those with academically strong credentials, were $10 \%$ more likely to leave teaching because of lack of financial gain or professional support, than those in other teaching fields (Alliance for Excellent Education, 2008; Smith \& Ingersoll, 2004). Other reasons cited for leaving teaching included dissatisfaction with the profession or feelings of inadequate preparation for the work (Alliance for Excellent Education, 2008; Henke, Chen, \& Geis, 2000; Smith \& Ingersoll, 2004). 
In recent years, school systems have implemented induction programs to address these shortcomings (i.e. Alliance for Excellent Education, 2008; Brewster \& Railsback, 2001; Looney, 2011; Russell, 2006). More recent comprehensive induction programs have proven most successful in lowering attrition rates among new teachers. These induction programs include an inclusive plan incorporating additional teacher training, support systems involving more qualified teachers or professionals, and some form of end-of-year assessment technique (Alliance for Excellent Education, 2008; Brewster \& Railsback, 2001).

Henke and Zahn (2001) suggested that reducing attrition should begin during pre-service teacher programs. To enhance teacher preparation, pre-service STEM educational programs have taken a more holistic view in their curriculum design (e.g. Darling-Hammond \& McLaughlin, 1995). In order to gain a full sense of the impact that a teacher education program has on the development of the PST, teacher educators have increased focus on the cognitive, psychomotor, and affective components of pre-service mathematics education courses. In particular, an increased awareness as to how the affective domain influences teachers' performances in the classroom has emerged. The affective domain is defined as the role that sentiments, emotions, and feelings influence the progress of a teacher. Recommendations from this division of education include suggestions of having specific affective objectives developed for mathematics teachers' educational courses which focus on the growth in attitudes, beliefs and feelings toward teaching mathematics (Brahier, 2009; Miller, 2005).

Teacher Concerns and Attrition Characteristics. Empirical research has revealed links between teacher maturity evident in the affective domain arena and the 
corresponding level of teachers' concerns as first recognized by Fuller (1969).

Researchers found that teacher concerns evolved into three developmental stages:

(a) self-preservation; (b) task-related issues; and (c) impact on pupil needs and the effects of teaching (Fuller, Parsons, \& Watkins, 1974). Several studies (e.g. Adams \& Martray, 1981; Bunendwa, 1996; Conway \& Clark, 2003) found that teachers' concerns appear to be sequential in nature. Less experienced teachers seemed to possess more self-preservation concerns; whereas more experienced teachers appeared to be concerned about the impact that their teaching had on student learning. Borich (1996) observed that lack of support during pre-service training hampered the PSTs' transition from self-preservation concerns to student-driven concerns. When an interruption in this progression was evident, or a series of events caused a delay in this progression, PSTs developed characteristics that could contribute to early attrition. Increased levels of "anxiety," "stress," and "burn-out" seemed to influence the progression of teachers' concern characteristics. The following section provides a brief summary of each tendency and how these inclinations relate to signs of early attrition.

Anxiety. Teacher anxiety has been described as a cognitively, motorically, or physiologically tension reaction to circumstances in the classroom (Coates \& Thoresen, 1976). It can be manifested in three ways: (a) cognitively, through negative or frightful thoughts and images; (b) physiologically, through increased heart rate, rapid respiration and perspiration; and (c) motorically, through stuttering, shaking, and increased muscle tension. While conducting a literature review on the components of test anxiety, Wine (1971) noted that teachers who were more prone to anxieties during evaluations were also more self-preoccupied than those who were less anxious. 
Teacher anxiety was also related to styles of teaching. Teachers who possessed a higher level of anxiety tended to be more dogmatic (Campbell \& Williamson, 1973; Rokeach, 1960; Soderberg, 1964). Furthermore, these teachers could extend their anxiety traits onto their students (Beilock, Gunderson, Ramirez \& Levine, 2010). In a seven-year study, Marso and Pigge (1998) linked attrition to higher levels of teacher anxiety during the early stages of professional teaching.

Stress. The presence of stress has long been recognized as a healthy approach to daily demands placed on the body; however, too much stress or prolonged periods of stress can be detrimental to physical and emotional well-being (Dohrenwend \& Dohrenwend, 1981) . Several studies (e.g. Borg, Riding, \& Falzon, 1991; Schonfeld, 1990; Troman \& Woods, 2000) revealed that high stress levels in conjunction with related job dissatisfaction, served as a primary reason that teachers left the profession, mostly during their novice years.

Burnout. Many teachers who have left teaching claimed to experience early "burn-out" during their pre-service training or novice years. Studies have shown that early "burn-out syndrome" can be attributed to: (a) unrealistic expectations; (b) lack of mentoring support; and/or (c) insufficient content knowledge (Fimian \& Blanton (1987; Fives, Hamman, \& Olivarez, 2007; Gold, 1985; Murray-Harvey, Slee, Lawson, Silins, Banfield, \& Russell, 2000).

These studies also indicate that many negative characteristics occur during pre-service training (e.g. Fives, Hamman, \& Olivarez, 2007; Gold, 1985). Suggestions for reducing these characteristics have included: stress management techniques; increasing the number of field experiences; and implementing effective mentoring 
programs during pre-service teaching experiences and in induction programs (Greer \& Greer, 1992). However, supporting evidence of teacher concerns of STEM teachers was lacking. Interestingly, components of pre-service teachers' curriculum could significantly lower these concerns and attrition tendencies before entering their teaching career (Greer \& Greer, 1992). The present study focused the extent to which increasing the number of highly engaged field experiences and amount of quality mentoring during a preparation program reduced teachers' self-preservation concerns, and consequently, reduced attrition tendencies before they began teaching professionally.

Two Programs of Study. This study looks at the effects of highly engaged field experiences and multi-facet mentoring strategies on reducing the self-preservation concerns of pre-service teachers. In order to conduct an investigative approach, PSTs were chosen from two STEM preservice programs that were being implemented at Western Kentucky University (WKU). The first pre-service program, known as SKyTeach, incorporated instructional experiences and an assortment of mentoring models, prior to student teaching. The second program, known in this study as the Traditional program, utilized primarily observational field experiences and academic advisors preceding student teaching. Using student-teaching candidates from these two programs, this study will investigation how two particular components of these two programs will aid in reducing self-preservation concerns. 


\section{Research Questions}

The research questions for this study are:

RQ1: What is the nature and level of pre-service teacher (PST) concerns about teaching for PSTs in the traditional STEM program and PSTs in the SKyTeach program, at two key points in their program: immediately prior to and upon completion of the student-teaching experience?

RQ2: How and to what extent does SKyTeach's emphasis on high-engagement field experiences, compared to the relative absence in the traditional program, affect self-preservation concerns of senior pre-service teachers prior to entering and upon completion of their student-teaching experiences?

RQ3: How and to what extent does SKyTeach's emphasis on systematic, intentional support of trained mentors, compared to the relative absence in the traditional program, affect self-preservation concerns of senior pre-service teachers prior to entering on and upon completion of their student-teaching experiences?

\section{Significance of Study}

Since its conception, UTeach has been found to produce highly qualified STEM middle and secondary teachers who remained in the teaching profession longer than the national average (National Mathematics and Science Initiative, 2012). Proponents of UTeach have reported that its accomplishments are based on nine "Elements of Success." Some universities have become replications sites of the UTeach program during the last decade; others have opted to adopt similar programs; and still others have embraced only 
portions of UTeach. The SKyTeach program, investigated as one of the teacher preparation programs in this study, was based on the UTeach model. This program included two major components of interest emphasized in this study -continuous highly-engaged field experiences, and first-class incessant mentoring by skilled, trained teachers. This study explored the significance of these two major components of the UTeach model, with regard to their impact on the success of the program. By concentrating on these two key components of the UTeach model, compared to a more traditional PST STEM program lacking the same rigor of these components, this study will seek to determine which components are necessary to reduce self-defeating apprehensions or strengthen self-efficacy traits of pre-service teachers so their attention can be directed to effective teaching practices. The extent to which continuous highly-engaged field experiences and multi-faceted mentoring by skilled, trained teachers also strengthened the resolve to move away from possible attrition caused by anxiety, stress, or burnout will be investigated.

\section{Terminology}

Attrition: A reduction in number of employed teachers due to teachers who leave the profession permanently without administrative dismissal or by retiring.

Early Field Experience: Observation experiences or active instruction experiences executed by pre-service teachers at times other than, and usually prior to, the student-teaching experience.

IEP: Individualized Education Plan written for a child with a disability.

Mentor: Person who gives academic, personal, or professional advice, usually to a novice. In this study, the novice is recognized as a pre-service teacher. 
Master Teacher: An employee of the university who serves as an instructor and academic, professional, and emotional mentor to SKyTeach students.

NMSI: National Mathematics and Science Initiative. An organization begun in 2007 and financially backed by private investors such as Exxon Mobile Corporation, the Bill and Melissa Gates Foundation, and the Susan Dell Foundation for the purpose of preparing more students in STEM educational positions by replicating successful STEM educational programs.

PST: Pre-service teacher. In this study, a pre-service teacher is an undergraduate student who is attending classes and training in a higher education institution to obtain a teaching certificate.

SAS: Statistical Analysis System. SAS is a statistical software program that operates on both PC and UNIX platforms (Salkind, 2010). This statistical software program was used to analyze the quantitative components of this study.

SKyTeach: The STEM middle and secondary pre-service teacher curriculum implemented at Western Kentucky University beginning in 2008. It was a replication of the UTeach program developed at the University of Texas at Austin. Of particular interest for this study are two components of SKyTeach: highly engaged continuous field experiences and multi-faceted mentoring strategies used by skilled, trained teachers.

SMED: Science and Mathematics Education courses developed by the UTeach Institute and adopted by SKyTeach Program that incorporated an inquiry-based approach. This term may also refer to the Science and Mathematics Education major required by SKyTeach pre-service teachers. 
STEM: Science, Technology, Engineering, and Mathematics.

Student Teaching: The culminating supervised instructional school-based experience conducted before receiving an educational degree and teaching certificate from a higher education institution.

TCC: Teacher Concern Checklist. A quantitative survey developed by Fuller and Parsons (1974) to measure the level of teachers' concerns in three areas.

Traditional Program: The middle and secondary STEM pre-service teacher curriculum implemented at Western Kentucky University from 1989 until 2011. This program did not include the same intensity and rigor of field experiences and mentoring as SKyTeach and serves as the comparison program for purposes of this study.

UTeach Institute: A middle and secondary pre-service STEM teacher curriculum created in 1997 at the University of Texas at Austin.

Veteran Teacher: A middle or secondary teacher who serve as a short-term mentor with in the SKyTeach curriculum. Assignments usually last one semester.

WKU: Western Kentucky University, a regional state university located in Bowling Green, Kentucky. 


\section{CHAPTER 2}

\section{REVIEW OF LITERATURE}

\section{Introduction}

Middle and high schools in the United States are suffering from a national crisis with regards to teacher shortages in mathematics and science. The National Science Foundation (NSF, 2008) reported that $74 \%$ of public secondary schools had teacher vacancy positions in mathematics and 52\%-56\% had vacant positions in biology/life sciences and physical sciences. Not since the sixties, with the advent of NASA and its Apollo missions, has the desire to improve mathematics and science programs in the public schools been as urgent as in the last decade (Sanders, 2004).

The Business-Higher Education Forum (BHEF, 2006) predicted that by the year 2015 , a shortage of 283,000 secondary mathematics and science teachers would exist. This staggering statistic can only be partially explained by retirements. One-third of the teachers retiring this decade were those who entered classrooms during the historical period of the sixties. The remaining two-thirds cited working conditions as the primary reason that they either transferred or left the profession permanently (Alliance for Excellent Education, 2008). Research found that $14 \%$ of the teachers leave after their first year of teaching, 33\% leave by their third year, and about $50 \%$ leave within five years (Huling-Austin, 1986; Ingersoll, 2003a; Rogusky, 2003: Steffy \& Wolfe, 2001). 
The National Commission on Teaching and America's Future (Rogusky, 2003) defined teacher attrition as one of the most critical problems in the teaching profession. The Commission noted that up to $57 \%$ of mathematics and science teachers leave because of job dissatisfaction and around 29\% leave for professions outside teaching (Alliance for Excellent Education, 2008; Ingersoll \& Perda, 2009). These troubling statistics revealed a need for developing programs to encourage young teachers to stay in the classroom.

Teachers with strong educational credentials were found to be more likely to stay in the classroom (Alliance for Excellent Education, 2008). Sanders (2004) realized that those teachers with strong backgrounds in their subject matter develop more depth in their teaching, which translates into student understanding. Teachers obtaining degrees in their field of expertise were more likely to have the knowledge to make classroom experiences informative and interesting. Unfortunately, 20-25\% of secondary science and mathematics teachers did not possess at least a minor in their teaching area (National Commission on Mathematics and Science Teaching for the $21^{\text {st }}$ Century, 2000).

Having qualified teachers in the classroom may seem obvious, but many inexperienced teachers were not comfortable teaching mathematics and science upon graduation from college. A survey conducted by the Bayer Corporation reported that only one-third of the schools polled offered an algebra class at the eighth-grade level (Sanders, 2004). One explanation offered by Schmidt, Burroughs, and Cogan (2013) was that many middle school teachers do not receive adequate mathematics training, with three-fifths graduating from the bottom quarter of the United States mathematics teacher preparation programs. Other studies (e.g. Kaufman, \& Moss, 
2010; Simonsen, Briere, \& MacSuga-Gage, 2013) showed that many PSTs graduate without being adequately prepared to effectively manage student behavior resulting in increases teacher distress levels. Programs which continue to produce novice teachers that are ill equipped to adequately teach mathematics topics or handle the daily pressures of the educational profession increased the chances of teacher attrition. Well prepared teachers were more likely to remain in the teaching profession and produce higher levels of student success rates (NCATE, 2013).

Having content knowledge is a fundamental principle for teaching any subject, but the value of pedagogical training is paramount in predicting student achievement gains (Allen, 2003; NCATE, 2013). Research on the value of having a solid foundation in content knowledge and its influence on student success has been a topic of discussion, primarily in the field of mathematics. Findings indicate that having a strong foundation in the subject offers moderate support for student success (Allen, 2003). However, having a strong content foundation in mathematics and science, coupled with pedagogical courses based on these fields, positivity relates to higher levels of student achievement (Goldhaber, 2006; Monk, 1994). In addition to increasing student success, having some pedagogical training helps reduce early teacher attrition (Ingersoll, 2003c).

Finding a way to keep up with the demands of our increasing population of middle and high school STEM classrooms with teachers who are knowledgeable and pedagogical skilled in the nuances of their fields is critical. Given the consensus about the importance of mathematics and science education, teacher educators and school administrators must examine factors that lead novice teachers to leave the profession, as well as those factors that will attract them to and keep them in the profession. 


\section{Conceptual Framework}

The conceptual framework upon which this project was based focused on the developmental nature of career trajectories of teachers. Theorists suggest that the career paths of teachers follow somewhat predictable patterns, up to and including teachers' decisions to stay in or leave the profession. To the extent that such patterns can be identified and observed, key variables associated with these trajectories might also be identified and ultimately altered in ways that decrease the odds of teachers leaving the profession.

The following sections will begin by describing different perspectives of teacher career trajectory categories and the developmental characteristics of each. A description of how student teachers have similar developmental characteristics will also be discussed. This discussion will be followed by an introduction to the problems of attrition among teachers, particularly among mathematics and science teachers at the middle and high school levels. A summary of how school systems presently use induction programs to lessen attrition will be offered. For this discussion, the broader term 'science, technology, engineering, and mathematics' (STEM) will be used to refer to teachers who work in any of these fields at the middle and high school levels. This section will be followed by discussions of teachers' concerns, as outlined by Fuller (1969), and teacher self-efficacy, as discussed by Guskey and Passaro (1994). The connections among these characteristics and the characteristics of teachers who leave the teaching profession due to increased levels of "anxiety," "stress," and "burn-out" will also be explored. A description of how student teachers also possess early signs of these tendencies will be presented. This portion of the chapter will include techniques that may reduce such 
tendencies in in-service teachers and a proposal of which induction methods should be introduced during STEM pre-service training to begin alleviating these tendencies. The chapter continues with an outline of concepts that universities use to re-envision how STEM teacher programs might be structured. Attention will be drawn to one program's attempt to address these concerns in the STEM pre-service teacher curriculum as a possible means to reduce attrition rates. It includes a robust content and pedagogical basis as well as strong mentor support and extensive field experiences. These latter components will be discussed at length, and their specific purpose, rationale, and theoretical basis in the replication programs will be highlighted.

\section{Teacher Career Trajectory}

Developmental changes follow many different paths and include both cognitive and conceptual growth (Greeno, 2007; Piaget, 1971; Schaie; 1979) or growth in values, ego, and interpersonal relations (Kohlberg, 1969; Loevinger, 1966; Selman, 1980). For this study, these types of changes will be used as developmental foundations for teacher career decisions. It is important to note that while developmental change tends to grow linearly, career trajectories can be revisited several times throughout one's career.

Professional Teacher Career Trajectories. Teaching career trajectories have been described in multiple ways (Berliner, 1988; Brand, 1983; Burke, Christensen, \& Fessler, 1984; Cady, Meier, \& Lubinski, 2006; Caruso, 1977; Kagan, 1992; Katz, 1972; Lynn, 2002). The majority of these studies found that most teachers follow a collective career path through three general stages: novice, advanced beginning, and competent. At the novice stage, beginning teachers tend to doubt their ability to organize and implement effect lesson plans. They tend to follow the prescribed curriculum verbatim. As they 
progress through advanced beginning stages and competent stages of the teaching trajectory, teacher efficacy strengthens (Burke et al. 1984). A rise in teacher efficacy often leads to increase awareness in professional development and experimentation in lesson planning.

In some cases, researchers (e.g. Belinger, 1988; Kagan, 1992; Katz, 1972) subdivided these general stages into more detailed sub-stages which describe in further detail what the teachers experience within the more generic stages. This allowed researchers, induction directors, and professional development teams to apply more precise intervention techniques at specific times during the teaching career to off-set any negative effects, such as attrition.

Katz (1972) divided transitional time of the teaching profession, starting with the advanced beginning stage and becoming a competent teacher, into three sub-sections: consolidation, renewal, and maturity. During the consolidation period, teachers pass the survival mode and begin to experiment with student development issues. Teachers in this stage often seek the advice of other professionals through written or verbal forms, since such skills are undeveloped. In the renewal period, developing teachers instigate renewed interest in professional growth through workshops and professional memberships.

Finally, during the maturity period, teachers begin to view themselves as professionals willing to share information and gain insight from others. This progression, from novice to competency, has been theorized to take between five to six years (Cady, et al., 2006; Katz, 1972). 
Berlinger (1988) described the career trajectory of teachers in five stages:

(a) novice, (b) advanced beginner, (c) competent teacher, (d) proficient teacher, and (e) expert teacher. In 1992, Kagan reviewed 40 studies that supported this progression. Hattie (2003) and Steffy and Wolfe (2001) confirmed this progression and found that teachers attained higher levels beyond the competence stage, which they denoted as achieving the distinction of an 'expert teacher' or 'distinguished teacher.' A review of these studies revealed that expert teachers differed from competent teachers in that they were able to: (a) organize and integrate depth of content across subject matter; (b) assess individual student misconceptions and levels of understanding more accurately, thus being able to adjust lessons to create an optimal learning environment; (c) provide more practical feedback; (d) anticipate and plan for challenging topics and modify classroom management as needed; and (e) expand their proficiency in all areas of teaching through many sources of renewing experiences (Hattie, 2003; Steffy \& Wolfe, 2001).

Other studies expanded the teacher career trajectory to include wind-down and exiting stages (Brand, 1983; Burke et al.; 1984, Lynn, 2002; Steffy \& Wolfe, 2001). These studies also included the natural progression of teachers to reflect, evaluate, and look forward to a new phase in life outside of teaching.

Brand (1983) and Fessler (as cited by Lynn, 2002) indicated that the competent stage was a critical stage in a teacher's career cycle. Those teachers that grew professionally during this stage generally found teaching to be a satisfying and rewarding career. These teachers generally remained in the teaching profession, at some capacity, until retirement. Those teachers that experienced career frustrations were likely to leave the profession if intervention was not implemented. Many others found the novice period 
daunting and left teaching before reaching the competent stage (e.g. Burke et al., 1984; Lynn, 2002). While it should be noted that in many cases exit did not occur until after numerous years in the profession, the current study investigated ways to reduce early exit by including aggressive induction methods throughout the student-teaching experience.

Phases in Student Teaching. Student teachers also experience stages of growth during the student-teaching experience. Furlong and Maynard (1995) identified five developmental stages: (a) early idealism; (b) personal survival; (c) dealing with difficulties; (d) hitting a plateau; and (5) moving on. While similar to those of professional teachers, these stages tended to hold dual traits depending on the specific incident. These dual traits are: (a) anxiety/euphoria; (b) confusion/clarity; (c) competence/inadequacy; (d) criticism/new awareness; (e) more confidence/greater inadequacy; and (f) loss/relief (Caruso, 1977).

Pre-service teachers (PSTs) usually begin student-teaching experiences with a perception of early idealism characterized with a simultaneous sense of anxiety and excitement at the prospect of their new assignments. These views are quickly transformed into the personal survival stage. This stage is characterized as either confusion or clarity depending on the support offered by university supervisors and cooperating teachers. In a conventional student-teaching model, a PST is placed under the guidance of a cooperating teacher who provides support through day-to-day instructional modeling. University supervising teachers visit periodically to observe how the PST is doing. Pre-service teachers sometimes struggle to please both the university supervising instructor, who is responsible for assigning a grade for the course, and the classroom cooperating teacher, who is responsible for the day-to-day activities and feedback (Diem 
\& Schnitz, 1978; Furlong \& Maynard, 1995; Traister, 2005). Problems may arise when little or inconsistent guidance is provided by the two supervisors. In this case, student teachers are faced with confusion as to what is necessary to successfully complete the requirements of their student-teaching assignment. On the other hand, if the student teacher is presented with a cooperating team whose is supportive of each member of the student-teaching triad (the student teacher, the cooperating teacher, and the university supervisor), this stage of the student-teaching experience becomes a positive experience (Love, 1992; Nguyen, 2009). The PST is aware of the requirements of assignment and is ready to advance to the next stage.

Once PSTs have had an opportunity to understand the role that is required of them, they begin testing their professional competency. At this point, student teachers begin to undertake limited responsibilities. With adequate support from both managerial parties, PSTs quickly progress to the next stage which can be fraught with difficulties (Furlong \& Maynard, 1995). PSTs have to deal with the dualities of criticism and new awareness. They begin to observe and evaluate: (a) whether or not university-taught theory is implemented; (b) how classroom management procedures are being applied; (c) how constructive lesson planning is employed; and (d) how they can mimic or improve upon these observations (Caruso, 1977). Unfortunately many PSTs do not fully experience the substantial growth at this stage because of dichotomous conflict between practice and theory. If a philosophical conflict exists between the classroom cooperating teacher and the university supervisor, progressive techniques can be overshadowed and student teachers may become custodial and behaviorist if these techniques mimic the actions portrayed by the cooperating teacher (McIntyre, 1984). 
During the plateau stage, the PST is asked to teach several sequential lessons or a unit (Furlong \& Maynard, 1995). The student teacher displays either more confidence or greater inadequacies. Many times, pre-service teachers chaff under the restraints of the cooperating teacher (Caruso, 1977). When cooperating teachers are not trained how to relinquish the classroom to the student teachers, then student teachers become involved in only few carefully selected classroom activities over which they generally have little control. These experiences usually do not lead to effective learning or teaching experiences for either the PST or the cooperating teacher (Keogh, 2005, McIntyre, 1984). According to Caruso (1977), PSTs may experience additional pressure with regard to their evaluated teaching performance. Implications of this study indicate that many develop lower levels of self-efficacy without proper guidance at this critical stage.

Finally, PSTs go through the moving-on stage which is depicted by a sense of loss, or relief. If the student-teaching experience has been a positive learning experience for the PST, all classroom stakeholders (the PST, the cooperating teacher, and the students of the classroom) experience a sense of loss at the departure of the PST. A wise cooperating teacher will recognize this possibility and involve the PST in creating a "farewell" occasion. In addition, PSTs often experience a reflective period of success and failures. As they reassess their performance during the student-teaching experience, they can hopefully discard unrealistic expectations of the teaching profession and place productive expectations into a proper perspective (Caruso, 1977; Furlong \& Maynard, 1995). If these beliefs are not realized, then anxiety of continuing in the educational field may surface, and the prospect of eventual attrition may materialize. 
In summary, when given adequate and supportive guidance from university supervisors and cooperating teachers, most student teachers evolve through growth progressions similar to practicing teachers. As discussed above, these stages involve: (1) early idealism; (2) personal survival while developing competency; (3) dealing with difficulties as they become aware of classroom situations; (4) more experience; and (5) a sense of loss or relief at the end of their experience before redefining themselves as professional teachers. If inadequate support or lack of cooperation occurs during the student-teaching experience, early exit from the program is found to be more likely. As a result, student teachers experience feelings of inadequacies and confusion regarding their career choice. Unfortunately, these sentiments may continue into their subsequent professional work. Many teachers that do not overcome these feelings of inadequacies and have lower sense of self-efficacy leave the teaching profession before they reach the competency stage (e.g. Burke et al., 1984; Lynn, 2002). Others may leave teaching out of frustration during this pre-service teacher stage. In light of this early exodus, a number of school systems have implemented induction programs during the novice years of teaching to reduce attrition rates.

\section{Attrition Rates and the Induction Programs}

In recent years, attrition of mathematics and science teachers has increased. As a result, interventions in the form of induction programs into teaching have increased.

Attrition. Retirements account for only one-third of the 283,000 teachers that the BHEF predicted in 2006 would leave education. The remaining teachers who left cited unsatisfactory working conditions as the primary reason for transferring to another school--a practice that is commonly called migration. Other teachers who left did not 
remain in the educational field. This departure is also known as teacher attrition (Alliance for Excellent Education, 2008; Ingersoll \& Smith, 2003). Henke and others (2000) reported that approximately $24 \%$ of teachers left the teaching profession because they did not like it or were not satisfied with it. An additional $25 \%$ left to pursue careers outside teaching.

Many disillusioned teachers who leave the profession entirely were novice teachers. Approximately $14 \%$ of the teachers left after their first year of teaching and nearly 50\% left within their first five years (Henke, Chen, \& Geis, 2000; Ingersoll, 2003a; Ingersoll, 2003b; Smith \& Ingersoll, 2004). Studies indicated that new teachers in the mathematics and science fields, especially those with strong academic credentials, were $10 \%$ more likely to leave the teaching profession than teachers in other fields. Their reasons included financial gain or lack of professional support (Alliance for Excellent Education, 2008; Smith \& Ingersoll, 2004).

Induction programs. Ingersoll $(2003 \mathrm{a} ; 2003 \mathrm{~b})$ found that up to $50 \%$ of new teachers in the profession leave before they reached the previously described competent stage. Other studies (Henke et al., 2000; Murnane, Singer, Willett, Kemple, \& Olsen, 1991) confirmed these findings. To counteract this attrition in recent decades, states have developed induction programs for novice teachers (Looney, 2011; Russell, 2006). "The National Commission on Teaching and America's Future reported that the number of states requiring mentoring has increased from seven states in 1996 to thirty-three states in 2002" (Looney, 2011, para.3).

Teacher induction is usually defined as additional training and support during the first (and sometimes the second) year of teaching. The training occurs mainly in school 
settings and often includes professional development designed to enhance the induction process (Smith \& Ingersoll, 2004). Comprehensive induction programs that have been most successful in lowering attrition rates among new teachers have the following characteristics: (1) often included additional training; (2) took advantage of the expertise of more qualified teachers or professionals; and (3) integrated some form of end-of-year assessment (Alliance for Excellent Education, 2008; Brewster \& Railsback, 2001). "The combination of professional development and exposure to their mentors' and other teachers' experiences can shorten the time it takes for new teachers to perform at the same level as an experienced teacher, which is, on average, from three to seven years without induction" (Alliance for Excellent Education, 2008, p. 6).

A successful induction program, which results in a higher level of retention, often incorporated a "high quality" comprehensive program (Smith \& Ingersoll, 2004; Villar \& Strong, 2007). To be considered "high quality," the New Teacher Center at the University of California, Santa Cruz, (NCT, 2007) indicated that the program must include the following six components: (a) at least two years of intervention programs; (b) allotted time for interaction between mentors and novice teachers; (c) strict selection procedures for mentors; (d) training throughout the mentors' term; (e) appropriate pairings of mentors and novice teachers that includes subject matter and grade levels; and (f) clearly defined assessment techniques to document growth of novice teachers. The NCT also noted that the cost of such programs could run as high as $\$ 7000$ per teacher. Unfortunately, administrators may find the cost of running such comprehensive induction programs a burden (both financially and on staffing demands) in light of financial cutbacks in education during recent years (Villar \& Strong, 2007). Recently 
policymakers and administrators have begun to use strategies such as reducing the number of professional development seminars and recouping some of the cost from novice teachers to offset the rising costs (e.g. Sutter County Superintendent of Schools, 2012).

If incorporating such comprehensive tactics in pre-service programs can produce similar results in retaining novice teachers as they progress through their beginning years, the implications have the potential to be financially and professionally valuable. Thus, the potential use of "induction" strategies in a pre-service setting may reduce teachers' risk of attrition, which provided the impetus for the present study. Specifically, the plan is to explore, not only how PST programs help teachers navigate through the pre-novice stage, but whether specific components of these programs diminish the variables that later cause attrition of STEM teachers.

\section{Teacher Concerns and Self-Efficacy Beliefs}

In recent decades, appreciation regarding the influence of the affective domain on both pre-service and in-service teachers' performances in the classroom has increased. The affective domain is defined as the extent to which sentiments and feelings influence the work and progress of a teacher. Affective objectives in a mathematics teachers' educational course development include growth in attitudes, beliefs and feelings toward teaching mathematics (Brahier, 2009; Miller, 2005). Teacher affective constructs that can determine how effective a teacher will be in a classroom include concerns and efficacy beliefs. Further empirical research on the connections between teachers' concerns and efficacy beliefs in the classroom can contribute to better understanding of 
the teaching activities or experiences that aid in the development of an effective mathematics teacher.

Teacher Concerns. Teacher concerns, as they relate to the different aspects of teaching such as retention and teacher effectiveness, have been the subject of research for over 50 years. In an effort to increase the enrollment and strengthen the curriculum of pre-service teacher programs, Fuller (1969) studied concerns held by pre-service teachers with regard to the teaching profession. Fuller originally included a pre-teaching non-concern stage, but later revised the list to focus exclusively on the presence of concerns within teaching (Fuller, Parsons, \& Watkins, 1974). These concerns were: (a) self-preservation; (b) task-related issues; and (c) impact on pupil needs and effects of teaching. As such, they revealed information about the psyche of a teacher.

Self-preservation concerns were defined as the most primal level of concern. It was characterized as being anxious about securing the approval of peers, students, and employers as well as other anxious tendencies fostered by focusing on protecting job security and deficiencies of self-adequacy. The next stage of concerns was task-related concerns. At this stage, teachers were fixated on the daily tasks of teaching. Teachers in this stage could become consumed with the negative aspects of task-related concerns, such as developing a compulsive anxiety about maintaining classroom control and meeting time constraints. The final stage was identified as impact concerns of meeting pupil needs and improving the effects of teaching techniques. This stage reflected a transferal of concerns from an individual perspective to one that focuses on motivating students and promoting the educational advancement of all students (Borich \& Tombardi, 1997; Fuller, Parsons, \& Watkins, 1974). 
The Concerns Model developed from primarily a qualitative exploration to a more quantitative one. Originally, to understand how concerns were categorized, Fuller and Case (1972) developed a qualitative research tool called the Teacher Concerns Statements (TCS) instrument which posed six questions (i.e. five demographic questions and one open-ended question asking the participant to write down any teaching concerns). The responses were clustered into seven categories of concern: (a) non-teaching; (b) teacher role; (c) subject matter and classroom discipline; (d) relationships with students; (e) pedagogy and assessment; (f) pupil learning; and (g) professional development. Two years later, Fuller, Parsons, and Watkins (1974) condensed these teacher concerns into the three main classifications described in preceding paragraph (i.e. self-preservation concerns, teaching performance or task concerns, and impact of student concerns). Their study focused on 1359 pre-service and in-service teachers who completed the TCS. They found that PSTs had more concerns related to self-adequacy levels, but in-service teachers' concerns focused more on those that benefitted pupils. The qualitative nature of the instrument led to apprehension about the comprehension consistency of the answers, so Fuller and Parsons (1974) developed a quantitative component to their study. In 1974, they conducted a study comparing the TCS and the Teacher Concern Checklist (TCC). They concluded that the TCC was a more reliable instrument in identifying and prioritizing teachers' concerns at different stages. Other studies (e.g. Adams \& Martray, 1981; Bunendwa, 1996; Conway \& Clark, 2003) supported the sequential nature of Fuller's Teacher Concerns model. These studies also modified and strengthened the validity of the Fuller and Parson (1974) TCC diagnostic tool. 
The teacher concern model evolved through a natural progression of its own. Initially, Fuller's (1969) findings indicated that teacher concerns were developmental, following a natural growth in the teacher career trajectory. However, by 1975, Fuller and Bown revised Fuller's original concern theory by introducing the notion that teachers could repeat the sequence of concerns at critical career times, like moving to a new school or accepting a new teaching assignment at a different grade level. In 1988, Rust used the premise of Fuller's concern stage theory to conduct a study on the concerns of pre-service university supervisors. The findings coincided with the findings of Fuller and others (1974) in that beginning supervisors were concerned with perceptions of others and the technicalities of being a supervisor. In addition, more experienced supervisors sought ways to enhance learning among their student teachers. This study showed the value of Fuller's concern stage theory to review the developmental growth of subjects in other areas without a regard for age. In 1992, Kagan reviewed 40 pre-service or novice teacher studies and concluded that these studies agreed that Fuller's concern model was sequential in nature. Recent studies continue to use this model and to support the chronological progression of concerns (Beeth \& Adadan, 2006; Conway \& Clark, 2003; Pyper, 2009, Van den Berg, Sleegers, \& Geijsel, 2001).

In addition to a progression of concerns, Fuller (1969) found that shifts toward task-related concerns occurred as self-preservation concerns lessened. Through independent studies, Fuller, and others (1974) and Borich (1996) found that, as teaching experience increased self-preservation concerns decreased. Borich observed that a lack 
of support during pre-service training could impede the transition from self-adequacy concerns to student-driven concerns. He also noted that with effective teacher training, PSTs could more efficiently transition from one level of concern to another.

Some studies found contradictions with the sequential teacher career trajectory progression of Fuller's (1969) concern model. These studies reported that concerns could be experienced by those with little experience or exist simultaneously. A study by Rogan, Borich, and Taylor (1992) showed that both pre-service and experienced teachers had high levels of impact concerns, but experienced teachers reported larger impact scores. Capel's (2001) study of 240 post-graduate students revealed that during three separate administration times conducted over a year-long study, the participants possessed similar levels of self-preservation and impact concern. Task-related concerns were consistently recorded at low levels. Watzke (2007) found that rather than being chronological, concerns appeared to be reoccurring and indicated "the need to scaffold linkages between student learning, learning theory, and instructional practices early in teaching careers in lieu of singularly focused managerial aspects of teaching" (pg. 106). Other studies also found that the three areas of concern manifested themselves simultaneously or continuously (e.g. Dadlez, 1998; Evans \& Tribble, 1986; Reeves \& Kazelskis, 1985).

Another study conducted by McVey in 2004 showed that the Concerns Model was not sequential. In her study, McVey expanded the TCC to review not only teacher concerns but also how many of these concerns were addressed in a university teacher preparation program. Her findings indicated that no significant differences between self or task concerns existed among apprentice teachers; however, the apprentice teachers 
had higher levels of impact concerns similar to those in the study by Rogan and others (1992). Furthermore, McVey (2004) noted that strategies to alleviate these concerns were addressed in experiences provided in student teaching, field experiences, and methods courses. External teaching experiences, like volunteer assignments and tutoring sessions, also lessened teaching concerns.

The Fuller teacher-concern design was developed to incorporate other aspects of the reform design and the concerns associated with adopting a new educational reform. This expanded model, entitled the Concerns-Based Adoption Model (CBAM), was first conceptualized by Hall, Wallace, and Dossett (1973). The CBAM used three instruments of measure: the Stages of Concern (SoC), the Levels of Use (LoU), and the Innovation Configuration survey (IC). The Stages of Concern was verified by studies conducted by Hall and associates (Hall, 1979; Hall, George, \& Rutherford, 1986) and extended Fuller's Teachers Concern by expanding the stages of concerns to six levels: awareness, informational, personal, management, consequences, collaboration and refocusing concerns. McKinney, Sexton and Meyerson (1999) used the SoC to show in order for an educational reform to be successful, teachers must move through a sequence of concerns that aligns with Fuller's hierarchy of concerns. The TCC and SoC instruments have been used in studies to examine concerns in areas such as multicultural education, program development involving educational technology, and programs integrating students with disabilities into the general population (Lienert, Sherrill, \& Myers, 2001; Marshall, 1996; Newhouse, 2001). These instruments have been used to find the levels and progression of concerns in education programs and mathematics curriculum reform (Charalambous \& Philippou, 2003; Charalambous \& Philippou, 2010; Tunks \& Weller, 2009). 
Self-Efficacy Beliefs. Bandura $(1977,1994)$ described self-efficacy as “one's belief about his or her ability to organize and execute tasks to achieve specific goals" (Charalambous \& Philippou, 2003, p. 1). The levels of efficacy that one possesses can be influenced or strengthened from four sources: mastery experiences, vicarious experiences, social influences, and physical and emotional well-being. Through mastery experiences, a person physically engages in an activity that "requires experience in overcoming obstacles through perseverant effort" (Bandura, 1994, para. 6). Vicarious experiences are actions that gain confidence through watching someone similar to oneself succeed and transferring onto oneself those beliefs of being able to master comparable activities. Social influences strengthen self-efficacy through verbal affirmations. People bolstered by such affirmations are likely to increase their levels of self-confidence and persistence. Unfortunately, verbal nullification seems to undermine self-efficacy much more easily than affirmations can raise it. Thus, to increase efficacy beliefs, efficacy builders (such as mentors) must construct activities that facilitate personal growth by placing the mentee in an atmosphere suitable for success. Finally, people often use physical and emotional reactions to make a personal judgment about their ability to succeed. A state of affective arousal can be perceived by some individuals as an energizing catalyst; whereas others would view it as evidence of anxiety (Bandura, 1994; Charalambous \& Philippou, 2003; Steele, 2010).

Teacher Efficacy Beliefs (TEB) is a subset of generic efficacy beliefs. These beliefs focus on a teacher's perceived ability to organize and execute learning activities that promote effective learning (Gowie, 2010). Educators that possess a high level of TEB tend to be more open to student ideas and less likely to experience "emotional 
burnout" (Charalambous \& Philippou, 2010; Charalambous et al., 2008). Charalambous and others (2008) stated that PST efficacy beliefs tend to be unpredictable and may change repeatedly during pre-service training. These beliefs, however, are often strengthened as PSTs gain experience within the teacher education programs.

Teacher efficacy beliefs can be measured using the Teacher Efficacy Scale (TES). The original TES, developed by Gibson and Dembo, contained 30 items that focused on two dimensions of teacher efficacy (Gibson \& Dembo, 1984, Tschannen-Moran, Hoy, \& Hoy, 1998). These two dimensions were general teaching efficacy and personal teaching efficacy. General teaching efficacy is the belief that one possesses the ability to overcome student hardships, like social-economic or demographic hardships, through increased education. Personal teaching efficacy is the belief that a teacher has the ability to change a life through effective teaching (Gowie, 2010). Subsequent research revealed that several items loaded onto both factors. After several attempts to clarify the construct, Hoy and Woolfolk (1993) modified the teacher efficacy questionnaire into a new model called the Teacher Efficacy Scale Short Form that contained 10 items (Hoy \& Woolfolk, 1993; Tschannen-Moran, Hoy, \& Hoy, 1998).

In 2001, Tschannen-Moran and Hoy developed the Teachers' Sense to Efficacy Survey (TSES), a 24-item Likert scale that measured in-service teachers' efficacy level across three domains (student involvement, teaching strategies, and classroom management). When the instrument was used with pre-service elementary mathematics teachers, the factor analysis clustered all domains onto one factor (Charalambous et al., 2008). This clustering showed that, while the instrument is appropriate for measuring the efficacy beliefs of experienced teachers in general, more work needs to be done in 
developing a quantitative instrument that will be reliable for pre-service elementary mathematics teachers.

Studies integrating teacher concerns and efficacy beliefs. The previous topics allude to the idea that teachers' concerns and efficacy beliefs can have an effect on teacher performance. Fuller (1969) suggested that, only after self-preservation concerns have been addressed, can teachers become concerned about teaching and meeting the needs of the students. Bandura (1994) hypothesized those teachers with high efficacy beliefs are confident in their ability to influence student learning. The following section reviews studies that investigate either one, or both, of these traits and discusses how the results from these studies can strengthen these areas in pre-service teacher courses.

Capel (2001) examined the sequential nature of concern stages (e.g. Fuller \& Bown, 1975) of 240 secondary PSTs during a yearlong postgraduate certification course. The Teacher's Concern Questionnaire (TCQ) was also examined to determine its accuracy with regard to capturing pre-service teachers' concerns. The survey was administered three times to determine changes in concern levels. The findings revealed that PSTs were consistently concerned about self-preservation and impact-related issues. This coexistence of self and impact concern was contrary to Fuller and others' (1974) sequential stages of concern. The results also indicated that overall concern levels dropped as students gained more experience in teaching. This finding implied that an increase in field experiences within pre-service courses could be beneficial in reducing PST's concerns. The TCQ proved useful in identifying concerns of the PSTs in a general population. However, it was limited in logging individual concerns. Capel (2001) recommended using a mixed-methods approach to identify concerns of individual 
students so that instructors in pre-service courses could better help them address individual concerns.

Another study recorded the concerns of novice teachers using Fuller's teacher concerns theory (Fuller et al., 1974). McVey (2004) investigated differences in the concerns of novice teachers working in public or private schools and teachers at the elementary and middle school levels. The study focused on the components of a pre-service teacher-training program that were perceived as most effective in helping teachers manage their concerns. McVey (2004) found novice teachers held predominately higher student impact concerns than other concerns. This finding did not align with Fuller's sequential theory. No notable differences in concerns among any of the populations were found. The pre-service teacher-training program components that appeared to be most effective in alleviating teacher concerns were student teaching, field experiences, and methods courses. These findings provided guidance for teacher educators who might be interested in reducing teaching concerns (McVey, 2004).

Charalambous and others (2008) measured changes in pre-service elementary teachers' efficacy beliefs during mathematics fieldwork. The goals of the study were: (1) to determine the accuracy of a mathematical adaptation of the Teachers' Sense to Efficacy Survey (TSES) (Tschannen-Moran \& Hoy, 2001) in measuring the level of self-efficacy of PSTs while teaching mathematics; (2) to determine whether efficacy beliefs change among PSTs during mathematics fieldwork; and (3) to record factors that caused variations when change positive affective traits in the efficacy beliefs were found during the mathematics fieldwork (pg. 128). The study revealed that the TSES, with modifications, adequately measured levels of self-efficacy mathematics beliefs of PSTs. 
Pre-service elementary education mathematics teachers' efficacy beliefs changed, but not in a particular pattern, and revealed a need to explore further individual patterns. In the study, efficacy beliefs increased as a result of highly engaged field experiences and mentors providing support through vicarious and social influences. This study revealed that efficacy beliefs increased as PSTs gained experience in teaching from field experiences and with the aid of a trained mentor (Charalambous, Philippou, \& Kyriakides, 2008).

Each previous study used either the Fuller (1974) teacher concern model or Gowie's (2010) teacher efficacy model as measurement tools. However, as early as the 1980's, several studies made connections between teacher concerns and efficacy beliefs. Evans and Tribble (1986) explored how these two constructs affected novice teachers and PSTs early in their educational preparation. The results were compared to the findings of Veenman's (1984) review of 83 studies on beginning teacher problems. Not coincidently, teacher impact concerns dominated both groups. However, novice teachers viewed discipline (task concern) as their primary concern (Veenman, 1984); whereas the study by Evans and Tribble (1986) showed generating student motivation (impact concern) was pre-service teachers' primary concern followed closely by concern of subject matter knowledge (self-preservation concern). This disparity in results was explained by the lack of experience that PSTs had with classroom culture. In addition, pre-service elementary and female teachers had higher levels of self-efficacy than did pre-service secondary or male teachers (Evans \& Tribble, 1986; Veenman, 1984). Pigge and Marso (1995) later confirmed that female PSTs showed a higher concern for their impact on student learning. 
Two later studies revealed that teachers who had high efficacy tended to have more concerns about making an impact on student learning, while teachers with sequentially earlier concern levels tended to have a lower sense of efficacy (Ghaith \& Shaaban, 1999; McKinney et al., 1999). Ghaith and Shaaban (1999) found that years of experience and personal teaching efficacy were negatively correlated to teaching concerns among 292 in-service teachers of varied experience levels. McKinney and others (1999) conducted an efficacy-based change model study on 101 in-service teachers of diverse backgrounds using three different data instruments. They found that teachers who acquired higher levels of teacher efficacy also acquired higher levels of student impact concerns.

Two additional studies explored connections between efficacy and teaching concerns of PSTs. Newman, Lenhart, Moss, and Newman (2000) conducted a four-year study on these connections. They focused on elementary PST learning in a Professional Development School during a year-long field assignment. They found that efficacy beliefs were high at the beginning of study, dropped in the middle, and then rose again near the end of the study. The concerns of the PSTs shifted from self-preservation to student-impact factors. Boz and Boz (2010) conducted a study involving 339 pre-service STEM teachers in Turkey. The findings aligned with those of Fuller's (1969) in that self-preservation concern decreased with experience. In addition, teacher concern variables were negatively correlated with efficacy variables. That is, PSTs with higher scores with regard to self-preservation concerns had lower self-efficacy scores. This study was the only one that focused on efficacy and teaching concerns of STEM pre-service teachers. 
In each of these studies, researchers made no attempt to determine if efficacy beliefs and concerns were dependent on each other. The results of these studies indicated that all teacher concerns were inversely related to levels of efficacy beliefs. In a later study, Charalambous and Phillippou (2010) tested the interaction between teachers' concerns and efficacy beliefs of elementary teachers five years into a mathematics reform program. It explored three premises: (1) early concerns in the reform will dictate later concerns; (2) efficacy beliefs are formed and informed by concern; and (3) efficacy beliefs prior to the introduction of the reform may influence concerns during the reform (Charalambos \& Phillippou, 2010, p. 4). Their findings indicated that a bilateral relationship existed between efficacy beliefs and concerns. Therefore, by simply looking at the level of self-efficacy, a researcher can determine what sequential teachers' concerns will likely be manifested and vice versa. The researchers also investigated how pre-reform efficacy beliefs affected concerns during a reform. If teachers were comfortable with mathematics instruction methods before the reform, they were more likely to exhibit task and impact concerns about the reform. Finally, the level of concern at a later stage may be related to the level of concern in earlier stages. This last implication is useful in helping teachers cope with management concerns in order to hasten progress toward learning impact concerns.

In summary, both teacher concern and level of teacher efficacy belief appear to have an impact on the level of effectiveness with regard to pre-service or in-service teachers' performance of educational duties. Several studies explored whether concern levels and efficacy beliefs changed during inquiry and if these changes followed pre-described theoretical frameworks (Boz \& Boz, 2010; Charalambos \& Philippou, 
2010; Evans \& Tribble, 1986; Ghaith \& Shaaban, 1999; McKinney et al., 1999;

Veenman, 1984). While results from studies by Evans and Tribble (1986) and Veenman (1984) did not support Fuller and Bown's (1975) sequential progression of concerns; both indicated that instructional practice experiences improved efficacy levels which, in turn, reduced teaching concerns. The studies by Ghaith and Shaaban (1999), McKinney and others (1999), and Boz and Boz (2010) supported the inverse correlation between teacher

concerns and sequential teacher concerns. A study by Charalambos and Philippou (2010) identified a bilateral relationship between teachers' concerns and efficacy beliefs. Their finding implied that a reduction of self/task concerns indicates an increase in efficacy beliefs, and vice versa, in experienced teachers. This result will be drawn upon extensively in this study.

Other studies (e.g. Ghaith \& Shaaban, 1999; McKinney et al., 1999) recognized that under ideal situations, teachers progressed through a sequence of concerns that allowed them to move away from self-centered concerns and toward more constructive concerns focused on impacts on their students' learning. In the process, efficacy beliefs were strengthened and enabled the transformation into becoming an effective teacher. When an interruption in this progression occurred, or a series of events that caused a delay in this progression emerged, teachers tended to develop characteristics that could lead to early attrition.

\section{Anxiety, Stress and Burnout}

This section will define the characteristics of "anxiety"," stress," and "burn-out", In addition, the connections among increased levels of "anxiety," "stress," and "burn-out" tendencies and the how these tendencies hinder the progression of positive affective 
characteristics will be explored. These tendencies seem to indicate early onset of attrition. Also this segment summarizes what measures can be taken in pre-service teacher education programs to reduce these undesirable affective traits.

Affective Attrition Characteristics. In the research that reviewed characteristics of teachers that left teaching, a pronounced disparity in identifying demographic and affective characteristics of these teachers was found. Few studies could conclusively identify demographic characteristics, such as gender and race, as contributors to attrition. The only demographic characteristic repeatedly linked to early attrition was age. Several studies found that younger teachers were more likely to leave or express a desire to leave than any other age group (Billingsley, 2004; Henke et al., 2000; Ingersoll, 2003a; Ingersoll, 2003b; Smith \& Ingersoll, 2004). In addition to age, other more affective characteristics were found to lead to attrition. These characteristics include teaching anxiety, teacher stress or distress, and career burnout.

Anxiety in the teaching profession. Anxiety has been described as a tension reaction "experienced directly by the person cognitively, motorically, or physiologically in response to a specific life situation" (Coates \& Thoresen, 1976, p. 176). It can be manifested in three ways: (a) cognitively, through negative or frightful thoughts and images; (b) physiologically, through increased heart rate, rapid respiration, and perspiration; and (c) motorically, through stuttering, shaking, and increased muscle tension. These traits can hamper the progression of positive affective characteristics as it relates to growth in any professional career trajectory.

While anxiety can affect all careers, this study focused on the effects anxiety had on teachers. Identifying exactly what constituted teacher anxiety has been area of 
disagreement among researchers. Most researchers interpreted teacher anxiety in two different ways. One way is to regard teacher anxiety as synonymous to teacher concern (Ahlering, 1963; Fuller, 1969; Morton, Vesco, Williams, \& Awender, 1997; Parsons, 1973). Increased anxieties as they relate to professional evaluations, and student misbehavior can be identified with self-preservation and task-related concerns. However, other researchers indicate that this equivalency is not accurate since not all concern manifests itself as anxiety. Instead, these studies viewed teacher anxiety as a vague manifestation of fear of different aspects of the classroom (i.e. Coates \& Thoresen, 1976; Johns, 1992; Keavney \& Sinclair, 1978; Thompson, 1963). For example, many anxieties expressed by student teachers were based on rumors and unfounded expectations. In a study conducted by Thompson (1963), 125 student teachers identified what anxieties they had before or during their student-teaching experiences. While females reported more anxieties, such as job expectations and apprehensions about content, all groups reported having more anxieties prior to the actual student-teaching experience than during it. These findings were supported by a subsequent study conducted on 299 secondary education students (Campbell \& Williamson, 1974) in which student teachers anticipated that the student-teaching experience would be much more difficult than it actually was.

Excessive amounts of teacher anxiety can affect the dynamics of a productive learning environment. The following paragraphs show what effect excessive anxiety has on student behavior and on the style of teaching. This discussion is followed by reports of how anxiety can be transferred to others in the classroom. Finally a discussion about the relationship between teacher anxiety and attrition will be provided. 
One aspect of increased teacher anxiety is how it influenced student behavior. It has been noted that teachers with high levels of anxiety tended to create environments with low levels of rapport between teachers and students. These low levels of tolerance, coupled with the presence of high teacher anxiety, have been linked to significant levels of student misbehavior. Students of high anxiety teachers tended to be more disruptive (Coates \& Thoresen, 1976; Petrusich, 1966). Keavney and Sinclair (1978) noted that the increase in student misbehavior may not be the result of teacher anxiety but may be the cause of renewed teacher anxiety. This negative classroom atmosphere was not beneficial for student learning. Furthermore, research found that when anxious teachers were taught systematic techniques to resolve conflicts and anxious moments, the levels of negative teacher behavior and student misbehavior lessened (Coates \& Thoresen, 1976; Havis, 1975).

This correlation between teacher anxiety and student misbehavior was not limited to professional teachers. In 1979, Preece observed 100 secondary science PSTs and measured the relationship between pre-service teachers' anxiety levels and classroom behavior during two points in the student-teaching experience. The results indicated that the science PSTs who exhibited traits of anxiety were also more likely to have class-control problems. Hart (1987) confirmed and strengthened these results. His study not only revealed that PST anxiety caused issues regarding classroom control, but also that as anxiety level increased due to the additional pressure of performance evaluation, a positive correlation with classroom disruptions was found. Each of these studies suggested that there is a significant correlation between higher teacher anxiety and student misbehavior. 
Teacher anxiety has also dictated the styles of teaching in the classroom. Studies have indicated that teachers who possess higher levels of anxiety tend to be more dogmatic (Campbell \& Williamson, 1973; Rokeach, 1960; Soderberg, 1964). For example, teachers in the upper elementary grades who demonstrated higher levels of mathematics anxiety were more likely to develop more traditional approaches to teaching mathematics. They were slightly more inclined to depend on seatwork and practicing skills instead of developing concepts (Bush, 1989, p. 508). Adams and Martray (1981) found that teachers who were more authoritative revealed similar dogmatic traits linked to Fuller's (1969) self-preservation concerns.

Not all studies focused on the impact that anxious teachers had on instruction. Another group of studies investigated the merits of less anxious teachers' styles. For example, studies by Petrusich (1966) and Strawitz (1975) revealed that less anxious teachers were more inclined to use constructive approaches in the classroom to encourage conceptual understanding; whereas, a study conducted by Mattson (1974) indicated that secondary students in medium-sized cities regarded teachers with low levels of anxiety as most effective. Through a comparison of the beliefs of 60 students, 61 PSTs, and 22 in-service teachers, Murphy, Delli, and Edwards (2004) found that a dogmatic climate had a negative effect on classroom climate. Their findings showed that as each of the groups promoted student-centered instruction there was an atmosphere of positive classroom climate and an increase of conceptual understanding. In a recent meta-analysis study, Cornelius-White (2007), found that learner-centered classrooms were beneficial with regard to advancing critical thinking skills, increasing mathematics achievement, and reducing student disruptive behavior. These studies indicated that student 
involvement in the learning process is more beneficial to conceptual understanding and conducive to a more learner-friendly environment than the use of dogmatic approaches.

Likewise, the influence of the supervising teacher can be crucial in shaping a student teacher's beliefs about styles of teaching. In a study that monitored eighty pre-service student teachers, Johnson (1969) found that student teachers who were placed with dogmatic supervising teacher increasingly imitated the dogmatism without regard to the initial level of dogmatism possessed by the student teacher. This finding suggested that care must be taken in assigning student teachers to supervising teachers with less dogmatic traits. In each of these studies, strong evidence links the traits of less anxious teacher with effective teaching styles.

The effects of the anxious teacher are not limited to behavioral problems or teaching styles. Other studies (Beilock, Gunderson, Ramirez \& Levine, 2010; Doyal \& Forsyth, 1973; Sellinger, 1972) noted that generally anxious teachers had a tendency to extend anxiety traits to their students. Teachers with content anxiety, such as mathematics anxiety, tended to pass that subject matter anxiety on to their pupils (Beilock et al., 2010). In contrast, Anderson, Greene and Loewen (1988) found that teachers with high efficacy beliefs were confident in their ability to influence effective student learning. These findings lead to the belief that a less anxious teacher is more inclined to elicit higher levels of student achievement and self-confidence.

Teachers with more experience were prone to have lowered levels of anxiety (e.g. Parsons, 1973; Petrusich, 1966). In other words, as teachers stayed in the profession longer, their anxiety decreased. A longitudinal study focused on 540 novice teachers conducted by Marso and Pigge (1998) also suggested that connections between 
cases of early teacher attrition and characteristics of an anxious person exist. This information implied a need for more information on implementing effective methods to lower anxiety levels of novice teachers so that anxiety does not become the cause for early attrition.

To summarize, anxiety has been described as manifestations of teachers' concerns or indications of unfounded expectations of future events. It has produced low levels of student/teacher rapport while increasing higher levels of student misbehavior. Anxious tendencies of a teacher were transferrable to students. Anxiety served to influence dogmatic styles of teaching as a preservation technique without regards to the negative implications to student learning. Finally, there was a slight inclination that high levels of anxiety can increase teacher attrition. In addition, anxiety has been associated with anticipated stress. This onset of stress is just one component of a much more serious problem associated with attrition--distress in the teaching profession.

Stress, or distress, in the teaching profession. Stress is a normal daily occurrence. It is the body's way of responding to any physical or physiological demands placed on it. As such, both positive and negative aspects of stress exist. The absence of stress can promote boredom, depression, and low levels of achievement. When a stressor is introduced, the body releases hormones that allow the person to react mentally and/or physically to the stressful event. As stress increases, the body shifts into a resistance stage, allowing it to adapt by remaining in a persistent state of arousal. At this level, the productivity of the person increases to meet the demands imposed. Too much stress or prolonged periods of stress, however, can have negative effects on performance and health (Dohrenwend \& Dohrenwend, 1981). The body is overwhelmed by the severity of 
the stress or the amount of stressors present and health concerns become prominent (e.g. Dohrenwend \& Dohrenwend, 1981; National Education Health Association Health Information Network (NEAHIN), 2001; Selye, 1950). This high level of stress, also called distress, can impact the performance and physical health of teachers.

Teaching has been identified as a stressful profession. Several studies (e.g. Borg, Riding, \& Falzon, 1991; Schonfeld, 1990; Troman \& Woods, 2000) revealed that high stress levels in conjunction with related job dissatisfaction was the main reason teachers left the profession--especially during their novice years. Several reasons for this situation exist. First, personal expectations of effective teaching and classroom management techniques, coupled with limited interaction with colleagues, can create stressful conditions for many teachers (Hollingsworth, 1990; Smylie, 1996). Also, some teachers experience persistent levels of stress from factors such as: mandatory high-stakes testing; increasing size and changing demographics of the classroom; insufficient training in new technology or programs; and conflicting demands from federal and local mandates and concerned parents (NEAHIN, 2001; Rajeswari, Santhanam, Babu, \& Rao, 2008).

Many of these stressors are linked to teacher attrition. In 1994, Bandura speculated that persons with low efficacy were more likely to relate to the negative aspects of the profession and focus on coping techniques instead of efficient performance. In conjunction with these negative tendencies, Hollingsworth (1990) noted that a causal relationship between teacher isolation and teacher stress exists. By the very nature of classroom settings, teachers have little opportunity to receive support from colleagues. These feelings of isolation, coupled with low efficacy beliefs, increased the likelihood that teachers relied on negative reinforcement and dogmatic techniques to 
enforce disciple in the classroom (Campbell \& Williamson, 1973; Rokeach, 1960; Soderberg, 1964). As outlined in the previous section, several studies found that student responsiveness to such techniques were counterproductive and led to more disruptions (e.g. Coates \& Thoresen, 1976; Hart 1987; Havis, 1975). Canrinus, Helms-Lorenz, Beijaard, Buitink and Hofman (2012) investigated how key indicators such as self-efficacy, job satisfaction and commitment were related. Their findings revealed that teachers with lower self-efficacy and limited professional relationships had low job satisfaction and were not as committed to the teaching profession.

Other studies have linked teacher distress and attrition with student misbehavior. Clunies-Ross, Little and Kienhuis (2008) used self-reporting and observational techniques to investigate the correlation between teacher stress levels and student behavior. They found that moderate levels of stress experienced by the teachers were caused by workload stress and student misbehavior. They noted that teachers who were proactive in their classroom management techniques were more equipped to handle stress. Those teachers that used reactive management strategies were more likely to experience stress created by student misbehavior and workload difficulties as well as problems associated with lack of time or resources and relational distress. These findings about teacher stress are compatible with Fuller's (1969) first and second levels of concern: self-preservation concerns and task-related concerns.

Sass, Seal and Martin (2011) sampled 479 teachers in kindergarten through $12^{\text {th }}$ grade using structural equation modeling techniques. They sought to determine what stressors most accurately predicted job dissatisfaction and intent to leave the teaching profession. The study revealed that the number of student stressors served as the highest 
correlation between the degree of teacher efficacy, level of job satisfaction, and the retention rate of teachers. Students also suffer from teacher stress in the classroom. Murray-Harvey, Slee, Lawson, Silins, Banfield, and Russell (2000) noted that "large amounts of teacher stress decrease classroom effectiveness, lower pupil achievement, and increase pupil anxiety" (p. 21).

Having unusually high expectations of students can also lead to high stress levels. Lewis (1999) surveyed teachers in 15 secondary schools in Melbourne, Australia and discovered that those teachers who worked toward empowering their students in managerial and educational matters had more idealistic expectations of the classroom management--which in turn led to more stress, more cases of illness, and possible attrition. This form of distress demonstrated the compulsive degree of Fuller and others' (1974) second level of task-related concerns and the third level of impact concern.

Lack of administrative support and workload/role conflicts represent other factors that have been attributed to attrition as it relates to teaching distress. Teachers with high levels of distress generally cited lack of professional support from superiors, over burdening workloads and conflicts over curriculum reform (Betoret, 2006; Littrel, Billingsley, \& Cross, 1994; Moriarty, Edmonds, Blatchford, \& Martin, 2001). These factors also provide support for Fuller and colleague's (1974) first and second levels: self-preservation concerns and task-related concerns as it may be associated to attrition. Sass and others (2011) and Canrinus and others (2012) also noted that teachers who received social support from superiors were less likely to leave the teaching profession.

These factors significantly contribute to the organization and structure of teacher education programs. They reveal how prominent the emotional stress among practicing 
teachers and student teachers is. Understanding how this stress affects student teacher behavior and ultimately identify possible ways to develop coping techniques during the pre-service years is essential.

Not surprising, teacher stress was present during student-teaching practica. Most PSTs spend three or four years of pre-service training in preparation and anticipation of the student-teaching practicum and eventually of acquiring their own classroom. The majority learned by experimenting with lesson-planning exercises, recognizing different classroom philosophies, and identifying teaching models through classroom observations. These experiences served as examples of Badura's (1994) lower level mastery experiences and vicarious experiences. While most student teachers viewed the student-teaching practicum as a necessary component of their educational training, it was the most stressful experience they had encountered (Black-Branch \& Lamont, 1998, Greer \& Greer, 1992). The scope of stressors in the student-teaching practicum differed from those of the practicing teacher because of the dual role that the student teacher has: that of a student and of a classroom leader (Murray-Harvey et al., 2000). This duality has launched many studies to discover if, in spite of this difference, student teachers experienced some of the same stressors as practicing teachers. This research focused on the characteristics of those who have higher levels of stress to the origins of those stressors.

This body of research has a long history. An early study measured the levels of stress that giving lectures had on student teachers. Teaching to peers in a standardized lecture format was more stressful than lectures given to about 30 students in a post-secondary classroom. The level of stress diminished as students gained more 
experience (Houtman \& Bakker, 1987). A study conducted by Capel (1997) investigated the causes of stress in 124 secondary physical education student teachers. By administering a questionnaire at the beginning and end of two practice teaching rotations, Capel found that the greatest source of anxiety during the teaching experience was being observed and evaluated by their supervisors. This study verified a finding of Houtman and Bakker (1987) that the levels of anxiety decreased as student teachers gained more experience as classroom leaders. It also recommended that pre-service programs include coping techniques for PSTs as well as an emphasis on supervisors' training that reveals the impact that the supervisor's presence and philosophies about teaching may serve in guiding how supervisors conduct their student teachers' evaluations.

A study by Sumsion and Thomas (2006) explored the stress levels of early childhood PSTs during their student-teaching practicum. The results indicated that training PSTs in relaxation and visualization techniques before their student-teaching practicum reduced stress levels during the student-teaching experience. During this time period, other studies explored demographic differences of stress levels. These studies compared differences of stress levels among students of different ages, gender, degree status, and locus of control (Murray-Harvey et al., 2000; Sadowski, Blackwell, \& Willard, 1986). While demographic characteristics are important, this study was more interested in identifying external sources of teacher stressors.

In a survey given to 52 student teachers attending a private college in northern Georgia, Clement (1999) found five areas of stress to be most prominent in the following ranked order: classroom management; formal observation; social or emotional problems of classroom student; job searching; and personal/family issues. Many student teachers 
indicated that pleasing their evaluators was more stressful than evaluating the students in their classes (Clement, 1999, p.22). A study by Murray- Harvey and others (2000) indicated that one-third of the preservice teachers developed increased stress levels as they tried to achieve the high expectations of their teaching performance. Other areas of concern were linked to classroom management, teaching loads, time management in school, and personal matters ( $\mathrm{p} 25$ ). In both studies, researchers found more evidence of self-preservation and task-related concerns than student impact concerns as listed by Fuller and others (1974). In addition, these studies showed that the first two concerns of student teachers (classroom management and formal observation) and those of in-service teachers (student misbehavior and lack of administrative support through evaluations) were similar.

These findings indicated that, while differences between the primary motivation of pre-service teachers' and in-service teachers' stressors existed, notable parallels in the stress that pre-service teachers' and in-service teachers' experienced were also evident. Some prominent solutions recommended additional training in proactive classroom management techniques, reflective journaling, additional field experience, collaborative and simulated teaching experiences, and increased support by supervisors that lessen the adverse effects of teacher distress (Murray- Harvey et al., 2000; Wadlington, Slaton, \& Partridge, 1998). If left unchecked, the most severe cases of teacher distress will likely lead to teacher burnout.

Burnout in the teaching profession. Burnout was first identified by Freudenburger (1974, as cited by Fisher, 2011) while studying the effects of working conditions on employees working in a free clinic environment. Later research revealed 
that burnout occurred most often among service professionals including, but not limited to, police officers, those in the medical field, counselors, and teachers who have the additional burden of the well-being of others (Dworkin, 1987, Maslech, 2003). Burnout has been described as a "prolonged response to chronic emotional and interpersonal stressors on the job" (Maslach, 2003, p. 189). As indicated above, job-related stress does not automatically lead to burnout. However, those professionals who have had a considerable amount of distress or have experienced a chronic level of emotional distraught and emotional exhaustion have been diagnosed as experiencing "burnout" (Lloyd, 2010).

Research indicates that burnout is a multi-dimensional syndrome which includes: (1) overwhelming exhaustion; (2) feelings of cynicism or detachment; and (3) an overpowering sense of ineffectiveness on the job (Maslech, 2003, pg. 190). While exhaustion is a primary trait; the correlations to the other two traits (cynicism and feelings of ineffectiveness) make the burnout issue a major one (Maslach, 2003). These multidimensional aspects of burnout separate it from typical the one-dimensional trait of stress. It encompasses the individual's experience and their overall feelings of worthlessness. For example, Schwab (1986) described teacher burnout as a multi-faceted condition of: (1) having a sense of overwhelming exhaustion; (2) having low or no sense of professional accomplishment; and (3) showing no emotional commitment (pg. 15).

Several studies have explored personality traits that may influence the onset of burnout (e.g. Carson, Plemmons, Templin, \& Weiss, 2011; Houkes, Jassen, de Jonge, \& Nijhuis, 2001; Kahn, Schneider, Jenkins-Heikelman, \& Moyle, 2006). Two personality 
traits emerged: (1) positive affectivity (PA)--those individuals who express positive emotions like enthusiasm and excitement; and (2) negative affectivity (NA)--those individuals who express negative emotions like hostility or irritability (Watson \& Clark, 1988). Since this study explores the effects of burnout on teachers, and teachers comprise the largest population of service professionals (Gold, 1985a), this section will focus on teacher burnout.

Recent studies explored how these two personality traits affect teacher burnout. A mixed methods study conducted by Carson and others (2011) investigated the impact of personality traits and school related factors on 85 full-time middle school teachers in the mid-western region of the United States. The study revealed that these two dispositions were not exclusive to the individual. That is, teachers who were generalized as persons with positive affective traits (PA) can exhibit some negative feelings, and teachers who were prone to negative traits (NA) can show some positive qualities. Having identified this duality, the authors concluded that the domain affective persona contributes significantly to teacher burnout. Those teachers who were identified as having a NA disposition were more likely to experience burnout, and those with PA tendencies experienced low levels of burnout.

Another study surveyed 374 full-time secondary vocational teachers. The results indicated that a positive correlation between individuals that possessed a NA disposition and those that had emotional exhaustion existed. In fact, this personality trait overshadowed any workload or social engagement interactions (Houkes et al., 2001, p. 278). A national survey of 339 secondary teachers revealed that teacher's affectivity traits and emotional social support should be considered in predicting burnout. 
However, while indicating that the disposition of teachers was significant, the study also found that teachers who engaged in authentic social interchanges with colleagues exhibited less emotional burnout independent of their affective disposition (Kahn et al., 2006). Due the conflicting results of these last two studies, it remains unclear how strongly affectivity contributes to teacher burnout.

Health-related issues that have also been associated with burnout include symptoms such as fatigue, irritability, substance misuse, and depression (e.g. Ducharme, Knudsen, \& Roman, 2007; Glass \& Mcknight, 1996). Other more severe physical symptoms might include migraines, peptic ulcers, respiratory ailments, and cardiovascular problems, such as heart palpitations and hypertension (Campbell, 1983). In a study of 365 north Texas school teachers, burnout symptoms included stomach aches, excessive alcohol consumption, and depression (Seidman \& Zager, 1991). Demographic variables also lead to burnout tendencies. Age seems to be a factor for young teachers with burnout tendencies more often that older teachers (Gold, 1985b; Lau, Yuen, \& Chan, 2005; Maslach, 2003). Chapman and Lowther (1982) noted that younger teachers, males, and teachers with personal attributes like strong leadership qualities can lead to dissatisfaction with teaching and teacher burnout. Lau and others (2005) found that teachers with demographic factors including being single, lower teacher ranking, and no religious affiliation had higher incidents of burnout.

Burnout has also been linked to job-related concerns. A number of researchers (Campbell, 1983; Cunningham, 1983; Farber, 1984; Murphy, 2010) noted that when burnout is present, teacher productivity declined in different ways. Burnout has been associated with excessive absenteeism, low productivity, and ineffectiveness 
(Cunningham, 1983). Miller and Wilte (as cited by Campbell, 1983) noted that teachers with burnout characteristics might become excessively strict, overreact to classroom situations, punish excessively, become dictatorial and verbally abuse students. Because of its potential to effect student learning and welfare, burnout has been labeled more harmful to the classroom climate than job change or early retirement. Although teachers may be deemed unfit to teach, many remain in the classroom for a variety of reasons (Dworkin, 1987; Farber, 1984). Finally, when teachers reach a breaking point in health or psyche, they often leave the teaching profession. The intent to leave and actual teacher attrition due to burnout are significant (e.g. Campbell, 1983; Ducharme, et al., 2007; Fisher, 2011). In a study of special education programs, Lawrenson and McKinnon (1982) reported an attrition rate of $48 \%$ over a three-year period. The reasons for the high attrition rate were linked to physical and mental harm and lack of concern for student learning. Lack of well-being and high attrition indicates that a closer examination of the factors that lead to burnout is warranted.

Recent literature attributes many causes for burnout in teaching such as oversized classrooms; problems with colleagues; low salaries; cutbacks in supplies; rise in school violence; and changing attitudes of education among students and the community as a whole (Campbell, 1983; McGuire, 1979). While conducting a literature review, Cunningham (1983) found that large class sizes, lack of resources, and limited promotional opportunities served as sources of high levels of stress that could potentially lead to teacher burnout. Cedoline (1982) identified seven standard causes of burnout: (a) lack of control over one's destiny; (b) lack of feedback and communication; (c) work overload or under load; (d) contact overload; (e) role conflict/ambiguity; (f) individual 
factors; and (g) training deficits. As schools alter curricula to accommodate national standards and high stakes testing and administrators impose more restrictive policies, teachers can become discouraged. This impersonal approach can lead to feelings of low self-efficacy (Cedoline, 1982).

A study of 1,597 elementary teachers, conducted by Friedman (1991), verified the negative impacts of an impersonal system, such as administration imposing high stakes goals and lack of trust regarding teacher competency, on increasing the levels of burnout. Reyes and Hoyle's (1992) analysis of 566 teachers in a mid-western state noted that younger, more inexperienced teachers were not satisfied with the level of communication with their principals. Teachers between the ages of 21 and 30 did not perceive that their principal adequately gave them precise instructions. Lack of administrative support was also considered a major factor in demoralizing teachers' perspectives of their schools. Suburban teachers felt that administrators were more interested in protecting their image than with improving conditions for teachers or students (Farber, 1984). This study also emphasized the importance of co-worker support in enhancing satisfaction within the teaching profession and dealing appropriately with stressful situations occurring during the workday. Educators with little co-worker support reported some level of burnout.

Other studies described different ways that burnout led to attrition. A study by Johnson and Birkeland (2002) revealed that $16 \%$ of the teachers who left the profession did so because they were overwhelmed with job demands and saw little chance for improvement. A study by Malanowski and Wood (1984) revealed that 211 public school teachers with a greater number students produced higher scores of depersonalization on three different measures. Dorman's (2003) study also recognized role overload as a 
compelling variable for emotional exhaustion and role conflict as attributing to significant levels of depersonalization. Bensky, Shaw, Gouse, Bates, Dixon, and Bean (1980) surveyed 114 special educators to determine significant predictors of stress and burnout. Their findings indicated a discrepancy between teachers' perceptions of work and others perceptions of teacher duties, which caused educators to question their role in the classroom.

Another reason for burnout is the perceived disconnect between theoretical training and its usefulness in the actual educational setting. Novice teachers can be overwhelmed by the prospect of not being able to implement pedagogical theories and techniques learned in educational preparation programs into their own classroom. This disconnect has been described as "reality shock." The sense of failure and work overload caused by this shock can cause burnout (Friedman, 2000; Murphy, 2010; Nahal, 2010; Warnath \& Shelton, 1976). In each of these studies, probable burnout causes were identified by Cedoline (1982).

In a study entitled "Why New Teachers Cry," McCann and Johannessen (2004) interviewed eleven novice teachers at the beginning of their professional careers and conducted follow-up interviews on six candidates about (1) their concerns and frustrations regarding the teaching profession and (2) coping strategies or support systems that influenced them to remain in teaching after the study. Findings indicated that teachers were not only initially concerned about relationships with students, parents, and school personnel, but also about workload management, content knowledge or curriculum issues, adequate evaluation of students, and classroom control or autonomy surrounding classroom dynamics. These concerns aligned with many of those noted by 
Fuller (1969) as self-perseveration and overwhelming task concerns. They also complimented several of Cedoline's (1982) potential burnout characteristics. By the end of the four-year study, two teachers had left teaching. These teachers appeared to be most vested in teaching at the beginning of the study, and each had intentions to try teaching again at a future point. Final interviews revealed that novice teachers believed that the most productive methods of retention came from a quality mentoring program. As a result of this research, novice teachers should be reminded of their contributions to students' success and assisted in finding the resources to accomplish this end. Genuine relationships with colleagues and mentoring opportunities that provided continuous support to encourage growth and alleviate feelings of isolation and depression increased the likelihood that a novice teacher would remain in the profession.

In a governmental brief from Great Britain, Smithers and Robinson (2003) identified several reasons that teachers left teaching in record numbers. While some former teachers cited reasons like spouse transfers or health issues (including pregnancy), others reported work overload and discipline problems. Nearly half 'wanted change' or were looking for a 'new challenge.' Of those educators that left, $47 \%$ cited leaving their current position to take another teaching position. Ingersoll \& Smith (2003) classified these teachers as migrators. The majority of those teachers, referred to as "leavers" (29\%), left for personal reasons and others indicated that they were leaving for retirement reasons $(13 \%)$.

Professional interventions have been used to address many of these concerns. A longitudinal interview study of 50 new teachers in Massachusetts revealed that teachers who showed a higher level of teaching efficacy and those who felt their schools 
supported them with collegial interaction, appropriate work assignments, adequate supplies and opportunities for professional growth had less inclination to leave the teaching professional than teachers who were not as fortunate to be placed in such environments (Johnson \& Birkeland, 2002; Murphy, 2010). Brissie, Hoover-Demdsey, and Bassler (1988) found that teachers who had strong support systems from family, friends, coworkers and school administrators, with principal support being the largest factor (also supported by Phi Delta Kappa, 1980), were less likely to suffer burnout. Reyes and Hoyle (1992) suggested providing more opportunities for younger teachers to interact and communicate with principals. By analyzing their conversations with more experienced teachers, principals have the potential to develop approaches that result in positive encounters with novice teachers. These inductive approaches appear to increase self-efficacy and reduce teachers concerns; however, attrition continues to be a concern. Another school of thought is to provide burnout intervention techniques in educational pre-service programs before teacher candidates enter the workforce (Gold, 1985b; Greer \& Greer, 1992; Murray-Harvey, et al., 2000).

Novice teachers experience burnout more frequently than experienced ones (Chapman \& Lowther, 1982; Gold, 1985b; Lau, et al., 2005; Maslach, 2003). Novice teachers often leave teaching during their first three years of service (Hemberger \& Stone, as cited in Greer \& Greer, 1992) Studies have shown that this early occurrence of the "burn-out syndrome" can be attributed to: (a) unrealistic expectations; (b) lack of mentoring support; or (c) low content knowledge (e.g., Fives, Hamman, \& Olivarez, 2007; Gold, 1985b; Murray-Harvey et al., 2000). Fives and others (2007) gathered data from 49 student teachers at two different intervals during their student-teaching 
practicum. Their results indicated that the student teachers possessed burnout symptoms related to emotional exhaustion and student depersonalization. Gold (1985b) and Schwab and Iwanicki (1982) noted that novice teachers reported that they were disillusioned about the teaching profession because of unrealistic expectations that bring with it greater amounts of emotional exhaustion and higher levels of depersonalization. Other studies revealed evidence of beginning teacher burnout when dealing with the common conditions of overwhelming tasks lists, never-ending responsibilities, and no time for self-rejuvenation (Kagan, 1992; Rorrison, 2005). Fimian and Blanton (1987) surveyed 375 PSTs and 38 novice teachers during a two-year study. The results indicated that their burnout rates were nearly identical as those of more experienced teachers. The most common burnout characteristic was in role ambiguity. When viewed with the pre-described causes of burnout outlined by Cedoline (1982), the results from these studies are unsettling.

Several preventions of burnout among PSTs have been offered. These preventions include: (1) developing realistic expectations through classroom discussions and numerous field experiences and (2) encouraging detached concern of pupils by providing discussions on how to strike a balance between empathizing with student problems and depersonalizing students' needs. Other suggestions included: (1) acquiring a realistic understanding of classroom successes and failures and (2) employing the use of stress reduction techniques such as establishing good dietary habits, muscle relaxation techniques, and good fitness habits (Greer \& Greer, 1992). Other suggestions support the previously described induction methods. A study by Murray-Harvey and others (2000) yielded a steady decline in burnout tendencies as the student-teaching practicum 
progressed. The student teachers reported that the reduction was due to social support networks and maintenance of a variety of copying strategies. Gold (1985b) suggested that students first be made aware of possible stress tendencies and offered a plan for how to resolve these tendencies. Student teachers were encouraged to establish open avenues of communication with supervisors and fellow student teachers. The student teachers were persuaded to participate in decision making and develop functional lesson plans. Finally, student teachers were introduced to a variety of stress reduction techniques. This arsenal of burnout techniques, which could be used in future classroom settings, provided a multi-functional approach to combat the variety of causes of burnout in PSTs.

In summary, affective characteristics like anxiety, distress, and career burnout can erode teacher effectiveness and possibly lead to teacher attrition. Anxious teachers tend to have lower self-efficacy, higher self-preservation and overwhelming task-related concerns. Anxiety can lead to dogmatic, traditional forms of education. A study focusing on mathematics anxiety at the upper elementary levels indicated some transfer of context anxiety onto students when teachers had high anxiety toward subject material (Beilock et al., 2010).

Stress is used by the body as a defense mechanism to the physical or physiological demands placed on it. While stress can be beneficial, too much stress or distress can be detrimental. High personal expectations and limited interactions with colleagues can create distressful situations for many teachers. Distressed teachers have lower self-efficacy and have higher task-related concerns. Unless teacher distress is recognized and reduced, burnout can develop and grow. 
Burnout is multi-dimensional. It encompasses feelings of overwhelming exhaustion, cynicism toward people, detachment from responsibilities, or an overpowering sense of ineffectiveness. This triad can affect the mental and physical state of the burned-out individual resulting in bouts of such ailments as fatigue, depression, migraines, and cardiovascular problems (e.g. Campbell, 1983; Ducharme, Knudsen, \& Roman, 2007; Glass \& Mcknight, 1996). In addition, student learning can be compromised by teachers who are 'just trying to get by' and students may be subjected to verbal abuse. Many causes range from demanding work conditions like large class sizes, limited resources, and high stakes testing to limited communication from colleagues and supervisors to role ambiguity. Most teachers usually leave the profession during the first five years of teaching. They cite personal reasons that include escape from anxiety, teacher distress, or burnout. Studies indicate that many of these negative characteristics occur during pre-service training (e.g. Chapman \& Lowther, 1982; Gold, 1985b; Lau, et al., 2005; Maslach, 2003). Suggestions for reducing these characteristics include stress management techniques and implementing effective mentoring programs during pre-service teaching experiences and in induction programs.

Overall, there has been much research conducted that examines the relationships between teachers' concerns and efficacy beliefs on pre-service elementary teachers, novice teachers, and experienced teachers (e.g. Charalambos \& Phillippou, 2010; Ghaith \& Shaaban, 1999; McKinney et al., 1999). A lack of supporting evidence that focuses on teacher concerns of STEM pre-service teachers exists. As such, the components of a STEM pre-service program that could significantly lower these concerns, and reduce attrition, before entering a teaching career, are not clear. None of the articles specifically 
used STEM pre-service teachers as samples to determine the effects of the three affective attrition characteristics described in this section. In light of this, my study will address teacher concerns and teacher self-efficacy and the extent to which these two concepts are dependent upon each other.

\section{Problem Statement}

This study investigated interventions that address the problem of the diminishing numbers of middle and high school secondary mathematics and science teachers in the American school systems as identified by the Business-Higher Education Forum (BHEF, 2006). Qualified teachers in these fields are leaving the profession after relatively short terms in the system (Henke, Chen, \& Geis, 2000; Ingersoll, 2003a; Rogusky, 2003: Steffy \& Wolfe, 2001). Often, replacement teachers do not have adequate credentials in teaching their courses (BHEF, 2006; National Science Board, 2008). Teachers obtaining a degree in their field of expertise are more likely to have the knowledge to make classroom experiences informative and interesting (Sanders, 2004). This translates into enhanced student understanding.

Pre-service programs for mathematics and science teachers at the middle and secondary levels must address not only pertinent content and pedagogical knowledge, but they must also intentionally address pre-service teachers' self-defeating concerns that lead to an attrition of novice teachers in the field (i.e. Adams \& Martray, 1981;CluniesRoss, et al., 2008; McCann \& Johannessen, 2004; Sass, Seal \& Martin, 2011 ). By strengthening teacher self-efficacy traits in these programs, teacher educators can reduce the self-defeating apprehensions of the PST so that their attention can be directed toward developing effective teaching practices and reduce characteristics that lead to attrition. 


\section{A New Vision of STEM Teacher Programs}

Populating our STEM classrooms with teachers who are not only knowledgeable in their disciplines but also know and use effective teaching strategies is critical. Comprehensive training will produce PST candidates who know content and possess realistic classroom expectations. Hopefully, with this enhanced knowledge, novice teachers will be less likely to leave the profession early. Due to the projected shortage predicted by Business-Higher Education Forum (BHEF, 2006), university education programs are developing strategies that will recruit successful science, technology, engineering and mathematics (STEM) majors into education. Therefore, programs must also provide PST with the skills necessary to enter the first phase of their teaching career with less risk of attrition. Having education professors and experts simply transfer as much knowledge as possible through lecture and observations, sometimes called the positivist tradition (Wideen, Mayer-Smith, \& Moon, 1998), has been shown to not the best approach to achieve this objective (Korthagen \& Kessels, 1999).

An appeal was offered during the United States Department of Education's Teacher Preparation and Institutions of Higher Education: Mathematics and Science Content Knowledge Conference (Sanders, 2004). This appeal outlined what higher educational leaders should do in order to achieve the goals of a quality preparation courses, as well as develop self-efficacy in pre-service teachers. 
The major points of this appeal were:

(a) Step forward as visible, vocal advocates for improving science and mathematics education at all levels.

(b) Take the lead in moving the education of teachers to the center of the institutional agenda.

(c) Initiate a comprehensive review of the quality of their institution's teacher education program.

(d) Make it clear that the responsibility for preparing teachers rest not just with the school of education, but with the institution as a whole-especially the arts and sciences faculty. (Sanders, 2004)

Under these guidelines, STEM teacher education must be viewed as the responsibility of the entire learning institution, not just the education departments.

Different Interpretations to Educational Program Structures. The implementation of Sander's (2004) objectives was daunting for those who adopted them. Although their article was written a decade before the appeal was issued, Bullough and Gitlin (1994) stated that increasing the time spent in schools and getting student teachers to "practice good teaching models" was not enough. They indicated that, in order to reform teacher education, PSTs needed to be: (a) involved in programs that were submersed in in-service projects; (b) meticulously evaluated on all aspects of work samples; (c) required to clarify and reflect on personal theories that they bring with them; and finally (d) reflective about all aspects of the program, especially as they address the aims and purposes of the educational process. Some universities interpreted these resolutions of teacher education reform to increase emphasis on educational research. This empirical-analysis approach required PSTs to study a content topic with pedagogical ramifications and use a deductive approach to enhance their teaching techniques. The approach that was adopted was discussed by Wideen and others (1998). The authors believed that positivist programs held little promise of changing flawed belief systems of 
pre-service teachers. The advent of progressive traditions used a more empirical-analysis approach that was implemented by university teacher educators to guide student teachers. They concluded that the use of systematic and consistent support of collaborative learning enhanced the growth of pre-service teachers' educational belief systems. Korthagen and Kessels (1999) suggested the use of a more inquiry-based approach that emphasized interactions among learners and use of reflection. Other universities implemented a combined program that developed competencies of content areas and improved pedagogical methods. Other educators blended all of these approaches. Some universities introduced a social critique tradition of teacher training that addressed issues of multiculturalism and systematic reform (Wideen et al., 1998). In all cases, the main objective was to involve both content departments and the education colleges to prepare teachers and deliver ideas (Bullough \& Gitlin, 1994).

Consistent with the last two objectives of Sanders' (2004) proposal, helping teachers learn content knowledge and how to convey that knowledge requires all aspects of their education. Learning should be viewed as a process of effective planning, problem solving, and experimentation (Weisbord, 1989). Pre-service teacher learning is best accomplished when guided by andragogy (methods used to teach adults) strategies and pedagogical theories. Results occur when pre-service teachers become actively engaged in their learning and practice these techniques in classroom situations (Korthagen \& Kessels, 1999). Pre-service teachers should be given the opportunity to: (a) become problem solvers; (b) reflect on their attempts at new strategies; and (c) ground their learning in theory. These opportunities should be coherent, intensive, and continuing. They should be given the opportunity to develop collaboration among peers, 
professionals, and teacher educators (Noble, 1970; Smylie, 1996). Furthermore, collaborations should require extensive field work and effective educational mentors willing to guide teacher candidates.

\section{Two Key Components: Field work and Educational Mentoring.}

This study examined whether the effects of two key components, field experiences and educational mentoring, served to minimize teacher concerns and thus increase self-efficacy in an effort to reduce characteristics that lead to early attrition. In order to better understand the how these components can contribute towards this goal, it is necessary to have a better understanding of each of these topics. The next section will examine the history and the progression of different types of mentoring and field experiences.

Early Field Experiences. The National Council of Accreditation of Teacher Education (NCATE) Standard \#3 mandates "the professional education unit and school partners to design and implement field and clinical experiences so that candidates develop and demonstrate the knowledge, skills, and dispositions so that all students learn" (NCATE, 2008). This mandate is vague and can be subject to interpretation. This section provides a brief historical overview of how field experiences have changed in the teacher education program over the years. Next, it will address two different practices that PSTs encounter when completing a field experience as a course component. Finally, it provides a summary of how the UTeach program (on which the SKyTeach program studied in this research was based) uses field experiences.

\section{Historical Overview of Field Experiences for Pre-service Teachers. Placing}

PSTs in classrooms as a way to integrate theory into practice (Shuff \& Shuff, 1972) is 
not a new strategy. Having students and teachers actively involved in classrooms began over a century ago in John Dewey's innovative Dewey Elementary School at the University of Chicago, which opened in 1896 (Harms \& DePencier,1996). [It was later renamed the Laboratory School in 1901]. As a founding father of pragmatic education, Dewey supported child-centered classrooms in which teachers actively engaged children in learning projects. This model was in sharp contrast to the "normal" classrooms where children sat in rows and completed rote-learning exercises. Preparing teachers in these laboratory schools was vital to realize the vision.

In a typical day, student teachers attended university classes and these child-centered classrooms. In the child-centered classrooms, PSTs assisted experienced teachers as collaborative apprentices in guiding children's learning. Teachers, student teachers, and children learned together in this program. Laboratory schools were instrumental in field-testing new educational theories and grounding these theories in classroom practice. Partnerships connected the school to researchers and provided fertile ground for training new teachers in pragmatic educational theory in actual classroom settings (DePencier, 1996, Harms \& DePencier, 1996).

This humanistic approach to teaching and learning spread to other universities. Laboratory school classes were taught by employees of a nearby university, and teacher candidates were assigned in this model similar to the Laboratory School in Chicago. Classes at these laboratory schools enabled teacher candidates to link classroom experiences to theories introduced in their education classes. Unfortunately, this type of schooling did not necessarily represent the typical public school. Critics claimed that the field experiences were too artificial. With this philosophical disagreement and rising 
financial constraints, laboratory training schools declined in numbers during the sixties. (Trachtman, 2007). Some laboratory schools however still exist. Eighty-five laboratory schools currently operating as preparatory schools with financial ties to local universities still exist (Illinois State University, 2012). Three examples are (1) the University of Chicago Laboratory School (University of Chicago Laboratory Schools, 2011), (2) the Model Laboratory School in collaboration with Eastern Kentucky University (Eastern Kentucky University, 2011) and (3) Thomas Metcalf and University High School with ties to Illinois State University (Illinois State University, 2012).

Schools that are not laboratory schools typically maintain a behaviorist orientation to learning in which teachers provide examples and students take notes (Brahier, 2009). In this design, most field experiences are conducted through partnerships with local public school systems. Traditionally, the schools operate as separate entities from the universities and provide only a physical location for pre-service field experiences. Cooperating teachers provide supervision for pre-service teachers in this setting. University instructors offer teacher candidates theoretical frameworks and philosophies (e.g. Beck \& Kosnik, 2002; Beeth, \& Adadan, 2006; Capraro, Capraro, \& Helfeldt, 2010; Diem \& Schnitz, 1978; McIntyre, 1984; Roth \& Tobin, 2001). In many instances, little correlation between what is taught at the university level and what is practiced in the classroom existed. Because of a separation in goals and missions, many power struggles arise (e.g. Beck \& Kosnik, 2002; Beeth, \& Adadan, 2006; Capraro et al., 2010; Diem \& Schnitz, 1978; Love, 1992; McIntyre, 1984; Roth \& Tobin, 2001; Veal \& Rikard, 1998). The result of this dichotomous conflict between practice and 
theory is counterproductive to the PST's learning, and they become increasingly unsure of many aspects of the teaching profession.

In order for pre-service field experiences to be effective, these problems must be resolved. The focus must move away from a power struggle between the classroom cooperating teachers and the university supervising teachers and focus on the needs of the PST. The needs of the PST include: (a) the freedom to imitate and/or develop their own teaching style; (b) being allowed to tackle the complexities of managing a working classroom; and (c) receiving prompt constructive feedback from the university supervising teacher and the cooperating teacher (Moody, 2009).

In the 1980s, the National Council of Teachers of Mathematics (NCTM) opposed behaviorist learning and teaching programs by suggesting that teachers should place problem solving at the center of student learning. During the next subsequent years, the NCTM released a series of standards describing what effective learning in the mathematics classroom entailed (Brahier, 2009). The standards were combined into one volume entitled Principles and Standards for School Mathematics (NCTM, 2000).

Professional Development Schools (PDS) emerged in the 1980s as a means to strengthen relationships among schools and universities and to develop relationships that would prove more effective in teaching prospective teachers. PDSs were collaborating institutions formed through partnerships among colleges and public school districts to strengthen school-university relationships, learning, and teacher preparation programs (Metcalf-Turner, 1999; Trachtman, 2007). The goals of the professional development schools were to offer places that: (a) established the role of the teacher (university, classroom, and pre-service) as an ongoing learner; (b) promoted a learner-centered 
environment of professional and curriculum development based on working theoretical models; and (c) provided a collaborative, ongoing, intensive and supportive model of coaching, problem solving, and learning/teaching among all members of the educational triad (Darling-Hammond \& McLaughlin, 1995).

As a result, field experiences include collaborative efforts among all parties of the educational triad in order to provide new visions for teaching and the teaching experience (Darling-Hammond, Bullmaster, \& Cobb, 1995). University classes are developed and taught through collaborative efforts among university faculties and schoolteachers that are aligned with state and professional standards like NCTM's Principles and Standards for School Mathematics (NCTM, 2000). Several of these methods classes are taught in the PDS setting. This strategy gives pre-service students access to classrooms that model theories taught in their university courses. This strategy allows a blending of theory and practice. Classroom teachers and university instructors are encouraged to visit each other's classrooms to gain insight into 'how the other side works.' Pre-service and in-service teachers are encouraged to discuss and implement new ideas in lesson planning and implementation (e g. Bay-Williams, Scott, \& Hancock, 2007; Dallmer, 2004; Darling-Hammond \& McLaughlin, 1995).

Although specific advice regarding how to accomplish these goals was not offered, the goals of the PDS were supported by the National Council for Accreditation of Teacher Education (NCATE, 2001). Nine standards were recently proposed and accepted by the National Association for Professional Development School (NAPDS, 2008). More than 200 PDS schools have been established since the turn of the century (MetcalfTurner, 1999). 
Other universities have not adopted the total PDS framework, but they were recognized for having innovative teacher education programs. For example, one program was the previously mentioned UTeach program. The nine Elements of Success aligned with many of the characteristics of the PDS, such as cross-college and school district collaboration, rigorous research-based instruction, and intensive field experiences (Metcalf-Turner, 1999; Trachtman, 2007). Although university faculty was not physically present in the public schools on a daily basis, a considerable amount of collaboration between university master teachers and public school teachers occurred. The program emphasized training PSTs to use inquiry-based learning and teaching techniques. With constant mentoring support during frequent field experiences, pre-service teachers often lead classroom activities using this mode of instruction (Cavanagh, 2007). This teacher education program was one of many that have been developed in the past few decades.

Characteristics of Field-Experience Programs. The National Commission on Teaching and America's Future (NCTAF, 1996) wrote:

"Prospective teachers learn just as other students do: by studying, practicing, and reflecting; by collaborating with others; by looking closely at students and their work; and by sharing what they see. For prospective teachers, this kind of learning cannot occur in college classrooms divorced from schools." (p. 31).

In keeping with the NCTAF's and NCATE's (2008) definitions, field experiences are described as experiences that provide developmental growth for future professional educators. The experiences include observations, serving as teaching assistants, and/or 
opportunities to experience lesson delivery. When PSTs are asked to complete a field experience component in their coursework, no defining guidelines are usually offered. The amount of time spent in the classroom varies from university to university, course to course, or instructor to instructor. Some examples of early field experiences include observational learning experiences. Others require strategies for modeling teaching. Innovative pre-service teacher education programs usually introduce some form of field experience in early years of the teacher preparation program, while other more traditional programs wait until the student-teaching experience to place teachers in a classroom setting (e.g. Austin-Martin, Bull, \& Molrine, 1981; Beeth \& Adadan, 2006; Capraro et al., 2010; McIntyre, 1984; Scherer, 1979). All student-teaching practica require student teachers to develop lesson plans and units, but some require only a few weeks of actual instruction time. Others require students to complete a year-long student-teaching practicum (Spooner, Flowers, Lambert, \& Algozzine, 2008). According to the research, all forms of field experience have some merit; however, some are more effective for helping pre-service teachers learn how to teach. This section will focus on the effective and ineffective qualities of field experiences that involve aspects of observation and/or instructional practice.

Many pre-service teacher programs require classroom observations as key components prior to student-teaching experiences (Lawrence \& Butler, 2010). The observation experience can be classified into two types: general or guided (focused) observations. In general observations, the PSTs are given few or no pre-identified topics or behaviors on which to focus. In these situations, PSTs observe classroom situations and report what they observed. During these sessions, student behavior or teaching style 
were commonly reported. In guided observations, PSTs are given specific behaviors, like coding the level of questions being asked. In other incidences, the topics were continuous, like how teachers manage transitions or whether teachers treat students in equitable ways. (Anderson, Barksdale, \& Hite, 2005).

The research indicated that when PSTs were given specific objectives on which to focus and reflect, observational field experiences proved to be effective learning tools (Anderson, Barksdale, \& Hite, 2005; Austin-Martin et al., 1981; Steele, 2010). When PSTs were asked to review how teachers handled management issues in class or to identify what forms of learning or what levels of Bloom's taxonomy for questioning was most prominent in the observed classroom, educational learning seemed to occur. Bandura (e.g. 1977, 1986, 1994) labeled this type of learning "vicarious learning." However, it is not considered the most efficient way to "glean a deep understanding of the complexities of teaching" (Hammerness, Darling-Hammond, \& Bransford, 2005, pg. 368). Observing an effective lesson does not ensure that PSTs will teach effective lessons (Inman, 2000).

Another common field experience is more engaging, requiring PSTs to demonstrate growth through instructional practice. This can be conducted early in the educational process or during the student-teaching practicum (Austin-Martin, et al, 1981; Scherer, 1979). Instructional practice involves tutoring small groups of children, delivering a ready-made lesson, or planning and co-teaching a lesson with a peer instructor or mentor teacher (McIntyre \& Killian, 1987, Steele, 2010). It also involves developing full lesson plans and delivering them to students. All of these activities are considered by Bandura (1986) as varying levels of mastery experiences. They can raise 
self-efficacy if mentoring teachers allow PSTs to grow through progressively harder tasks. Overcoming obstacles also enhances self-efficacy. Once pre-service teachers succeed in smaller tasks, they are more willing to persevere if the lesson does not go smoothly (Steele, 2010). In order to achieve this goal, mentoring teachers must be supporters, advisors, role models, and encouragers. They must also deliver prompt, constructive feedback (Hall, Draper, Smith, \& Bullough, 2008; Moody, 2009). These actions are considered critical strategies used by successful mentors (Dallmer, 2004; Traister, 2005).

Lawrence and Butler (2010) believed that developing understanding "regarding the complexities of helping students learn is a critical component of PST education that should not be one of the last aspects of teaching on which PSTs focus" (p. 176). They found that delaying instructional field experiences until the student-teaching experience in teacher training programs bred feelings of inadequacy and anxiety before the student-teaching experience began. These findings were collaborated by Beeth and Adadan (2006). Pre-service teachers often conjure up unrealistic visions of perfect classroom experiences and become discouraged when such experiences did not occur (He, 2009). Pre-service teachers need to explore different teaching methods. As a result, they learn that teaching is not a stagnant experience, but an experience to be continuously reflected upon and improved.

Mentoring. Mentoring, when applied to education, involves the personal guidance of a quality veteran teacher. Smith and Ingersoll (2004) found a mentor increased the likelihood of new teacher retention past one year by thirty percent. Thus, including mentors in teacher education programs seems important in the development 
and retention of quality teachers. Traditional supervision of PSTs or novice teachers involved a hierarchical relationship in which a more experienced teacher became a role model and provided knowledge to a less experienced person. This expert/novice relationship transmitted knowledge in a top-down linear fashion. In recent years, supervision of PSTs or novice teachers has been replaced by the more robust role of mentoring. The most obvious change was that the term 'supervisor' had a negative connotation of having a superior position over another person whereas the term 'mentor' suggests a more congenial role involving assisting or advising (Ambrosetti \& Dekkers, 2010).

An effective mentor/mentee relationship can enhance teacher and personal self-efficacy traits and reduce attrition. Newman and others (2000) found that constructive mentoring controlled the rise of teacher concerns during a year-long field experience in a PDS setting. Smith and Ingersoll (2004) found that having a mentor in one's content field reduced the likelihood that a novice teacher would move to another school or leave the teaching profession. Thus, having a mentoring component appears to benefit the development and retention of quality teachers. The following sections will summarized the research regarding how mentors and mentees define their roles and the different types of mentoring models have been implemented.

Characteristics of Mentoring Programs and Effective Mentors. While most mentoring programs have been shown to be beneficial to teachers (Boreen \& Niday, 2000; Smith \& Ingersoll, 2004), care must be taken in developing them. Mentoring generally involves the personal guidance of a veteran teacher. However, several studies indicate that many mentoring programs lack (a) appropriate pairings; (b) a chance for 
observation opportunities between the mentor's and the novice teacher's classes; or (c) review of lesson plans between the parties (Johnson \& Birkeland, 2002; Kardos, Johnson, Peske, Kaffman, \& Liu, 2001; Kardos, 2002;). Johnson and Birkeland (2002) noted that mentees expected mentoring programs to include: (a) encouragement from veteran teachers; (b) assistance with curriculum decisions; (c) advice on lesson planning and development; and (d) feedback on enacted teaching strategies (p. 42). In a case study, Boreen and Niday (2000) observed that the majority of concerns by PSTs focused on three topics: assessment, classroom management, and diversity. This overwhelming concern of task management concerns was described initially in research by Fuller (1969). Care must be taken by administrators to address these concerns when constructing a mentoring program.

In developing a successful mentoring program, administrators should also describe key characteristics that mentors and mentees must possess. The roles of mentors and mentees are complex. Ambrosetti and Dekkers (2010) conducted a literature review of mentor/mentee relationships. The studies noted that mentors often had different roles that included: (a) providing support for the mentee; (b) serving as a critical evaluator; (c) modeling, coaching or offering appropriate advice and feedback; (d) counseling and motivating; (e) observing, and (f) serving as a team teacher or equal partner. Comments from mentees included similar qualities and characterized the effective mentor as someone who: (a) provided support and opportunities of inclusion into the school social structure; (b) personified the role of a critical friend; (c) became a collegial partner; and (d) served as a role model. Hall and others (2008) supported these characteristics and included roles that also involved performing university duties like 
filing paperwork and conducting assessments focused on teaching performance and professional knowledge. The mentees indicated that the desirable qualities of a mentor included "credibility, approachability, confidence, and air of authority, and be able to possess motivational skills" (Hall et al., 2008, p. 329). Boreen and Niday (2000) indicated that the most successful veteran teacher mentors offered a range of teacher strategies to their mentees, including "modeling, illustrating, affirming, questioning, qualifying, and reflecting." Several studies revealed that mentors helped mentees develop relationships with others in the school and district (Ambrosetti \& Dekkers, 2010; Fletcher \& Barrett, 2004). To summarize these characteristics, an effective mentor is a person who is committed to the success and welfare of the mentee and is willing to collaborate in a reflective learning environment with the mentee.

In order for mentors and mentees to establish a successful working relationship, mentees must also have certain traits. They must be willing to engage in professional conversations and work with mentors to develop their own professional skills and knowledge. The mentee must observe the mentors (or other teachers) during their classes and discuss topics of interest. A successful mentee must be willing to: (1) perform professional tasks as required and requested; (2) set personal goals; and (3) strive to meet those goals (Ambrosetti \& Dekkers, 2010). Mentees will benefit from completing induction programs or support sessions (Smith \& Ingersoll, 2004). In conclusion, a mentee must possess a willingness to work with and learn from others in a private setting or a more formal workshop setting. They must set professional goals and work to achieve those goals. 
Lai (2005) illustrated the complexity of the mentor/mentee partnership by triangulating contexts within the partnership. She indicated that the components of the partnership should include relational, developmental, and contextual dimensions. The relational dimension included give-and-take between mentor and mentee. In the developmental dimension, the focus of the relationship was on "promoting the professional and/or personal development of both the mentor and the mentee" (Lau et al., 2005, p. 2). Finally, in the contextual dimension, the mentor recognized the merits of strengthening relationships beyond the two and introduced the mentee to the culture of teacher collaboration and the powerful influences connected with the school or district. When considering the characteristics of both effective mentors and effective mentees, meeting these goals should benefit the personal and professional growth of both partners.

Different Models of Mentoring Programs. Concentrated efforts of educational mentoring programs have appeared in student teacher experiences and in induction programs. Both types have different models that warrant review in order to establish what aspects were found to elicit positive effects on the mentee.

Within the student-teacher experience, the mentoring aspects took on a duality of responsibilities between the cooperating classroom teacher and the university supervisor. This duality can create two different models of mentoring. In one model, the parties had a tendency to work as separate entities to impart the art of teaching. The other model worked as a partnership in an effort to create a more constructive approach to teaching.

In many student-teaching archetypes, the cooperating teachers often viewed themselves as experts of classroom experiences. They perceived their roles as the ones who introduce PSTs to the realities of teaching profession (Beck \& Kosnik, 2002). 
Research found that cooperating teachers often had bigger influences on PSTs than the university supervisors because of the amount of time spent with the PSTs (Love, 1992; Nguyen, 2009; Traister, 2005; Yee, 1969). Cooperating teachers viewed university supervising teachers as intruders from the 'ivory tower' and whose roles were redundant and useless (Monson \& Bebb, 1970). Visits by university supervising teachers were often regarded as sporadic and nonproductive.

In the defense of the university supervising teachers, many wanted to be more involved in their student teachers' classroom experiences, but due to other responsibilities, like heavy teaching loads and obligatory research responsibilities, their efforts are hamper their ability to make frequent school visitations (Beck \& Kosnik, 2002). These classroom visits became mandates imposed by state and university standards. Under such circumstances, the advice that was offered by the university supervisor to the student teacher was often viewed as judgmental or overcritical (Veal \& Rikard, 1998). To counter this "harsh treatment," cooperating teachers would avoid making critical reviews even when it was merited (McIntyre, 1984). The role of the student teacher in this type of atmosphere was regarded as confusing and learning about the art of teaching became minimal at best.

In order to promote a more efficient and effective learning environment for the student teacher, research has found that the roles of the university supervisor and the cooperating teacher must be well defined and complementary (Love, 1992; Nguyen, 2009). The position of the university supervisor was clearly defined as a liaison between the PST and the cooperating teacher and between the school and the university. The university supervisor clarified, to both the cooperating teacher and the PST, the program's 
requirements and guidelines that were used in all evaluations by both evaluators (university supervisor and cooperating teachers). The university supervisor employed coaching strategies to help PSTs analyze and solve challenges that were grounded in theory (Love, 1992; Nguyen, 2009). Love and Nguyen indicated that the role of the classroom cooperating teacher should include shared responsibility in the stewardship of the student-teaching experience. Cooperating teachers were instructed to lead classrooms that were conducive to the effective learning of the student teacher.

When reviewing the effects of induction programs on novice teachers, it was found that those novice teachers who were involved in induction programs were more likely to remain in teaching and generated higher student success rates (Ingersoll \& Strong, 2011; Serpell, 2000). A literature review (Serpell, 2000) on the characteristics of successful induction programs noted that mentoring and release time were the two key components of professional development since the 1980's. These induction programs included coherent requirements of the novice teacher and mentors as well as employing a mentoring model that required training in effective mentoring methods and effective teaching techniques. This review also indicated that university involvement was important in successful and smooth transitions into the teaching career.

With the previous recommendations of characteristics of successful student-teaching and induction programs as benchmarks, this section will compare two philosophical mentoring designs and address how mentoring can be effective in a conventional setting or in a collaborative setting. Whereas the purposes of mentoring in induction usually are to support novice teachers and to reduce early attrition, the purposes 
of the pre-service mentoring design are usually to model teaching practices and encourage the growth of the PST.

The collective problem-solving and the strength-based mentoring models were two physiological mentoring models that were found effective. Mentoring programs were developed to provide teacher candidates emotional support, establish professional socialization opportunities, and maintain pedagogical guidance. He (2009) claimed that teachers needed to develop resistance strategies that continued to grow teacher efficacy and motivational strategies so that they were prepared for future conflicts. These two approaches addressed these objectives using different approaches.

The collective problem-solving model. The more conventional mentoring model is the collective problem-solving model. Also known as the apprenticeship model, it is grounded in the belief that (1) the mentor is the guide or expert and (2) the optimal outcome is a change in the behavior of the mentee to correct a deficit. In this model, mentors work with pre-service or novice teachers to set pre-defined goals that will improve the mentee's work as a teacher or improve teaching methods (He, 2009). This method is the most commonly used mentoring program in education. The model is grounded in the belief that teaching can be learned through imitating the actions of a high-quality experienced teacher (Maynard \& Furlong, 1995).

In the collective problem-solving approach to mentoring, a teaching problem is identified first. The mentor engages the mentee in a discussion focused on interventions from observations and experiences observed in the classroom. Finally, the mentee (with direction from the mentor) chooses one approach to solve the problem. This process can be repeated as many times as necessary to arrive at a workable solution (Maynard \& 
Furlong, 1995; Miles, Saxl, \& Lieberman, 1988). Ackley and Gall (1992) reported four reasons for the popularity of this model. First, the apprenticeship problem-solving model can be used to fill gaps in teacher candidates' education or classroom strategies. This model offers a means to reflect together on past experiences and to suggest ideas to overcome deficiencies. The mentor introduces several ideas, and the teacher candidate attempts those that seem most appropriate for the situation. Another reason for the popularity of this strategy is that it allows both parties to address the mentee's lack of self-efficacy. Beginning teachers (pre-service or novice) are often unsure of their problem-solving capabilities with regard to teaching. This team effort allows mentors to help beginning teachers reflect on situations before suggesting alternatives. A third reason this strategy is so prevalent is that it is usually instigated by the mentee. Although the mentor initiates the conversation by pointing out a particular deficit, the mentee often mentions a weakness to discuss. This opportunity allows the mentee to take responsibility for professional growth. This trait is an important quality for a mentee (Ambrosetti \& Dekkers, 2010). The final reason for using the collective problem-solving model is its availability. Pre-service and novice teachers often has many questions that were not addressed during training. As situations or problems present themselves in the classroom, new teachers begin asking other teachers (including peers) how they would respond. Because teaching is so complex, many solutions are possible. The mentee can ask a colleague who might offer suggestions. These reasons explain why the collective problem-solving strategy is commonly used to address mentee weaknesses (Ackley \& Gall, 1992). 
In this conventional pre-service apprenticeship/mentoring model, a PST is under the guidance of a cooperating mentor teacher. University supervising teachers visit periodically to observe how the PST is doing. In studies involving this conventional setting, cooperating mentor teachers that had training in supervising skills were more likely to let their mentees interact more frequently with students in the formal classroom setting and in informal settings before or after class. Mentees were also more likely to be involved in planning and implementing lessons and receiving prompt constructive feedback (McIntyre \& Killian, 1987). This conventional model shows that 'traditional' mentoring can be effective if mentors are equipped with research-based effective techniques (McIntyre \& Killian, 1987).

A study that did not involve proper training reviewed how mentors conducted feedback sessions with their mentees. This case study revealed that, while one mentee had many different classroom opportunities, little learning came from 'reflective discourse meetings' with the mentor. The cooperating teacher assumed the role of benevolent expert, and the student teacher did not refute this role. The cooperating teacher initiated most of the conversation in the recorded feedback sessions. The student teacher gave short, superficial answers to questions. This study concluded that, if the cooperating teacher had been trained how to illicit constructive conversations with a student teacher, then the resulting mentor/mentee relationship could have been beneficial to both (Keogh, 2005).

The strength-building model. The second mentoring model described in research is the strength-based mentoring model. The objective of this model is mentoring should not be built on a derogatory foundation. Whereas the problem-solving model began 
with a problem or a deficit that could be corrected through the wisdom of an expert, the strength-based approach is built upon a pre-service teacher's strength to enhance teaching performance. The strength-based mentoring model depends on three basic principles to ensure that a collaborative educational experience was obtained (He, 2009).

First, the strength-based model requires that the mentoring team start by identifying the strengths and talents of the team. This activity nurtures an open relationship built on trust and respect. Next, a strength-finding instrument is used to uncover the strengths and gifts of each team member (He, 2009). This allows each member of the mentoring team to recognize the strengths of others through an objective technique.

The second goal of the strength-building model requires the team to make a conscious effort to develop collaborative competency goals to be met by a given time. It involves constructing motivational steps to keep mentors and mentees dedicated to the goals of the lesson. During this stage the team decides which forms of mentoring are best suited for the team in order to attain the competency levels discussed. The tactics include coaching techniques, co-teaching strategies, and demonstration sessions. It also includes implementing formal or informal mentoring meetings, debriefing sessions, and videotape analyses. While all these methods may appear in a supervisory model, in this model, the mentor(s) and mentee discuss each method and negotiate which methods would best fit the team. Once methods are selected, a reflective component evaluates the teaching tasks. Learning through reflection not only involves evaluating the task or lesson as it was presented, but it also includes expanding the lesson to promote 
alternative pedagogical methods or diversity learning techniques (He, 2009, Maynard \& Furlong, 1995 ).

The final goal of the strength-based mentoring model challenges each member of the team to become involved in every phase of the model. Team members are required to challenge the ideas and methods of others respectfully. Questioning reasons why specific actions were taken not only allows those asking questions to learn the answer, but it also requires those answering the questions to reflect and defend their actions. When done correctly, this strategy develops self-monitoring and teacher self-efficacy (He, 2009).

The strength-building mentoring model was accepted more readily in environments that promoted continual educational and professional growth of mentors and mentees. This model was based on meaningful conversations and social collaborations to facilitate all the frameworks needed to take advantage of its components.

The Professional Development Schools (PDS) setting used a more collaborative strength-building approach to mentoring. The PDS design sought to illicit collaborative growth among teacher candidates, cooperating teachers, and university supervising teachers. A change in terminology of roles under this design reflected this construct. The PST was called an "intern," cooperating teachers were labeled "mentors," and supervising teachers were named "university faculty members" (Lefever-Davis, Johnson, \& Pearman, 2007).

The idea of mentoring the intern under this design is viewed as “... a non-hierarchical, reciprocal relationship between mentors and 
mentees who work towards specific professional and personal outcomes for the mentee. The relationship usually follows a developmental pattern within a specified timeframe and roles are defined, expectations are outlined and a purpose is (ideally) clearly delineated" (Ambrosetti, \& Dekkers, 2010, p. 52).

Theoretically, this design had relatively few weaknesses in capturing the characteristics of effective mentor/mentee relationships described in the more conventional model. However, care had to be taken to remove two concerns that might arise in the implementation of the model. One concern was a lack of communication between any two members of the educational triad. A second concern was the possibility of ambiguous characteristics in any of the three roles. To be effective, each member of the triad must be recognized for his/her team contributions. Each member must also develop a mutual respect for other team members. Student learning, teacher development, and the equity of roles must be at the forefront of this design for the model to be successful (Lefever-Davis et al., 2007).

When these mentoring models were used in pre-service teacher preparation programs, the bond between a veteran teacher and the pre-service/novice teacher generally remained beyond the original assignment. This continuing relationship maintained growth in the two individuals and respect between mentors and mentees. Boreen and Niday (2000) noted that when veteran teachers view PSTs as professionals, they "encourage them to explore multiple perspectives and model continual learning" (p. 161). The veteran teachers seemed to have the most to offer a mentoring program. 
Furthermore, this continued support encouraged novice teachers to continue in the educational field (Johnson \& Birkeland, 2002).

In summary, these two models strengthened pre-service and novice teachers' skills and provided them support systems. Both methods advocated use of reflection and working on defined sets of goals in mentoring PSTs. They also incorporated constructive dialogue throughout the learning process. The major difference was how that model assisted growth from mentee to effective teacher. The problem-solving model established an expert/novice relationship that depended on the knowledge and expertise of the mentor to guide the mentee toward appropriate goals. The strength-building model encouraged the team to develop a working relationship that recognized and respected the strengths and gifts of each person. The team chose its own mentoring models and used continual reflection.

These two models represent components of more complex models rather than reflecting two separate mentoring models (Maynard \& Furlong, 1995). As such, these models can work together harmoniously. For example, one might begin with a field experience in which the teaching triad works as a team to recognize the others' strengths and weaknesses. This team might draw on this information to create goals for the mentee to achieve with the help of others. Likewise, occasions may arise where the mentor feels a problem needs to be addressed. The problem-solving model is beneficial in developing collaborative reflection techniques to assimilate different strategies from which the mentee can select. The experience that the mentor brings to the situation is a strength that can guide the mentee when appropriate. Thus, both mentoring methods have merit in mentoring pre-service teachers. 
The UTeach Institute. A pre-service model that is consistent with these ideas is currently in use in the United States. This model, named UTeach from the University of Texas at Austin, actively recruits STEM majors into pre-service classes that incorporate inquiry-based learning techniques, offers extensive classroom experience before graduation, initiates collaboration between PSTs and educators, and continues mentoring and supporting teachers entering the workforce. In the last decade, this program has expanded to a nationwide program. This study investigates the extent to which two of the original components are implemented at a single replication site and instrumental in reducing teaching concerns that lead to future attrition.

Faculty at the University of Texas at Austin developed an innovative PST preparation program for pre-service middle/high school mathematics and science teachers called UTeach. The program blended many of the previously mentioned philosophies. The UTeach program was an original program that offered "enrollees an academically challenging course schedule and curriculum that provides them with early and frequent experiences in the classroom and has firm grounding in math and science content" (Cavanagh, 2007, para. 4).

The UTeach program has gained national recognition from several organizations. One in particular came from the Congressional study of the challenges facing the economic progress of the United States entitled "Rising above the Gathering Storm." It was listed as a promising program designed to produce teachers with "deep disciplinary grounding" (Rising Above the Gathering Storm, 2006). To increase the number of qualified STEM middle and high school teachers nationwide, UTeach listed its objectives 
as: (a) actively recruit mathematics and science majors into the program; (b) prepare outstanding teachers in the STEM areas; (c) support students with continuous mentoring; and (d) provide outreach educational opportunities to its students and educators in the area. As a result of these efforts, UTeach doubled the number of students graduating with a teaching certificate at the University of Texas at Austin (The UTeach Institute, 2013). It also had a teacher retention rate exceeding the national average of $60 \%$ after four years, and nearly half of its graduates worked in low-income schools (Ibid, 2013; University of Texas College of Education, 2007).

On March 9, 2007, the UTeach program, in conjunction with National Mathematics and Science Initiative (NMSI), expanded the program nationally. Thirteen universities were selected from over fifty NMSI grant applicants to be the first institutions outside Texas to replicate the NMSI and UTeach curriculum design. These universities were: Florida State University, Louisiana State University, Northern Arizona University, Temple University, University of California--Berkeley, University of California--Irvine, University of Colorado at Boulder, University of Florida, University of Houston, University of Kansas, University of North Texas, University of Texas at Dallas, and Western Kentucky University (UTeach Institute, 2012).

During the last four years, the goals and objectives of UTeach and its replication sites have expanded to nine program objectives. The new objectives, called the "Elements of Success" include: (a) having a distinctive program identity; (b) maintaining cross-college and school district collaboration; (c) requiring long-term institutional and community support; (d) incorporating compact and flexible degree plans; (e) continuing an active plan for student recruitment and support; (f) employing 
dedicated master teachers; $(\mathrm{g})$ conducting rigorous, research-based instruction; (h) incorporating early and intensive field experience; and (i) encouraging continuous program improvement (UTeach Institute, 2011).

While the program encourages both formative and summative evaluations, no concentrated evaluation to determine whether the field experiences and mentoring components achieved these purposes at the replication sites could be found. The intent of this study was to study two major objectives of the program at one replication site. The objectives were (1) looking at the consequences of implementing early and highly engaged field experiences and (2) determine the effects of specific mentoring techniques used by dedicated master teachers with pre-service teachers. The study evaluated the extent to which these components reduced self-defeating apprehensions of PSTs so that their attention could be directed toward developing more effective teaching practices and thereby reducing causes for attrition. The purpose of the field experience component of the "Elements of Success" is to "promote confidence and accelerate professional development." The mentoring characteristics of the master teachers were described as "being exclusively dedicated to student support and program success" (UTeach, 2011, p. 2).

\section{Summary}

According to the National Science Board (2008) and the Business-Higher Education Forum (2006) the United States is dealing with a national shortage of secondary mathematics and science teachers. While one-third of this shortage can be explained by retirements, a vast amount of shortages come from dissatisfied or underprepared teachers that either transfer or leave the profession permanently (Alliance 
for Excellent Education, 2008). Research indicates that around 50\% of those that leave do so by the fifth year of teaching (Huling-Austin, 1986; Ingersoll, 2003a; Rogusky, 2003: Steffy \& Wolfe, 2001). When tracking the teacher career trajectory, the critical time for this departure appears at the end of the novice stage and beginning of the competent stage (e.g. Brand, 1983; Lynn, 2002). Student teachers have a similar trajectory during their student-teaching experience. While many evolve into qualified teachers ready to embrace the responsibilities of the teaching profession, those who that encounter hardships through inadequate support or lack of cooperation within the student-teacher triad are more likely to leave the program before embarking into the career. Others who have not overcome feelings of inadequacies or have a lower level of self-efficacy leave the teaching profession before reaching the competency stage (e.g. Burke et al., 1984; Lynn, 2002).

In an effort to minimize this exodus of teacher candidates, states have mandated induction programs for novice teachers in recent decades. From 1996 to 2002, a 450\% increase of teacher retention occurred in states requiring some form of induction intervention (Looney, 2011; Russell, 2006). Those induction programs that yielded a higher level of retention usually included extensive training on the part of the mentors, allotted time for interaction between mentors and mentees, and clearly defined assessment techniques to document growth of novice teachers. In addition, these programs required at least two years of intervention to take place (NCT, 2007). While such programs have been able to retain teachers, the burden to finance and staff such programs has proven daunting in light of major cut-backs of recent years (Villar \& Strong, 2007). If incorporating such comprehensive tactics in pre-service programs can 
produce similar results in retaining novice teachers as they progress through their beginning years, the implications have the potential to be financially and professionally valuable to the educational profession.

One such appeal was presented during the United States Department of Education's Teacher Preparation and Institutions of Higher Education: Mathematics and Science Content Knowledge Conference (Sanders, 2004). While higher education found implementing the suggestions offered by the speakers at the conference daunting, several began implementing more affective objectives in their teacher educations programs.

Affective objectives in a mathematics teachers' educational course development included growth in attitudes, beliefs and feelings toward teaching mathematics (Brahier, 2009; Miller, 2005).

Teacher affective constructs that can determine how effective a teacher will be in a classroom include concerns and efficacy beliefs. Teacher concerns have been identified as self-preservation concerns, task-related concerns, and student-impact concerns (Fuller, et al. 1974). Studies have shown that these concerns can be sequential (Beeth \& Adadan, 2006; Conway \& Clark, 2003; Pyper, 2009, Van den Berg, Sleegers, \& Geijsel, 2001); while others have found that they can appear simultaneously (e.g. Dadlez, 1998; Evans \& Tribble, 1986; Reeves \& Kazelskis, 1985). Self-efficacy has been described as “one’s belief about his or her ability to organize and execute tasks to achieve specific goals" (Charalambous \& Philippou, 2003, p. 1). The levels of efficacy that one possesses can be influenced or strengthened from four sources: mastery experiences, vicarious experiences, social influences, and physical or emotional well-being. Research indicates an inverse correlation between teacher concerns and efficacy beliefs; that is as the levels 
of self-efficacy rises; the lower the level of self-preservation concerns become (e.g. Boz \& Boz, 2010; Charalambos \& Philippou, 2010; McKinney et al., 1999). In an effort to obtain this result, it is pertinent to understand the underlying characteristics that could lead to early attrition.

Teacher anxiety, distress, and burnout which can hinder the progression of teachers from self-centered concerns and toward more constructive student impact concerns can be avoided by focusing on increasing self-efficacy and simultaneously increasing student learning. In each case exhibiting undesirable affective characteristics, the stronger the negative characteristic, the more dogmatic the teaching style and the lower the tolerance in student behavior (e.g. Adams \& Martray, 1981; Bush, 1989; Campbell, 1983; Campbell \& Williamson, 1973; Coates \& Thoresen, 1976; Hart 1987; Hollingsworth, 1990). These characteristics appear to escalate until the teacher eventually leaves the profession (e.g. Campbell, 1983; Ducharme, et al., 2007; Fisher, 2011). Since these characteristics can be equated to self-preservation and task-related concerns (Fuller, et al. 1974), it follows that the more a teacher possesses these concerns, the more likely the chance that attrition will occur. Research indicated that techniques that include large quantities of observational and highly engaging field experiences in less dogmatic environments, support from supervisors, and training in proactive classroom management techniques seem to lessen these negative characteristics in novice teachers and pre-service teachers in the elementary settings (e.g. Murray-Harvey et al. 2000; Wadlington, Slaton, \& Partridge, 1998). This study will look at what effects highly engaged field experiences and a variety of mentoring techniques have on STEM preservice teachers. 
A significant amount of research that examines the relationships between teachers' concerns and efficacy beliefs on pre-service elementary teachers, novice teachers, and experienced teachers has been conducted (e.g. Charalambos \& Phillippou, 2010; Ghaith \& Shaaban, 1999; McKinney et al., 1999; Murray-Harvey et al. 2000; Wadlington, Slaton, \& Partridge, 1998). However, the literature review conducted here identified only one study which focused specifically on concerns and efficacy beliefs of STEM pre-service teachers (Boz \& Boz, 2010). Therefore a lack of supporting evidence focuses on teacher concerns of STEM teachers exists. Furthermore, the components of a STEM pre-service program that could significantly lower these concerns, thus increasing self-efficacy and reducing attrition, before entering a teaching career, are not clear. A gap in the research exists as it pertains to solving the problem of STEM middle and secondary teachers or pre-service teachers leaving the profession. In light of this, the current study addressed teacher concerns and teacher self-efficacy and the extent to which two concepts, continuous highly engaged field experience and multi-faceted mentoring strategies lessened the self-preservation concerns.

\section{Overview of the Two Programs Used in this Study}

In the next chapter, the methodology will largely center around two programs, the Traditional program and the SKyTeach program. The Traditional program was labeled as such because it was based on typical past practices. This program utilized primarily observational field experiences and academic advisors as recognized mentors preceding the student-teaching experience. The SKyTeach program, a university-designated name to characterize the region it served-southcentral Kentucky and surrounding areas, modeled the UTeach program. This program employed frequent active field experiences 
throughout the pre-service training years and had an assortment of mentoring models. The following section more fully explains the details of each program.

\section{Characteristics of the two contrasting programs}

The treatment group includes PSTs who studied under SKyTeach, the UTeach replication curriculum, at mid-sized university. This university is located in the south central portion of the United States. The treatment group is referred to as SKyTeach Group for the remainder of the study. The non-treatment comparison sample included PSTs who were trained in a middle/secondary teaching program using a more conventional STEM teacher preparation program at the same university. This group shall be referred to as the Traditional Group. The following section compares and contrasts the characteristics of the SKyTeach program and the Traditional Program. In particular, the means of field experiences and mentoring practices of each program will be examined.

The Traditional Program. The traditional program at the university prepared STEM middle/secondary PSTs by providing rigorous content courses in the PST's chosen major along with courses focused on pedagogical techniques. To emphasize its commitment to establishing a comprehensive teacher education program, the university became a charter member of Renaissance Group for Teacher Education in 1989. This organization sought "to improve teacher preparation programs by reflecting on past practices, celebrating accomplishments, embracing present and future educational challenges, and by sharing strategies and practices designed to improve local, regional and national learning environments" (Giovannetti, 2012, pg. 1).

Preservice teachers who sought certification in a STEM area at the middle or secondary level were required to obtain a minor or major degree in a STEM area and seek 
a teaching certificate through the Department of Curriculum and Instruction. In order to receive secondary mathematics or science teacher certification, PSTs were required to major in a mathematics-based or science-based specialty that required between 30 and 54 credit hours in mathematics or science. PSTs who chose the lower amount of credit hours were required to obtain a compatible double major or minor. Middle school PSTs were required to select either two areas of certification requiring 24-27 semester hours each or a single subject certification with a minimum of 54 hours in either mathematics or science (Western Kentucky University, 2005). The education curriculum portion of the Traditional Program included more than 35 hours of professional education courses.

Field experience. The Traditional Program required that PSTs complete a total 150 hours of field experience outside classroom coursework. This was a core component of the ten professional education courses taken in the sophomore year and continuing until the student teaching experience. Student-teaching hours were not included in this portion of the program (R. Tyler, personal communication, April 4, 2013). Each course had a fifteen hour field experience requirement as a standard qualification. These experiences were generally set up by the university with some placement suggestions made by students being honored. According to university personnel, the field-experience portion of the degree was not externally monitored by university personnel, but was documented by area teachers (K. DuCloux, personal communication, April 2013; S. Evans, personal communication, April 9, 2013; R. Tyler, personal communication, April 4, 2013). The nature of the field experience varied from instructor to instructor. A sample of twenty-four education syllabi from spring 2009 to spring 2010 revealed that most early field experiences were observational and general in nature. Some instructors 
required that field experiences be conducted through focused observations. In rare incidences, students were encouraged to engage in limited active teaching.

Mentoring. PSTs in the Traditional program were assigned two "mentors." The roles of the mentors usually involved serving as "academic advisors" for the PST degree rather than those characteristics described as a "mentor" in the previous chapter. One academic "mentor" offered guidance regarding the content courses needed in the area of certification concentration. The other served as an educational resource who offered advice about what courses should be taken in the Department of Curriculum and Instruction. While university guidelines of the course sequencing were available in university catalogues, no formal training was required for either type of advisor. Neither did either type of mentor typically addressed affective concerns of the PSTs unless specifically asked to do so by the PST. These advisors were not trained to undertake these concerns or questions regarding topics other than course placement. (S. Evans, personal communication, April 9, 2013).

This program produced STEM teachers from the 1970's to the early 2000's; however, the number of middle and secondary STEM teacher enrollment declined during the nineties (S. Evans, Personal communication, April 9, 2013). With increased awareness caused by an appeal from the United States Department of Education's Teacher Preparation and Institutions of Higher Education: Mathematics and Science Content Knowledge Conference (Sanders, 2004), the Western Kentucky University (WKU) administration searched for a program that would complement the existing program and increase STEM teacher enrollment. 
This university applied for the NMSI grant to duplicate the UTeach program at WKU. It became one of 13 original recipients of the NMSI grants. Upon acceptance of into the replication program, the traditional program slowly phased out until the replication program was completely integrated into the curriculum. The transition from the Traditional program to the SKyTeach program occurred over five years--from the fall of 2007 through the spring of 2012.

The SKyTeach Program. The goal of the original UTeach program in Texas was to increase the number of qualified STEM middle and high school teachers nationwide by: (a) actively recruiting mathematics and science majors into the program; (b) preparing outstanding teachers in the STEM areas; (c) providing pre-service teachers with continuous mentoring; and (d) providing outreach educational opportunities to its pre-service teachers and area educators. One of the accomplishments of UTeach was graduates of the program remained in teaching beyond the national average of five years (Cavanagh, 2007). On March 9, 2007, the UTeach program, in conjunction with National Mathematics and Science Initiative (NMSI), began duplicating its program nationally (University of Texas College of Education, 2007).

During the last four years, the goals and objectives of UTeach and its replication sites have expanded. The new objectives, called the "Elements of Success" include:

- $\quad$ Distinctive program identity

- Cross-college and school district collaboration

- $\quad$ Long-term institutional and community support

- $\quad$ Compact and flexible degree plans

- $\quad$ Active student recruitment and support 
- $\quad$ Dedicated master teachers

- $\quad$ Rigorous research-based instruction

- $\quad$ Early and intensive field experiences

- $\quad$ Continuous program improvement (UTeach Institute, 2011)

This study focused on two of the objectives of the SKyTeach program: (a) mentoring support of students in the program and (b) implementation of early and intensive field experiences. This study also sought to explore the extent to which these objectives were implemented effectively and were more successful in reducing teachers' concerns than those used in the traditional program. Support for those students in the program was promoted through "mentoring throughout the program and continued support after graduation" (SKyTeach Overview, 2012, p. 1). With regard to the field experience component of the "Elements of Success," the program's purpose was to “promote confidence and accelerate professional development” (UTeach, 2011, p. 2). While the program encourages both formative and summative evaluations, no evaluation of these two components, effective mentoring and early field experiences, was conducted to determine if the purposes were achieved, as far as my inquiries were able to determine. The treatment group in this study participated in one of the pilot replication programs of the UTeach Institute. It was named SKyTeach to identify its operating district in southern Kentucky and surrounding areas.

Although the mentoring and field experience components of the two programs were quite different, the SKyTeach program held to same course content requirements as the Traditional program. All students under the SKyTeach program concentrated their interests in a content area major as well as in a STEM education major called a Science 
Mathematics Education (SMED) major. In order to complete a secondary mathematics or science major, PSTs had to complete a degree in mathematics or a specific science area of concentration requiring at least 30 credit hours. Middle school science PSTs were required to complete 46 semester hours in a variety of science courses. Middle school mathematics PSTs were required to complete a content program of 32 hours of mathematics-based courses. In addition, all STEM pre-service teachers had to complete a second major in science and mathematics education (SMED), which required completion of STEM education classes using an inquiry-based approach (Western Kentucky University, 2011 ).

Field experiences. Another characteristic of SKyTeach was early and highly engaged field experiences by PSTs during all four years of their undergraduate program. During the first semester, PSTs were mentored as they taught pre-designed mini-lessons in an elementary school. This guided instruction was increased to three field-teaching experiences in the middle school level by the end of the second semester. During their sophomore year, PSTs completed classes taught by educational psychology faculty and curriculum and instruction faculty. Students learned about research methods and analyzed the strengths and weaknesses of different models of teaching. Pre-service teachers learned how technology enhances the learning experience. In addition, PSTs applied what they had learned by delivering at least one lesson in a high school setting. The junior year focused on historical impacts of education, as well as in mathematical or scientific instructional procedures in the classroom setting. Their senior year featured classroom practice sessions on how to present lessons clearly and correctly. It culminated with the student-teaching practicum during the last semester (Burch, 2008). 
Mentoring. In addition to frequent teaching opportunities throughout the program, the PSTs participated in focused mentoring programs in the pre-service training stage. This program employed a variety of advisors or mentors. First, students were paired with academic advisors who guided them in selecting courses, similar to those responsibilities of the advisors in the traditional program. SKyTeach also employed other two additional types of mentors: master teachers and veteran classroom teachers. The master teachers were employed by the university and served as instructors as well as mentors. Their duties included: (a) instructing pedagogical content; (b) modeling science and mathematics lessons at different grade levels; (c) reviewing pre-service teachers written lesson plans; (d) observing and providing critiques of fieldwork experiences; and (e) advising pre-service teaches with regard to professional and personal growth issues. Another source of mentorship in this program came from veteran classroom teachers. Local classroom teachers served as short-time mentors with an assignment usually lasting one semester. Veteran teachers guided PSTs in specific classroom logistics such as: (a) demonstrating techniques of classroom discipline and addressing diversity concerns at different developmental stages; (b) encouraging PSTs to embrace different pedagogical styles in their presentations; and (c) advising PSTs regarding school policies (R. Tyler, personal communication, November 19, 2010; The UTeach Curriculum, 2009).

Both types of mentors in the SKyTeach program advocated the philosophy of Hargreaves and Fullan (2000), in which mentoring was "a way of preparing teachers to become effective change agents who are committed to making a difference in the lives of young people and are skilled at the pedagogical and partnership developments that make success with students possible" (pg. 54). Formal training for academic advising began as 
a volunteer program in the fall of 2009 (Advisors of Excellence Program, 2013); however, most college instructors used informal advising procedures. These procedures included using the university's undergraduate advising handbook, interdepartmental support, and online resources (S. Bateiha, personal communication, April 2, 2012; S. Evans, personal communication, April 9, 2013). Master teachers at the replication sites trained faculty at a two-day workshop conducted annually at the University of Texas at Austin. Continuing training was available for new master teachers through: (1) shadowing veteran mentor teachers at the replication site and (2) workshops available at different times during the year and at the UTeach Convention each May. Initially, veteran teachers attended a local three-hour workshop conducted by local master teacher trainers in order to understand the requirements of that position. New additions to the veteran teacher pool were mentored by master teachers and trained by veteran teachers on replication philosophies and expected responsibilities (R. Tyler, communication, December 12, 2012; UTeach Curriculum, 2009).

Comparing SKyTeach pilot program to UTeach program. To verify that the pilot program of the SKyTeach program was consistent with the pilot UTeach program, the following data were collected. At the end of the first semester of SKyTeach program, 29 students were enrolled (K. Long, personal communication, April 13, 2011). This number is compatible to the original UTeach class which had 28 candidates enrolled in the fall of 1997 (Rodriguez \& Gerrow, 2003). As with the UTeach program, all students of the replication program were recruited from majors of STEM programs. These student were introduced to STEM teaching by being enrolled in the Science and Mathematics Education class (SMED 101) entitled "Introduction to Inquiry-Based Approaches to 
Teaching." The course encouraged students to contemplate a college career in STEM education through field experiences in an elementary school and using science or mathematics content knowledge.

During the next four years, several students withdrew from the program. As of fall 2010, 18 pilot students remained in the SKyTeach program. The students that quit the program were primarily white females who decided to pursue a different career. One female decided to pursue a career as an elementary teacher and was no longer eligible for the SKyTeach program. Two males also left the education program (K. Long, personal communication, April 13, 2011). UTeach and its replication programs were designed to encourage students to enter the STEM education field by providing them a realistic picture of the daily trials of teaching. Under this premise, understandably some students found that a career in education was not desirable and left before investing four years of preparation. This early attrition of students in the UTeach/ SKyTeach program was identified and addressed as favorable for both financial gains in reducing potential attrition for school districts and personal gains in guiding these students toward more appropriate careers for themselves. By all indications, the SKyTeach pilot program was compatible to the UTeach pilot program thus implying that the same standards were being met.

In summary, these two programs were designed to train qualified middle and high school teachers in the STEM areas by having the PSTs train under a dual program encompassing a major in a STEM area and a parallel emphasis on pedagogical course work. However, the SKyTeach program also used an extensive array of frequent highly engaged field experiences throughout their pre-service training as well as utilizing 
multi-faceted mentoring techniques to enhance their PSTs' training prior to student-teaching training. The Traditional program largely depended on observational field experiences beginning in the sophomore year and offered the PSTs guidance on course work with academic advisors preceding the student-teaching experience. Table 1 provides an outline of the similarities and differences between the Traditional Program and SKyTeach Program. 
Table 1.

Comparison of Characteristics of Programs

\begin{tabular}{|c|c|c|}
\hline Characteristics & Traditional & SKyTeach \\
\hline \multirow{11}{*}{$\begin{array}{l}\text { Core content } \\
\text { criteria }\end{array}$} & Secondary: STEM Content & Secondary: STEM Content \\
\hline & Major & Major \\
\hline & Also second STEM & 30 credit hours \\
\hline & Major or a STEM & \\
\hline & Minor if first & \\
\hline & Major has around 30 & \\
\hline & hours & \\
\hline & Middle: $33-35$ hours in one & Middle: STEM Content \\
\hline & STEM area or & Major \\
\hline & 24-27 hours in two & Math : 32 hours \\
\hline & STEM areas & Science: 46 hours \\
\hline \multirow{5}{*}{$\begin{array}{l}\text { Education } \\
\text { content criteria }\end{array}$} & Math/Science Major & STEM Major \\
\hline & 30 hours of & SMED major \\
\hline & education courses & (science/mathematics \\
\hline & Teachino Certificate & Teaching Certificate \\
\hline & Student Teaching & Student Teaching \\
\hline \multirow{3}{*}{$\begin{array}{l}\text { Field } \\
\text { experiences }\end{array}$} & 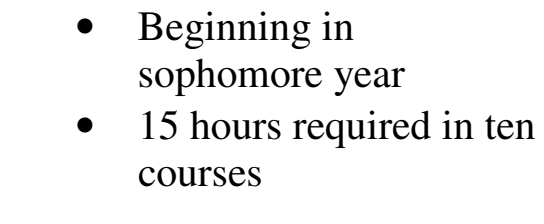 & $\begin{array}{l}\text { - } \quad \text { Beginning in fall of } \\
\text { Freshman year } \\
\text { - } \\
\text { Required every } \\
\text { semester with }\end{array}$ \\
\hline & $\begin{array}{l}\text { - Mostly observational in } \\
\text { nature }\end{array}$ & $\begin{array}{l}\text { increasing frequency } \\
\text { - Some observational } \\
\text { but gradual change to } \\
\text { classroom instruction }\end{array}$ \\
\hline & $\begin{array}{l}\text { - Not externally } \\
\text { monitored }\end{array}$ & $\begin{array}{l}\text { Monitored by mentor } \\
\text { teachers and/or } \\
\text { veteran teachers }\end{array}$ \\
\hline \multirow{5}{*}{ Mentors } & - $\frac{\text { Two academic }}{\text { advisors: }}$ & - $\frac{\text { Two academic }}{\text { advisors: }}$ \\
\hline & $\begin{array}{ll}\text { - } & \text { Content advisor } \\
\text { - } & \text { Educational } \\
& \text { advisor }\end{array}$ & $\begin{array}{ll} & \text { Content } \\
& \text { advisor } \\
\bullet & \text { Educational }\end{array}$ \\
\hline & & advisor \\
\hline & & $\begin{array}{ll}\text { - } & \text { Master Teacher } \\
\text { - } & \text { Veteran Teachers }\end{array}$ \\
\hline & - No training required & $\begin{array}{l}\text { Training for Master } \\
\text { Teacher and Veteran } \\
\text { Teachers }\end{array}$ \\
\hline
\end{tabular}




\section{CHAPTER 3}

\section{METHODOLOGY}

\section{Introduction}

The purpose of this study was to examine what the effects of two key components, continuous highly engaged field experiences and multi-faceted mentoring strategies, served to minimize teacher concerns and increase self-efficacy, while reducing those characteristics that lead to early attrition. Using Fuller and Parson's (1974) framework of teacher concerns, variations in concerns were recorded of pre-service teachers who were trained using two different pre-service STEM programs. Selfpreservation concerns were of special interest, so this concern was meticulously investigated.

Understanding the impact of continuous highly engaged field experiences and multi-faceted mentoring in reducing these concerns is relevant to this research project because it informed the researcher of strengths and weakness of the specific topics within the two programs. The results of this study will be used to advocate what changes need to be made in current STEM pre-service teacher curricula which will improve teacher development experiences.

This study employed a quasi-experimental design to determine the extent to which continues highly engaged field experiences and multi-faceted mentoring strategies reduced pre-service teachers' concerns during a student-teaching 
practicum. Quantitative and qualitative data were gathered. The quantitative portion of the study used the Teachers' Concern Checklist to obtain empirical data about the pre-service teachers' concerns. The TCC had been established as a reliable resource for identifying self-preservation concerns, task-related concerns, and student-impact concerns (Borich \& Rogan, 1988; Borich, 1992; Rogan, Borich, \& Taylor, 1992). Qualitative data were obtained from open-ended questions on the surveys, online blogs and interviews. This collection of responses provided information from different sources in order to render a more complete picture of the effects that the different types of field experiences and mentoring models had on reducing self-preservation concerns before and during the student-teaching practicum.

\section{Research Questions}

The research questions for this study are:

RQ1: What is the nature and level of pre-service teacher (PST) concerns about teaching for PSTs in the traditional STEM program and PSTs in the SKyTeach program, at two key points in their program: immediately prior to and upon completion of the student-teaching experience?

RQ2: How and to what extent does SKyTeach's emphasis on high-engagement field experiences, compared to the relative absence in the traditional program, affect self-preservation concerns of senior pre-service teachers prior to entering and upon completion of their student-teaching experiences? 
RQ3: How and to what extent does SKyTeach's emphasis on systematic, intentional support of trained mentors, compared to the relative absence in the traditional program, affect self-preservation concerns of senior pre-service teachers prior to entering on and upon completion of their student-teaching experiences?

\section{Research Design}

In order to conduct a focused topic program evaluation of the two pre-service teacher training programs with regard to reducing teachers' concerns, a quasi-experimental research design (Shadish, Cook, \& Campbell, 2002; Rossman \& Rallis, 2003) was implemented. An expanded version of the static-group comparison was employed as was described in Campbell and Stanley (1963).

The study included a treatment group - PSTs who experienced the SKyTeach program with enhanced field experiences and mentoring - and a comparison group PSTs who experienced a traditional preparation program. A purposive sampling, exclusively selecting both middle and secondary STEM preservice teachers attending the Student Teaching Seminar, was employed to establish the treatment and comparison groups (Shadish, Cook, \& Campbell, 2002, Teddlie \& Tashakkori, 2009).

\section{Participants}

The participants in this study were selected from 91 students across four consecutive semesters and who entered their final semester of study in their respective STEM teacher preparation programs. This study followed the transition of the STEM curriculum from a more traditional curriculum to the SKyTeach curriculum.

Initially all 91 students who registered for the Student Teaching Seminar during four consecutive semesters beginning in spring 2011 and concluding in fall 2012 were 
invited to participate in the study. The first semester, consisting of 28 students, was used as a pilot for testing the study's instruments. Because of the valuable insights gathered during this process, the responses of six focus group members and five students interviewed were compiled and included in the study. From the remaining three semesters that included 63 students, 45 students (71.4\%) completed all components of the survey; 13 PSTs were from the Traditional program and 32 PSTs were from the SKyTeach program. This is response rate was determined acceptable for dissertation questionnaires by Roberts (2004). Of those that completed all the survey components, 14 students $(31.1 \%)$ were male, and two students (4.4\%) were from under-represented minority groups. The study was divided into two groups: the comparison group called the Traditional student teachers, and the treatment group formed from the SKyTeach student teachers.

The Traditional students were included in the study to increase the internal validity of this study (Shaddish et al., 2002). This group included the STEM pre-service seniors who followed the traditional curriculum during the transition period from fall 2007 to graduation. Thirteen students, of the original 26 Traditional seniors taking the Student Teaching Seminar, matched this criterion and participated in all aspects of the survey. Four were male. No information had been gathered regarding the attrition of this group before the student-teaching semester; therefore, selection-mortality reviews between this group and replication students were not possible (Shadish, Cook, \& Campbell, 2002). 
The SKyTeach program enrolled 65 student teachers in the Teaching Seminar beginning in spring 2011 and ending in fall 2012 semesters. Of these PSTs, 32 (49.2\%) completed all the components of the survey. Ten SKyTeach student teachers were male. This sample was used as the basis for the statistical analysis of the treatment group for this study.

Table 2.

Samples

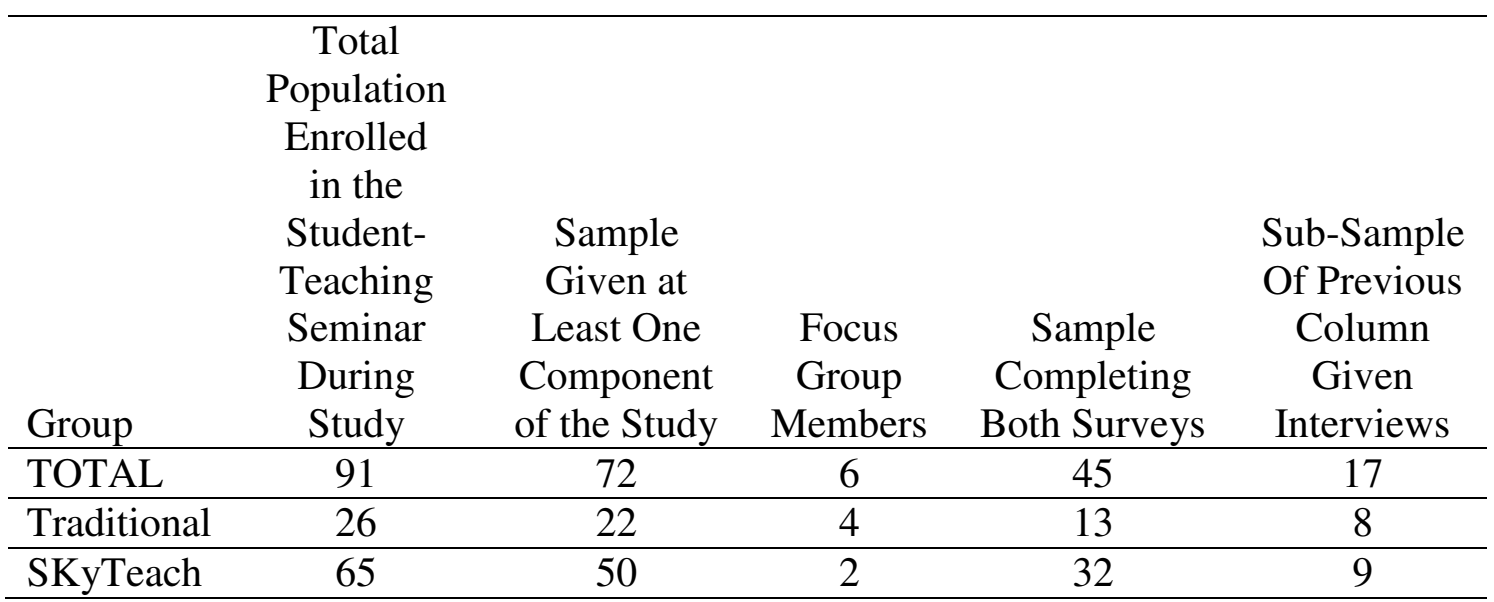

Note. Data gathered from the last three columns were used in study's analysis. These groups are not independent.

\section{Instruments}

Data were gathered before, during, and after the student-teaching experience and subsequently analyzed. The three main sources of data included: (a) two analytical semi-structured interviews (Glesne, 2006); (b) a survey containing both qualitative and quantitative questions; and (c) a collection of responses to reflective Blackboard blogs about the student-teaching experience as they related to the study. All data collection strategies were appropriate for assessing teacher education programs as outlined in Darling-Hammond (2006). 


\section{Interviews}

Developing the Semi-structured interviews. A draft of interview questions focused on program differences, such as field experiences, mentoring aspects, and apprehension about teaching, was developed from questions found on the Graduate Questionnaire Survey (SKyTeach, 2010). These questions were reviewed by Student Teaching Seminar instructors to establish content validity regarding specific issues addressed above. Once reviewed and revised by the researcher, the interview questions were tested in a focus-group setting. This focus group, consisting of six PSTs, was conducted in the second session of the Student Teaching Seminar using a semi-formal approach. Of the six randomly selected students, four PSTs were in the Traditional program, and two were in the SKyTeach program. This strategy strengthened the internal validity of the measure by having representatives from both groups to review the questions (Teddlie \& Tashakkori, 2009). The purpose of the discussion in a focus group setting was to: (a) get a more intimate view of the thoughts about the two programs; (b) determine how prepared the PSTs felt before entering the student-teaching portion of their education; and (c) explore the PSTs' aspirations for teaching. In addition, questions focused on fieldwork and mentoring experiences were evaluated for clarity and understanding. Given the small sample of students in the Student Teaching Seminar class, students in the focus group may be swayed to conform to relaying the same experiences in a similar fashion with those in their same program instead of conveying personal information about mentoring experiences, highly engaged field experiences, and apprehensions about teaching (Teddlie \& Tashakkori, 2009). A validity threat of transferability might arise with the focus group members relaying information about the 
topics of discussion to the general population (Shaddish et al., 2002, Teddlie \& Tashakkori, 2009).

The focus group interviews lasted an hour and twenty minutes. The responses from this pilot focus group interview proved to be enlightening. Members of the focus group saw no need to revise any interview questions; however, evidence of teacher concerns arose throughout the interview. Many of the focus group responses were aggregated with the rest of the interview data to answer the first and second research questions (RQ1 \& RQ2). The student teacher instructors were informed that the focus group interviewees found the original questions to be suitable for the study.

The focus group discussion was digitally recorded and transcribed. Using a fundamental coding scheme, the key topics of each programs' highlights and career preparations were recorded. Teachers' concerns component needed to be added to the study, because their concerns appeared to be a dominant theme in the focus group discussion. However, the different programs revealed different levels of concern during the focus group. The teacher instructors agreed to add an additional element of teacher concerns to the study, and the researcher proceeded with the interviews. Reviewing the questions prior to the interviews strengthened the trustworthiness of the study by eliminating unclear or predisposed questions that might bias the responses of the questions. (Glesne, 2006; Rossman \& Rallis, 2003).

Semi-structured Interviews Executed. During the study, 17 additional PSTs were individually interviewed twice. Of these, eight PSTs participated in the Traditional program and nine PSTs participated in the SKyTeach program. The interviews were semi-structured and followed the prescribed interview questions (Rossman \& Rallis, 
2003). The first initial interview was conducted three weeks after the start of the spring 2011 Student Teaching Seminar class and before student instructional teaching had occurred. In the following semesters, interviews were conducted a month before the class and during an introductory session outlining components of the student-teaching semester and distribution of school assignments. The components of the initial interview included: (a) background information; (b) confidence in teaching content material; (c) impressions of content classes and pedagogical classes; (d) impact of field experiences; and (e) impact of mentoring on preparation for the student-teaching experience. The initial interviews ranged from 25 minutes to 40 minutes depending on follow-up questions. In addition to the questions asked during the interview, the interviewer encouraged students to be diligent in participating in the weblog activities recording their student-teaching experiences. The initial interview was analyzed using a revised coding scheme that included the section on concerns (Appendix C).

After students had an opportunity to teach a unit during student teaching, they were individually interviewed again. The second set of interview questions revisited major topics in the initial interviews using a list of questions only as a guideline of topics (Appendix B). In addition, some follow-up questions were asked based on answers given prior to the teaching experience. This follow-up interview also focused on concerns about the student-teaching experience mentioned in the first interviews. The second interviews were more conversational in nature (Rossman \& Rallis, 2003) and generally lasted 30 to 40 minutes. All initial and follow-up interviews were digitally recorded, transcribed, and coded using the same scheme (Appendix C). A pictorial timeline of when the interviews were held can be found in the Table 3. 
Table 3

Timeline to be used for Interviews (Spring 2011-Fall 2012)

\begin{tabular}{|c|c|c|c|c|c|}
\hline GROUP & & $\begin{array}{l}\text { Previous } \\
\text { Training }\end{array}$ & $\begin{array}{l}\text { Early Semester } \\
\text { Before any } \\
\text { teaching had } \\
\text { occurred }\end{array}$ & $\begin{array}{l}\text { Student } \\
\text { Teaching } \\
\text { Experience }\end{array}$ & $\begin{array}{l}\text { Late Semester } \\
\text { After teaching } \\
\text { occurred }\end{array}$ \\
\hline 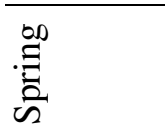 & & & $\begin{array}{c}\text { Focus Group } \\
n=4\end{array}$ & & \\
\hline 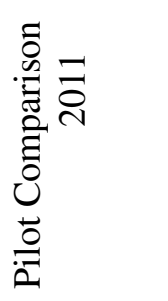 & NR & Traditional & $\begin{array}{c}1^{\text {st }} \text { round initial } \\
\text { Interview } \\
n=3\end{array}$ & & $\begin{array}{l}\text { 1st round exit } \\
\text { Interview }\end{array}$ \\
\hline 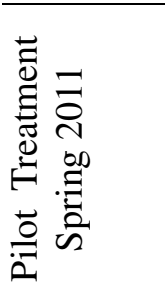 & NR & SKyTeach & $\begin{array}{c}\text { Focus Group } \\
n=2 \\
1^{\text {st }} \text { round initial } \\
\text { Interview } \\
n=2\end{array}$ & & $\begin{array}{l}\text { 1st round exit } \\
\text { Interview }\end{array}$ \\
\hline
\end{tabular}

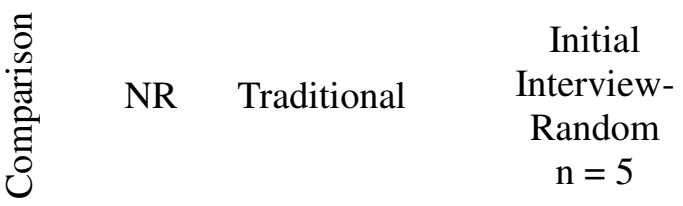

Exit Interview

\begin{tabular}{|c|c|c|c|}
\hline $\begin{array}{l}\vec{\Xi} \\
\text { छ }\end{array}$ & NR & SKyTeach & $\begin{array}{c}\text { Initial } \\
\text { Interview- } \\
\text { Random }\end{array}$ \\
\hline & & & $\mathrm{n}=7$ \\
\hline
\end{tabular}

Note. SKyTeach: Treatment following UTeach Replication Curriculum

Traditional: Comparison group following Traditional STEM Curriculum Focus: Focus Group

Interview: Interview of Students randomly selected from each group

Plausibility of Qualitative Results. The plausibility of the recording and analyzing responses was tested through a series of constant comparison techniques described in Rossman and Rallis (2003). By reviewing previous studies' interpretations (i.e. Adams et al., 1981, Borich \& Tombardi, 1997; Boz \& Boz, 2010; Fuller \& Bown, 
1975), doing a cross-case analysis with the responses previously received from the focus group, and looking for recurring themes in the pilot pre-student-teaching interviews, the presence of underlying topics within Fuller's (1969) teacher concerns was discerned before the student-teaching experience began. By following Miles and Huberman's (1994) techniques of noting patterns and comparing and contrasting information, a significant amount of information was gathered during these initial contacts. The next procedure was to refocus on the field experiences and mentoring effects themes and how they relate to teacher concerns during the pre-service teachers exit interviews. This qualitative portion of the study allowed for further investigation to extract subtle differences in PTSs' teacher concerns and the effects of field experiences and mentoring had on these concerns that might go undetected by quantitative analysis.

Rater-ReliabilityTesting. To further test the plausibility of my analysis of responses by pre-service teachers, coding techniques were reviewed by another doctorate student at the end of spring 2011. A random sampling of 40 quotes was coded using the study's Qualitative Coding charts (Appendix C). The individual teacher concerns were rated on a semi-continuous scale containing (a) high levels of concern, (b) moderate (medium) levels of concern and (c) lower levels of concern or confidence. This raterreliability check revealed an $82 \%$ agreement of coding standards. Much of the variability occurred when trying to discern between low/moderate concern levels and moderate/high levels of concern. No solitary comment was deemed specifically as "having a medium level of concern". Thus, to improve the rater-reliability score the coding was reduced to a dichotomy scale. This included the two extremes of either having high levels of concern or lower levels of concern (confidence). When the medium range was removed 
the rater-reliability of assigning scales to qualitative data improved to a $92 \%$ agreement of coding. Figure 1 illustrates the initial process of data collection and the sequential changes made to coding.

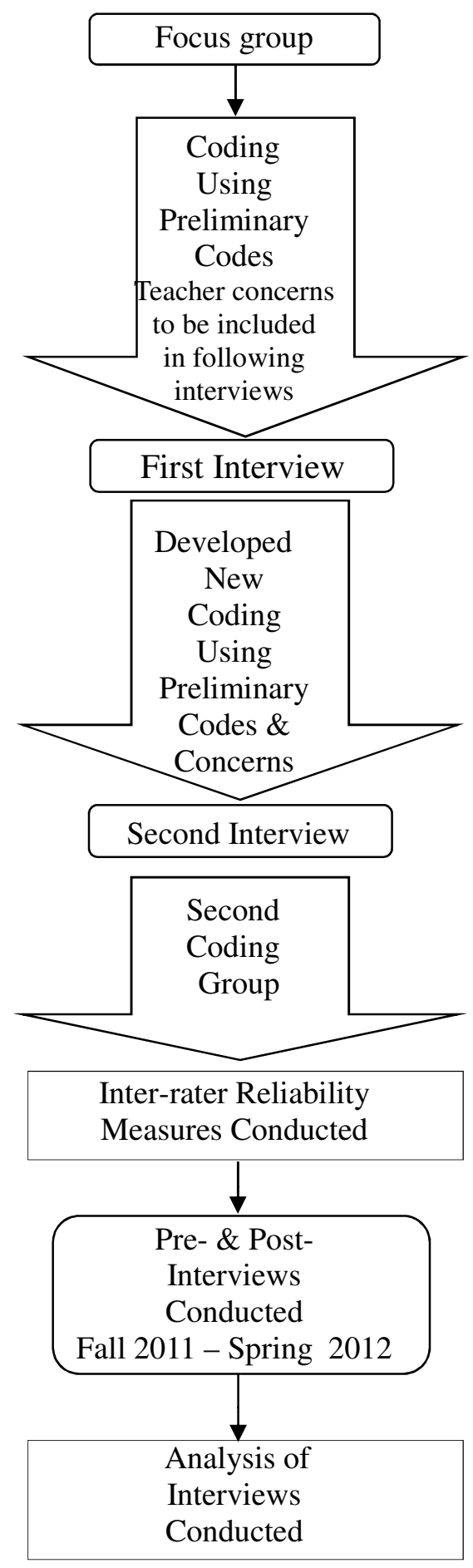

Figure 1. Data Collection procedure for interviews 


\section{The Teacher Concern Survey}

The study used a Likert-style survey to assess the levels of concerns that the PSTs had before and after their student-teaching experience. The survey was based on the teacher's concerns checklist by Fuller and Borich (Borich, 1988). It contained 45 statements--each focusing on one of the three stages of concern: self-preservation concerns, task-related concerns, and student impact concerns. The responses were configured on a 5-point Likert type scale ranging from Not Concerned to Totally Preoccupied. The participants of this study completed a modified version of Fuller's Teacher Concern checklist used by McVey (2004) twice. McVey's survey not only measured teachers' concerns but also recorded how well they felt that their teacher education program addressed these concerns. In addition to the 45 questions reviewed by Fuller, McVey had 45 parallel statements to determine the teacher education effectiveness of each statement (See Appendix D-survey). These additional answers related to teacher education effectiveness. The results from these questions will be used in future research. The PSTs were directed to respond to each statement by supplying the best response for their current degree of concern.

Validity and Reliability of the TCC Survey. Fuller's teacher concerns checklist has been repeatedly tested, improved, and found reliable (Borich \& Rogan, 1988; Borich, 1992; Rogan, Borich, \& Taylor, 1992). Initially, Fuller (1969) investigated the level of teachers' concerns using a qualitative instrument. To enhance reliability to the subject matter, Fuller and Parsons (1974) subsequently developed a quantitative component to measure concerns. That instrument included less than ten concern statements. 
George (1978) improved the instrument and published a manual describing the 15 Likert-like survey items to measure the levels of self, task, and impact concerns. After several other adaptations, a revised 50-item Stages of Concerns was developed in 1988 by Fuller and Borich (Borich, 1988). This version was administered to teachers, pre-service teachers, and graduate students with some teaching experience. The analysis was both descriptive and inferential. The factor analysis revealed that only 31 items loaded on to their predetermined concerns prompting the need to create a new modified version. Nineteen other statements were modified or replaced to create a survey that contained 45 statements with 15 statements addressing each concern. After field testing the second version, a final adaptation was made by replacing four statements.

This final version was analyzed by Rogan and others (1992) using 778 pre-service or student teachers and 191 in-service teachers. A factor analysis showed that 30.4 percent of the variance loaded on impact concerns; 8.9 percent loaded on self-preservation concerns; and 7.2 percent loaded on task concerns. Overall these three factors accounted for 46.6 percent of the total variance. Each of the individual concerns was subjected to a varimax rotation analysis. The 15 items designated as impact concerns generated coefficients of 0.55 or above. Two task concerns items also generated coefficients of 0.53 and 0.45 . Fourteen of the task concerns loaded to its designated variance with coefficients of 0.49 or above. This study also found that 13 of the task items had coefficients of 0.37 or higher. One self-preservation item did not load on any of these factors.

Rogan and others (1992) explored the mean scores of concerns across the samples as well as the means of each concern level by teaching experiences using a one-way 
analysis of variance (ANOVA). These tests indicated that PSTs with less teaching experience had the most concerns across all factors. The study also showed that with increased teaching experience, a steady decrease in self-preservation concerns occurred as outlined by Fuller's model. Cronbach's alpha held a construct reliability rating of 0.91 .

Researchers concluded that the questionnaire could be used with confidence in determining teachers' concerns; however, they noted that teachers' concerns may not follow a sequential pattern because teachers may repeat a concern stage. This study used a modified version (Appendix D-survey) similar to the one used in McVey's (2004) study that included teacher education effectiveness ratings on concerns.

The rest of the survey was qualitative in nature. These questions focused on the amount of time spent in educational field experiences before the student-teaching experience. Questions explored: (a) the purpose of the field experience (observation, administrative, instructional practice); (b) the amount of time spent at each task; and (c) the quality of the field experience as it relates to preparing for the student-teaching experience. The type and amount of mentoring that the pre-service teacher received throughout the program was also explored through open-ended questions. The mentoring questions asked how much time the pre-service teacher spent with an advisor during an average semester and what role(s) the mentor served. The complete survey (Appendix D) was administered at the beginning of the Student Teaching Seminar class and before any teaching has been performed by the PST to establish concerns and then again after the PST has delivered at least a ten day unit in a classroom setting to see if any additional 
insights can be gathered about the student-teaching experience with regards to teacher concerns. Each survey took approximately thirty minutes to complete.

Reflective Journaling Using Blackboard. All class members were asked to participate in a class Blackboard blog discussing their student-teaching experiences. These postings followed most of the protocols of informal reflection as explained by Shoffner (2008), who was a proponent of student-led web-based reflective journals. In this study, PSTs were encouraged to introduce topics of interest or concern throughout the course. While participation was a requirement of the class, no guidelines were placed on the content or frequencies of the entries. The PSTs were told that the main goal of these reflective entries was to explore and reflect on the student-teaching experience. Additional guidelines about using personal expression on a semi-public domain were also suggested. Only postings that were related to this study were recorded for assessment purposes and were qualitatively coded for reoccurring themes. When viewing the submission of weblog entries relating to this study, it was important to note the personal reflective pieces could have inflate results due to self-reporting issues. Some PSTs may not want to be completely forthcoming with their concerns knowing their instructors were reading the blogs.

\section{Data Collection Procedures}

This study spanned four semesters--spring 2011 through fall 2012. Data were gathered using a four-stage process outlined in Table 4. The table outlined the sequence of data gathering during the pilot semester and following semesters. 
Table 4

Timeline to be used for Data Gathering (Spring 2011-Fall 2012):

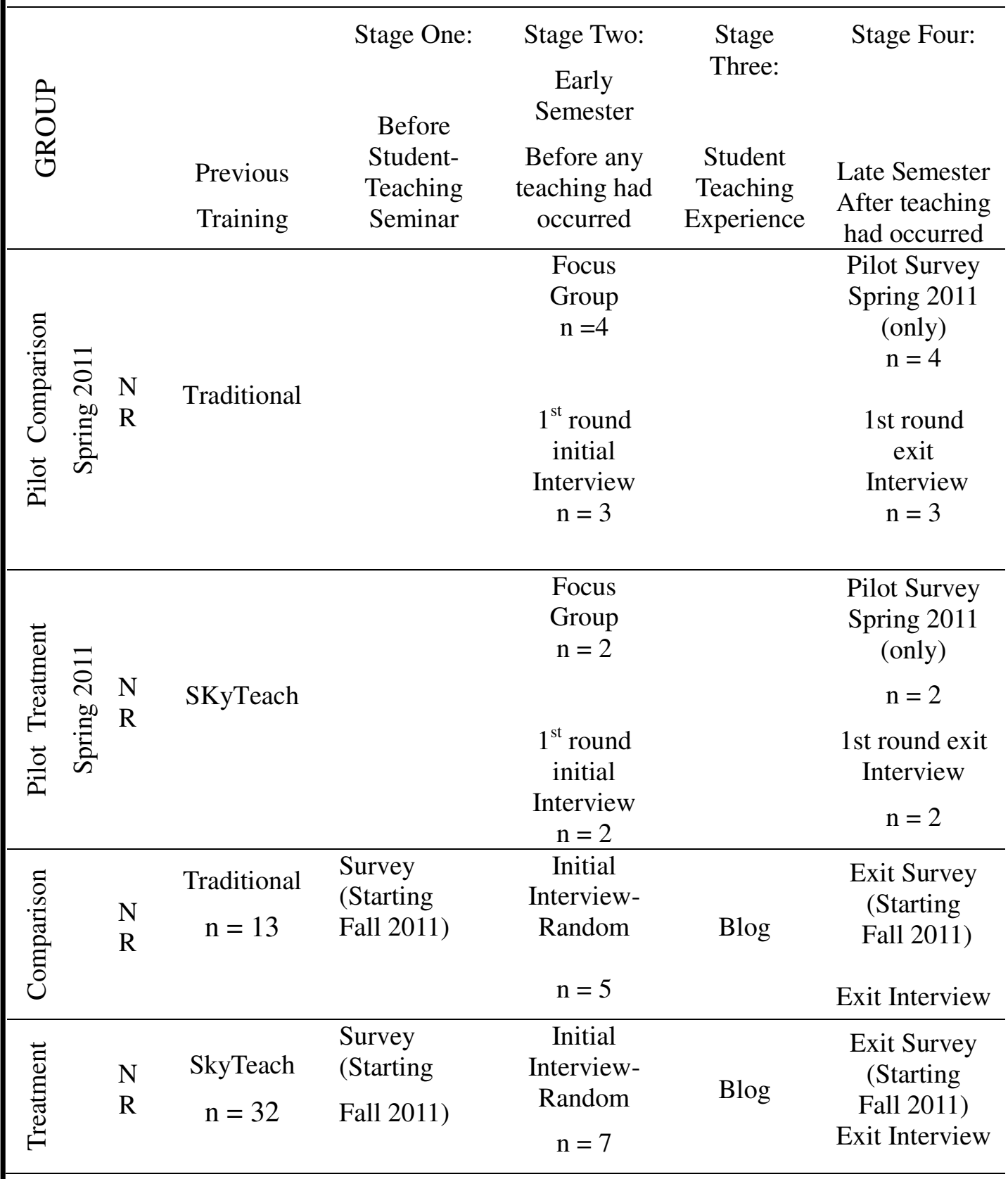

Note. SKyTeach: Treatment following UTeach Replication Curriculum

Traditional: Comparison Group following Conventional STEM Curriculum

Focus: Focus Group/Pilot Study of Survey

Interview: Interview of Random Students

Survey: Survey Administered to Students

Blog: Reflective Journal on Blackboard 
The focus group interview, the first round of interviews, and an initial trial of the survey were conducted during the spring of 2011. Data collection was monitored by Student Teacher Seminar instructors. To promote support by the Student Teacher Seminar instructors, a review period was conducted after each of the initial trials. The instructors were appraised on the preliminary findings of the initial data collection instruments. An appeal for modifications of interview questions or additional input regarding any of the data collection was requested at this time. While modifications regarding the interview were proposed by the researcher, no additional changes were suggested by the instructors.

The initial quantitative survey was conducted at the end of the semester by those persons involved in the focus group and first round of interviews. The schedule followed in the Student Teaching Seminar was rigid-providing the student teachers access to a maximum amount of information in a minimum amount of time. The class instructors noted that the time allotted to finish the survey exceeded the 30-minute limit; therefore, a request that fewer questions be asked on the survey was made. This request was accommodated with cooperation between the researcher and instructors.

Qualitative questions were revised to extract the same material with fewer questions. Five (task-related) questions from the TCC were deemed irrelevant to the student teachers in this area. Having questions that were deemed irreverent to the participants in the study was an issue raised by a study conducted by Reeves and Kazelskis (1985). These questions numbers were 1, 11, 12, 25, and 38 (Appendix D). Since the total number of PSTs in this study would not exceed the required 100 needed for an effective factor analysis (Gorsuch, 1983; Kline, 1979) and that previous studies by 
Fuller and Borich (Borich, 1988) and Rogan and others (1992) had deemed the questions on this survey as reliable, removal of these items did not severely impact the overall goals of how the components of highly engaged field experience and multi-faceted mentoring strategies reduced concerns. The Student Teacher Seminar instructors were pleased with the modifications, supportive in encouraging PSTs to participate, and made a concentrated effort to gather delinquent materials throughout the rest of the study.

Following the pilot semester, data collection was more standardized. During an informational session conducted the previous semester or during the first day of first Student Teaching Seminar meeting, PSTs who were enrolled members of Student Teaching Seminar class were asked to participate in the study. They were provided an IRB passive consent form because most of the evaluation included pre-existing components of the course. This will reduce the threat of lack of participation and, hopefully, stabilize my effect size. All participants were told that they could voluntarily remove themselves from the evaluation at any time. This statement removed any legal or ethical concerns about participating in the evaluation.

The Teacher Concern Survey and its qualitative additions were administered to all members of the class during the introductory meeting in the following semesters. The survey was administered by class instructors in the presence of the researcher. The revised survey was scheduled to be completed in approximately 30 minutes.

Initial individual interviews with randomly selected PSTs were conducted during the second stage of the evaluation before teaching had occurred. The interviews occurred during the first or second meeting of the Student Teaching Seminar. They were administered by the researcher in a room adjoining the Student Teacher Seminar 
classroom. They were scheduled to take from 30 to 40 minutes, depending on the number of follow-up questions. All interviews began with a digitally recorded affirmation that the participant was a willing volunteer. In addition, consent to record and confidentiality clause was chronicled. The use of the consent and confidentiality statements were used since such a small sample of participants were interviewed (Appendix A). These statements are given to assure the interviewees that the researcher was aware that responses could be easily identifiable but every consideration would be taken to protect their identities. The interview ended with remarks emphasizing the importance of their participation and an expression of gratitude for their input.

The third stage of the study involved gathering information from the reflections of the pre-service teachers during their student-teaching experiences. During this stage, the pre-service teachers performed the duties in the clinical student-teaching experiences. Postings to the reflective weblogs provided information about clinical experiences. These postings continued formally until the end of the semester. Postings that were relevant to the study were logged as they related to teaching experiences and to previous field experiences and mentoring opportunities.

During the fourth stage of the evaluation, two measures were gathered. Students again completed the Teacher Concern Questionnaire for comparison to the previous questionnaire. Only the results from those students who submitted both surveys were analyzed. Procedures for administrating the survey were the same as with the initial survey. In addition, another round of interviews with the same PSTs was conducted to determine if changes in concerns had occurred or if additional improvement was offered. Protocols regarding consent-to-record and the confidentiality clause were repeated as 
well. These interviews lasted 30 to 40 minutes and were more conversational in nature, although a guideline was provided (Appendix B). Questions about information gathered from the two surveys and the online postings were asked. These interviews were conducted by the researcher and were digitally recorded following the same protocol as the initial interviews. On a few occasions, the final interviews were conducted using SKYPE or involved the use of a written questionnaire. In these cases, the PST interviewees had been assigned a teaching abroad assignment, which creating challenges to gather quality information during the second interview.

Data-Analysis Procedure. Both quantitative and qualitative data collected (Fitzpatrick, Sanders, and Worthen, 2011; Teddlie \& Tashakkori, 2009) were analyzed to determine what effects highly engaged teaching experiences and multi-faceted mentoring strategies might have had on reducing teachers' concern during the student-teaching experience.

Descriptive and inferential analyses of the quantitative data were done using a Statistical Analysis System (SAS) data analysis program. A descriptive analysis of those who participated in the study was conducted. To align questions to concerns a confirmatory factor analysis was attempted even though sample size was small. A MANOVA was run to determine a change in overall concern from the beginning of the study to after student teaching had taken place. To determine significance in the differences among the means between self-preservation, task, and impact concerns between traditional and SKyTeach samples, several ANOVAs and ANCOVAs were conducted. Finally a Repeated Measures ANOVA was run on individual concerns within each program to see if there was a change in each concern. 
This study also employed qualitative methods to describe both models of teacher training in more detail. The focus group interview and private interviews were digitally recorded and transcribed. Copies of the blackboard journal entries related to this study were logged. These results were coded and reviewed using the method of continual analysis described in Rossman and Rallis (2003). Miles and Huberman (1984) defined codes as "tags or labels for assigning units of meaning to the descriptive or inferential information.” By using an inductive approach to review key topics and reoccurring themes in the pre-student-teaching interviews, the exit interviews focused on differences in teachers' concerns since the beginning of the semester.

A second interview was included to determine if the additional mentoring support of a cooperating teacher or the master experiences preformed during the student-teaching assignment alleviated some previous teacher concerns. If the hypotheses are correct, by removing more superficial self-preservation concerns, these student teachers would be able to focus more of their efforts on student learning and effective teaching practices. 


\section{CHAPTER 4}

\section{RESULTS OF TEACHER CONCERNS}

In this chapter, the results related to the first research question will be presented. An analysis of the data will begin by giving a demographic summary of the STEM pre-service teachers in the study. This will be followed by the quantitative results of overall teacher concerns present between the Traditional and SKyTeach programs before and after the student-teaching experience. A subsequent section will explore if there was any significant change in relation to the individual teacher concerns, classified as self-preservation, task-related, and impact-related concerns, between and within the Traditional and SKyTeach PSTs during the student-teaching semester. Finally, a rigorous exploration of the qualitative results will explore the intricate details of how each teacher concern impacted the PSTs of the Traditional and SKyTeach programs. This outline is detailed in the following figure:

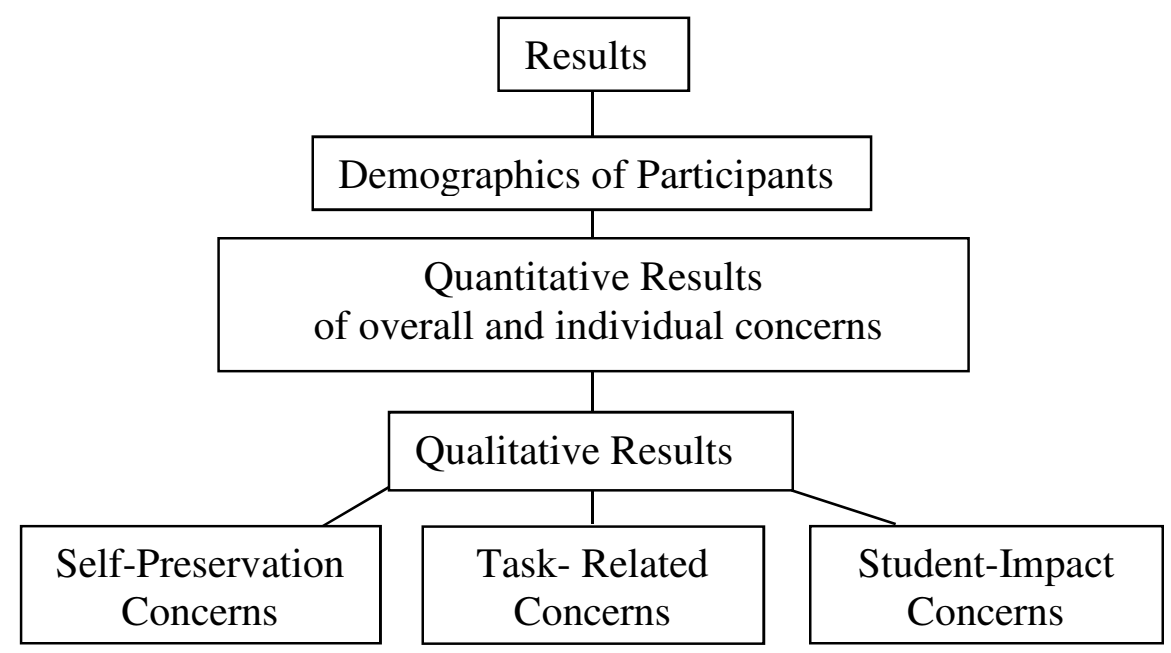

Figure 2. Outline of Chapter 4 


\section{Demographics of the Quantitative Study Participants}

A total of forty-five PSTs completed all of the components of the survey; 13 from the Traditional program and 32 from the SKyTeach program. Of those that completed the survey, 14 (31.1\%) PSTs were male; four from the Traditional program and 10 from the SKyTeach program. Two (4.4\%) SKyTeach PSTs were from under-represented minority groups. Seven (15.5\%) PSTs were over the age of 25. Four of these were part of the Traditional Program and three from the SKyTeach Program.

The Traditional PSTs consisted of a diverse group of seniors. Six seniors were completing their degree program in order to obtain a middle school teaching certificate and seven PSTs were seeking to acquire a secondary teaching certificate. Eight were classified as Mathematics majors and five were Science majors. The average age of the Traditional PSTs was 27 years old. If the older PSTs were removed from this count, the average age was 22.6 years.

The SKyTeach PSTs also consisted of a heterogeneous group of students. There were 17 who were seeking a teaching certificate at the middle school level and 14 were seeking a secondary teaching certificate. One PST was earning both middle and secondary certification degrees. Seventy-five percent (24) SKyTeach PSTs were majoring in Mathematics. Those seniors in the SKyTeach program had an average age of 23.9 years of age. If the older students were removed from this sample, the average age was 22.1 years.

Seventeen PSTs participated in the two interview sessions. A total of eight PSTs were members of the Traditional program and nine were members of the SKyTeach program. Nine of these students completed both TTCs surveys and their TTC open- 
ended responses were included in the qualitative portion of this study. In addition to the 17 interview participants, five participants were members of the pilot interviews; three were traditional PSTs and two were SKyTeach PSTs. All the responses from these participants were used in the qualitative review of the study.

\section{Teaching Concerns of Traditional and SKyTeach PSTs}

In order to determine what teaching concerns exist among the Traditional and SKyTeach PSTs prior to entering and immediately after the student-teaching experience, a mixed-method approach was implemented. First, the quantitative information was analyzed to find the significance, if any, of each of Fuller's (1969) teaching concerns. A further investigation using qualitative data was used to delve deeper into each concern to see if any difference could be determined within a particular concern.

Quantitative Results of Teacher Concerns. To analyze the level of concern that each group possessed, the modified Teacher Concern Checklist (TCC) was analyzed by looking at the pre-measurement of teacher concerns and post-measure of teacher concerns as illustrated in Figure 3. As discussed in Chapter three, only 40 of the 45 items (Appendix D) were used in this study because of the relevance to the concerns of these PSTs and time restraints. The choices were tabulated and calculated using a five-point scale. The value " 0 " indicated the lowest level of concern and " 4 " indicated the highest level of concern. A score of "2" indicated a level of "moderately concerned", the midpoint of the scale. Only the portion of McVey's (2004) survey that related to personal concerns was used in this study. Those questions addressing the extent to which PSTs perceived their teacher education program prepared them for teacher concerns will be used in future studies. 


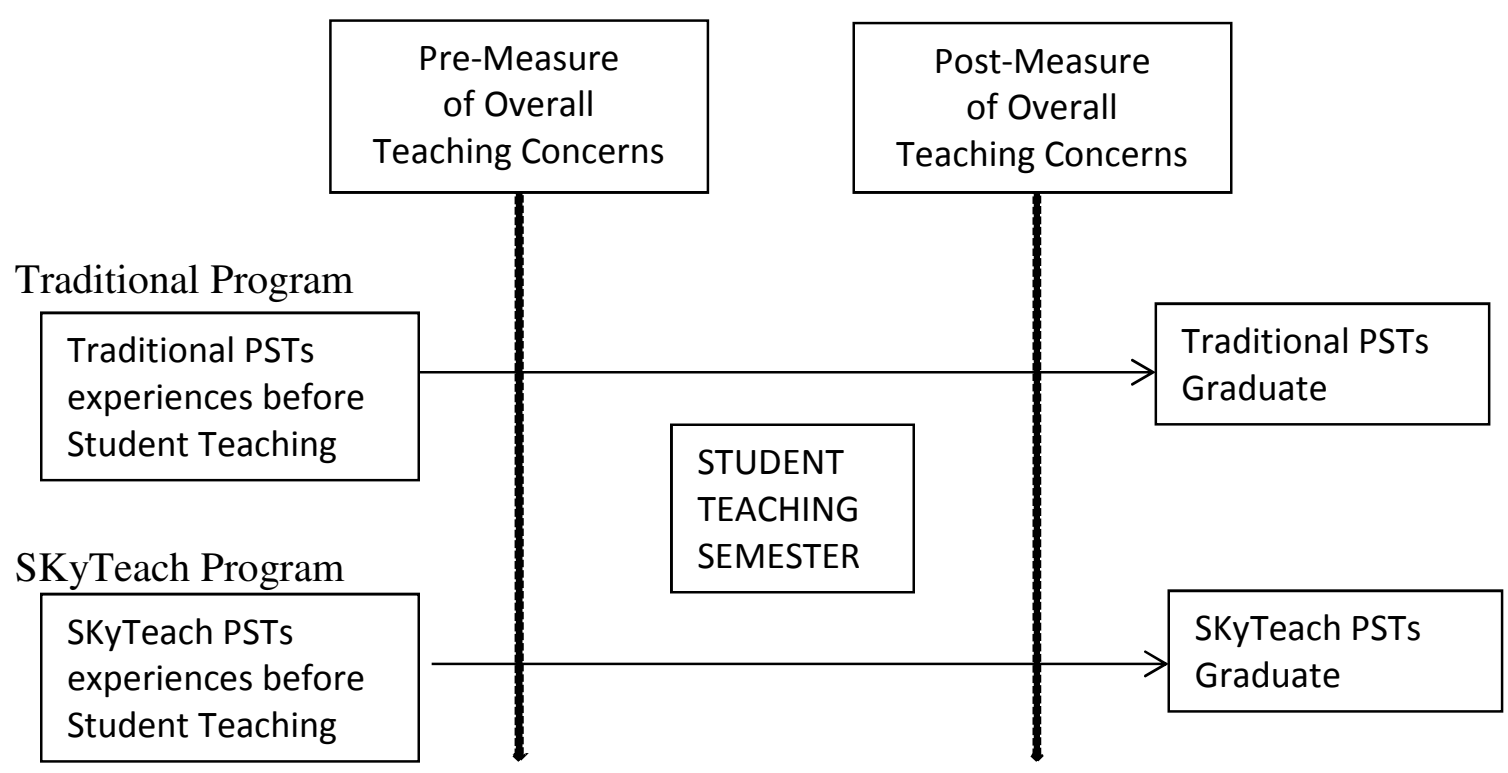

Figure 3. Quantitative Measures of Teacher Concerns Between \& Within Programs Exploring overall teacher concerns. First, a confirmatory factor analysis of the three factors was run on 52 TCC pretests in exploratory fashion, but because of the relatively limited sample size the results should be interpreted with caution. (Some of these PSTs did not complete the posttest survey so their results were not used in the final analysis). This factor analysis showed all the items loaded on one factor: overall concerns rather than falling into the three types of concern documented by Fuller (1969). Using this information, a descriptive analysis and an ANOVA were conducted to see if there was any difference in overall teaching concerns of the 45 participants that completed both a pre-survey and a post-survey. In order to calculate the level of overall teachers' concern between the Traditional and SKyTeach PSTs, first each individual PST's mean score was calculated by dividing the sum of the scores by the total number of questions, in this case, 40. The higher the score, the more overall concern the student teacher had about teaching. All mean scores were then tabulated and a total mean score 
was calculated for both the Traditional group and SKyTeach group. The descriptive statistics of the mean scores of pre-concerns and post concerns are found in Table 5.

Table 5

Mean (Standard Deviation) scores of overall teaching concerns before and after student teaching.

\begin{tabular}{cccc}
\hline & Before & After & $\begin{array}{c}\text { Change within } \\
\text { program? }\end{array}$ \\
\hline Traditional $(\mathrm{n}=13)$ & $1.58(0.65)$ & $1.30(0.76)$ & No change $(p=0.33)$ \\
SKyTeach $(\mathrm{n}=32)$ & $1.64(0.68)$ & $1.57(0.84)$ & No change $(p=0.74)$ \\
$\begin{array}{c}\text { Comparison across } \\
\text { the two groups } \\
\text { (p-value })\end{array}$ & $\begin{array}{c}\text { Same across } \\
\text { each group } \\
(p=0.80)\end{array}$ & $\begin{array}{c}\text { Same across } \\
\text { each group } \\
(p=0.32)\end{array}$ & \\
\hline
\end{tabular}

Note. Concern scores on a scale of $0-4$, with higher score signifying greater concern.

These results indicate that both groups of PSTs teaching concerns ranged between "slightly concerned" and "moderately concerned". A series of statistical tests were run in order to assess whether these results indicated a significant difference. An alpha level of .05 was used for analysis on all statistical tests.

To determine any significance in the difference between the programs, an ANOVA was conducted on concerns of those PSTs that had completed both surveys before the student-teaching experience $(F(1,43)=0.07, \mathrm{p}=.80)$ and after the student-teaching experience $(F(1,44)=.98, \mathrm{p}=.32)$. These results revealed no significance difference between concerns and type of program at either stage of the study.

To determine if there was any significant difference within the Traditional PSTs' overall teaching concern levels from the beginning of the student teaching and after the student -teaching, an ANOVA was calculated $(F(1,24)=.98, \mathrm{p}=.33)$. This test was also calculated for the SkyTeach PSTs $(F(1,62)=.11, p=.74)$. Neither program show significant changes in the degree of overall teaching concerns as the semester progressed. 
According to Stevens (2009), in order to run a factor analysis so as to be confident of the results, one should have a sample size that would equal 15 times the number of variables. In this case, that would mean this study would have to have 600 pre-service teachers. Similarly, the total number of PSTs in this study did not exceed the required 100 needed for an effective factor analysis as outlined by Gorsuch (1983) and Kline (1979). Because of these reasons, the alignment of survey questions to the three individual teaching concerns generated by the factorial analysis of Rogan and others (1992) was used to continue the investigation.

When the SAS program was constrained to find three factors or concerns indicated by Rogan and others (1992), it showed that 14.9 percent of the variance loaded on the first factor (student-impact); 2.9 percent loaded on the second factor (selfpreservation); and 2.4 percent loaded on last factor (task-related). Overall these three factors accounted for 20.2 percent of the total variance as it aligned to the structure of the TCC question loading conducted by Rogan and others (1992).

Next, both programs were combined to see if any of the individual types of concerns: self, task, or impact concerns had been reduced from the beginning of the study to the end of the study. This portion of the investigation was pursued using MANOVAs. Results indicated that there was no significant changes in overall concerns of self-preservation $(\mathrm{F}(1,44)=1.91, \mathrm{p}=.17)$, task-related concerns $(\mathrm{F}(1,44)=.73, \mathrm{p}=$ $.40)$ or student impact concerns $(\mathrm{F}(1,44)=.94, \mathrm{p}=.34)$. The results show no significant change of individual concerns when viewing results from Wilks' Lambda, Pillai's Trace, Hotelling-Lawley Trace, or Roy's Greatest Root tests. 
Comparing individual types of teacher concerns between programs. Next, the level of individual teachers' concerns between the Traditional and SKyTeach PSTs was examined using the same pre- and post- measurement surveys as outlined in Figure 3. In order to examine the level of individual types of teachers' concern between the two programs, mean scores for individual concerns, self-, task-, and impact- concerns, were calculated by dividing the sum of the scores by the total number of items related to that individual type of concern. The higher the score, the more association the student teacher had with that individual concern. The results in Table 6 indicate the descriptive statistics of each teaching concern throughout the study.

These results indicate that both groups of students were "moderately concerned" about all concerns at the beginning of their student-teaching experience. In order to establish whether there was any statistically significance between programs on individual types of concern, an alpha level of .05 was used for all statistical tests. To determine any significance in the difference in the scores at this time, an ANOVA was conducted on self-preservation concerns $(F(1,43)=0.09, p=.76)$; task-related concerns $(F(1,43)=0.02, p=.88)$; and student impact concerns $(F(1,43)=0.03, p=.58)$. These results revealed no significance difference between types of concerns and type of program prior to student teaching. 
Table 6

Mean (Standard Deviation) scores of self-, task-, and impact-related concerns.

\begin{tabular}{|c|c|c|c|}
\hline & Before & After & $\begin{array}{c}\text { Change within } \\
\text { program? }\end{array}$ \\
\hline & \multicolumn{3}{|c|}{ Self-Preservation Concerns } \\
\hline Traditional $(\mathrm{n}=13)$ & $1.49(0.68)$ & $1.22(0.79)$ & $\begin{array}{c}\text { Approaching } \\
\text { significant reduction } \\
(p=0.059)\end{array}$ \\
\hline SKyTeach $(n=32)$ & $1.55(0.67)$ & $1.49(0.83)$ & No change $(p=0.56)$ \\
\hline \multirow[t]{2}{*}{$\begin{array}{l}\text { Comparison across } \\
\text { the two groups } \\
\text { (p-value) }\end{array}$} & $\begin{array}{l}\text { Same across } \\
\text { each group } \\
(p=0.76) \\
\end{array}$ & $\begin{array}{c}\text { Same across } \\
\text { each group } \\
(p=0.32)\end{array}$ & \\
\hline & \multicolumn{3}{|c|}{ Task-Related Concerns } \\
\hline Traditional $(\mathrm{n}=13)$ & $1.65(0.68)$ & $1.34(0.76)$ & No change $(p=0.11)$ \\
\hline SKyTeach $(n=32)$ & $1.68(0.70)$ & $1.63(0.86)$ & No change $(p=0.63)$ \\
\hline \multirow[t]{2}{*}{$\begin{array}{l}\text { Comparison across } \\
\text { the two groups } \\
\text { (p-value) }\end{array}$} & $\begin{array}{c}\text { Same across } \\
\text { each group } \\
(p=0.88) \\
\end{array}$ & $\begin{array}{l}\text { Same across } \\
\text { each group } \\
\quad(p=0.30)\end{array}$ & \\
\hline & \multicolumn{3}{|c|}{ Impact-Related Concerns } \\
\hline Traditional $(\mathrm{n}=13)$ & $1.55(0.78)$ & $1.38(0.76)$ & No change $(p=0.42)$ \\
\hline SKyTeach $(n=32)$ & $1.69(0.72)$ & $1.63(0.89)$ & No change $(p=0.67)$ \\
\hline $\begin{array}{c}\text { Comparison across } \\
\text { the two groups } \\
(p-\text {-value })\end{array}$ & $\begin{array}{l}\text { Same across } \\
\text { each group } \\
(p=0.58)\end{array}$ & $\begin{array}{l}\text { Same across } \\
\text { each group } \\
(p=0.39)\end{array}$ & \\
\hline
\end{tabular}

Note. Concern scores on a scale of $0-4$, with higher score signifying greater concern.

Significance shown at $\mathrm{p}<0.05$ level.

The results in Table 6 are also indicative of the descriptive statistics for the mean scores of each concern at the conclusion of the student-teaching semester. While all the scores once again rank in the "moderately concern range", the consistently slightly higher scores of SKyTeach group suggests there may be a programmatic difference between the two. An ANOVA was conducted to see if these results were statistically significant. The 
results indicated that at the end of the student-teaching semester, there was no significant difference between the two programs as it related to either self-preservation concerns $(F(1,43)=0.99, \mathrm{p}=.32) ;$ task-related concerns, $F(1,43)=1.12, \mathrm{p}=.3) ;$ and student impact concerns $(F(1,43)=0.76, \mathrm{p}=.39)$. In addition an ANCOVA was also conducted using the pre-concerns as a covariant to see if any significant differences between programs would be observed on the post- concerns. There was no evidence of difference between self-preservation concerns $(F(1,1)=1.19, \mathrm{p}=.28)$; task-related concerns $(F(1,1)=$ $1.51, \mathrm{p}=.23)$; or student impact concerns $(F(1,1)=.46, \mathrm{p}=.50$ after student teaching.

Comparing individual types of teacher concerns within programs. Finally, there was a review of the change in the level of each concern from the beginning of the student teacher semester to the end of the semester within a program. Table 6 allows the comparison between the mean scores of each individual concern for the entire study within each program. A decrease of mean values when comparing before student teaching mean scores and after student teaching mean scores of each individual concern indicates that there was a decrease of that particular individual concern. There was a visible decrease in self-preservation concerns and task-related concerns among the Traditional PSTs. There was also a slight decrease in student impact concerns. The SkyTeach PSTs showed only a slight change among every individual concern from the beginning of the semester to the end of the semester.

A Repeated Measures ANOVA was run on each concern within a program to determine if any of the changes in concern were the significant. When looking at the changes within the Traditional sample, the self-preservation concern decrease $(F(1,12)=$ 4.33, $\mathrm{p}=.059)$ ) was approaching significance. The other two concerns of the Traditional 
sample: task-related concerns $(F(1,12)=2.92, \mathrm{p}=.11)$; and student impact concerns $(F(1,12)=0.69, \mathrm{p}=.42)$ showed no statistical significance it the change in concerns. There also was no statistical significance change of self-preservation concerns $(F(1,31)=$ $0.33, \mathrm{p}=.56)$; task-related concerns $(F(1,31)=0.23, \mathrm{p}=.63)$; and student impact concerns $(F(1,31)=0.18, \mathrm{p}=.67)$ within the SKyTeach sample.

Overall, the quantitative data analyses yielded no significant differences of variations of teacher concerns between the two programs or among a program from the beginning of the student teacher semester to end of the semester. These results are substantially dependent on sample size and measurement sensitivity to the constructs of interest, and given the relatively low sample size for each group in this study, there is a nontrivial possibility that these quantitative survey results may not have fully captured teacher concerns. This will be further discussed in the final chapter.

The qualitative data reported next further investigates this small sample size. This approach offers opportunities for a deeper perspective into PST thinking, in an effort to uncover differences in teacher concerns across the two groups that the quantitative survey may have missed because of the relatively small sample sizes of the groups.

Qualitative Results of Teacher Concerns. The qualitative data permitted another lens for investigating how teacher concerns might be differentially impacted by each program. There were a total of 59 PSTs who contributed to the comments reviewed in the qualitative portion of the study. Six belonged to the focus group, 17 participated in two individual interviews, and 36 only took both a pre- and post- TCC survey. Of these 21 were Traditional PSTs and 38 were SKyTeach PSTs. The qualitative data sources came from verbal comments made among the focus group members and the individual 
interviewees, as well as the written comments made on the open-ended portion of the TCC survey and the weblogs entries regarding individual teacher concerns which were partitioned from other topics. Once the focus group comments and all the individual interviews had been transcribed, the task of coding the qualitative results into the three different teaching concerns began. All quotes that related to a particular type of concern and time (before, during, or after the student-teaching experience) were cataloged. Comments of each individual concern were coded into further subthemes as they emerged from the data. Each subtheme was analyzed to determine if there had been a shift in underlying focuses of each concern from the beginning of the semester to the end of the semester.

Self-Preservation Concerns. An investigation of comments relating aspect of self-preservation were tallied at two different time periods, at the beginning of the student teaching semester and immediately after the student teaching experience. The pre-measure allowed me to record self-preservation concerns that PSTs had upon entering the student teaching semester. The post-measure allowed me to chronicle if any shift occurred in the self-preservations concern by the end of the student teaching experience. In addition, weblog entries were recorded. These authentic, non-prompted comments gave another insight to the self-preservation concerns the PSTs were experiencing during their time in the classroom. The timeline of these data collection sources were outlined in Figure 4. 


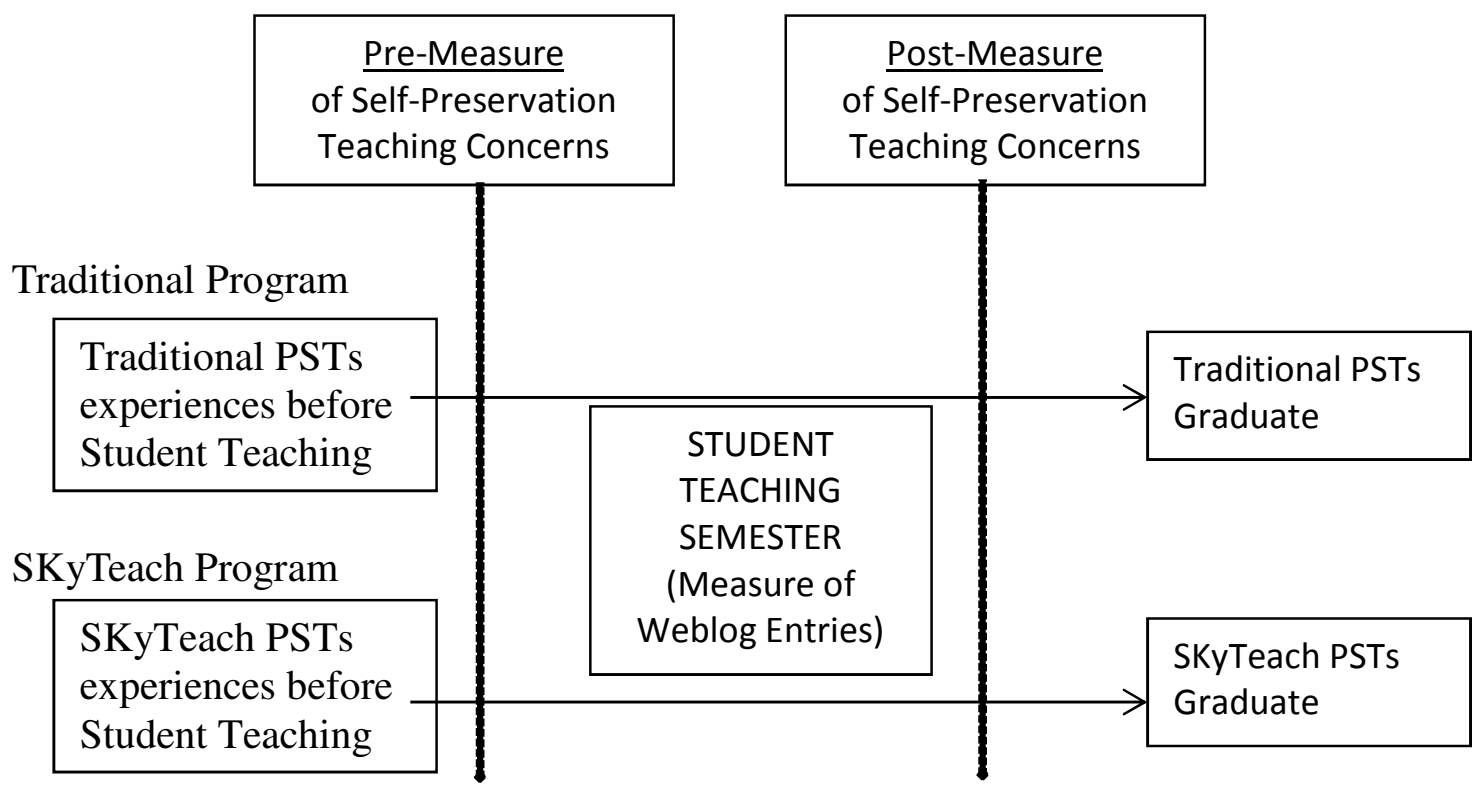

Figure 4. Qualitative Measures of Self-Preservation Teacher Concerns

Once separated, these comments were classified as having high levels of concern or having confidence (low levels of concern) using the coding, which had been established as having an interrater reliability score of $92 \%$. This rating score was detailed in Chapter 3. The time they were spoken or written (before or after the student-teaching experience) were cataloged.

The frequency distribution chart of the ratio of responses related to self-preservation concerns can be found in Table 7. Since the samples size of the Traditional and SKyTeach PSTs were disproportionate, the numerals in the table indicate the ratio of statements per contributing pre-service teacher in that category. This table does not include the open-ended responses to the survey because these responses were too nonspecific to be coded into subsequent subthemes uncovered in self-preservation concerns. However, the open-ended responses could be coded into general self-preservation states of possessing high levels of concern or low levels of concern (having confidence). The table showing all the self-preservation comments and their 
level of concern, including open-ended question responses, can be found in Appendix E as Table 7B.

Table 7

Ratio of Responses related to Self-Preservation Concerns throughout the Study

\begin{tabular}{cccc}
\hline & Before & After & During \\
\hline & \multicolumn{3}{c}{ High Concerns } \\
\cline { 2 - 4 } Traditional $(\mathrm{n}=21)$ & 1.58 & 1.75 & 0.67 \\
& $(T=12)$ & $(T=8)$ & $(T=9)$ \\
SKyTeach $(\mathrm{n}=38)$ & 1.27 & 0.78 & 0.83 \\
& $(S=11)$ & $(S=9)$ & $(S=6)$ \\
\cline { 2 - 4 } & \multicolumn{3}{c}{ Confident (not Concerned) } \\
Traditional $(\mathrm{n}=21)$ & 0.75 & 0.50 & 0.78 \\
& $(T=12)$ & $(T=8)$ & $(T=9)$ \\
SKyTeach $(\mathrm{n}=38)$ & 1.45 & 1.44 & 0.17 \\
& $(S=11)$ & $(S=9)$ & $(S=6)$ \\
\hline
\end{tabular}

Notes. Values in the table cells are ratio of responses-per-person. T designates the number of possible contributing Traditional PST participants. S designates the number of possible contributing SKyTeach PST participants. Groups within a program are not independent.

Before student teaching, Traditional PSTs were slightly more likely to comment on high levels of self-preservation concerns than the SKyTeach PSTs. During the same period of time, SKyTeach PSTs' comments nearly double the registered number of comments conveying confidence of the Traditional PSTs (1.45 SKyTeach statements per person to 0.75 Traditional statements per person). The blog comments revealed a shift in this perception during the student teaching experience SKyTeach PSTs more readily recognized higher levels of self-preservation concerns (.83 statements per person) than the Traditional PSTs did (.67 statements per person). The trend was once again reversed after student teaching with Traditional PSTs logging three and a half more comments regarding higher self-preservation concerns per person than Traditional PSTs' comments relating to self-confidence. SKyTeach PSTs' relayed almost twice as many comments 
revealing higher levels of self-confidence concern statements per student than those SKyTeach PSTs with high levels of concern. Throughout the study, Traditional high concerns rose slightly higher when comparing pre-concern to post-concern; whereas SKyTeach PSTS high self-preservation concerns went down 0.41 statements per person. All of these shifts were explored more thoroughly as it was divided into additional precise data categories to tell a more complete story.

In previous studies, self-preservation concerns were characterized as concerns which propagated apprehensions concerning job security and deficiencies in self-adequacy in teaching (i.e. Borich \& Tombardi, 1997; Fuller \& Bown, 1975). A closer inspection of the comments was conducted to see if any subthemes would emerge to explain more fully the impacts of this concern. This coding partitioned the self-preservation concern responses into the four emergent subthemes of (a) seeking respect of others, (b) being concerned over external evaluations, (c) managing a classroom, and (d) having concerns relating to writing, implementing, and reflecting on lesson plans. These subthemes paralleled the findings of several studies (i.e. Borich \& Tombardi, 1997; Boz \& Boz, 2010; Fuller \& Bown, 1975).

To clarify the development of the emergent themes about self-preservation concerns and their level of concern, a summary of recurring comments from PSTs in both programs were documented (see Table 8). High levels of concerns were identified by statements that show some evidence of uneasiness or lack of confidence. Confidence statements revealed a lack of self-preservation concern. In general, the comments of PSTs in both the Traditional and SkyTeach programs were quite similar. Table 8 shows a representative list of those statements from both groups that were the most frequent high 
levels of concern and confident (not concerned) statements for respect concerns,

evaluation concerns, and content concerns. There were other concerns that did not fall

into any of these categories; these were recorded as general self-preservation concerns.

Table 8

Representative Examples of Self-Preservation Sub-Themes Comments

EMERGING Level of Represented Comments

SUB- concern

THEMES

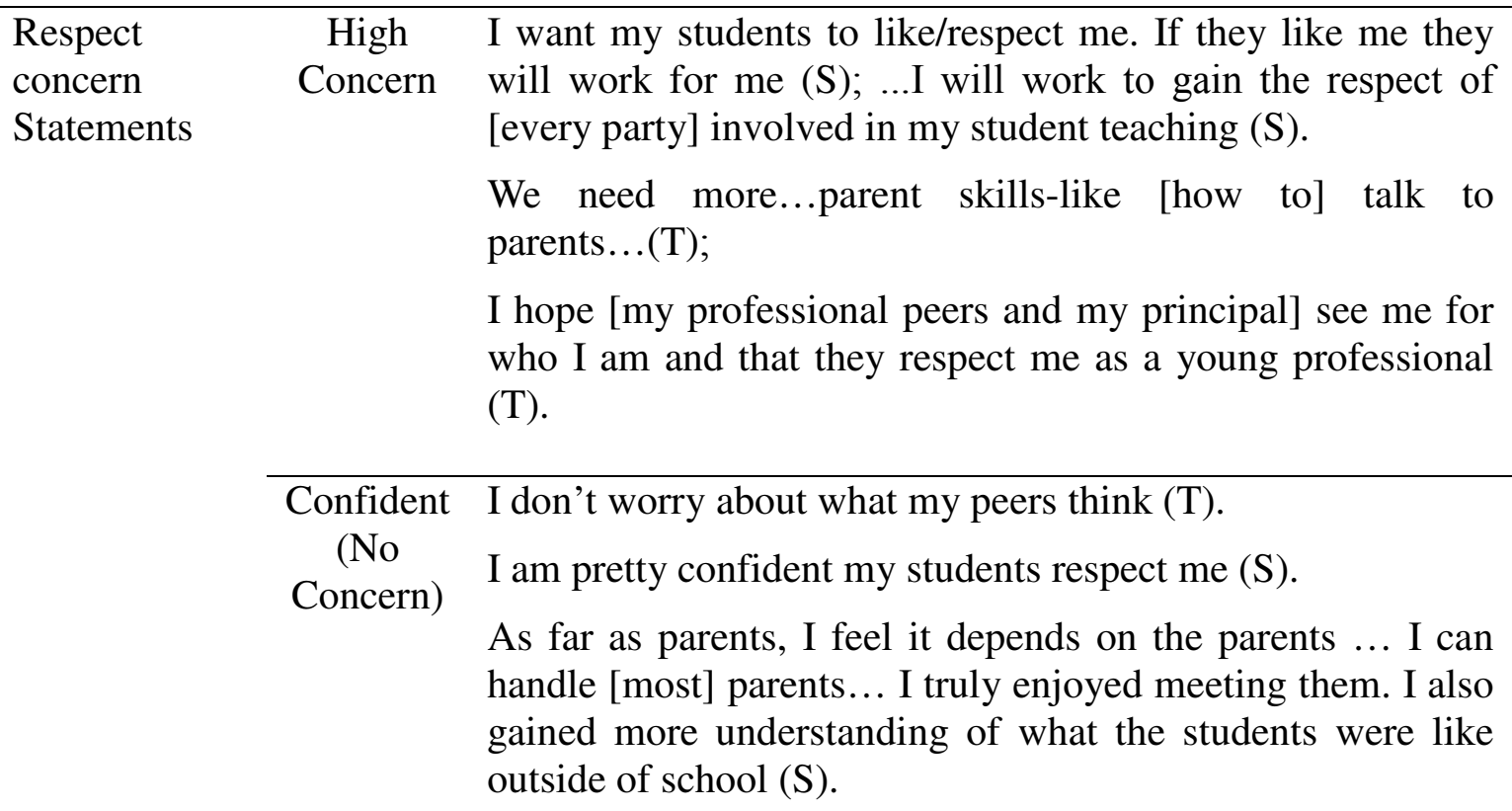

\begin{tabular}{lll}
\hline $\begin{array}{l}\text { Management } \\
\text { concern }\end{array}$ & $\begin{array}{l}\text { High } \\
\text { Concern }\end{array}$ & $\begin{array}{l}\text { Nervous about classroom management issues (S); wish } \\
\text { SKyTeach had a discipline class (S); I want to maintain class } \\
\text { control I am ok with [maintaining class control but I want to } \\
\text { do better (T); we need more management classes and skills } \\
\end{array}$ \\
& & $(\mathrm{T})$; this [area] needs more attention (T).
\end{tabular}

Confident [One instructor] taught a management class (S); my military training helped with management issues (S). [Student teaching] helped me learn about management because I considered that one area my program did not prepare me for (S). 


\begin{tabular}{|c|c|c|}
\hline $\begin{array}{l}\text { Evaluation } \\
\text { concern } \\
\text { Statements }\end{array}$ & $\begin{array}{l}\text { High } \\
\text { Concern }\end{array}$ & $\begin{array}{l}\text { I want to do well when [other teachers and my principal] } \\
\text { observe me (T \& S); I got really, really nervous when I } \\
\text { noticed my cooperating teacher was filling out the } \\
\text { daily/weekly evaluations (S). I am a little concerned because } \\
\text { I have not that much experience teaching so I have some } \\
\text { concern about being evaluated (T). }\end{array}$ \\
\hline
\end{tabular}

Confident I feel my program prepared me [to be evaluated] (S). We were always being observed (S)... I think I will be getting good evaluations of my teaching ( $\mathrm{S} \& \mathrm{~T}$ ); it's about getting into the classroom and getting the 'nerves out' (S). I know if I had waited [to teach in front of students], I would not be as confident as I am today...(S)

\begin{tabular}{lll}
\hline Content & High & I felt like I was thrown to the sharks the first time I stepped \\
concern & Concern & $\begin{array}{l}\text { in the classroom...I thought "Oh, my gosh, what am I } \\
\text { doing? (T)." The first time around I didn't feel confident } \\
\text { Statements }\end{array}$ \\
& enough to explain it to them so I quit (T).
\end{tabular}

I am not sure that I am doing my lesson plans correctly (T); I don't know how practical my lesson plans are (T). [Traditional PSTs] don't even know if they can speak in front of a classroom of students every day and get their point $\operatorname{across}(\mathrm{S})$.

My experience with the new [Common Core] standards has been very frustrating. My cooperating teacher and all the other $8^{\text {th }}$ grade teachers are teaching the standards in the exact order they are printed...It is frustrating because of all the instructional gaps they are creating $(\mathrm{T})$.

Confident SkyTeach is about reflection (S). [It's] about thinking about what you did and ...figuring out what you did good and ...not so well. You change it, you fix it...The goal always involves using what you've done, prior knowledge, prior mistakes to build to the next level (S); I know how to write an effective lesson plan that is aligned to the standards and has measureable objectives (S); they have prepared me to reflect on my teaching practices (S); I feel like they have prepared me for questioning [at all levels] (S).

My supervising teacher is the standards representative for the math department [at my school] and is very in tune to with the new standards and how they are to be implemented into the curriculum; ... [she] printed them out and organized for me and we discussed them in great depth (T). 
General

Self-

Preservation

Concern

Statements
I was a nervous wreck! Just because I didn't know what was going on or what to expect. I was...mainly just nervous. (High Concern) (T)

I was talking to a WKU student who was completing his student teaching this semester. Sadly, during his experience he realized the teaching profession wasn't for him. (High Concern) (S)

Notes. Comments recorded from focus group discussions, both interviews, and blogs. (T): Representative comment made by a Traditional PST. (S): Representative comment made by a SKyTeach PST.

Table 9 reflects the division of these self-preservation sub-themes before and after the student teaching experience. The numerals in the table indicate the ratio of statements per contributing pre-service teacher in that category. The blog responses were not tallied here because the emphasis of this table is to see a difference in level of individual subthemes as the study progressed. A total of 96 self-preservation concern statements were made during the focus group, interviews, and on open-ended responses on the TCC survey. Forty-six of all statements (before and after) came from Traditional PSTs and 50 statements were made by SKyTeach PSTs. 
Table 9

Reoccurring Sub-Themes Responses Relating to Self-Preservation Concerns

\begin{tabular}{|c|c|c|c|}
\hline $\begin{array}{l}\text { BEFORE } \\
\text { STUDENT } \\
\text { TEACHING }\end{array}$ & $\begin{array}{l}\text { Level of } \\
\text { Concern }\end{array}$ & $\begin{array}{c}\text { Traditional } \\
\begin{array}{c}\#=28 \\
n=21\end{array}\end{array}$ & $\begin{array}{c}\text { SkyTeach } \\
\begin{array}{c}\#=30 \\
n=17\end{array}\end{array}$ \\
\hline \multirow{2}{*}{ Respect concerns } & HIGH CONCERN & 0.14 & 0.35 \\
\hline & CONFIDENT & 0.14 & 0.11 \\
\hline \multirow[t]{2}{*}{ Evaluation concerns } & HIGH CONCERN & 0.19 & 0.0 \\
\hline & CONFIDENT & 0.095 & 0.06 \\
\hline \multirow{2}{*}{$\begin{array}{l}\text { Class Management } \\
\text { Concerns }\end{array}$} & HIGH CONCERN & 0.0 & 0.118 \\
\hline & CONFIDENT & 0.095 & 0.06 \\
\hline \multirow[t]{2}{*}{ Content concerns } & HIGH CONCERN & 0.48 & 0.29 \\
\hline & CONFIDENT & 0.095 & 0.65 \\
\hline \multirow[t]{2}{*}{ General concern } & HIGH CONCERN & 0.095 & 0.0 \\
\hline & CONFIDENT & 0.0 & .0 .12 \\
\hline \multirow{2}{*}{$\begin{array}{l}\text { Total Concern } \\
\text { Before Student } \\
\text { Teaching }\end{array}$} & HIGH CONCERN & 0.91 & 0.82 \\
\hline & CONFIDENT & 0.43 & 0.94 \\
\hline AFTER & Level of & Traditional & SkyTeach \\
\hline STUDENT & Concern & $\#=18$ & $\#=20$ \\
\hline TEACHING & & $n=21$ & $n=17$ \\
\hline \multirow[t]{2}{*}{ Respect concerns } & HIGH CONCERN & 0.24 & 0.06 \\
\hline & CONFIDENT & 0.14 & 0.29 \\
\hline \multirow[t]{2}{*}{ Evaluation concerns } & HIGH CONCERN & 0.14 & 0.18 \\
\hline & CONFIDENT & 0.0 & 0.18 \\
\hline \multirow{2}{*}{$\begin{array}{l}\text { Class Management } \\
\text { concerns }\end{array}$} & HIGH CONCERN & 0.19 & 0.12 \\
\hline & CONFIDENT & 0.0 & 0.06 \\
\hline \multirow[t]{2}{*}{ Content concerns } & HIGH CONCERN & 0.05 & 0.06 \\
\hline & CONFIDENT & 0.05 & 0.0 \\
\hline \multirow[t]{2}{*}{ General concern } & HIGH CONCERN & 0.05 & 0.0 \\
\hline & CONFIDENT & 0.0 & 0.24 \\
\hline \multirow{2}{*}{$\begin{array}{l}\text { Total Concern } \\
\text { After Student } \\
\text { Teaching } \\
\end{array}$} & HIGH CONCERN & 0.67 & 0.41 \\
\hline & CONFIDENT & 0.19 & 0.77 \\
\hline
\end{tabular}

Notes. Values in the table cells are ratio of responses-per-person. \# designates the number of contributing statements from that program before/after student teaching. $\mathrm{n}$ designates the number of contributing participants from that program. Comments tallied from focus group discussions, both interviews, and blogs. This table does not include open-ended responses. 
The top portion of the chart displays the responses relating to self-preservation concern before student teaching had occurred. Traditional PSTs' statements reveal that their top self-preservation concern was concentrated around the subtheme of content concerns with almost half $(0.48)$ of the comments per person relating to this topic. SkyTeach PSTs statements reveal mixed responses on the topic of content concern. These PST responses show about a fourth (0.29) of the comments per person having high levels of content concern; while over half $(0.65)$ of the statements per person reveal these PSTs were confident about this subtheme. SkyTeach PSTs also were slightly more concerned about being respected, with around a third (0.35) of the statements per person being made at this time. Traditional PSTs are equally split between being confident and having high respect concerns, with 0.14 statements per student on each level corresponding to the respect subtheme.

Further scrutiny shows that Traditional students possessed some minor levels of high concerns about classroom evaluations, with roughly a fifth (0.19) of the statements per Traditional PSTs being made on this topic. SKyTeach PSTs show no indications of high levels of concern on classroom evaluations. Overall, the statements made by Traditional PSTs show higher levels of total self-preservation concerns; while, SKyTeach PSTs statements are nearly equally divided between high levels of self-preservation concerns and being confident regarding their perception of self-preservation concern before student teaching.

During the student-teaching experience, the Student Teaching Seminar required the PSTs to post topics on a weblog for discussion about the student-teaching experience. These topics were created by the PSTs and ranged from classroom issues like "Stress 
While Student Teaching" and "Using Technology" to more personal topics like "Your Most Memorable Moments" and "Your Perfect Job". Only those posting that related to this study were used in the tabulation of concerns. There were 19 such statements that were related to self-preservation concerns. Thirteen of these statements were made by six Traditional PSTs and six statements were made by four SKyTeach PSTs.

Seven PSTs posted 19 blog entries on the Weblogs regarding respect concerns; four from Traditional PSTs and the remainder from SKyTeach PSTs. Two SkyTeach students and three Traditional students felt becoming involved with experience outside the classroom setting helped foster respect of students towards PSTs and thus lowered any respect concerns. Two SkyTeach also noted the lack of respect of students towards their peers and those in authority. The majority of the remaining entries dealing with content and evaluations concerns were related to the new Common Core Curriculum standards that were implemented during those years. Most PSTs had been exposed to these standards during their training and felt less concern about the new standards than they perceived their supervising teachers had on implementing the curriculum and the corresponding evaluations. There were two general blog entries that discussed the concerns of becoming a teacher. Both entries came from PSTs in the SKyTeach program. One discussed the discouragement surrounding a peer student teacher that decided to drop out of the education program during his student-teaching experience. The other continued this line of thinking but took a different viewpoint saying that the studentteaching experience had validated his determination to become a teacher.

After the student-teaching experience, PSTs showed a shift in the comments from a major focus on content concerns to respect concerns as documented in Table 9. 
Traditional PSTs rated this as the highest level of concern during their student-teaching experiences (0.24 comments per person) and SkyTeach PSTs rating it as the subtheme with the lowest concern ( 0.29 comments per person).

Traditional students also showed a marked increase in the number of comments regarding higher levels of classroom management concerns from no statements to 0.19 statements per person; whereas the number of comments that SKyTeach PSTs discussed about this issue remained the same. After the student-teaching experience, both Traditional and SkyTeach PSTs who were interviewed showed almost equal amount high levels of classroom evaluations concerns; but SKyTeach also reported the same level of confidence on evaluations.

Overall, after the student-teaching experience the traditional PSTs comments still revealed more high concern levels of self-preservation concerns, with two-thirds (.67) statements per PSTs revealing this statistic. However; the SKyTeach PSTs had a decrease in overall self-preservation concerns noted by the .77 of the statements per SKyTeach PSTs showing confidence concerning self-preservation concerns. These results will be discussed further in the discussion chapter.

Task-Related Concerns. According to Fuller (1969), as a teacher begins to become more familiarized with teaching expectations, self-preservations concerns begin to wane and a new set of concerns begin to emerge. This next set of teachers concerns is called the task-related concerns. These concerns are linked to the preoccupation towards the day-by day struggles of professional teaching. The comments related to task-related concerns were assessed in the same way as the self-preservation concerns; before, during, and after the student teaching experience (refer to Figure 4). 
Table 10 reveals the nature of the responses made by the members of the focus group, the interviews, and the weblogs regarding task-related concerns. The frequency distribution chart reporting the results of this examination are included in this table. Statements that show some evidence of uneasiness or lack of confidence were classified as possessing high levels of concern. Confidence statements revealed a lack of concern. To be able to compare the frequency of comments made by each group, the numerals in the table indicate the ratio of statements per contributing pre-service teacher in that category. This was done since the samples size of the Traditional and SKyTeach PSTs were composed of vastly different quantities.

This table does not include the open-ended responses to the survey because these responses were too nonspecific to be coded into subsequent subthemes uncovered in the task-related concern. However, the open-ended responses could be coded into the more broad-spectrum states of possessing high levels of concern or having confidence when dealing with task-related concerns. Table 10B, found in the Appendix E, shows all comments and their level of concern. This table also included the open-ended questions.

Overall, both programs expressed high levels of task-related concern as compared to those who expressed confident statements. The SKyTeach PSTs remained fairly constant in the number of statements made before and after the student-teaching experience. The Traditional PSTs tripled the number of high level of task-related concerns from before to after the student-teaching experience. 
Table 10

Ratio of Responses related to Task-Related Concerns throughout the Study

\begin{tabular}{llll}
\hline & Before & After & During \\
\hline & \multicolumn{3}{c}{ High Concerns } \\
& & \multicolumn{2}{c}{1.22} \\
Traditional $(\mathrm{n}=21)$ & 0.42 & 1.38 & $(T=9)$ \\
& $(T=12)$ & $(T=8)$ & 1.0 \\
SKyTeach $(\mathrm{n}=38)$ & 0.73 & 0.88 & $(S=6)$ \\
& $(S=11)$ & $(S=9)$ & 0.11 \\
& & Confident (not Concerned) \\
Traditional $(\mathrm{n}=21)$ & 0.17 & 0.25 & $(T=9)$ \\
& $(T=12)$ & $(T=8)$ & 0.17 \\
SKyTeach $(\mathrm{n}=38)$ & 0.45 & 0.44 & $(S=6)$ \\
\hline
\end{tabular}

Notes. Values in the table cells are ratio of responses-per-person. T designates the number of possible contributing Traditional PST participants. S designates the number of possible contributing SKyTeach PST participants. Groups within a program are not independent.

The final coding placed these concern responses into three emerging subtopics of (a) having concerns about student behavioral problems, (b) being concerned about external administrative responsibilities and interruptions, and (c) having feelings of distress from insufficient time to plan and grade, as well as interact with other professionals. These subthemes were similar to those found in previous studies (e.g. Adams et al., 1981; Boz \& Boz, 2010; Fuller \& Bown, 1975). A summary of the recurring task-related comments made by PSTs in both programs were documented on the following pages. Table 11 chronicles a representative list of those statements that were the most frequent high concerns and confident statements as they related to task-related concerns. High levels of task-related concerns were identified by statements that show some evidence of apprehension or lack of confidence. Confidence statements revealed a lack of task-related concern. 
Table 11

Summary of Task-Related Sub-Themes Comments

EMERGING Level of Represented Comments

SUB-THEMES concern

\begin{tabular}{lcl}
\hline $\begin{array}{l}\text { Behavioral } \\
\text { concern } \\
\text { Statements }\end{array}$ & $\begin{array}{c}\text { High } \\
\text { Concern }\end{array}$ & $\begin{array}{l}\text { I wish I had spent time on handling behavioral } \\
\text { problems/disruptions (S); I am concerned about } \\
\text { behavioral disruptions (T). }\end{array}$ \\
\cline { 2 - 4 } & $\begin{array}{c}\text { Confident } \\
\text { (No } \\
\text { Concern) }\end{array}$ & $\begin{array}{l}\text { My educations did well with ... how to deal with certain } \\
\text { students; I had a quite a lot of experience with student } \\
\text { disruptions (T). }\end{array}$ \\
\hline $\begin{array}{l}\text { Administrative } \\
\text { concern } \\
\text { Statements }\end{array}$ & $\begin{array}{c}\text { High } \\
\text { Concern }\end{array}$ & $\begin{array}{l}\text { I have high concerns about extra duties (T); there is so } \\
\text { much paperwork (in the Teacher Work Sample) to do (S). }\end{array}$
\end{tabular}

Statements

I hated when classroom test scheduling was rearranged due to outside activities (S); about $25 \%$ of the time is done teaching...75\% is done doing something else like grading papers, watching kids...,selling t-shirts $(\mathrm{T})$; there is an unwritten rule that students can't fail...it puts teachers in a really hard overworked situation (T). I hate all the administrative interruptions and changes in the schedule (T).

Confident They prepared me well for teaching practices and preparing effective and measureable lesson plans $(\mathrm{S})$.

Insufficient High I am nervous that I won't be able to keep everything time concern Concern organized (S); I don't have the best time management Statements (system) (S); I am trying to figure out how to balance my time and get everything graded(S). I have concerns about lack of rest and I did not feel like I had enough time with my supervising teacher $(\mathrm{T})$.

Confident My education classes did well preparing me for time management (T); I have been given all the tools I need (to stay ahead);... most of your grading and planning will be done at home, anyone who thinks otherwise is naïve (T); I got (a system) of grading during planning periods... when it came to planning I did (a full week's worth) on the weekends (S).

Notes. Comments recorded from focus group discussions, both interviews, and blogs. (T): Representative comment made by a Traditional PST. (S): Representative comment made by a SKyTeach PST. 
The result of regrouping the task-related concerns gathered during the focus group, interviews and on the open-ended responses on the survey into these emerging subthemes is exhibited in Table 12. The numerals in the table indicate the ratio of statements per contributing pre-service teacher in that category.

Before student teaching began, Traditional PSTs were slightly more vocal about high administrative responsibility concerns than SkyTeach PSTs $(0.14$ versus 0.12 statements per person); whereas SKyTeach PSTs mentioned behavioral problems more frequently ( 0.18 versus 0.095 statements per person). There were more concerns among SKyTeach PSTs regarding having insufficient time to accomplish tasks $(0.24$ statements per PST) as compared to no statements being made by the Traditional PSTs. The Traditional PSTs did not describe any concerns about time management issues before student teaching.

During the student-teaching experience there were 19 weblog postings referencing task-related concerns as recorded in Table 12. Twelve of these posts came from Traditional PSTs and seven came from SKyTeach PSTs. The comments were varied. One Traditional PSTs posted a comprehensive comment about student misbehavior and how it undermined his resolve to stay in teaching. Fourteen comments (eight from Traditional PSTs and six from SKyTeach PSTs) addressed the stress accompanying time management concerns with three Traditional entries and two SKyTeach entries offering suggestions on how to reduce this stress. These included exercise, time with family and friends, and keeping a calendar to keep track of upcoming due dates. The remaining entries, three entries from Traditional PSTs and one entry by a SKyTeach PST, addressed administrative concerns such as trying to implement 
technology into the classroom and the frustrations PSTs face when students are more excited with extracurricular activities than with keeping up with their assignments. In addition, there was one mention of the new Common Core standards causing problems in scheduling classroom activities and assessments to be completed in a timely manner.

Table 12

Reoccurring Sub-Themes Responses Relating to Task-Related Concerns BEFORE STUDENT TEACHING

\begin{tabular}{|c|c|c|c|}
\hline & $\begin{array}{l}\text { Level of } \\
\text { Concern }\end{array}$ & $\begin{array}{c}\text { Traditional } \\
\quad \#=7 \\
n=21 \\
\end{array}$ & $\begin{array}{c}\text { SkyTeach } \\
\begin{array}{c}\#=13 \\
n=17\end{array}\end{array}$ \\
\hline \multirow{2}{*}{$\begin{array}{l}\text { Behavioral } \\
\text { concerns }\end{array}$} & HIGH CONCERN & 0.095 & 0.18 \\
\hline & CONFIDENT & 0.05 & 0.0 \\
\hline \multirow{2}{*}{$\begin{array}{l}\text { Administrative } \\
\text { concerns }\end{array}$} & HIGH CONCERN & 0.14 & 0.12 \\
\hline & CONFIDENT & 0.05 & 0.12 \\
\hline \multirow{2}{*}{$\begin{array}{l}\text { Insufficient } \\
\text { Time concerns }\end{array}$} & HIGH CONCERN & 0.0 & 0.24 \\
\hline & CONFIDENT & 0.0 & 0.12 \\
\hline \multirow{2}{*}{$\begin{array}{l}\text { Total Concern } \\
\text { Before Student } \\
\text { Teaching }\end{array}$} & HIGH CONCERN & 0.24 & 0.53 \\
\hline & CONFIDENT & 0.095 & 0.24 \\
\hline \multicolumn{4}{|c|}{ AFTER STUDENT TEACHING } \\
\hline & $\begin{array}{l}\text { Level of } \\
\text { Concern }\end{array}$ & $\begin{array}{c}\text { Traditional } \\
\quad \#=13 \\
n=21\end{array}$ & $\begin{array}{c}\text { SkyTeach } \\
\#=11 \\
n=17\end{array}$ \\
\hline \multirow{2}{*}{$\begin{array}{l}\text { Behavioral } \\
\text { concerns }\end{array}$} & HIGH CONCERN & 0.095 & 0.06 \\
\hline & CONFIDENT & 0.0 & 0.12 \\
\hline \multirow{2}{*}{$\begin{array}{l}\text { Administrative } \\
\text { concerns }\end{array}$} & HIGH CONCERN & 0.24 & 0.18 \\
\hline & CONFIDENT & 0.05 & 0.0 \\
\hline \multirow{2}{*}{$\begin{array}{l}\text { Insufficient Time } \\
\text { concerns }\end{array}$} & HIGH CONCERN & 0.14 & 0.18 \\
\hline & CONFIDENT & 0.095 & 0.12 \\
\hline \multirow{2}{*}{$\begin{array}{l}\text { Total Concern } \\
\text { After Student } \\
\text { Teaching }\end{array}$} & HIGH CONCERN & 0.48 & 0.41 \\
\hline & CONFIDENT & 0.14 & 0.24 \\
\hline
\end{tabular}

Notes. Values in the table cells are ratio of responses-per-person. \# designates the number of contributing statements from that program before/after student teaching. $\mathrm{n}$ designates the number of contributing participants from that program. Comments tallied from focus group discussions, interviews, and blogs. This table does not include open-ended responses. 
After the student-teaching experience, the Traditional PSTs had an increase of comments referring to high levels of concern related to time constraints from no comments before student teaching to a total of five comments made from the 21 PSTs after student teaching. Three of these comments ( 0.14 comments per PST) showed high concerns related to time management issues; while two (0.095 comments per PST) stated that time management was a new reality of the teaching profession. These latter comments revealed that these PSTs were attempting to put these concerns into prospective. SKyTeach PSTS remained fairly uniform on time management concerns; still being concerned with all the paperwork involved in teaching. On the other hand, SkyTeach PSTs comments revealed a decrease in high behavioral concerns with 23\% (0.18 statements per PST) being made before student teaching and 9\% (0.06 statements per person) being made after student teaching. Both Traditional and SkyTeach PSTs who were interviewed showed an increase in administrative concerns mostly dealing with additional responsibilities that they were unaware of before student teaching, such as bus duty and faculty meetings. Statements from both programs showing illustrations of these administrative type of task-related concerns are (a)"About $25 \%$ of the time is done teaching during the day and $75 \%$ is done doing something else--like grading papers, watch the kids do something else such as physical time at the gym, selling t-shirts before school...", (b) "I hate all the administrative disruptions and the changes in scheduling." and (c) "The extra duties worry me. If you put more stuff on me I am going to get nervous and freak out!" Gold (1985b) and Schwab and Iwanicki (1982) recognized these task concerns of time restraints and additional responsibility as evidence of early signs of disillusionment about the teaching profession. 
Student Impact Concerns. The final phase in Fuller and Bown's (1975) hierarchy of teacher concerns is termed "student impact" concerns. In this phase, teachers become increasing concerned about the impact their instruction has on student learning. Thus, it is considered a good quality to have a high concern for the students' well-being. In this study, qualitative data on student-impact concerns were gathered and recorded as the previous concerns; before, during, and after the student-teaching experience (Refer to Figure 4).

Table 13 shows a record of the timetable and number of statement responses made by the members of the focus group, the interviews, and the weblogs regarding impact concerns among these individuals. The presence of a higher level of student-impact concern is advantageous for effective teaching to occur (Borich \& Tombardi, 1997; Hattie, 2003; Fuller, Parsons, \& Watkins, 1974); thus those statements that contained evidence of this trait were designated has having high levels of concerns for students well-being. Those statements that did not convey evidence of concern towards student impact were categorized as having a lack of concern for student impact measures. The time the comments were spoken or written is tabulated. Since the samples size of the Traditional and SKyTeach PSTs were disproportionate, the numerals in the table indicate the ratio of statements per contributing pre-service teacher in that category. This table does not include the open-ended responses because these responses were once again too nonspecific to be coded into student-impact subsequent subthemes. However, the open-ended responses could be coded into the basic states of possessing the recommended high levels of student-impact concern or lacking concern in regards to 
student-impact. The table showing all the student-impact comments and their level of concern, including open-ended questions, can be found in Appendix E as Table 13B.

Table 13

Ratio of Responses related to Student-Impact Related Concerns

\begin{tabular}{llll}
\hline & Before & After & During \\
\hline \multicolumn{3}{c}{ High Concern for Student Well-Being } \\
& 0.67 & 1.63 & 1.7 \\
Traditional $(\mathrm{n}=21)$ & $(T=12)$ & $(T=8)$ & $(T=9)$ \\
& 1.73 & 2.44 & 2.3 \\
SKyTeach $(\mathrm{n}=38)$ & $(S=11)$ & $(S=9)$ & $(S=6)$ \\
& Lack of Concern for Student-Impact Measures \\
& 0.0 & 0.0 & 0.8 \\
Traditional $(\mathrm{n}=21)$ & $(T=12)$ & $(T=8)$ & $(T=9)$ \\
& 0.18 & 0.11 & 0.7 \\
SKyTeach $(\mathrm{n}=38)$ & $(S=11)$ & $(S=9)$ & $(S=6)$
\end{tabular}

Notes. $\mathrm{n}$ designates the number of possible contributing participants in that data category. $\mathrm{T}$ designates the number of possible Traditional PSTs in that data category. S designates the number of possible SKyTeach PSTs in that data category. Values in the table cells are ratio of responses-per-person. The number in the parenthesis represents the average number of statements per person in that data program category. Groups within a program are not independent.

The preceding table indicates that both Traditional and SkyTeach PSTs increased their concern for student well-being after the student teaching experience. However, the Traditional PSTs expressed more growth in this area than did the SKyTeach PSTs throughout the study. Both groups also showed confidence in being able to identify different student needs as expressed by the low number of comments per person in the confidence section.

Emergent subthemes were identified. Previous studies documented that teachers in this phase make a concentrated effort to modify their lessons to meet the diverse academic needs of the students. In addition, there is more awareness of the characteristics of the whole child and concerns about how to address the emotional, 
physical, and social needs each student may have (Borich \& Tombardi, 1997; McVey, 2004). A shift from concerns of personal needs and performance towards being concerned about the students' academic and emotional development are predominate characteristics of this phase (Borich \& Tombardi, 1997; Boz and Boz, 2010). Fuller (1969) and Borich and Tombardi (1997) recognized this impact teacher concern as being a characteristic of a highly committed teacher. Thus, the appearances of statements that relate to more levels of concern are to be viewed as commendable.

This study's final coding revealed three subtopics: (a) being able to adapt lessons to meet the needs of students, (b) helping students achieve their potential, and (c) being able to recognize/diagnose student needs. These sub-themes were expressed in compatible comments by both groups of PSTs. A synopsis of these common comments as they related to student-impact related comments were chronicled in Table 14. This table was created to show the differences between high and low concerns comments among adapting lessons to meet the needs of the students concerns, concerns relating to encouraging students to meet their potential, and concerns related to diagnosing academic, physical and emotional needs of the students. 
Table 14

Summary of Student-Impact Sub-Themes Comments

EMERGING Level of concern

SUB-

Represented Comments

THEMES

Adapting

High

I need to figure out how to relate [formulas to

Lesson conceptual understanding] (S); I know what is

concern essential to having an effective lesson plan and

Statements how to reflect to make mine more like one $(\mathrm{S})$; The goal always involves using what you have done ...to build to the next level (S).

I am trying to modify all my lessons to meet my students' needs (S); I am having problems accommodating everybody in class, like the IEPs and incorporating diverse things (S).

Lack of Concern The new standards are making it harder for my for Student-Impact supervising teacher she (we) are having to change

Measures

(Low Concern) things $(\mathrm{T}) ; \ldots$ there are huge gaps in where the students are and where 'they should be' (T).

\begin{tabular}{|c|c|c|}
\hline \multirow[t]{2}{*}{$\begin{array}{l}\text { Achieving } \\
\text { Potential } \\
\text { concern } \\
\text { Statements }\end{array}$} & High & $\begin{array}{l}\text { I need to figure out how to make them want to } \\
\text { learn (T); The degree of focus on special needs is } \\
\text { so great-and collaboration is more involved with } \\
\text { these students (T). } \\
\text { We are having to spend so much time on [remedial } \\
\text { topics] (T). }\end{array}$ \\
\hline & $\begin{array}{l}\text { Lack of Concern } \\
\text { (Low Concern) }\end{array}$ & $\begin{array}{l}\text { I don't know how they made it this far without } \\
\text { knowing the basics (S); Students can't [do basic } \\
\text { calculations] without a calculator (T); I am shock } \\
\text { at the lack of attention students give to instructions } \\
\text { and test questions (T); all they know is the } \\
\text { [mnemonic] stuff (S); They all have potential but } \\
\text { getting them to use it- that is another story (S). }\end{array}$ \\
\hline $\begin{array}{l}\text { Identifying } \\
\text { Needs concern } \\
\text { Statements }\end{array}$ & High & $\begin{array}{l}\text { I definitely want to know the background of my } \\
\text { students ... and how that affects the students and } \\
\text { their work (T); I want to know how do I handle } \\
\text { [different situations of student needs] (S); I do } \\
\text { concern myself with how they are doing } \\
\text { emotionally, how they are intellectually, how they } \\
\text { are developing-I want to know whether they are } \\
\text { understanding the concepts and be able to apply } \\
\text { them }(\mathrm{T}) \text {. }\end{array}$ \\
\hline & & \\
\hline
\end{tabular}

Note. Comments recorded from focus group discussions, both interviews, and blogs. 
The result of dividing the impact concerns into these emerging subthemes is exhibited in Table 15. There were a total of 21 remarks recorded from Traditional PSTs and 44 remarks were made by SKyTeach PSTs before and after the student teaching experience.

Table 15

Reoccurring Sub-Themes Responses Relating to Student-Impact Related Concerns BEFORE STUDENT TEACHING

\begin{tabular}{|c|c|c|c|}
\hline & $\begin{array}{l}\text { Level of } \\
\text { Concern }\end{array}$ & 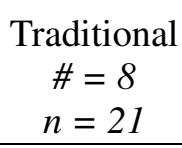 & $\begin{array}{c}\text { SkyTeach } \\
\quad \#=21 \\
n=17\end{array}$ \\
\hline \multirow{2}{*}{$\begin{array}{l}\text { Adapting } \\
\text { Lessons } \\
\text { Concern }\end{array}$} & HIGH CONCERN & 0.14 & 0.47 \\
\hline & $\begin{array}{l}\text { LACK OF } \\
\text { CONCERN }\end{array}$ & 0.0 & 0.06 \\
\hline \multirow{2}{*}{$\begin{array}{l}\text { Achieving } \\
\text { Potential } \\
\text { concerns }\end{array}$} & HIGH CONCERN & 0.19 & 0.59 \\
\hline & $\begin{array}{l}\text { LACK OF } \\
\text { CONCERN }\end{array}$ & 0.0 & 0.06 \\
\hline \multirow{2}{*}{$\begin{array}{l}\text { Diagnosing } \\
\text { concerns }\end{array}$} & HIGH CONCERN & 0.05 & 0.06 \\
\hline & $\begin{array}{l}\text { LACK OF } \\
\text { CONCERN }\end{array}$ & 0.0 & 0.0 \\
\hline \multirow{2}{*}{$\begin{array}{l}\text { Total Concern } \\
\text { Before Student- } \\
\text { Teaching }\end{array}$} & HIGH CONCERN & 0.38 & 1.12 \\
\hline & $\begin{array}{l}\text { LACK OF } \\
\text { CONCERN }\end{array}$ & 0.0 & 0.12 \\
\hline
\end{tabular}

AFTER STUDENT TEACHING

\begin{tabular}{|c|c|c|c|}
\hline & $\begin{array}{l}\text { Level of } \\
\text { Concern }\end{array}$ & $\begin{array}{c}\text { Traditional } \\
\#=13 \\
n=21\end{array}$ & $\begin{array}{c}\text { SkyTeach } \\
\begin{array}{l}\#=23 \\
n=17\end{array}\end{array}$ \\
\hline \multirow{2}{*}{$\begin{array}{l}\text { Adapting } \\
\text { Lessons } \\
\text { Concern }\end{array}$} & HIGH CONCERN & 0.29 & 0.47 \\
\hline & LACK OF CONCERN & 0.0 & 0.0 \\
\hline \multirow{2}{*}{$\begin{array}{l}\text { Reaching } \\
\text { Potential } \\
\text { concerns }\end{array}$} & HIGH CONCERN & 0.14 & 0.65 \\
\hline & LACK OF CONCERN & 0.0 & 0.0 \\
\hline \multirow{2}{*}{$\begin{array}{l}\text { Diagnosing } \\
\text { concerns }\end{array}$} & HIGH CONCERN & 0.19 & 0.18 \\
\hline & LACK OF CONCERN & 0.0 & 0.06 \\
\hline \multirow{2}{*}{$\begin{array}{l}\text { Total Concern } \\
\text { After Student- } \\
\text { Teaching }\end{array}$} & HIGH CONCERN & 0.62 & 1.29 \\
\hline & LACK OF CONCERN & 0.0 & 0.06 \\
\hline
\end{tabular}

Notes. Values in the table cells are ratio of responses-per-person. \# designates the number of contributing statements from that program before/after student teaching. $\mathrm{n}$ designates the number of contributing participants from that program. Comments recorded from focus group discussions, interviews, and blogs. This table does not include open-ended responses. 
Before student teaching, both programs demonstrated high levels of student impact concerns. Traditional PSTs comments contained no statements of lack of concern; while the 11 SKyTeach PSTs made two "lack of concern" statements. The student-impact subtheme relating to aspiring to find ways to maximize student learning potential yielded the greatest number of comment per person in both groups. This was followed closely by the desire of both programs to adapt lesson plans to meet the needs of the diverse learning environments they were to encounter.

During the student-teaching experience, weblogs continued recording this high level of student impact concern as was defined in Table 13. There were a total of 40 postings related to impact concerns: Traditional PSTs had 22 responses and SKyTeach PSTs had 18 responses. Nine Traditional PSTs made 15 high level impact-concern statements and six SKyTeach PSTs making 14 of these statements.

A closer look at the impact concern weblog statements revealed that 10 Traditional PSTs responses and eight SKyTeach PSTs responses offered comments that addressed being able to adapt lesson plans to meet the needs of their students. Traditional PSTs logged over half of the comments per person regarding concerns about encouraging academic student potential. These PSTs offered suggestions on how to promote student potential such as asking a variety of questions that could appear on later tests and tutoring individual students. However, most of the comments in this area revealed how surprised and shocked PSTs from both programs were regarding the lack of initiative that students possessed. They recognized the potential of the students but many were amazed at students' reliance on calculators and their inability to retain previously taught information. Two statements that were widely agreed upon in both programs contained 
comments about the carelessness of students to read directions or their dependence on mnemonic devices. The presence of diagnosing learning needs of students were beginning to develop with two Traditional PSTs and four SKyTeach PSTs posting statements regarding new insights about meeting student needs while they collaborated with supervising teachers about students with Individual Education Plans (IEPs).

After the student-teaching experience, the presence of higher levels of impact concerns among the areas of adapting lesson plans to meet the needs of students and striving to increase student potential awareness continues to be paramount. A more detailed look shows that SKyTeach PSTs mentioned adapting lesson plans more often than Traditional PSTs did (0.47 statements per SKyTeach PST versus 0.29 statements per Traditional PST). SKyTeach PST were more aware of addressing the need for helping students reach their learning potential, with over half of the SKyTeach PST responses (0.65 statements per PST) compared to the small proportion of Traditional PSTs (with 0.14 statements per person) relating to this sub-theme). There is a steady rise in the number of statements regarding the need to be able to recognize or diagnose academic, physical, or emotional problems. Before student teaching, only one of the 21 Traditional PSTs and one of the 17 contributing SKyTeach PSTs commented on this subtheme concern. After student teaching the number of persons who commented on this subtheme concern rose to four Traditional PSTs and three SKyTeach PSTs. As reported by Borich and Tombardi (1997), this reveals progression in the growth of the PST towards anticipating the needs of the student. 


\section{Summary}

A summary of the data associated with finding the concerns between and among the Traditional PSTs and the SKyTeach PSTs before, during, and after the student-teaching experience follows. This section began with a factor analysis of the presurvey results. The result indicated that all the questions loaded onto to one factor, namely overall teacher concerns. A further investigation of the quantitative results showed no significant difference of overall teacher concerns between the Traditional PSTs and the SKyTeach PSTS either before or after the student- teaching experience. Next, the questions were aligned in accordance with the results of the factor analysis performed by Rogan and others (1992). ANOVA tests were administered to determine any significance between the two programs related to self-preservation concerns, taskrelated concern, and student impact concern before and after the student-teaching experience. Both programs had moderate levels of concerns on all three teachers concerns at the two measurement periods. No significant difference was discovered at either juncture nor was there any significant change within each program from the beginning to the end of the study.

Following the quantitative analysis, a more extensive investigation of each concern was completed using a constant comparison qualitative data approach. The comments given during the focus group, the interview statements made before and after the student-teaching experience, and the relevant postings made on the weblog discussion during the student-teaching experience were reviewed. While the quantitative results showed no significance between each of the concerns, the qualitative data suggested subtle difference across PSTs in the two programs. 
When the qualitative results about the self-preservation concerns were investigated before the student-teaching experience, it was discovered that Traditional PSTs were more concerned about content issues than the SKyTeach PSTs $(0.48$ statements per person versus 0.29 statements per person); whereas, SKyTeach PSTs were slightly more preoccupied by respect concerns than Traditional PSTs $(0.35$ statements per person versus 0.14 statements per person). During the student-teaching experience, blog entries show an increased awareness of the topic of respect and suggestions on how to improve the level of respect towards PSTs was investigated. After the student-teaching experience, Traditional PSTs revealed a shift from content issues to respect concerns, while the SKyTeach had lower levels of self-preservation concerns on all issues.

Task-related concerns also showed a difference in subthemes before student teaching with Traditional PSTs having higher levels of administrative responsibilities and interruption concerns. SKyTeach PSTs were more concerned about having insufficient time to accomplish tasks at the onset of the student-teaching experience. Weblog entries mirrored the insufficient time concern during the student-teaching experience. Both programs continued discussing the insufficient time concern after the student-teaching experience but also added an addition concern of administrative disruptions at the end of the study.

Finally, the student impact concern levels revealed that both programs had higher levels of student impact concern related to exploring ways to maximize student learning potential and to adapt lesson plans to meet the needs of students before student teaching had begun. This desire of adapting lesson plans to meet the needs of the students continued to be discussed on blog reflections during the student-teaching experience. 
After the student-teaching experiences, both programs continued to portray high levels of concern over meeting the needs of their students.

In conclusion, the quantitative results showed that both the Traditional PSTs and the SKyTeach PSTs possessed moderate concern levels for self-preservation, task-related, and student impact concerns at both measurement periods. There was no significant difference between programs at the beginning and end of the student-teaching experience. Nor were there any significant differences between concerns within each program. However, a qualitative look at each individual concern yielded a kaleidoscope of information about the subtle differences within each concern.

Self-preservation concerns are a key feature in this study as one of the objectives is to find ways to lessen this type of concern during pre-service training. Both programs had lower levels of self-preservation concerns at the conclusion of the study. It is note-worthy to recognize that Traditional PSTs shifted from content concerns at the beginning of the study to respect concerns at the end of the study; whereas, SKyTeach PSTs began with the respect concerns and had lowers levels on all subtopics of selfpreservation concerns by the end of the study. This information will be used to draw inferences about what impact mentoring and field experiences may have contributed to create these differences. 


\section{CHAPTER 5}

\section{RESULTS OF FIELD EXPERIENCES AND MENTORING ON AMELIORATING PRE-SERVICE TEACHER CONCERNS}

This chapter will document the results related to the second and third research questions. Data for this chapter were gathered through qualitative means before and after the student teaching experience. These two research questions targeted self-preservation concerns explicitly; because, according to Fuller (1969), hierarchically the first concern new teachers must master is self-preservation concerns in order to best be able to shift focus from self-preservation towards task-related and, eventually, student impact concerns as part of their professional teacher trajectory. The second research question will explore the effect that perceived impact active field experiences have on reducing self-preservation concerns on pre-service teachers. This investigation will begin by reviewing what components of field experiences were required by the PSTs in the Traditional and SKyTeach programs. Recording the specific types and amount of observational and instructional practice experienced in each program will follow this account. Once the frequency of each type of field experience was chronicled, beneficial or non-beneficial aspects of reducing self-preservation concerns among the observational and instructional practice experiences will be documented. The beneficial characteristics will be explored in greater detail to determine which practices appear to reduce the selfpreservation concerns. 
The chapter will continue by presenting results to answer the final research question. This question relates to the perceived impact that different types of mentoring models have on reducing self-preservation concerns. First, a frequency distribution will be conducted, listing who PSTs (in both the Traditional and SKyTeach) recognized as primary mentors before and after their student-teaching experience. Once this was established, data to characterize what types of mentoring the PSTs had received will be presented. Those characteristics of the mentoring practices which were chronicled as effective or ineffective in reducing self-preservation concerns were explored. This chapter outline is detailed in the following figure.

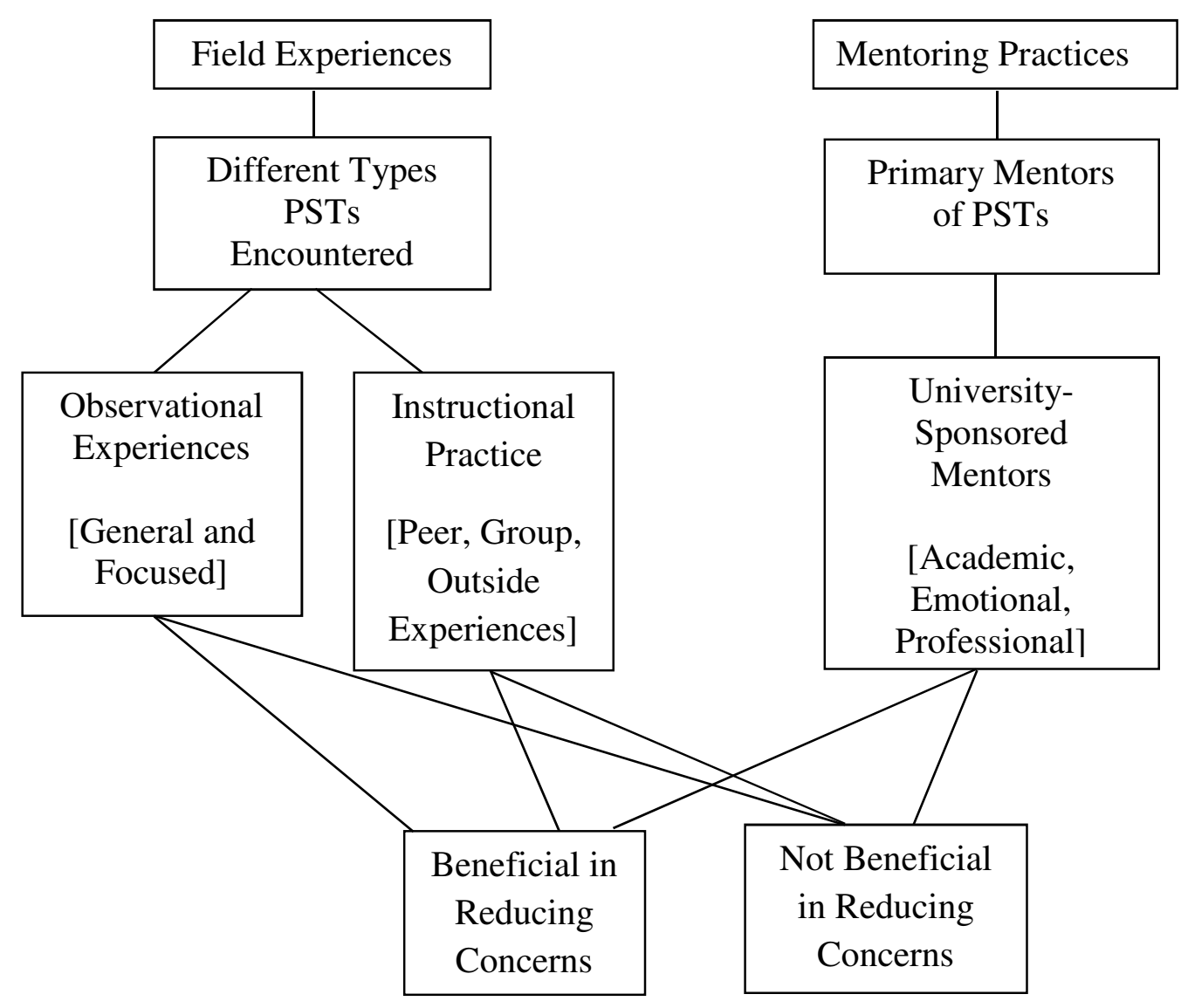

Figure 5. Outline of Major Topics of Chapter 5. 


\section{Field Experiences Perceived as Effective in Helping Reduce Self-Preservation}

\section{Concerns}

In compliance with NCTAF (1996) mandate that field experiences were necessary components of the comprehensive education of prospective teachers, both programs had a mandatory component of some type of field experience. The Traditional program required PSTs to complete 150 contact hours of field experiences outside classroom coursework beginning in the sophomore year and ending before the studentteaching semester. (R. Tyler, personal communication, April 4, 2013). As outlined in Chapter 3, the nature of this field experience varied from instructor to instructor. The SKyTeach program stated that its field experience began in the first semester of freshman year and continued every semester until graduation. SKyTeach instructors recommended the first experience be a heavily mentored pre-designed instructional experience in an elementary school setting. Following semesters allowed for more opportunities of observational and instructional practice at higher grade levels (Burch, 2008). By the student-teaching experience, SKyTeach PSTs had done group and individual presentations at the elementary, middle, and secondary levels with more experiences in the latter two settings. First, the investigation began by verifying exactly what type of field experience each program had encountered before and during student teaching.

This portion of the investigation was initiated by reviewing responses made during the focus group. This inquiry determined that PSTs were exposed to three types of early field experiences: observational, instructional, and administrative. Observational field experiences were identified as vicarious field experiences-they were passive in nature, where the PST tasks were to observe only. Instructional field experiences 
included any type of mastery experience from tutoring to leading a class (Badura, 1994).

These experiences were active in nature with the PST expected to actively lead at least some portion of the instructional experience. Finally administrative field experiences were included because several PST mentioned that grading papers and running off classroom copies of notes, worksheets, or assessments helped aid in preparation for doing similar tasks as a professional. Another general category was included to provide for any additional forms of field experience not envisioned before the survey was administered.

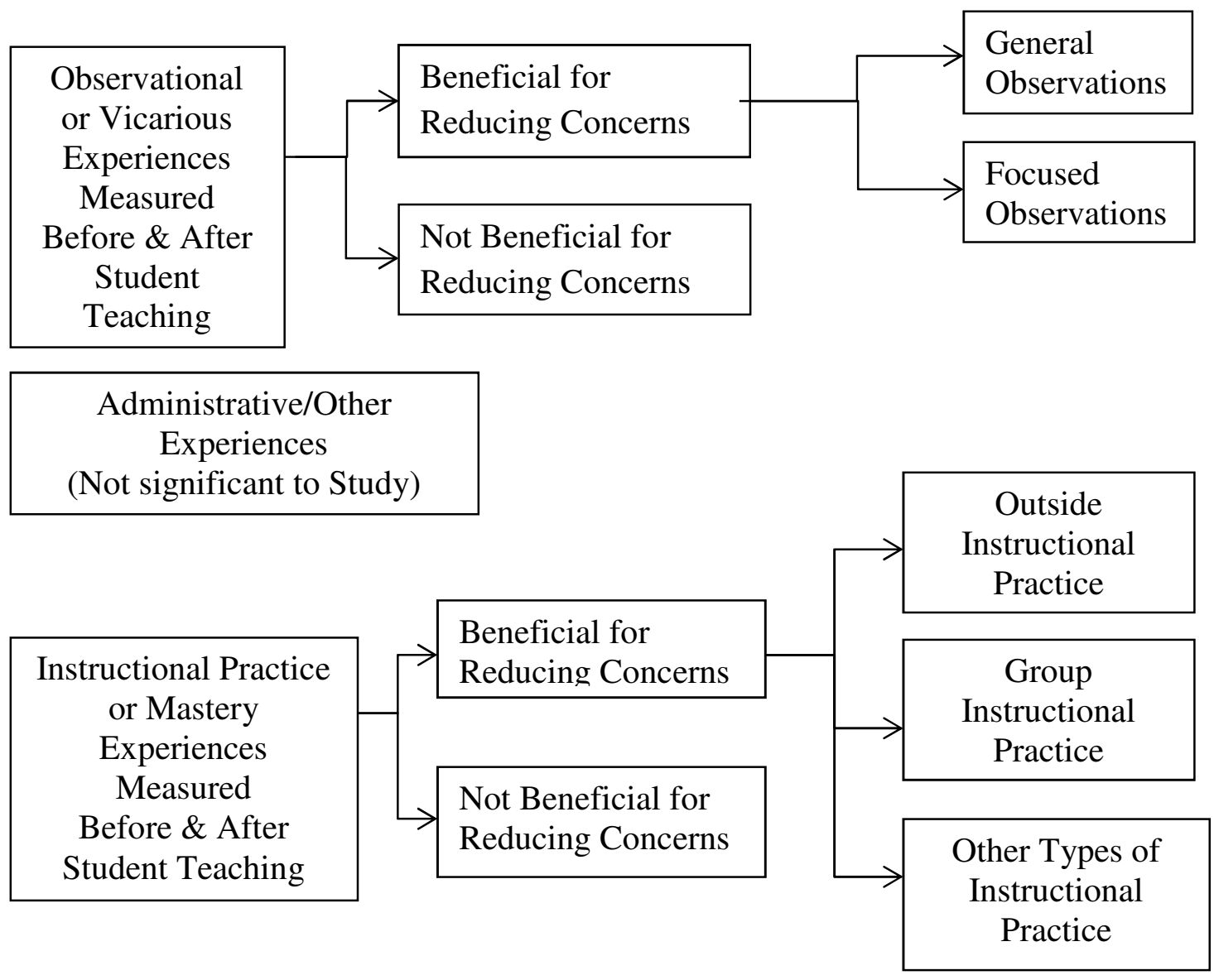

Figure 6. Types of Field Experiences 
Table 16 shows the percentages of each type of field experience before and during the student-teaching experience by those students that completed both surveys. The survey given after student teaching captured percentages during the student teaching experience, whereas the survey before the student teaching experience captured the total sum of field experiences up to that point. Percentages were determined by finding the mean of time percentage answers given Question \#51 on the open-ended portion of the survey (Appendix D).

Table 16

Percentages of Different Types of Early Field Experiences

\begin{tabular}{lcccc}
\hline \multirow{2}{*}{ Type of } & \multicolumn{2}{c}{ Before Student } & Teaching & \multicolumn{2}{c}{ During Student Teaching } \\
Field Experience & TRAD & SKY & TRAD & SKY \\
\hline Observation & $\mathrm{n}=13$ & $\mathrm{n}=32$ & $\mathrm{n}=13$ & $\mathrm{n}=32$ \\
\hline Instructional & $82 \%$ & $31 \%$ & $16 \%$ & $19 \%$ \\
\hline Administrative & $11 \%$ & $63 \%$ & $62 \%$ & $62 \%$ \\
\hline Other & $6 \%$ & $5 \%$ & $19 \%$ & $17 \%$ \\
\hline
\end{tabular}

Notes. $\mathrm{n}$ designates the number of participants in that program. Values in the table cells are percentages of time given in TTC Question \#51

Before student teaching, the majority ( $82 \%)$ of the field experience Traditional PSTs experienced was observational in nature, followed by instructional experiences (11\%) and administrative tasks (6\%). Three PSTs listed outside experiences of substitute teaching or tutoring soldiers at a military setting. For other types of experiences, one Traditional PST listed being a parent volunteer in a local school. Another Traditional PST listed an after school one-on-one literary based project, in which the PST helped a student complete the project. SKyTeach listed instructional experiences $(63 \%)$ as their primary experience before student teaching, followed by observational (31\%) and administrative (5\%). There were two PSTs who listed planning for instructional 
experiences and "getting to know teachers" as other field experiences. These percentages match the predesigned requirements of each program (R. Tyler, personal communication, April 4, 2013; Burch, 2008).

After student teaching another data collection of the survey was taken. The results in Table 16 showed that there was a shift towards instructional experience during the student-teaching experience with both programs reporting $62 \%$ of their day performing instructional duties. This was followed by observational field experience (Traditional 16\% and SKyTeach 19\%). There was an increase in administrative duties, such as grading classwork and assessments, with both programs reporting approximately $17 \%$ to $19 \%$ of their student-teaching experience being spent doing these tasks.

\section{Instructional and Observational Field Experiences}

A further analysis was conducted on two of these types; the instructional and observational field experiences. This was done to see whether PSTs perceived these two types of their field experiences as being beneficial to preparing them for the student-teaching experience, and thus, reducing teaching concerns. Data about field experiences and perceived benefits were gathered from focus group responses, openended survey questions entries, and interviews. A total of 59 independent sources were analyzed: six focus group students, 17 pre- and post-interviews, and 36 students who completed two surveys but were not interviewed. Twenty-one of these individuals were Traditional PSTs and 38 were SKyTeach PSTs.

In general, the comments of PSTs in both the Traditional and SkyTeach programs tended to be quite similar. PST comments that suggested beneficial attributes to alleviate self-preservation concerns or encourage growth in the professional teacher trajectory 
were designated as "Beneficial for Growth" statements. Other PST comments that did not ascribe to professional growth or alluded to preventing growth were designated as "Not Very Beneficial" statements. In order to characterize what comments were gauged as beneficial or not beneficial, Table 17 combined and summarized comments and statements from PSTs both groups. Frequency counts of statements made by PSTs were separated by program and then registered in Table 18 to compare the collective opinions of PSTs in each program.

Table 17

Summary of Field-Experiences Type Comments

EMERGING

TYPES Level of Benefit

Represented Comments

Observation Beneficial classroom management and teaching styles $(\mathrm{T})$; The for Growth observation hours have allowed me to see other strategies and techniques that weren't discussed in classes or maybe those that weren't heavily (discussed), and see their effects (S).This [observation] helped me to learn how to deal with students, understanding there may be more than meets the eye to their problems (T); I got to see what the teachers did and how they acted towards the students $(\mathrm{T})$.

Observation Beneficial It helped me to be more analytical about teaching (T); (continued) for Growth Observing different teachers at different schools helps see the variety of students and many teaching styles [before student teaching] (T).

I don't think I got enough at all (observation) (T); Not Very Observations themselves are nigh unto worthless (T); Beneficial $\quad \ldots$ it was more to get in your 20 hours (S); Field experience before student teaching was limited to observation which were not helpful (T); ... You just get bored (T); teachers that just told me to sit here and watch (T); Even my teachers were not really supportive of observation. They preferred volunteer work (T). 
I would think focused observation would be beneficial (T); We always had general observations. We weren't really sure what we were supposed to be looking at. We had little to no guidance as to what to look for (S).

Instructional Beneficial I gained real experience teaching a class, planning for for Growth the class, assessing the class, and reflecting on both my performance and ability to improve (S); Going out in the field and teaching a lesson will be pivotal to making the transition to student teaching [easier] (T); We see our teaching strengths and weaknesses and we get to work on them before student teaching (S).

I have been in front of a classroom two or three times every semester (S); I taught 3 elementary lessons, 4 middle school lessons, \& 5 or 6 high school lessons. I have taught in city and county schools. I have had a lot of classroom experience $(S)$.

Actually teaching a lesson to my peers and having it videotaped was very beneficial (S); I did some substitute teaching before student teaching (T); I led a lot at the alternative school (T); I use to teach the soldiers in the military too $(\mathrm{T})$.

I already have that initial confidence so I focus on improving as a teacher and less on dealing with stage fright $(\mathrm{S})$.

Instructional (continued)

Not Very Beneficial
I feel I was very limited with working with students (T), everything up to this point has been pretend scenarios $(\mathrm{T})$; We did "peer teaching", but those weren't very helpful at all (T); It didn't help as much I thought it would with three others teaching with me (T); There is no preparation for the real classroom in that aspect (intervention training) (S). When you go [to do field work], those kids have been threatened (to behave) with every inch of their lives. These are "perfect classroom experiences" (S). 


$\begin{array}{ll}\text { Not Very } & \text { I've talked to some in the traditional } \\ \text { Beneficial } & \text { program that have never taught a class until } \\ \text { they student teach and their (sic) petrified } \\ \text { (S); I just wish I had had more experience } \\ \text { teaching anything in a classroom before } \\ \text { being thrown into student teaching (T); I } \\ \text { have had friends that found out during } \\ \text { student teaching that they hated it. Then } \\ \text { what do you do? }(\mathrm{T})\end{array}$

Notes. Comments recorded from focus group discussions, all interviews, and blogs. (T): Representative comment made by a Traditional PST. (S): Representative comment made by a SKyTeach PST.

The result of dividing the field experiences into two key types of observational and instructional experiences is exhibited in Table 18. From the original total of 59 PSTs (21 Traditional PSTs and 38 SKyTeach PSTs) who were either a part of the focus group, participated in the interviews, or completed two surveys, all 21 Traditional PSTs and only 22 SKyTeach offered comments about observational field experiences before student teaching. After student teaching, 15 SKyTeach PSTs and 10 Traditional PSTs offered comments on the same topic. There were a total of 74 observational field experience remarks recorded from Traditional PSTs and 58 remarks from SKyTeach PSTs. These remarks were divided among those that the respondents felt were beneficial field experiences, in preparing for the student-teaching experience by reducing teaching concerns. or those that were not so beneficial. The numerals in the table indicate the ratio of statements per contributing pre-service teacher responding to the beneficial or non-beneficial characteristics of observational and instructional practice field experiences. 
Table 18

Perceived Beneficial Characteristics of Field Experiences

Observational

\begin{tabular}{|c|c|c|c|c|c|c|c|}
\hline \multirow[b]{3}{*}{$\begin{array}{c}\text { Trad } \\
(N=21) \\
\#=51\end{array}$} & \multicolumn{3}{|c|}{ Before } & & \multicolumn{3}{|c|}{ After } \\
\hline & Beneficial & $\begin{array}{c}\text { Not } \\
\text { Beneficial }\end{array}$ & $\begin{array}{c}\text { No } \\
\text { Answer }\end{array}$ & & Beneficial & $\begin{array}{c}\text { Not } \\
\text { Beneficial }\end{array}$ & $\begin{array}{c}\text { No } \\
\text { Answer }\end{array}$ \\
\hline & $\begin{array}{c}1.7 \\
(n=21)\end{array}$ & $\begin{array}{c}0.7 \\
(n=21)\end{array}$ & 0 & $\begin{array}{c}\text { Trad } \\
(N=21) \\
\#=23\end{array}$ & $\begin{array}{c}1.5 \\
(n=10)\end{array}$ & $\begin{array}{c}0.8 \\
(n=10)\end{array}$ & 11 \\
\hline \multirow[t]{4}{*}{$\begin{array}{c}\text { SKy } \\
(N=38) \\
\#=40\end{array}$} & $\begin{array}{c}1.6 \\
(n=22)\end{array}$ & $\begin{array}{c}0.2 \\
(n=22)\end{array}$ & 16 & $\begin{array}{c}\text { SKy } \\
(N=38) \\
\#=18\end{array}$ & $\begin{array}{c}0.1 \\
(n=15)\end{array}$ & $\begin{array}{c}0.07 \\
(n=15)\end{array}$ & 23 \\
\hline & \multicolumn{7}{|c|}{ Instructional } \\
\hline & \multicolumn{3}{|c|}{ Before } & & \multicolumn{3}{|c|}{ After } \\
\hline & Beneficial & $\begin{array}{c}\text { Not } \\
\text { Beneficial }\end{array}$ & $\begin{array}{c}\text { No } \\
\text { Answer }\end{array}$ & & Beneficial & $\begin{array}{c}\text { Not } \\
\text { Beneficial }\end{array}$ & $\begin{array}{c}\text { No } \\
\text { Answer }\end{array}$ \\
\hline $\begin{array}{c}\text { Trad } \\
(N=21) \\
\#=33\end{array}$ & $\begin{array}{c}1.1 \\
(n=15)\end{array}$ & $\begin{array}{c}1.1 \\
(n=15)\end{array}$ & 6 & $\begin{array}{c}\text { Trad } \\
(N=21) \\
\#=24\end{array}$ & $\begin{array}{c}0.9 \\
(n=15)\end{array}$ & $\begin{array}{c}0.7 \\
(n=15)\end{array}$ & 6 \\
\hline $\begin{array}{c}\text { SKy } \\
(N=38) \\
\#=81\end{array}$ & $\begin{array}{c}2.1 \\
(n=37)\end{array}$ & $\begin{array}{c}0.1 \\
(n=37)\end{array}$ & 1 & $\begin{array}{c}\text { SKy } \\
(N=38) \\
\#=63\end{array}$ & $\begin{array}{c}1.6 \\
(n=33)\end{array}$ & $\begin{array}{c}0.3 \\
(n=33)\end{array}$ & 5 \\
\hline
\end{tabular}

Note. Values in the table cells are ratio of responses-per-person answering the question.

$\mathrm{N}$ designates the number of PST in that program. $\mathrm{n}$ designated the number of contributing participants in that program. \# designates the number of contributing statements from that program before/after student teaching.

Before the student-teaching experiences, both programs viewed observational experiences as beneficial. Beneficial characteristics included general topics like viewing veteran teachers teaching strategies and instructional procedures. Other focused on more specific ideas like questioning strategies and tactics to manage misbehavior. However, the Traditional PSTs were more inclined to also report negative or non-beneficial aspects (0.7 statements per PSTs from those who offered answers) of their observational 
experiences than were SKyTeach PSTs (0.2 statements per students from those who offered answers). These negative statements included such themes as viewing observation time as excessive and "boring", not having or not reporting on focused reflective experiences, and not perceiving the experience as valued learning experiences.

When focusing on the instructional field experiences before the student-teaching experience, only one SKyTeach PST did not offer an opinion; whereas, six Traditional PSTs chose not to offer an opinion. In Table 18, SKyTeach PSTs found the effects of these experiences more beneficial offering slightly over two statements per SKyTeach PST from those who offered answers, than did the Traditional PSTs who only gave 1.1 statements per Traditional PST. Some beneficial aspects of early instructional field experiences comments offered by SKyTeach PSTs included being able to teach using a variety of discovery-bases and research-based lessons to different age groups. Others had an opportunity to modify their presentation skills and practice engaging students. Traditional PSTs were mixed in their view of instructional field experiences with 52\% (17 of 33 contributing comments) of those contributing statements finding the experiences beneficial and 48\% (16 of 33 contributing comments) of those contributing statements finding them not. In both instances, approximately 1.1 statements were offered by each Traditional PST who submitted an answer. Negative comments made by Traditional PSTs regarding instructional field experiences tended to reject the effectiveness of peer and group teaching. Several other Traditional PSTs resented that they did not have many opportunities to do instructional field experience prior to the student-teaching experience. 
After the student-teaching experiences, PSTs were asked to reflect on how they perceived that their field experiences prior to student teaching assisted them during student teaching. In many instances, PSTs did not offer any comments. With regards to observation, 11 Traditional PSTs and 23 SKyTeach PSTs did not offer any comments. Also, six Traditional PSTs and five SKyTeach PSTs did not offer any comments about how their earlier instructional field experiences assisted them during student teaching.

Of those that did choose to answer the question, 65\% (15 of 23 contributing comments) of Traditional PSTs and 94\% (17 of 18 contributing comments) of the SKyTeach PSTs who answered the question found beneficial effects of previous observational experiences, with each student in both programs offering slightly over one comment each. While the majority of both programs offered the generic answers of 'just being in the classroom' as being a positive experience and 'learning things they hadn't been aware of learning at the time', others were more analytical in their answers. Some of the more detailed answers offered suggestions of being able to discern different styles of teaching, as well as, being able to draw on different kinds of classroom and behavior management experiences as they watched their teachers. Others offered content delivery ideas they were able to use or offer in the student-teaching experience.

Looking at the comments offered after the student-teaching experience regarding early instructional field experiences, SKyTeach PSTs proposed more beneficial statements ( $83 \%$ of the 63 contributing statements) such as being in front of a classroom helped them increase their confidence levels and overcome any concerns about presenting content. Others said the additional experiences helped them be able to deal with behavioral problems and offered them a variety of activities they could use in the 
classroom. Traditional PSTs continued to be divided on their thoughts regarding instructional field experience. Those Traditional PSTs who found early instructional field experience beneficial (51\% of the 24 contributing statements); many had the opportunity to take one of the SKyTeach Science and Mathematics Educational (SMED) classes. These students repeated the same positive comments mentioned by the SKyTeach PSTs. Those Traditional PSTs that did not find the early instructional experiences beneficial (49\% of 24 contributing statements), felt that they did not have enough instructional experiences or that most of their experiences were artificial since they were mostly comprised of peer teaching experiences.

Beneficial Observational and Instructional Practices. Several PSTs in either program had reported experiencing multiple types of beneficial field experiences. The nature of these beneficial experiences was then characterized. The student comments were coded into different types of field experiences in order to explore what practices yield the most beneficial experiences for reducing self-preservation concerns. This coding was done in two levels. First, the field experiences were labeled as either observational (passive) or instructional (active). Observational experiences were subdivided into focused or general experiences. Instructional experiences were subdivided into peer teaching, experiences that occurred outside the realm of the program, or other more general instructional experiences.

When coding the beneficial observational experiences into sub-types, those PSTs which offered comments that contain phrases relating to observations when the PSTs were ask to observe, without given any guidance as to what to look for, were labeled as general observations. Comments PSTs offered that related to observational assignments 
to look for specific topics such as "how to teach [a specific topic]", "how to address discipline issues", "levels of questioning", and "looking for [a particular criteria] and then reflecting on it" were labeled as focused observations.

When looking at the beneficial instructional practice experiences, those PSTS that designated either "group teaching experiences" or "peer teaching" in their comments were combined into one sub-type. Several other PSTs commented that they had done instructional field experiences outside the university curriculum, such as substitute teaching. Since these experiences involved opportunities which had been reported as beneficial in reducing teaching concerns before the student-teaching experience, they were included. Most PSTs just referred to the instructional practice experiences as "teaching in front of middle or secondary students (emphasis added for clarification)". In order to in order to maintain the integrity of the portrayal of the instructional practice experiences, all non-descript generic instructional practice experiences were labeled as "Other". These encounters could have possibly included individual instructional experiences or group experiences but there was no way to identify the incidents except as being instructional. Table 19 summarized the findings of the data revealing the sub-types of perceived beneficial field experiences PSTs experienced before their student-teaching experience had occurred.

Of the 59 participants offering comments through focus group discussions, interview conversations, or open-ended responses, several students offered "no comment" or any distinguishing remark to decide whether the experience was beneficial or not. Looking at observational experiences before student teaching, four Traditional PSTs and 14 SKyTeach PSTs chose not to respond. After the student teaching 
experience, 18 Traditional and 23 SKyTeach PSTs did not offer an answer to the beneficial aspects of their observational experiences. The review of instructional practice experiences also had some PSTs who did not offer an answer or give an answer that allowed for it to be classified as a beneficial experience or not. Before student teaching, there were ten Traditional PSTs and one SKyTeach PST that fell into this category. After the student-teaching experience, nine Traditional PSTs and six SKyTeach PSTs did not offer any indication of their perceptions of the beneficial aspects of their instructional practice experiences.

Table 19

Sub-Types of Beneficial Early Field Experiences

Observational

\begin{tabular}{|c|c|c|c|c|c|c|c|}
\hline & \multicolumn{3}{|c|}{ Before } & & \multicolumn{3}{|c|}{ After } \\
\hline & General & Focused & $\begin{array}{c}\text { No } \\
\text { Answer }\end{array}$ & & General & Focused & $\begin{array}{c}\text { No } \\
\text { Answer }\end{array}$ \\
\hline $\begin{array}{c}\text { Trad } \\
(N=21) \\
\#=36\end{array}$ & $\begin{array}{c}1.4 \\
n=17\end{array}$ & $\begin{array}{c}0.8 \\
n=17\end{array}$ & 4 & $\begin{array}{c}\text { Trad } \\
(N=21) \\
\#=15\end{array}$ & $\begin{array}{l}1.3 \\
n=3\end{array}$ & $\begin{array}{c}3.7 \\
n=3\end{array}$ & 18 \\
\hline $\begin{array}{c}\text { SKy } \\
(N=38) \\
\#=36\end{array}$ & $\begin{array}{c}0.96 \\
n=24\end{array}$ & $\begin{array}{c}0.5 \\
n=24\end{array}$ & 14 & $\begin{array}{c}\text { SKy } \\
(N=38) \\
\#=17\end{array}$ & $\begin{array}{c}0.9 \\
n=15\end{array}$ & $\begin{array}{c}0.2 \\
n=15\end{array}$ & 23 \\
\hline
\end{tabular}

\section{Instructional}

\begin{tabular}{|c|c|c|c|c|c|c|c|c|c|}
\hline & \multicolumn{4}{|c|}{ Before } & & \multicolumn{4}{|c|}{ After } \\
\hline & $\begin{array}{c}\text { Outside } \\
\text { Teach }\end{array}$ & $\begin{array}{l}\text { Peer } \\
\text { Teach }\end{array}$ & Other & $\begin{array}{c}\text { No } \\
\text { Answer }\end{array}$ & & $\begin{array}{c}\text { Outside } \\
\text { Teach }\end{array}$ & $\begin{array}{c}\text { Peer } \\
\text { Teach }\end{array}$ & Other & $\begin{array}{c}\text { No } \\
\text { Answer }\end{array}$ \\
\hline $\begin{array}{c}\text { Trad } \\
(N=21) \\
\#=17\end{array}$ & $\begin{array}{c}0.3 \\
n=11\end{array}$ & $\begin{array}{c}0.3 \\
n=11\end{array}$ & $\begin{array}{c}1.0 \\
n=11\end{array}$ & 10 & $\begin{array}{c}\text { Trad } \\
(N=21) \\
\#=13\end{array}$ & $\begin{array}{c}0.08 \\
n=12\end{array}$ & $\begin{array}{c}0.08 \\
n=12\end{array}$ & $\begin{array}{c}0.9 \\
n=12\end{array}$ & 9 \\
\hline $\begin{array}{c}\text { SKy } \\
(N=38) \\
\#=77\end{array}$ & $\begin{array}{c}0.08 \\
n=37\end{array}$ & $\begin{array}{c}0.08 \\
n=37\end{array}$ & $\begin{array}{c}1.9 \\
n=37\end{array}$ & 1 & $\begin{array}{c}\text { SKy } \\
(N=38) \\
\#=52\end{array}$ & $\begin{array}{c}0 \\
n=32\end{array}$ & $\begin{array}{c}0.03 \\
n=32\end{array}$ & $\begin{array}{c}1.6 \\
n=32\end{array}$ & 6 \\
\hline
\end{tabular}

Note. Values in the table cells are ratio of responses-per-person answering the question.

$\mathrm{N}$ designates the number of PST in that program. $\mathrm{n}$ designated the number of contributing participants in that program. \# designates the number of contributing statements from that program before/after student teaching. 
Table 19 revealed some interesting findings regarding the types of beneficial observational and instructional practice experiences encountered before the student-teaching experience. Both Traditional and SKyTeach PSTs offered the same number of comments each regarding observational experiences. When noting the differences in sizes of each group related to total observational experience comments before student teaching, it was realized that Traditional PSTs comprised a total of 2.12 comments per PST versus SKyTeach PSTs rendering a total of 1.5 statements per PST. It was also noted that both programs reported that the majority of these experiences were general in nature (64\% of 46 of the total 72 contributing statements from both groups) versus those that were more focused (36\% the total 72 contributing statements from both groups).

When looking at instructional practice experiences before student teaching, SKyTeach PSTs offered 77 comments versus the 17 statements the Traditional PSTs proposed. This reaffirmed the sentiments earlier mentioned in this chapter that the SKyTeach curriculum supported a large amount instructional field experiences. The majority of the field experiences were labeled as 'other' (Traditional PSTs 65\% of 11 contributing Traditional statements and SKyTeach $92 \%$ of 71 contributing SKyTeach statements) as no distinction was made in the comments as to the nature of the experience. It was also noted that SKyTeach PSTs offered twice as many comments per PST regarding 'other' experiences as Traditional PSTs. Traditional PSTs were more likely to identify group/peer teaching as beneficial ( 0.3 comments per PST) than were SKyTeach (0.08 comments per PST) due to their training experiences. It was interesting to note that some PSTs in both the Traditional and SKyTeach programs mentioned that 
external experiences helped reinforce their field experiences with each program submitting 3 comments.

After student teaching, the results revealed that Traditional PSTs most common beneficial experiences mentioned were their focused observations with 73\% (3.7 comments per PSTs) 15 of the statements offered corroborating this fact. Support for this finding was found in comprehensive comments relating to how to address discipline issues and specific administrative aspects which were clarified with observations. SKyTeach PSTs gave more general answers (.93 comments per contributing PST) stating comments like "In student teaching you only observe two weeks and then you are teaching the rest of the time. I feel like the time helps you know how to engage the class" and "It (observation) helped me more than I imagined (emphasis added for clarification)."

In their after student-teaching comments, PSTs in both programs considered instructional practice most common beneficial aspect mentioned in reducing teaching concerns. SKyTeach PSTs' reflections usually referred to experiences that occurred before student teaching with comments like "The field experiences I had before student teaching helped me so much". While this question was intended to direct attention to instructional field experience before student teaching, most of the Traditional PSTs regarded the instructional experiences during the student-teaching experience as beneficial with comments such as "Student teaching helped me to get closer to the students that I felt needed the extra attention or to develop a more personable relationship with the students, instead of saying 'Hey, I'm an education student and I would like to watch y'all today'." Additionally, participants from both programs continued to reflect 
on 'general' field experiences that allowed them to be "able to teach students before doing student teaching” as being helpful.

\section{Summary of Early Field Experiences}

Several studies (e.g. Anderson, Barksdale, \& Hite, 2005; Austin-Martin et al., 1981; Steele, 2010) have found that when beneficial field experiences have been offered to PSTs, self-efficacy tends to increase before the student-teaching experience. The findings of this portion of the study began by focusing on what types of early field experiences were experienced by the PSTs in the Traditional and SKyTeach programs. It was discovered that there were three main types of field experience encounters. These were (a) observational, (b) instructional and (c) administrative in nature. Traditional PSTs were exposed to a large amount of observational field experiences while SKyTeach had more instructional field experience opportunities before student teaching. Administrative experiences were rare before student teaching, but were found to be desirable experiences.

Next a review of the benefits of observation and instructional experiences was conducted. It was noted that beneficial observational experiences allowed for PSTs to see different ways to present content material and a variety of teaching styles. It permitted PSTs to appreciate different strategies and techniques that weren't discussed in classes as well as different ways to decorate a classroom to promote learning. By watching different teachers, PSTs were exposed to different classroom management styles, a variety of methods to assist struggling students, and ways to handle misbehavior. Finally, some PSTs were given the opportunity to reflect on what they had observed, thus 
allowing them to formulate personal teaching techniques. As outlined by Bandura (1994), this transferal increases self-efficacy.

Yet, not all observation field experiences were viewed as beneficial for growth. Several PSTs viewed observation assignments as a task to be endured. They expressed feelings of boredom. PSTs mentioned that other administrative tasks or instructional work would have been more beneficial for growth than 'just observing'. Others did not like the non-specific nature of many of the observation assignments. On many instances the PSTs reported that they were not sure what to observe, wishing instead that a more focused project had been assigned.

The comments made regarding instructional field experiences were varied as well. Many PSTs felt that instructional field experiences allowed them to grow professionally and allowed them to become increasingly more comfortable with leading the classroom. Several PSTs listed skills they acquired by executing instructional field experiences such as preparing and implementing lesson plans, evaluating students misconceptions, working on classroom management, and then reflecting on their performance. Other PSTs in the SKyTeach discussed being able to begin teaching in their first semester. They related that they taught all grade levels, in rural and urban settings, and several times each semester before starting student teaching.

PSTs in both programs listed a variety of sub-types of instructional experiences. They included teaching their peers, co-teaching or team teaching; as well as solo teaching. Some SKyTeach PSTs compared their instructional experiences to the predominately observational field experiences of the Traditional program, stating that the SKyTeach field experiences helped the transition into student teaching be less 
intimidating. Finally, there was a small portion of PSTs that said the most beneficial instructional experiences they had were not part of either program but came from substitute teaching, working in the military, and working in other classroom settings like a weekend academic camp called "Super Saturdays".

Not all instructional experiences were viewed as beneficial in preparing for student teaching or alleviating teacher concerns. The majority of the PSTs which taught in a peer setting stated that teaching their peers was artificial and not very beneficial at all. Others stated that working in a team teaching situation did not allow for a true sense of leading the classroom. Finally there were those Traditional PSTS who believed that only having a few exposures to instructional experiences increased concerns instead of reducing them.

Next, sub-types of observational and instructional experiences the PSTs in each program perceived as most effective or helpful before student teaching were documented. Observational experiences were divided into general and focused events. PSTs in both programs had experienced more general observational experiences and that these had been viewed as beneficial. After student teaching, Traditional PSTs were more likely to regard their focused observations as most beneficial in helping them in their student teaching, while SKyTeach PSTs were more apt to give a general answer like "my previous observational experiences were helpful in student teaching".

Instructional field experiences were divided into (a) peer/group teaching experiences, (b) outside experiences and (c) "other experiences" for generic experiences. Before student teaching, most PSTs viewed general experiences as most helpful in developing them into effective student teachers. Unfortunately, no distinction was made 
as to the nature of these experiences (peer/group instruction or individual instruction) with many only referring to the benefits of teaching in front of a classroom. It was also noted that a small percentage of PSTs in both programs performed some of their instructional field experience outside each of the programs' curricula.

\section{Mentoring Experiences Perceived as Effective in Helping Reduce Self-Preservation}

\section{Concerns}

Educational mentoring involved the personal guidance of a quality veteran teacher. Smith and Ingersoll (2004) noticed that the novice teachers were 30\% more likely to remain in teaching if they possessed a mentor. An effective mentor was defined as one who is committed to the success and welfare of the mentee while providing a collaborative learning environment (e.g. Ambrosetti \& Dekkers, 2010; Fletcher \& Barrett, 2004). This study sought to identify what types of mentors the recognized as having and how these types of mentors were beneficial in reducing teacher concerns.

In order to analyze which mentoring aspects were perceive as effective in helping PSTs ameliorate self-preservation concerns, the qualitative data regarding mentoring experiences were obtained from the open-ended questions on the survey, the comments gathered from the focus group meeting, and the responses from both interview sessions were analyzed using an inductive approach as recommended by Miles and Huberman (1984). A total of were analyzed: six focus group students, 17 pre- and post-interviews, and 36 students who completed two surveys but were not interviewed. Twenty-one of these individuals were Traditional PSTs and 38 were SKyTeach PSTs.

Information was gathered from the 59 independent sources mentioned above regarding whether PSTs in each program recognized the presence of a mentor during 
their studies. Twenty-one of these individuals were Traditional PSTs and 38 were SKyTeach PSTs. If they recognize a mentor, this fact was recorded by indicating how this person was affiliated with the PST. Table 20 shows the recorded results of tallied comments revealing who the Traditional and SKyTeach PSTs viewed as mentors before and after their student-teaching experience. The cooperating teacher (also known as the classroom practicing teacher) was often intermingled with comments with the university supervisor (the person hired to observe by the university) so these two persons were combined into one category because it was difficult to sort which individual was being identified in these comments.

Table 20

Statements which Identified Mentors of the Traditional and SKyTeach Programs

\begin{tabular}{|c|c|c|c|c|}
\hline & \multicolumn{2}{|c|}{ Before Student Teaching } & \multicolumn{2}{|c|}{ After Student Teaching } \\
\hline $\begin{array}{l}\text { Reporting } \\
\text { No Mentor }\end{array}$ & $\begin{array}{l}\text { TRAD } \\
n=10\end{array}$ & $\begin{array}{l}\text { SKY } \\
n=1\end{array}$ & $\begin{array}{c}\text { TRAD } \\
n=0\end{array}$ & $\begin{array}{l}\text { SKY } \\
n=5\end{array}$ \\
\hline Person(s) Reporting & $n=11$ & $n=37$ & $n=21$ & $n=33$ \\
\hline At Least One Mentor & $\#=38$ & $\#=74$ & $\#=66$ & $\#=69$ \\
\hline & \multicolumn{4}{|c|}{ Category Of Mentor } \\
\hline University Faculty & 1.0 & 1.7 & 0.3 & 0.7 \\
\hline Family & 0.4 & 0.08 & 0.2 & 0 \\
\hline Peer & 0.2 & 0.14 & 0.14 & 0.2 \\
\hline External Mentor & 0.2 & 0.05 & 0.7 & 0.2 \\
\hline $\begin{array}{l}\text { Cooperating Teacher / } \\
\text { University Supervisor }\end{array}$ & 0 & 0 & 1.81 & 0.9 \\
\hline \multicolumn{5}{|c|}{$\begin{array}{l}\text { Note. Values in the table cells are ratio of responses-per-person answering the question } \\
\text { designated the number of contributing participants in that program; \# designated the } \\
\text { number of contributing statements from that program before/after student teaching. } \\
\text { These groups are independent. }\end{array}$} \\
\hline
\end{tabular}

Before student teaching, ten Traditional PSTs reported "None" or left the question blank indicating that they did not identify someone as a mentor in their program or chose not to comment. While all of the PSTs in both programs are required to meet with at 
least one academic advisor each semester, the Traditional PSTs who did identify a specific mentor did not feel that any category listed offered substantial mentoring during their training. One male Traditional PST expressed the relative absence of a mentor by summarizing his experience. "Advising was more of a sounding board for class selection. It was less involved that I thought necessary. [My advisor/mentor] signed me up for the wrong class, but it turned out it helped me for teacher preparation. Otherwise, my advisor did not help me prepare for student teaching." Three PSTs stated that they had an advisor but "on paper only", all contact was through phone calls and emails.

Those eleven Traditional PSTs who did identify a mentor before the student-teaching experience selected the WKU faculty (1.0 statement per contributing person) as their choice. If the advisor was also the PST's instructor, the students alleged that this familiarity favorably influenced them to seek additional content guidance. A closer look at the responses made by nine of these PSTs revealed that, in addition to being generally helpful, these advisors offered (a) advice about class selections, (b) suggestions about content matters and teaching issues, and (c) resolutions to personal issues. One 41-year old female PST relayed that the Traditional advisors she was assigned to were not helpful so she sought guidance from "all of the teachers in the SKyTeach program and they were all very supportive, even though, I was not in the program." Other comments about mentoring revealed that help and advice came from family members ( 0.4 statements per contributing Traditional comments), peers $(0.2$ statements per contributing Traditional comments) and other teachers outside the WKU faculty ( 0.2 statements per contributing Traditional comments). 
Those PSTs training in the SKyTeach program mentioned the WKU faculty as their primary mentors before the student-teaching experience in their comments $85 \%$ of the time (an average of approximately 1.5 statements being made from the 74 contributing SKyTeach PST comments). Most of these mentors were part of the SKyTeach program with all but three PSTs specifically commented on how instrumental the SKyTeach faculty was to their pre-student-teaching training. These mentors conducted an "open-door" policy and encouraged PST to discuss academic and emotional concerns. One of the focus group participants explained, "[One of my SKyTeach mentors] is always there for that emotional support. That's one of the best things about SKyTeach, even when you're a little sophomore, you have several mentor teachers". Another SKyTeach PST said, "This was the difference in making or breaking me on the academic and emotional level."

These mentors supported PSTs both inside and outside the classroom on the academic and emotional parameters. This was portrayed by two statements from SKyTeach PST's: (a) “Dr. M is also an outside mentor to me and I can SKYPE her anytime I need help. I am very thankful for all my mentors", and (b) "I have plenty of opportunities to engage with my advisor about concerns with my teaching and/or degree program.” Five SKyTeach PSTs viewed their peers as mentors (0.14 statements per contributing SKyTeach comments), three listed family members (0.08 statements per contributing SKyTeach comments), and two included high school teachers that still offered advice as means of additional mentoring avenues ( 0.05 statements per contributing SKyTeach comments). One SKyTeach PST did not identify a mentor before the student-teaching experience. 
After the student-teaching experience, all the Traditional PSTs were able to identify a mentor. The majority of these PSTs agreed that their cooperating teacher and/or their university supervisor (the people that saw them teach) offered the most meaningful mentoring experiences with 1.81 statements being made by the 21 contributing Traditional PSTs. In addition, other teachers or administrators (external mentors) at the PSTs assigned schools were also listed 58\% (0.7 statements per contributing Traditional PST) of the time as offering additional advice. These were evident in statements like "My cooperating teacher is my mentor. I spend time with her every day, we talk at lunch. She helps me plans. She is a tremendous help" and "The whole faculty seems so supportive. My principal is always asking me how I am doing. It's is a friendly environment." Other Traditional PSTs also looked for guidance from previous WKU mentors (0.3 statements per contributing Traditional comments), family members that were also educators ( 0.2 statements per contributing Traditional comments) and peers (0.14 statements per contributing Traditional comments).

SKyTeach PSTs also recognized the cooperating teacher/university supervisor team $43 \%$ (0.9 statements per contributing SKyTeach comments) of the time as their primary source of mentoring during the student-teaching experience. This is illustrated through the statement, "I would normally address my students' concerns with both my supervisor and cooperating teacher whenever there is a chance. Issues such as classroom management and time management are brought up weekly." However, instead of drawing insight from other school personnel as the Traditional PSTs did, 33\% of the time the SKyTeach PSTs would contact their SKyTeach mentors (0.7 statements per contributing SKyTeach comments) for additional guidance. This could be a result of the 
differences between the predominantly lecture-based pedagogy used by the cooperating teachers and the recommended inquiry-based pedagogical approaches taught through the SKyTeach program. Supporting evidence was found in the several statements similar to the following: (a) "My student teaching has been very different from my educational program in SKyTeach since my cooperating teacher is very direct-teach and lenient with discipline," (b) "I did not have anyone to discuss concerns with at my field placement for fear of judgment... when I was able to speak to these mentors, it was extremely helpful to me; helpful for my role as a teacher and helpful emotionally"; (c) "I spoke to other professors because I felt unable to speak about my concerns with my supervisor. A few of my professors have been very supportive through my colliagete (sic) career. This semester has been a bad experience yet I still felt comfortable seeking the advice of these mentors", and (d) "I have at least two mentors in SKyTeach helping me with teaching strategies and give me activities." There were other SKyTeach PSTs that did seek the guidance from other school personnel (0.2 statements per contributing SKyTeach comments) and peers (0.2 statements per contributing SKyTeach comments). Five SKyTeach PSTs did not identify a specific mentor when reflecting on the student-teaching experience.

Beneficial Mentoring Practices. Johnson and Birkeland (2002) noted that mentees believed effective mentoring programs included: (a) encouragement from veteran teachers; (b) curriculum decisions assistance; (c) advice on lesson planning and development; and (d) feedback on teaching (p. 42). While these characteristics were used in the description of effective induction mentoring, further review of the comments made by those PSTs who identified a university sponsored mentor recognized parallel 
categories of these induction qualities that were compatible to pre-service mentoring. These were generalized into three main categories of advisors: academic advisors, emotional advisors, and professional advisor. An academic advisor guided the PST in curriculum decisions about coursework within their teacher preparation program. An emotional advisor was professional mentors who encouraged the PST during their pre-service experiences. A professional advisor offered advice on developing a PST into a professional teacher by giving advice on developing lessons and offering feedback on teaching practice experiences. The three categories of mentors were analyzed to see which types offered more support or were beneficial in reducing teacher concerns through their influence as is outlined below.

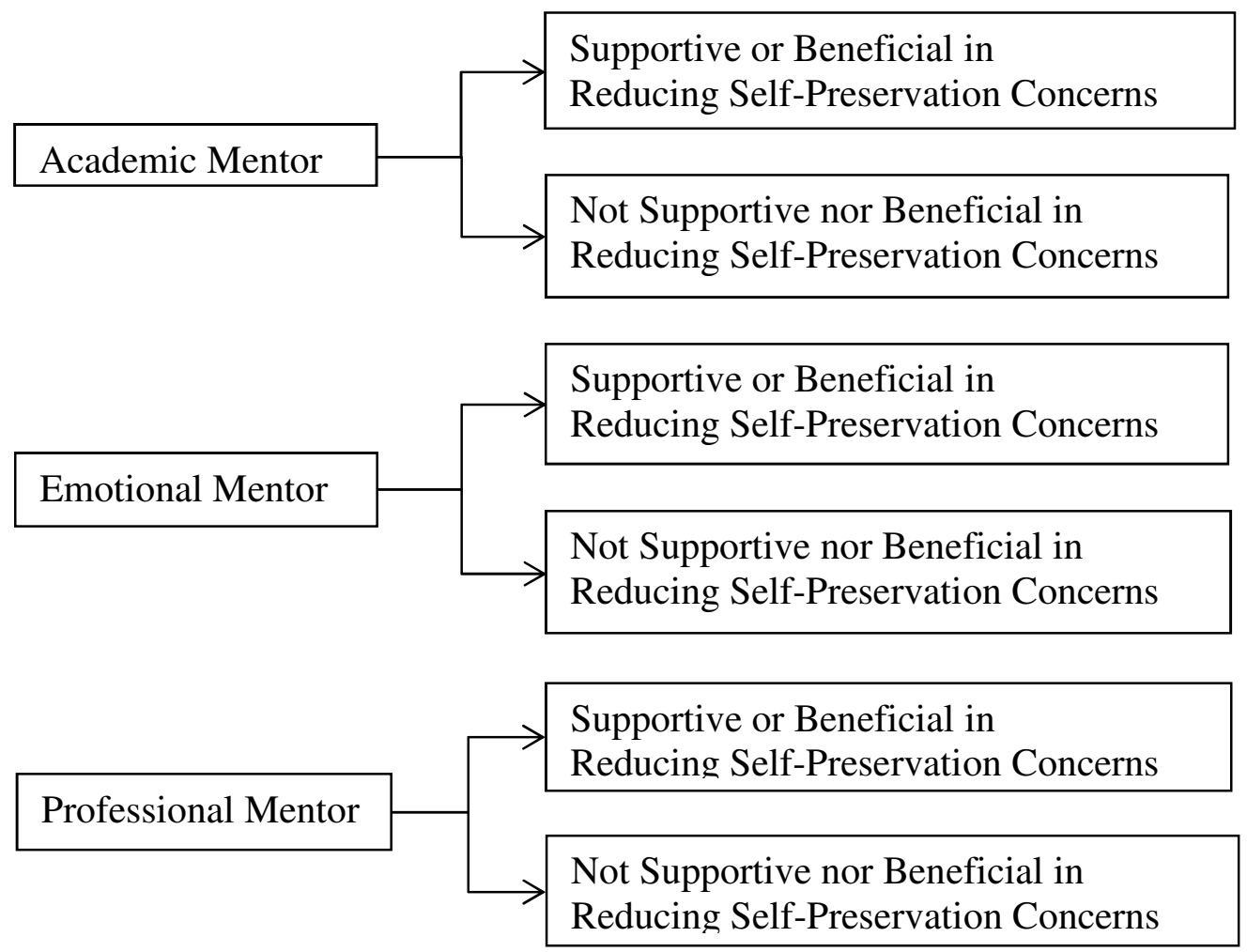

Figure 7. Categories of Mentors

Further analyses were conducted to understand what category of mentor the PSTs perceived the WKU faculty or cooperating teachers represented. The sample was limited 
to those PST in both programs that identified a WKU faculty member as their primary mentor before student teaching. This included ten Traditional PSTs (47.6\%) and 35 SKyTeach PSTs (92\%). In like manner, only those students that identified either the cooperating teacher/university supervising teacher team which had ties to the WKU STEM teacher education program or a WKU faculty member as a mentor after the student-teaching experiences were assessed. These involved comments made by 21 Traditional PSTs and 32 SKyTeach PSTs.

These statements lead to three reoccurring categories identified as the parallel categories. These categories were identified as mentors that offered (a) academic or curriculum advice, (b) encouragement and emotional support, and (c) advice on professional growth in areas like lesson planning and teaching strategies. Statements like "My WKU mentor helped me scheduled my classes and offered suggestions on how to improve my questioning skills" would be tallied as an academic and also as a professional mentor. Table 21 shows the results what category of mentor PSTs identified before and after the student-teaching experience and if that experience was beneficial in preparing them for their student-teaching experience by reducing self-preservation concerns or by receiving beneficial support. These comments were counted as "Beneficial for Growth" or as receiving "High Levels of Support" statements. Other comments that did not ascribe to professional growth or alluded to preventing growth were recorded as "Not Very Beneficial" statements. A representative collection of these statements are found in Table 22. 
Table 21

Perceived Characteristics of WKU Mentors and University Sponsored Mentors

\section{Academic}

\begin{tabular}{|c|c|c|c|c|}
\hline \multirow{5}{*}{$\begin{array}{c}\text { Traditional } \\
(N=21)\end{array}$} & \multicolumn{2}{|c|}{ Before } & \multicolumn{2}{|c|}{ During } \\
\hline & Beneficial & $\begin{array}{c}\text { Not } \\
\text { Beneficial } \\
\end{array}$ & Beneficial & $\begin{array}{c}\text { Not } \\
\text { Beneficial }\end{array}$ \\
\hline & 0.7 & 0.6 & 0.0 & 0.09 \\
\hline & $n=10$ & $n=10$ & $n=21$ & $n=21$ \\
\hline & $\#=26$ & $\#=26$ & $\#=50$ & $\#=50$ \\
\hline \multirow{6}{*}{$\begin{array}{c}\text { SKyTeach } \\
(N=38)\end{array}$} & 0.17 & 0.05 & 0.13 & 0.0 \\
\hline & $n=35$ & $n=35$ & $n=32$ & $n=32$ \\
\hline & $\#=115$ & $\#=115$ & $\#=76$ & $\#=76$ \\
\hline & \multicolumn{4}{|c|}{ Emotional } \\
\hline & \multicolumn{2}{|c|}{ Before } & \multicolumn{2}{|c|}{ During } \\
\hline & Beneficial & $\begin{array}{c}\text { Not } \\
\text { Beneficial }\end{array}$ & Beneficial & $\begin{array}{c}\text { Not } \\
\text { Beneficial }\end{array}$ \\
\hline \multirow{3}{*}{$\begin{array}{l}\text { Traditional } \\
(N=21)\end{array}$} & 0.4 & 0.1 & 0.48 & 0.05 \\
\hline & $n=10$ & $n=10$ & $n=21$ & $n=21$ \\
\hline & $\#=26$ & $\#=26$ & $\#=50$ & $\#=50$ \\
\hline \multirow{3}{*}{$\begin{array}{l}\text { SKyTeach } \\
(N=38)\end{array}$} & 0.8 & 0.17 & 0.53 & 0.38 \\
\hline & $n=35$ & $n=35$ & $n=32$ & $n=32$ \\
\hline & $\#=115$ & $\#=115$ & $\#=76$ & $\#=76$ \\
\hline
\end{tabular}

Professional

\begin{tabular}{cccccc}
\hline & \multicolumn{3}{c}{ Before } & & \multicolumn{2}{c}{ During } \\
\cline { 2 - 3 } \cline { 5 - 6 } & Beneficial & $\begin{array}{c}\text { Not } \\
\text { Beneficial }\end{array}$ & & Beneficial & $\begin{array}{c}\text { Not } \\
\text { Beneficial }\end{array}$ \\
\cline { 2 - 3 } Traditional & 0.4 & 0.4 & & 1.67 & 0.9 \\
$(N=21)$ & $n=10$ & $n=10$ & & $\mathrm{n}=21$ & $\mathrm{n}=21$ \\
& $\#=26$ & $\#=26$ & & $\#=50$ & $\#=50$ \\
\hline SKyTeach & 1.3 & 0.3 & & 1.03 & 0.3 \\
$(N=38)$ & $\mathrm{n}=35$ & $n=35$ & & $n=32$ & $n=32$ \\
& $\#=115$ & $\#=115$ & & $\#=76$ & $\#=76$ \\
\hline
\end{tabular}

Note. Values in the table cells are ratio of responses-per-person answering the question $\mathrm{N}$ designates the number of PST in that program; $\mathrm{n}$ designated the number of contributing participants in that program; \# designates the number of contributing statements from that program before/after student teaching.

An assessment of statements showed a change in how the PSTs perceived beneficial benefits of mentoring they received before the student teaching as compared to during the student teaching experience. In the Traditional program numerically there were more mentoring statements were made after the student-teaching experience 
(50 statements made by contributing Traditional PST) than before ( 26 statements made by contributing PST). The reverse was true for the SKyTeach program with 115 statements being made about mentoring before the student-teaching experience and an additional 76 statements being made afterwards.

Before student teaching took place, the Traditional PSTs reported that their WKU mentors predominantly provided academic support $27 \%$ of the time $(0.7$ statements per contributing Traditional PST). The comments were related to the support the Traditional PSTs received during their pre-service training. This was manifested in statements like: "We had advisors to help with class schedule(s);" "She told me what classes to take and when"; as well as, “...exchanged multiple emails and phone calls to discuss ideas on how to fix problems I was having in class". However, others in the Traditional program felt that their mentors lacked on this portion of their mentoring program with 0.6 statements per contributing Traditional PST (or 23\%) by making comments like: "WKU more of a sounding board for class selection. It was less involved that I thought necessary. My advisor signed me up for the wrong class...”. For those Traditional PSTs who could identify their WKU mentors responded 15\% of the time that their mentors may or may not be emotionally supportive (equally 0.4 statements per contributing Traditional PST). Statements showing this diversity in emotional mentoring ranged from “...[my] personal issues were resolved" and "...they were extremely helpful and encouraging" to "I'm not sure I had one of these; they were all [business]." Also, statements like "my mentor helped me to prepare for student teaching revealed that some traditional PSTs recognized that their mentors offered professional advice ( 0.4 statements per contributing Traditional PST) that could benefit them in their student-teaching experience. 
The SKyTeach program comments revealed that the different mentoring opportunities the PSTs encountered were predominately beneficial experiences before and after the student-teaching experience. Before student teaching, the SKyTeach PSTs comments reflected that they perceived that their WKU mentors provided higher amount of professional (1.3 statements per contributing SKyTeach PST) and emotional (0.8 statements per contributing SKyTeach PST) mentoring than academic mentoring (0.6 statements per contributing SKyTeach PST). All three areas reporting 'not beneficial' comments in these areas had considerably lower percentages by all contributing SKyTeach PSTs in comparison to beneficial comments. Comments like "They've always assisted me in my academics, job preparation, and been sensitive to personal problems" showed that SKyTeach PSTs recognized this trilogy of mentoring support.

During the student-teaching experience, both programs saw an increase in professional beneficial support with all Traditional students commenting and $86 \%$ of the SKyTeach PSTs submitting comments about mentoring (five SKyTeach PSTs did not offer insight about mentoring during student teaching). This would be deemed appropriate at this juncture in their educational training. Traditional PSTs also commented on the emotional benefits offered by their mentors with $20 \%$ ( 0.48 statements per contributing PSTs) commenting on this subject. However, SKyTeach PSTs were divided about the emotional benefits offered by their student-teaching mentors. Twenty-two percent ( 0.5 comments per the contributing PSTs) of SKyTeach PSTs confirmed beneficial emotional support; whereas, $16 \%$ ( 0.4 comments per the contributing PSTs) relayed receiving little emotional support. There were also four academic mentoring statements referenced by the SKyTeach PSTs. These statements 
gave reflections of how academic training had helped in their student teaching and questions regarding their up-coming graduation.

The larger percentages of low support of Emotional and Professional mentoring by SKyTeach came from differences between SKyTeach's inquiry-based teaching strategies and the more lecture-based teaching styles the cooperating teachers were using in the student-teaching classrooms. Several SKyTeach participants made comments that verified this confusion: "My student teaching has been very different for my Ed. Program in SKyTeach since my cooperating teacher is very direct-teach and lenient with discipline" and "It kinda made me mad at SkyTeach. Throughout the SkyTeach we talked about, yeah, you're going to have kids that disrupt class and all that. [Their solution was] "Find new lesson plans, do engaging things, play games, take them outside. Don't do the traditional way but, sometimes you have to do the traditional way to get through everything. It kinda upset me. I talked about this to my cooperating teacher". Others commented that there was an expert/novice relationship that was very judgmental in nature: "We kept a civil professional relationship, but I felt like it was a mother/teenage daughter relationship or expert/ apprentice. I was doted on before a lot and I don't mean she had to do that. I just wished she had played more of a mentor role; a helping role versus you did this wrong..." When these SKyTeach had strong ties to their master teachers, they would contact them for advice. This connection to the SKyTeach Master teachers was evident in statements like, "A few of my professors have been very supportive through my colliagete (sic) career. This semester has been a bad experience yet I still felt comfortable seeking the advice of these mentors". 
Table 22 shows a representative list of the statements that were most frequently mentioned as beneficial (or of receiving high levels of support) and not beneficial (or evidence of receiving low levels of support) regarding academic mentoring, emotional mentoring, and professional mentoring in both programs. The comments of both programs were very similar in nature when regarding this division of beneficial and not beneficial. The statements were gathered from comments made before and after the student-teaching experiences. While this listing offered a representative of all comments made, a vast majority of these statements were made by SKyTeach PSTS as they offered at total of 191 comments whereas Traditional PSTs offered a total of 76 statements.

Table 22

Summary of Mentoring Comments

EMERGING Level of support Represented Comments
CATAGORIES

\begin{tabular}{ccl}
\hline Academic & $\begin{array}{c}\text { Beneficial for } \\
\text { Growth/Support }\end{array}$ & $\begin{array}{l}\text { I had a lot experience with (this type of mentor) } \\
\text { on what classes to take and stuff and I was going } \\
\text { through the program and when to take the } \\
\text { (classes) (S); Very helpful with any questions } \\
\text { about classes or anything else involving my } \\
\text { education (S). }\end{array}$ \\
\hline Not as Beneficial & $\begin{array}{l}\text { I never saw my advisor in person (S); Mostly he } \\
\text { would ok'ed (sic) my schedule by phone (S); As } \\
\text { far as insight on classes to take, I had a rough } \\
\text { time because SKyTeach advisor would tell me } \\
\text { one thing and Chemistry advisor would tell me } \\
\text { another...which would make it more confusing } \\
\text { (S). }\end{array}$ \\
& $\begin{array}{l}\text { WKU more of a sounding board for class } \\
\text { selection (T). }\end{array}$ \\
\hline Beneficial & $\begin{array}{l}\text { I was really needing support, she is there for that } \\
\text { emotional support (S); Personal issues are keys to } \\
\text { us older students (S); Personal issues resolved and } \\
\text { overall helpful (T); Being able to voice my } \\
\text { concerns and understand that they are normal is }\end{array}$ \\
\hline High support &
\end{tabular}




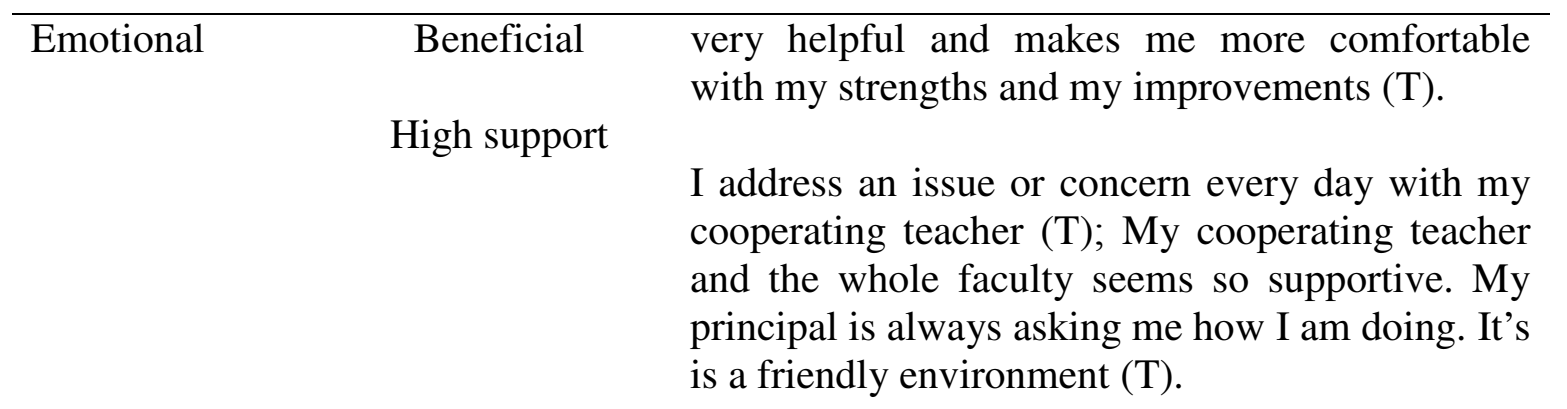

Not as Beneficial I feel that the master teachers in SKyTeach were stretched too thin at Low support times (S); they mostly strived to support or ensure us that we are ready instead of really hearing me out $(\mathrm{S})$. I'm not sure I had one of these. My advisors were too stuffy- you knowprofessional (T).

There was no collaborating (S). I felt she was not supportive of some of the extra-curricular things I had to do for my portfolio (S). Looking at the scores she gave me, I am almost embarrassed to turn them in $(\mathrm{S})$.

I had a feeling of terror knowing my university supervisor was coming in. More than one time when she left, I left in tears (S); I spoke to other professors because I felt unable to speak about my concerns with my supervisor (S). The relationship with my university supervising teacher was strained (T).

\begin{tabular}{|c|c|c|}
\hline Professional & $\begin{array}{r}\text { Beneficial } \\
\text { High support }\end{array}$ & $\begin{array}{l}\text { They advise you on your lesson plans, } \\
\text { they will tell you what to fix, and they } \\
\text { can come up with activities when you } \\
\text { can't think of anything. They give you } \\
\text { feedback of what you did wrong-and } \\
\text { right (S)! They help you develop (S); I } \\
\text { would say my mentor helped me to } \\
\text { prepare for student teaching helping } \\
\text { with whatever concerns I had (T). It } \\
\text { helped with professional development } \\
\text { (S) }\end{array}$ \\
\hline
\end{tabular}
(S). 


\begin{tabular}{|c|c|c|}
\hline \multirow[t]{3}{*}{$\begin{array}{l}\text { Professional } \\
\text { (continued) }\end{array}$} & $\begin{array}{r}\text { Beneficial } \\
\text { High support }\end{array}$ & $\begin{array}{l}\text { My supervising teacher and my team } \\
\text { teachers give me so many ideas to use } \\
\text { (T); I've built up a pretty good } \\
\text { relationship with my cooperating } \\
\text { teacher. I feel very confident that } \\
\text { should I get a job somewhere, I am } \\
\text { pretty sure if I had a teaching issue I } \\
\text { could email her. She could send me } \\
\text { back something that could help (T). }\end{array}$ \\
\hline & $\begin{array}{c}\text { Not as Beneficial } \\
\text { Low support }\end{array}$ & $\begin{array}{l}\text { None of my classes prepared me for } \\
\text { the political arena, we are going into } \\
\text { (S); There was some conflict between } \\
\text { master teachers and veteran teachers } \\
\text { that can get students involved }(\mathrm{S}) \text {. } \\
\text { The problem is the lack of } \\
\text { communication }(\mathrm{S}) \text {. }\end{array}$ \\
\hline & & $\begin{array}{l}\text { I wish we had more real-world } \\
\text { experiences with [lecturing } \\
\text { approaches]. My cooperating teacher } \\
\text { took it as "when you get your own } \\
\text { classroom and your own schedule" } \\
\text { (S). I feel like we need the traditional } \\
\text { way too (S); This semester has been a } \\
\text { bad professional experience (S). }\end{array}$ \\
\hline
\end{tabular}

Notes. Comments recorded from focus group discussions, all interviews, and blogs. (T): Representative comment made by a Traditional PST; (S): Representative comment made by a SKyTeach PST.

\section{Summary of Mentoring Aspects of Each Program}

A final look at the overall mentoring portion of their respective programs shows that everyone in both programs benefited from some form of mentoring developed at WKU either before or after the student-teaching experience. All 38 SKyTeach PSTs detailed contributions made either before or during the student-teaching experience; whereas the responses from the Traditional PSTs were not as frequent before the student-teaching experience. 
Nearly half of the Traditional PSTs did not identify a specific mentor before the student-teaching experience. Those that did recognize a mentor before student teaching felt that their mentors offered more academic guidance than any other mentoring role. Before the student-teaching experience, most SKyTeach PST respondents alluded to all the characteristics of a successful mentoring program as outlined by Johnson and Birkeland (2002) when paralleled to characterize the mentoring dimensions of a teacher training program before the student-teaching experience. These PSTs perceived that their mentors offered professional, emotional, and academic mentoring qualities to support their educational growth.

All Traditional PSTs stated that most of their mentoring came during the student-teaching experience. All but one of the 21 Traditional PSTs offered some positive comment regarding the mentoring contributions of either the cooperating teacher or the supervising teacher employed by WKU. As a secondary mentor, most Traditional PSTs sought guidance from other veteran teachers or administrative personnel working at their student-teaching assignment.

Most SKyTeach PSTs also viewed their experiences with their cooperating teacher or the supervising teacher as beneficial. However, due to the conflicts in the methods taught in the SKyTeach program and those being presented in the student-teaching placements, bonds between several SKyTeach PSTs and the cooperating teacher/supervising teacher were more strained with PSTs seeking validation from SKyTeach mentors as a second means of validation. 


\section{CHAPTER 6}

\section{DISCUSSION}

This study quantitatively and qualitatively examined the role that continuous highly engaged field experiences and multi-faceted mentoring strategies contributed in addressing teacher concerns of preservice teachers before and during their student-teaching experience. A total of 59 pre-service teachers entering their final semester of their teacher training in either the Traditional program or SKyTeach program participated in this study. These two STEM teacher education programs were running simultaneously during the time of the investigation.

The study was composed of two segments of investigation. The first involved identifying teacher's concerns that the PSTs possessed at two time points-before and after student teaching. Six members of a focus group and 45 participants who completed two TCC surveys were asked to classify what level of Fuller's (1969) self-preservation, task-related, student-impact teacher concerns they possessed before beginning their student-teaching experience and again after they had completed that experience.

In addition, a second investigation involving the six PSTs who participated in a focus group, 12 PSTs who participated in two interviews, and 36 PSTs who completed two surveys but were not interviewed about their early field experiences and their mentoring experiences and if these experiences were beneficial in reducing their teaching

concerns. Another inquiry asked PSTs to reflect on these same issues and to comment on any additional mentoring experiences which occurred during the student-teaching 
experience to see if teaching concerns had been addressed before venturing into the professional field.

\section{Concerns of Preservice Teachers}

Fuller's guidelines of Teacher Concerns (1969) theorized that preservice and professional teachers tend to progress sequentially from primal self-preservation concerns, through task-related concerns and finally arrive at a stage of teaching concerns focusing on impacting students' needs. The first most primal concern was self-preservation concerns. These were manifested as personal concerns about mastering the subject matter adequately and concerns about how others view their performance. Because pre-service teacher programs are working with teachers at the very beginning of their professional teacher trajectory, ameliorating self-preservation concerns could be viewed as one key goal in order to support the PSTs in reducing this type of concern and

aid in launching a successful career. As self-efficacy improved and experience increased, Fuller theorized that these concerns would be replaced with concerns of the daily responsibilities of teaching and would then progress towards focusing on meeting the needs of the student.

In this study, the student teachers were polled using the Teacher Concern Checklist developed by Borich (1997) before any student teaching had begun and again after the student-teaching experience. Before student teaching, Traditional preservice teachers had moderate levels of all three teaching concerns with task concerns being the highest, followed closely by impact concerns and self-preservation concerns. SKyTeach preservice teachers also had moderate levels of concerns but had higher levels of impact concerns and task concerns followed by self-preservation concerns. 
Quantitative testing showed that there were no significant differences between Traditional PST concerns and SKyTeach PST concerns when comparing overall concerns (see Table 5). A second test also revealed no significant difference between programs when comparing each type of concern (Table 6). After student teaching, Table 6 also revealed that Traditional preservice teachers' concerns shifted to moderate levels of impact concerns then followed by task and self-preservation concerns; while SKyTeach remained moderately concerned with impact concerns and task concerns followed by self-preservation concerns. This presence of impact concerns being the highest concern was consistent with studies by McVey (2004) and Reeves and Kazelski (1985). Once again, these quantitative results did not reveal any significant differences between the Traditional and SKyTeach PSTs levels of concerns; nor were there any significant differences among self, task, or impact concerns within the participants of a specific program from the beginning of the student-teaching experience to the end. While quantitative results in Table 5 indicated that there was a drop in overall teachers concerns in both programs after the teaching experiences, these reductions were not statistically significant.

While an initial look at Traditional preservice teachers concerns seem to support Fuller's (1969) sequential growth towards student-driven concerns by alluding to a modest progression from task towards impact concerns during the duration of this study, these findings were not statistically significant. Therefore, they did not support the Fuller's sequential progression theory but rather showed that concerns existed simultaneously. The findings that preservice teachers of different programs expressed similar levels of concerns coincide with the results of Dalez (1998) who compared the 
concerns of recent graduates of traditional teacher education program and graduates of a professional development school. Other studies which found simultaneous existences of teacher concerns among preservice teachers were reported by Capel (2001) and Evans and Tribble (1996).

The presence of a moderate level of all three concerns before the student-teaching experience validated the idea that student teaching was a stressful time in a preservice teacher's program (Black-Branch \& Lamont, 1998, Greer \& Greer 1992). In addition, the existence of all three concerns before and after the student-teaching experience indicated that concerns do not follow a fixed progression but change as situations change, a result found in Pigge and Marso's (1997) study. In the current study, these changes were identified as the culminating experience of the student-teaching practicum and the prospect of finding a teaching position.

Quantitative results are influenced by the sample size and measurement sensitivity to the constructs of interest. On several occasions, the small sample size found in this study may have detracted from showing the true nature of teacher concerns among the PSTs in this study. One such example presented itself when trying to determine how to load questions on the three concern factors, self-preservation, task-related, and student impact concerns. This issue was discussed in Chapter 3. Because a minimum of 100 subjects would have to be participating in the study in order to run an effective factor analysis (Gorsuch, 1983; Kline, 1979), and this study only contained 45 PSTs, a decision was made to use the loading developed by Rogan and others (1992). Also, given the relatively low sample size for each group in this study, there is a nontrivial possibility that the final quantitative survey results of finding significant overall differences and 
difference among each type of concern may not have fully captured. The small sample under powered the study and in doing so may have skewed the results like those found in Table 6 where the lowering of self-preservation concerns of the Traditional PSTs from the beginning of the study to the end was approaching significant reduction $(\mathrm{p}=0.059)$. Another aspect which cannot be verified due to underpowered nature of the study was the continued presence of a consistently higher moderate level of concern of all three types of teacher concerns among the SKyTeach PSTs than those recorded by the Traditional PSTs throughout the study. This may indicate that the SKyTeach PSTs possess a more realistic perspective of the challenges of teaching than the Traditional PSTs due to the extra exposure the SKyTeach PSTs obtained during their frequent and actively engaged field experiences.

In order to better understand the extent and nature of the simultaneous existence of self, task, and impact-related concerns, qualitative data were collected from 59 PSTs before, during and after the student-teaching experience. These results came from the six focus group participants, 17 PSTs who completed both interviews and 36 PSTS that completed two rounds of the survey but were not interviewed. In addition, 15 members of the study also contributed relative information on blog reflections. This data revealed that although PSTs in both programs possessed moderate levels of all the concerns throughout the student-teaching experience, the subtlety of subthemes within these concerns were different. 


\section{Self-Preservation Concerns}

The most primal concern is self-preservation concerns. These are manifested as personal concerns which proliferate apprehensions concerning job security and raise doubts concerning self-adequacy in teaching (i.e. Borich \& Tombardi, 1997; Fuller \& Bown, 1975). Upon reviewing the qualitative data collected, four subthemes of concerns emerged. These were (a) seeking respect of others, (b) being concerned over external evaluations, (c) being able to manage a classroom, and (d) having concerns relating to writing and implementing lesson plans, in addition to effectively reflect on these lessons. A similar division of topics was also used to identify self-preservation concerns by Borich and Tomardi (1997) as well as Boz and Boz (2010).

Before student teaching, the results indicated that the Traditional PSTs were more concerned about content issues about writing and, in particular, being able to implement these lessons (Table 9). An example of Traditional PSTs revealing content concern was "I can make a lesson plan but I am not sure about how practical my lesson plans are." Several studies (e.g. Murray-Harvey, Slee, Lawson, Silins, Banfield, \& Russell, 2000; Fives, Hamman, \& Olivarez, 2007; McCann and Johannessen; 2004) found that concerns surrounding low content knowledge or difficulties in conveying the content matter had been shown to be indicators of potential 'teacher burnout' if allowed to continue.

While some SKyTeach PSTS also listed content concerns as an area of discontent at the beginning of the study, most SKyTeach PSTs conveyed the topic of respect concerns as their primary pre-teaching self-preservation concerns (Table 9). This concern of seeking the approval of others was one of Fuller, Parsons, and Watkins (1974) 
descriptions of teacher survival tendencies in novice situations. It is noteworthy to mention that SKyTeach PSTs had mixed reviews concerning content concerns with one-third of the PST statements suggesting lower levels of concern and one-fifth having high level of concern over this issue. Statements from SKyTeach PSTs showing higher levels of content concern are (a)“....as you go through school you always get this feeling that math is this elusive, difficult thing to master." and (b) "I haven't had any experience with gifted students, so I am not quite confident to teach them.” Other SKyTeach PSTs revealed lower levels of content concern with statements like (a) "Thanks to this program I've changed levels in how I think about myself and how I think about what I am going to portray to students. I am very confident I will do well." and (b) "I know how to write an effective lesson plan that is aligned to the standards and has measurable objectives. They have prepared me to reflect on my teaching practices." This mixture indicates that while some SKyTeach PSTs recognize their foundation in mathematics and science content as it was coupled with pedagogical courses based on these fields; others have not. Previous studies have recognized that having this combination of training in content material combined the appropriate pedagogical training was found to positively correlate with higher levels of student achievement and lower levels of early teacher attrition (Goldhaber, 2006; Ingersoll, 2003c; Monk, 1994).

The online discussion blog postings suggested that respect was a topic of discussion during the student-teaching experience. Several postings suggested that outside involvement tend to foster respect between the PSTs and their students. This depicted one method of using social influence to raise lower levels of self-efficacy a technique that was recommended by Bandura (1994). 
After the student-teaching experience, Traditional PSTs revealed that their major concern centered around matters of respect; whereas, the SKyTeach had lower levels of self-preservation concerns on all issues ranging from a quarter of the statements relating to respect concerns to no content concerns statements (Table 9). The SKyTeach PSTs' comments showed that the subthemes of self-preservation concerns had been reflected upon, rehearsed, and partially reconciled. These pre-service students have addressed their shortcomings and have begun placing these concerns in a proper perspective. While these changes were not significantly different from before student teaching to after (see Table 6), these results do support the findings of Fuller, et al. (1974) and Borich (1996) who found that with an increase of teaching experiences self-preservation concerns had a tendency to decrease.

\section{Task-Related Concerns}

Another identified teacher concern was labeled task-related concerns. During this stage, teachers were fixated on the daily tasks of teaching. An extensive review of the qualitative task-related concern data in this study confirmed that the comments could be condensed into three subthemes: (a) student behavioral concerns, (b) being concerned about external administrative responsibilities and interruptions, and (c) having insufficient time to plan and grade, as well as interact with other professionals as described by previous studies (i.e. Adams et al., 1981; Boz \& Boz, 2010; Fuller \& Bown, 1975).

Before any student teaching had started, Traditional PSTs had higher levels of administrative responsibilities and behavioral concerns (see Table 12). These PSTs were primarily worried about issues regarding being assigned extra responsibilities in addition 
to the task of leading a classroom. SKyTeach PSTs were primarily concerned about having insufficient time to accomplish tasks at the onset of the student-teaching experience. Previous studies indicated that dealing with the common conditions of overwhelming tasks lists, never-ending responsibilities, and no time for self-rejuvenation lead to beginning teacher burnout (Kagan, 1992; Rorrison, 2005) unless interventions were taken to prevent this.

Weblog postings also indicated that insufficient time management approaches continued to be a major concern in the midst of the student-teaching experience. This concern of time restraints matched one of the impending characteristic of teacher distress over burdening workloads (Betoret, 2006; Littrel, Billingsley, \& Cross, 1994). Five of the fourteen postings addressing this issue offered ways to reduce stress accompanying time management issues such as (a) getting support from family and friends, (b) exercising or (c) taking a day off from class material. These duplicated stress-reducing suggestions found in other studies (Greer \& Greer, 1992; Murray-Harvey et al., 2000). After the student-teaching experience, Traditional PSTs most frequently expressed concern over insufficient time management abilities (see Table 12). In addition to remaining concern about time management issues, the SKyTeach PSTs also became equally concerned about administrative disruptions. These forms of task-related concerns after the student-teaching experience closely resemble early signs of disillusionment about the teaching profession because of unrealistic expectations (Gold, 1985b; Schwab \& Iwanicki, 1982). 
On the other hand, SkyTeach PSTs comments also revealed a decrease in high behavioral concerns with three statements being made before student teaching and one being make after student teaching. This finding suggests that SKyTeach PSTs may have found ways to manage misbehavior which is a trait Hart (1987) and Preece (1979) associated with PSTs who appear self-assured and relaxed in the classroom.

This mixture of higher and lower levels of task-related concerns, brought on by work overload and some indication of strides towards successful management roles, confirms the notion that student teaching can create a dichotomous conflict between high and low levels of task-related concern among student teachers. It suggests that more work needs to be done during student teaching to reduce task-related concerns from leading to early teacher burnout (Cedoline, 1982; Friedman, 2000; Murphy, 2010; Nahal, 2010; Warnath \& Shelton, 1976).

\section{Student-Impact Concerns}

The last teacher concern area under investigation involved the concern a teacher placed on impacting the needs of the student learning and developing effective teaching methods. This was considered a fundamental characteristic of high quality teachers and its presence shows a maturity in the professional teacher as described in several studies (e.g. Borich \& Tombardi, 1997; Fuller, 1969; Hattie, 2003; Steffy \& Wolfe, 2001).

It should be noted that this concern received the highest scored SKyTeach PSTs before the student-teaching experience and also collected the highest level of concern total by both programs after the student-teaching experience (Table 6). A closer examination of the subtopics of this concern discovered the intricate details among PSTs having this quality. The quantitative data results on student impact concern levels 
suggested there were also three subtopics related to this concern. These subtopics were (a) being able to adapt lessons to meet the needs of students, (b) helping students achieve their potential, and (c) being able to recognize/diagnose student needs. The appearances of statements that relate to high levels of impact-related concern are to be viewed as admirable qualities.

In the case of this study, both programs had commendably higher levels of student-impact concern related to exploring ways to maximize student learning potential and to adapt lesson plans to meet the needs of the diverse learning environments they were to encounter before student teaching had begun (see Table 15). One SKyTeach reflects a high level of student-impact concern when she summarized her goals in student teaching as "I want to teach students math content as well as life skills. I want to teach them some maturity and intellect. Being able to help students both intellectually, emotionally, and in maturation is quite a large feat...". The presence of student impact concerns imitates the findings of Watzke (2007) who suggested that this existence exhibited a strong sense of relationships among student learning, learning theory, and instructional practices early in the teaching career. He suggested that this should be the predominate focus of studies on novice teachers "in lieu of the managerial aspects of teaching" (pg. 106).

During the student-teaching experience, most of the high levels of concern weblog posts related to adapting lesson plans to meet the needs of the students. There were several posts on the weblog related to the despairing sense of students not want to aspire to their academic potential. The realization of this fact showed another characteristic of student-impacted concern as was reported by Evans and Tribble (1986), 
who found the concern of generating student motivation was a common one among pre-service teachers in their study.

After the student-teaching experiences, both programs continued to portray high levels of concern over meeting the needs of their students by adapting lesson plans and trying to generate interest in generating more opportunities for students to reach their potential (Table 15). While this study did not show statistical difference from before student teaching to after (Table 6), this subtle change in pattern suggested a possibility of growth towards a maturity that supersedes self-preservation tendencies and showed that these PST were beginning to veer towards higher levels of impacting the needs of the student. In addition, several PSTs, two from the Traditional program and four from the SKyTeach program, showed professional growth by commenting on their need to know more about diagnosing academic, social and behavioral issues. The growth exhibited by both programs parallels the findings of McKinney and others (1999) who reported that as teachers acquired higher levels of teacher efficacy, they also acquired higher levels of student impact concerns.

This consistency of having a large amount of impact-related concerns throughout the study revealed that both the Traditional program with its foundation in the Renaissance group (Giovannetti, 2012) and the SKyTeach program with its "Elements of Success" (UTeach Institute, 2011) have embraced the ideology of aligning teacher education curricula with high standards stipulated by NCATE (2000) and NCTM (2000).

\section{Summary of Teacher Concern Results}

In conclusion, the quantitative results showed that both the Traditional PSTs and the SKyTeach PSTs possessed moderate concern levels for self-preservation, task-related, 
and student impact concerns at both measurement periods. The mean levels of these concerns rated differently before and after the student-teaching experience.

Before the student-teaching experience Traditional PSTs ranked task-related concerns and then student-impact concerns as their two highest concerns and SKyTeach rated student-impact concern followed closely by task-related concerns in second place. Both programs rated self-preservation concerns as the lowest level of concern at this point (Table 6).

After the student-teaching experience, Traditional students had changed their major focus to impact concerns followed by task-related concerns. SKyTeach PSTs viewed both student-impact concerns and task- related concerns as primary concerns after the student-teaching experience. Self-preservation concerns remained the lowest concern before and after the student-teaching experience and had decreased levels from the first measurement. However, it must be stated that there was no significant difference of any of the concerns between programs or within a program neither at the beginning nor at the end of this study.

One suggestion of having the self-preservation concerns measuring lower at the beginning and end of the study may lie in the characteristics of the program. The Traditional PSTs may have a false sense of confidence because they underestimate the amount stress associated with teaching a class. SKyTeach PSTs may have slightly higher levels of self-preservation reflect a more informed perspective of the teaching profession. Another limitation that might have accounted for the lower evidence of self-preservation concern was in the understanding of the definition of the word "concern". Reeve and Kazelskis (1995) discussed having the same issue present in their study. Although, PSTs 
were prompted that "to be concerned" means "thinks about it frequently and would like to do something about it personally", a suggestion offered by George, 1978 as (cited in Reeve and Kazelskis, 1995), many of the PSTs seemed hesitant to reveal a presence of lack of confidence when completing the surveys. Also due to the small sample size of the study, the quantitative results of this study should be interpreted with caution regarding the full extent of the level of different types concerns possessed by the PSTs in this study. Because of these caveats indicating a possible misinterpretation of the level of different types PSTs concerns and how this misreporting might influence the student-teaching experience, a qualitative study of these concerns was conducted.

A qualitative analysis of each individual concern yielded a kaleidoscope of subtle differences within each concern. When examining self-preservation concerns, Traditional students moved from content concerns to respect concerns throughout the course of the study and SKyTeach had lowered all levels of self-preservation concerns (see Table 9) by the end of the study. Task-related concerns comments revealed that Traditional PSTs originally had indications of possessing high amounts of external administrative responsibilities and interruptions and SKyTeach were apprehensive about time management issues. After the student teaching, Traditional students had switched to time management concerns but SKyTeach PSTs remained concern about time management issues and had added the concern of administrative disruptions reducing teaching effectiveness (Table 12). Both groups possessed admirable traits of the student-impact concern. Evidence showed Traditional PSTs with previous teaching experience outside the traditional program and a few SKyTeach PSTs had ventured into wanting training in how to recognize and/or diagnose academic, social and behavioral issues (Table 15). 
While all these concerns are important and provide suggestions for future research, to be discussed later, the information gathered will be used solely on the selfpreservation concerns to draw inferences about what impact mentoring and field experiences may have contributed to create these perceived differences. A review of the qualitative results of the study show that Traditional students made strides of moving from rudimentary self-preservation concerns about developing and delivering lesson plans to focus their attention on obtaining respect as a new teacher. SKyTeach PSTs began the study with the same respect concerns that the Traditional PSTs had at the conclusion of the study. By the end of the study, SKyTeach PSTS had lowered all levels of self-preservation concerns and had shifted their attention towards more task-related and student-impact concerns (see Tables 9, 12, and 15). This shift suggests that the SKyTeach PSTs are further along the professional teacher trajectory. This allowed these PSTs to focus more attention on running the classroom and concentrating on impacting student learning. This difference in advancement in the teacher professional trajectory between the Traditional PSTs and the SKyTeach PSTs was examined and explained through the differences in beneficial field experiences and mentoring strategies.

\section{Reducing Self-Preservation Concerns before Student Teaching}

There has been evidence to show that novice STEM teachers tend to leave the education profession more often than teachers in other educational fields (Alliance for Excellent Education, 2008; Smith \& Ingersoll, 2004). Two traits that have been identified for this early attrition is job related stress issues and the burn-out (e.g. Bensky, Shaw, Gouse, Bates, Dixon, \& Bean, 1980; Borg, Riding, \& Falzon, 1991; Fives, Hamman, \& Olivarez, 2007; Schonfeld, 1990; Troman \& Woods, 2000). ). It has been 
established that the student-teaching experience has been viewed as a very stressful yet important time in the studies of pre-service teacher (Black-Branch \& Lamont, 1998, Greer \& Greer 1992). Several studies (e.g. Fives, Hamman, \& Olivarez, 2007; Gold, 1985; Preece, 1979) indicated that PSTs exhibit signs of early "burn-out" characteristics during their student-teaching experiences. Many of these signs of impending 'teacher burnout" characteristics were synonymous with self-preservation concerns and task-related teacher concerns (e.g. Adams \& Matray (1981); Ahlering, 1963; Clement, 1999; Littrel, Billingsley, \& Cross, 1994; McCann \& Johanneseen, 2004; Morton, Vesco, Williams, \& Awender, 1997; Murray- Harvey et al., 2000). This study explored how examples of different types of early active mentoring and early field experiences were used to minimize self-preservation concerns in STEM PSTs before the student-teaching experience as a possible means to reduce attrition rates in the future.

This investigation has produced a range of findings regarding self-preservation concerns and ways the two programs attempted to reduce these as the instructors prepared their pre-service teachers for student teaching. Before the student-teaching experience both programs had no significant differences between their levels of self-preservation concerns (see Table 6), however, a closer investigation using qualitative data revealed that the different programs offered different underlying traits of the self-preservation concern (Table 12).

One concern trait was content concerns, the ability to write and implement effective lessons plans. This particular concern has been identified as having low-esteem which could potentially develop into "teacher burnout" (e.g. Murray-Harvey, Slee, Lawson, Silins, Banfield, \& Russell, 2000; Fives, Hamman, \& Olivarez, 2007; McCann 
and Johannessen; 2004). The Traditional PSTs appear to be primarily focused on content concerns if they had not had any previous teaching experience. When Traditional PSTs sought opportunities to instruct in the capacity of a substitute teacher or as a training coordinator in the military before their student-teaching experience, these PSTs were found to have similar concerns to those in the SKyTeach program. Thus external teaching experiences appear to lessened self-preservation content teaching concerns; a finding consistent with McVey (2004).

The other prominent self-preservation concern was respect concern which was the desire to acquire respect from students, parents, peers, or professional teachers. The largest portion of SKyTeach PSTs had concerns related to gaining the respect of coordinating teachers and other professionals before their student-teaching assignments. Fuller, Parsons, and Watkins (1974) described this as a typical survival characteristic of teachers in novice situations. A closer look at mentoring methods and early field experience helped identify what may have caused these differences in self-preservation concerns before the student-teaching experience.

\section{Mentoring Effects on Self-Preservation Concerns before Student Teaching.}

Previous research conducted by Smith and Ingersoll (2004) showed having the person guidance of a mentor teacher helped the likelihood of retaining novice teachers. Newman and others (2000) found that having an effective mentor during teacher training also controlled the rise of teacher concerns in a PDS environment. Thus, including mentors in teacher education programs seemed an important contribution to any program.

The SKyTeach program was grounded in several types mentoring and continuous field experiences throughout the undergraduate program (Evans, 2005); whereas the 
Traditional program was not under these obligations. The Traditional program used two academic advisors: a content advisor and educational advisor to serve as mentors for PSTs. The SKyTeach program expanded this benchmark of their program to include not only two academic advisors but trained master teachers and veteran teachers to help guide SKyTeach PSTs in their educational pursuits. Master teachers were WKU employees who served as an instructor and mentors for STEM PSTs. Veteran Teachers were comprised of middle or secondary teachers who served as short-time mentors in the local school settings.

While all PSTs in both programs were mandated to visit an academic advisor every semester, nearly two-thirds of Traditional PSTs did not identify any WKU instructors as serving as the role of a mentor (see Table 20). This lack of a definite mentor within the framework of the Traditional program made it hard to comprehend the effect a mentor may have had on any of the Traditional PSTs. Borich (1996) observed that a lack of support during pre-service training could impede the transition through teacher concerns. Other studies have shown that early appearance of the "burn-out syndrome" can be attributed to several sources, with the lack of mentoring support being one of them (Fives, Hamman, \& Olivarez, 2007; Murray-Harvey, Slee, Lawson, Silins, Banfield, \& Russell, 2000).

While half of the Traditional PSTs did not identify any mentor, others identified their only mentors as family members, previous K-12 teachers, or peers. Whereas this shows a disconnect with the university sponsored mentors, this avenue of support has been documented to help lessen the effects of early burnout as was corroborated by Brissie, Hoover-Demdsey, and Bassler (1988) and Phi Delta Kappa, 1980). 
A final segment of the Traditional PSTs regarded WKU faculty as their primary mentor before student teaching. Nine out of 21 Traditional PSTs were part of this category. All but two SKyTeach PSTs viewed members of WKU SKyTeach teachers as their mentors. The responses of this set of PSTs were used to see what merits of the mentoring program reduced self-preservation concerns.

While Boreen and Niday (2000) and Smith and Ingersoll (2004) recognized that mentoring programs were beneficial to teachers, care must be taken in developing them. Johnson and Birkeland (2002) noted that effective induction mentoring programs needed to include (a) encouragement from veteran teachers; (b) assistance with curriculum decisions; (c) advice on lesson planning and development; and (d) feedback on enacted teaching strategies to be successful. These characteristics were paralleled to similar effective characteristics of mentors in a pre-service domain.

Those Traditional PSTs who did identify WKU instructors as mentors considered their mentors as offering assistance regarding academic decisions, followed by offering some emotional and professional guidance (Table 21). Most referred to advising session that mimic an apprenticeship model in that it is grounded in the belief that the mentor is the guide or expert $(\mathrm{He}, 2009)$. However, in each case there were as many reports of detrimental advice as beneficial ones; thus the effectiveness of reducing self-preservation concerns through only having academic advisors was minimal at best. This may be partially explained by the lack of formal training provided for Traditional mentors (S. Evans, personal communication, April 9, 2013). A study conducted by Keogh (2005) concluded that when a mentor/advisor is trained how to illicit constructive conversations 
with a mentee, the resulting relationship effectively solves impending issues and becomes beneficial to both parties (Keogh, 2005).

The SKyTeach students were very forthcoming on how their mentors were a beneficial source of support in academic, professional, and emotional issues. They perceived that their mentors were available to offer accurate academic advice. PSTs stated that SKyTeach mentors led discussions and offered suggestions and feedback on lesson planning and implementations. Finally, they commented on numerous occasions that SKyTeach mentors offered offer emotional support whenever needed (Table 21). These references indicate that the mentors of the SKyTeach program follow a customized mentoring program that utilize effective portions of both the collective problem-solving and the strength-based mentoring models (He, 2009). SKyTeach PSTs saw the merit in having someone to share their apprehension about teaching and ideas about lesson plans. All of these comments support evidence that self-preservation concerns were addressed through the different responsibilities of these mentors. These references were strong indications that the SKyTeach program's philosophy of having a multi-faceted concept when reviewing the role of the mentor as one to be developed and maintained as supported by the findings of Boreen and Niday (2000).

\section{Field Experiences Effects on Self-Preservation Concerns before Student}

Teaching. The National Council of Accreditation of Teacher Education (NCATE, 2008) mandated that any teacher preparation higher learning school and their school partners design and implement a field experience component to all educational training curricula. Both programs were in compliance of the NCATE mandates in that they both had components of field experiences. 
The field experience portion of the Traditional program required a total of 150 hours of interaction with local school systems; however, the field experiences were not externally monitored. As such, the field experience component varied from instructor to instructor. Most early field experiences in the Traditional program were observational and general in nature (Table 19). This supports the findings of Lawrence \& Butler (2010) who found that in order to include a field experience component to their teacher education program, many pre-service teacher programs required classroom observations as a key component prior to student-teaching experiences. These experiences serve as an example of Badura's (1994) vicarious experiences which emphasized the act of participating in observations allowing others to gain confidence through watching someone similar to oneself succeed; and then transferring the belief of being able to master comparable activities. A few instructors required directed or focused observations. In rare incidences, students were encouraged to engage in limited active teaching (K. DuCloux, personal communication, April 2013; S. Evans, personal communication, April 9, 2013; R. Tyler, personal communication, April 4, 2013). Mastery experiences involved a person physically engaging in an activity that "requires experience in overcoming obstacles through perseverant effort" (Bandura, 1994, para. 6).

Most Traditional PSTs verified that their field experience was composed of general observations or peer teachings (Table19). There were mixed reviews about general observations with many reporting that they were perceived as not beneficial in reducing concerns (see Tables 18 and 19). General observations were viewed as (a) "a waste of time", (b) did not promote learning" or (c) were "excessive". One traditional student commented that "even my veteran teachers were not really supportive of the 
[general] observations. They preferred volunteer work.” Others felt that general observations were lacking and "focused observation would be more beneficial." Those traditional PSTs that did have an opportunity to conduct a focus observational experience with reflection perceived the experience as helpful in becoming more analytical about teaching. These Traditional PSTs viewed focused observations as opportunities to learn about aspects of teaching like instructional strategies in [specific STEM topics], questioning strategies, how to help struggling students, and handle behavior problems. Previous studies confirm the belief that when PSTs were given specific objectives during focused observations and asked to reflect on their findings, observational field experiences proved to be effective learning tools (Anderson, Barksdale, \& Hite, 2005; Austin-Martin et al., 1981; Steele, 2010).

When investigating perceptions regarding the instructional practice experiences in the Traditional program, many wished that they had more opportunities to lead a classroom lesson before their student-teaching experience. Most identifiable instructional practice experiences were either peer instructional experiences or outside experiences. Peer instructional experiences involved teaching peers in the university classroom. These events were not regarded as effective being viewed as artificial and forced. A few Traditional PSTs professed to engage in field experiences at a military setting tutoring other soldiers or by doing substitute teaching. The presence of prior active field experience appears to have helped these PST overcome most of the content concern issues that other Traditional PSTs had. This was a result that was shared in a study done by McVey (2004). 
SKyTeach PSTs' field experiences were varied between observational and instructional practice experiences. The SKyTeach program required early and highly engaged fieldwork by PSTs during all four years of their undergraduate program. These highly engaged field experiences began with a guided instruction opportunity their freshman year and incorporated some observations and an increasingly larger amount of instructional practices in STEM instructional procedures in a variety of classroom settings during the next three years. SKyTeach PST's senior year culminated with the student-teaching practicum during the last semester (Burch, 2008). Lawrence and Butler (2010) declared that the prospect of being involved in active field experience appeared to promote self-efficacy thus lessening self-preservation concerns in the pre-service teacher.

SKyTeach PSTs were asked to reflect on their most frequent types of field experiences. While most of the comments were directed towards instructional practices, there were also observational field experiences mentioned. When SKyTeach students were asked about time spent time doing field observations, these field experiences were usually general in nature. However, when a SKyTeach PST commented on observing a pre-selected action, they revealed that this action was to be recorded and reflected upon. These observations were viewed as beneficial in preparing for upcoming instructional sessions and future teaching opportunities. These finding verified the comments made by previous studies (Anderson, Barksdale, \& Hite, 2005; Austin-Martin et al., 1981; Steele, 2010).

While the identifiable instructional experiences only included group teaching situations (Table 19), all SKyTeach PSTs but one reported having some kind of instructional practice "teaching in front of students". Evans and Tribble (1986) and 
Veenman (1984) viewed all instructional practice experiences as favorable experiences to reduce teacher concerns. SKyTeach PSTs offered comments recounting beneficial aspects of early instructional field experiences. One of these included being able to teach discovery-based or research-based lessons with increasing difficulties. This comment was supported by He (2009) who claimed that programs need to develop resistance strategies by experiencing a variety of mastery experiences which grow teacher efficacy and motivational strategies so that they were prepared for future conflicts. Other SKyTeach PSTs mentioned having opportunities to modify their presentation skills and practice engaging diverse groups of students which allowed them to feel comfortable in front of different age groups. This is an indication of introducing strategies in reducing respect concerns as defined by Fuller (1969). Negative aspects included the inefficiency of group teaching and one SKyTeach PST felt that all the classroom experiences did not prepare for student misbehavior or classroom politics as these early field experiences were 'hand-picked model classroom settings'.

In summary, before the student-teaching experience Traditional PSTs were more apprehensive about content concerns, in particular implementing their lesson plans. This was explained by a lack of trained mentoring personnel and instructional practice experiences. In particular the presence of active instructional experiences seem to be most beneficial in reducing content concern as was validated by those Traditional PSTs who did substitute teaching or tutoring in the military. While some SKyTeach PSTs reported having content concerns, the majority had lower levels of content concerns because their mentors provided suggestions and feedback on lesson planning. Likewise, instructional experiences allowed SKyTeach PSTs to endure increasingly more difficult 
assignments in an effort to develop resistance strategies and foster self-efficacy levels while reducing self-preservation concerns. At this point, the highest level of self-preservation concerns of SKyTeach PSTs was in respect concerns, which was viewed by Fuller, Parsons, and Watkins (1974) as understandable in light of the unknown student-teaching experiences before them.

\section{Reducing Self-Preservation Concerns during Student teaching}

After the student-teaching experience, the TCC survey was administered for a second time and there was a second round of interviews reviewing events that took place during student teaching. The quantitative results revealed that while overall concerns between and within the two programs had diminished these results were not statistically significant (see Table 5). This result is to be viewed with caution due to the small number of participants and its ability to produce errors due to the effect size, as was described earlier in this chapter. The qualitative information gathered from interviews and open-ended responses offered insight to underlying self-preservations concerns and how the effects of active field experiences and diverse mentoring aided in the shift in these sub-themes of this concern.

After the student-teaching experience, the Traditional PSTs' concerns shifted from content concerns towards concerns about respect followed closely by classroom management concerns (see Table 9). This finding showed that with more experience in the classroom, these Traditional PSTs have become more assured in their ability to implement their lesson plans, a finding that was consistent to the findings made by Houtman and Bakker (1987). The rise in the concern in classroom management can be justified in the phases of student teaching. (Caruso, 1977) found that as PSTs progress 
through the student-teaching experience they enter a phase where they test their professional competency. This phase of attempting to please their evaluators by achieving the high expectations surrounding their teaching performance would produce a high level of stress or concern in maintaining a learning environment in their classroom as was realized in studies by Clement (1999) and Murray-Harvey and others (2000). Finally the issue of respect concern was explained by Fuller, Parsons, and Watkins (1974) as a survival technique that could be explained by attempting to please their student-teaching evaluators or could be justified as a recent development with the onset of seeking teaching employment.

The quantitative results on the levels of self-preservation concerns among the SKyTeach PSTs show that all sub-themes of self-preservation concerns had diminished (Table 9). The highest tallied concern after student teaching was only reflected in 0.18 statements per student and involved the concern of evaluation. This would be an understandable concern in light of the student-teaching triad and the barrage of evaluations the student teacher must endure during their experience. As Cements (1999) indicated in her study, many PSTs revealed that pleasing their evaluators was more stressful than evaluating their classroom students. The results for all other concerns were minimal and show that with additional day to day classroom teaching experience self-preservation concerns decreased a finding discovered in independent studies by Fuller, et al. (1974) and Borich (1996). In order to detect what may have caused these changes in self-preservation concerns from before the student-teaching experience, the reflections about beneficial impacts multi-faceted mentoring strategies, and continuous highly engaged field experience had on producing these changes, was explored. 
Mentoring Effects on Concerns after Student Teaching. Responses from

interviews and open-ended results revealed that during the student-teacher experience, a majority of the Traditional PSTs solicited for as much of the guidance that their cooperating teachers and university supervisors could provide (Table 20). Many comments relate to having reflection sessions with their cooperating teachers several times daily. Others offered comments addressing how university supervisors gave non-partisan considerations about their observations. This cooperation between the student teaching triad allowed for a majority of Traditional PSTs to flourish under the guidance of their mentors. This complemented the findings of Love (1992) and Nguyen (2009) who found that with cooperation between the members of the student-teaching triad, the student-teaching experience becomes enjoyable.

All Traditional PSTs could actively recognize their mentors during this stage with all but one PSTs logging either their cooperating teacher, university supervisor, or another WKU professor (only four PSTs chose another WKU professor as their primary mentor). This is a major change from the previous survey (Table 22). During the student-teaching experience, Traditional PSTs perceived their 'newly acquired' mentors were persons who provided valuable professional advice and also as an emotional supporter. PSTs saw the merit in having someone to share their apprehensions about teaching and ideas about lesson plans. These beneficial traits allowed the Traditional PSTs to advance in areas that previously caused content concern. As a secondary means of advisement, Traditional PSTs would seek assistance from other teachers or administrations at their assigned schools. This additional help also helped reduce concerns surrounding the student-teaching experience. These findings coincide with 
those found in effective models of a collective problem-solving mentoring model or in a strength-based mentoring model described by He (2009). However, as has been previously noted, the presence of the supervising teacher mentor did not statistically reduce the level of self-preservation concerns during the student-teaching semester (Table 5); although small effect size may have cause a significant error the results. This lack of significant difference in the progression of concerns to follow a sequential pattern mimicked the results found in several studies (Kardos, Johnson, Peske, Kaffman, \& Liu, 2001; Kardos, 2002; Johnson \& Birkeland, 2003).

SKyTeach also recognized the beneficial impact that their cooperating teacher/university supervising team provided them after student teaching by identifying them the primary source of information for alleviating concerns about student teaching (Table 20). However, relationships between PSTs and previous SKyTeach mentors were not severed as they entered their student-teaching assignments. In several instances it became apparent that there was some discord within these PST's student-teaching triad. On more than one occasion there were references made revealing differences between the assigned classroom setting which promoted more seatwork and the SKyTeach's inquiry-based curriculum. In these instances SKyTeach PSTs comments disclosed their confusion as to what was necessary to successful complete the requirements of their student-teaching assignment while remaining dedicated to the objectives of the SKyTeach program. Similar struggles were assessed in several other studies (Diem \& Schnitz, 1978; Furlong \& Maynard, 1995; Traister, 2005). Previous master teachers became additional emotional and professional mentors in helping these pre-service teachers reach their goals of becoming teachers in the STEM areas. 
Field Experience Effects on Concerns after Student Teaching. PSTs were

asked to review what portions of their earlier (before student teaching) field experiences had been beneficial in reducing concerns they had about student teaching. Many PSTs in both programs chose not to answer this question, but those that did said that the observational experiences had turned out to be beneficial (Table 18). The majority of the comments made comments that they had learned more than they had originally thought; others perceived that the previous observations allowed them to able to be analytical when watching their cooperating teacher in areas such as administrative aspects and discipline issues. These reflections reveal the natural progression of the student teacher professional competency stage as outlined by Caruso (1977). In this stage of their teaching experience, Caruso explained that PSTs began to observe and evaluate: (a) whether or not there was a parallel with the university-taught theory is implemented; (b) how classroom management procedures were applied; and (c) how constructive lesson planning was employed. Then the PSTs assessed how they would mimic or improve on these observations.

Instructional experiences were also viewed as beneficial with a majority of the PSTs from both programs praising the benefits that leading in instruction had on helping them in their student-teaching experience (Table18). Those Traditional PSTs that had done experiences outside the university, such as substitute teaching, and those PSTs in the SKyTeach program reflected that the previous experience allowed them to focus on the meticulous details of becoming a more effective teacher instead of being concerned about the superficial apprehensions of being in front of a classroom. These comments were in accordance with the findings of studies by Capel, (2001), Parsons (1973) and 
Petrusich, (1966) who stated that teachers with more experience tend to have fewer self-preservation concerns.

There was a notable difference in the comments between the PSTs in the two programs and the comments they offered regarding field experiences. These comments revealed SKyTeach PSTs, and those with outside experiences in either program, referred to experiences before the student-teaching experience. Most of the comments made by the Traditional PSTs remarked that they did not have many previous experiences or they regarded those experiences worthless in preparing them for student teaching. As such, they commented on benefits of instructing students during student teaching as lowering concern. This validates the notion that highly engaged field experiences in a realistic environment were more conducive to reducing concerns. These results parallel the findings of similar studies on elementary PSTs (e.g. Charalambous, Philippou, and Kyriakides, 2008; Murray-Harvey et al. 2000; Wadlington, Slaton, \& Partridge, 1998).

\section{Discussion of Results}

The main purpose of this study was to examine what the effects of two key components, highly engaged field experiences and multi-faceted mentoring strategies, served to minimize teacher concerns. As such, these results would indicate an increase self-efficacy in an effort to reduce characteristics that lead to early attrition.

\section{Self-Preservation Concerns were Different Between Programs}

Initially, the quantitative results from the TCC survey indicated that there was no significant difference in the pre-service teachers' concerns between the two programs. However, the qualitative portion of the investigation using results from focus group answers, interviews and responses from open-ended questions uncovered differences 
across the programs in self-preservation concerns. These findings revealed that before the student-teaching experience, the comparison group, or the Traditional PSTs, was more concerned about implementing a lesson plan; whereas the treatment group, SKyTeach PSTs, was more concerned about respect issues. Blog entries also conveyed concerns about respect issues with several student providing suggestions on how to increase respect. After the student-teaching experience students were given the TCC survey a second time and a second interview was conducted. While all levels of concern had diminished, there remained no significant difference in teacher concern levels between the two programs. The qualitative results indicated that the Traditional PSTs had shifted from content concerns to respect concerns and classroom management concerns. The SKyTeach members had reduced the concern levels of all subthemes of self-preservation concerns. Once the differences in the self-preservation concerns had been identified, the emphasis changed to see what criteria caused these changes.

\section{The Importance of Trained, Effective Mentoring Practices}

Before the student-teaching experiences the majority of the Traditional PSTs could not identify a mentor figure. SKyTeach PSTs identified several mentors which provided academic, emotional, and professional advice. The ability to identify the different types of mentoring available gave these SKyTeach PSTs additional resources to support their educational pursuits. During the student-teaching experience, Traditional PSTs recognized their cooperating teacher and university supervisor as their primary mentors with other school teachers and administrators as secondary sources of guidance. These mentors allowed the Traditional PSTs to move from concerns regarding content issues to respect concerns. The SKyTeach PSTs also recognized their cooperating 
teacher/university supervisor team as their primary mentors. However, SKyTeach PSTs also remained connected with their SKyTeach master teachers, citing these master teachers as additional emotional and professional mentors. Comments indicated that several SKyTeach PSTs reflected that there was some discord within the student-teaching experience regarding the difference in teaching philosophies and as such they sought support from SKyTeach mentors.

The encouragement and advisory capabilities of an effective mentor appeared to lessen self-defeating tendencies. The findings also indicate that having an active mentor, who provides beneficial academic, professional, or emotional support, seemed to alleviate some of the immediate concerns of the pre-service students. The presence of trained, effective mentoring alleviating pre-service teachers' tendencies toward self-preservation inclinations verifies the findings of Gold (1985) and Wadlington, Slaton, and Partridge (1998).

\section{The Importance of Early and Engaged Field Experiences}

The results of this study also confirmed that as teaching experience increased self-preservation concerns decreased which corresponded to the finding of independent studies conducted by Fuller, et al. (1974) and Borich (1996). Both programs in this study had components of early field-experiences in their curriculum. However, the amount and substance varied between the two programs. The Traditional program relied heavily on observational field experiences. While there was some observational experiences, the SKyTeach program utilized active instructional field experiences throughout the program. Due to the increased time in the classroom prior to student teaching, PSTs in this program, and those Traditional PSTs who had outside instructional experiences, 
reported less self-preservation concerns regarding implementing lesson plans. These results indicate that the presence of prior focused observational and instructional field experience appeared to reduce basic self-preservation concerns regarding instruction. This correlates to the findings of Charalambous, Philippou, and Kyriakides (2008), Boreen and Niday (2000), and Lawrence and Butler (2010).

My findings indicate that the types of experiences in this study did not seem to contribute to the evolution of sequential teacher concern growth proposed by Fuller (1969). Instead, the presence of a variety of observational exercises and actively engaging in the art of instruction coupled with varying avenues of mentored support promoted the pre-service teacher self-efficacy thus lessening the effects of more basic self-preservation concerns. The effects of highly engaged field experiences and multi-faceted mentoring strategies appear to hold many benefits to reducing self-preservation concerns pre-service teachers have going into the student-teaching experiences. When the pre-service teacher begins shift his/her attention away from self-preservation concerns and toward nobler concerns like effective teaching techniques, the student-teaching experience becomes a more productive experience. These benefits may translate into prolong tenure in the teaching profession, a possible topic for a future study.

\section{Generalization and Limitations of the Study}

\section{Generalization}

The two main components of this study, highly engaged field experiences and multi-faceted mentoring can be generalized into other professions. Field experiences are found in a variety of internship situations of other professions like medicine and 
construction. Along with the fieldwork, mentoring is also found in many different professions. There are several companies that have found the long term benefits in mentoring new employees in managerial, professional, and technical positions (Dreher \& Ash, 2002). Instead of generalizing these findings to outside professions, this study will look at ways these components can become successful aspects of other more generic preservice teacher programs.

In accordance to the findings of this study, highly engaged field experience should be conducted as soon as possible, preferably during the freshman year, and frequently. There should be two components of this early field experience: focused observational experiences and instructional practice experiences. Observational experiences should incorporate observing specific objectives on which to focus and reflect. This combination been recognized as being effective learning instruments (Anderson, Barksdale, \& Hite, 2005; Austin-Martin et al., 1981; Steele, 2010). Instructional practice experiences should follow Bandura's (1994) and He's (2009) suggestion of incorporating instructional practice, or mastery, experience protocols. Educational field experiences should begin with short guided instructional practice sessions and increase in intensity as PSTs develop working lesson plans that they implement in increasingly longer instructional sessions. This progression is necessary to grow teacher efficacy and motivational strategies as they were prepared for future conflicts (He, 2009).

Retention issues continue to be paramount educational fields when applied to novice teachers. Reduction in attrition has been linked to induction programs that incorporate beneficial mentoring strategies (Smith \& Ingersoll, 2004). These beneficial trademarks can be replicated in STEM pre-service teacher programs. Primarily mentoring 
aspects within the educational arena need to be multi-faceted. Mentoring needs to include academic, emotional, and professional support by assisting mentors in becoming skilled at pedagogical and partnership developments. This is done in a quest to prepare pre-service teachers for present and future challenges (Hargreaves \& Fullan,2000;

Newman, et al., 2000), These two components seem to promote early advances in selfefficacy and reduce some divisions of the self-preservation concern.

\section{Methodological Limitations}

Several factors can contribute to the limitations of this study. The first limitation is the findings of this study are restricted to Western Kentucky University students who were involved in either the SKyTeach or Traditional education program for middle/high school STEM students. Because Western Kentucky is a state institution of moderate size, the results may not generalize to other state duplication sites that have a larger (or smaller) number of students in their pilot UTeach duplicate teaching programs. Also private institutions may obtain different outcomes. Future studies involving other duplication sites which allow for a more heterogeneous and larger sampling for the control group could overcome limitations found in this study.

Another limitation to the study is the realization that the SKyTeach pre-service teachers under review were part of the initial implementation this program. The novelty factor of starting any new program can affect teaching styles and depth of lectures and/or assignments (Shadish, et al., 2002). This study should be conducted over an extended period of several semesters to look at the implementations of the program, noting any changes that took place in treatment. The results of these treatment changes need to be analyzed to see if they led to improvement in the original program design. 
Several limitations exist regarding the use of the TCC and the Weblogs to collect data. First, several items on the TCC were removed because they deemed irrelevant to the student teachers in this area as was described in Chapter three. A similar remark about the irreverent nature of some of the questions was expressed in a study by Reeve and Kazelskis (1995). This may have affected the validity standards of the original survey as tested by Rogan et al. (1992). Secondly, several students had trouble understanding the definition of the term "concern". This was a previous issue recognized by George (1978) and discussed in a study conducted by Reeve and Kazelskis (1995). PSTs were prompted that "to be concerned" means "thinks about it frequently and would like to do something about it personally" (George, 1978 as cited in Reeve and Kazelskis, 1995 pg. 268). When viewing the submission of weblog entries consisted of personal reflective pieces that could inflate results due to self-reporting issues as some PSTs may not want to be completely forthcoming with their concerns.

Finally, the sample size completing both submissions of the TCC consisted of a very the small number of SKyTeach PSTs and Traditional PSTs, but especially the Traditional group. This small sampling produced results that allowed for errors due to the effect size. In addition, due to the small sample size there were internal reliability issues related to diffusion and treatment transferability. Students in both programs used an online registration site to sign up for classes so there was the possibility that Traditional PST could sign up for a SKyTeach SMED class. A few responses to interview questions suggested that indeed some Traditional PSTs had taken SKyTeach SMED classes. While this can cause diffusion issues with Traditional PSTs and SKyTeach PSTs discussing the differences in the two programs, this also allowed for 
both programs to reflect on the pros and cons of each of their programs when questioned about them.

\section{Implications for Future Research}

This investigation sought to examine what the effects of two key components, continuous highly engaged field experiences and multi-faceted mentoring strategies, served to minimize teacher concerns in STEM student teachers in an effort to reduce characteristics that lead to early attrition. Further investigations of this kind should be conducted on other universities in the process of converting from a more "traditional program" to an "UTeach-style" replication site. This would help to strengthen the research begun here by allowing the study to focus on only two parameters as the STEM content curricula should be duplicated in both programs within the university. As more and more universities replicate this program while maintaining individual state teacher preparation mandates, it would be interesting to see what outcomes other universities would have in these regards.

The research literature on the presence of early teacher concerns in PSTs and subsequent contributions to early teacher attrition could be further strengthened by conducting similar tests within a university with a larger STEM population. Larger sample size will reveal increasingly useful information regarding the formation of effective observational and instructional practice field experiences and appropriate training techniques for quality mentors.

In addition, supplementary tests should include in further investigations of early teacher concerns (Fuller, 1969) levels of PSTs and novice teachers. An instrument should be developed and tested to accurately measure divisions within self-preservation 
concerns, task-related concerns and/or impact concerns. One obstacle in this study was accurately identifying divisions of self-preservation tasks with only three to five questions associated to each division. A more precise questionnaire concentrating on only one of the three teacher concerns may produce more exact results. In addition, future studies should include an instrument to record levels of self-efficacy throughout the study. Also research is needed that looks more directly to the actions of PSTs in the classroom and does not rely exclusively on self-reporting instruments. The survey and interview/focus sessions allow participants to report what they perceive as reliable information. Observational data and interviews with cooperating teachers may offer additional information regarding other teacher concerns of PSTs in the student-teaching experience.

Finally, studies involving the collection of additional information regarding the effects of multifaceted mentoring strategies and continuous highly engaged field experiences in the preservice teacher programs had on teacher concerns should continue. In addition to self-preservation concerns, a look at task-concern topics (such as managing student misbehavior) could be pursued. These concerns were recognized as common concerns during both programs of pre-service training. It would be interesting to see how these novice teachers perceive to what extent their pre-service training helped them to prepare for these concerns. This extension can be explored by using McVey's (2004) Modified TTC survey regarding the implications of how the teacher education programs addressed teacher concerns. Background data from PSTs was also collected during this study allowing for a more complete analysis of the residual early teacher concerns to be monitored as PSTs enter their novice year(s) of teaching. These lines of study will gather 
information that could serve to support and strengthen teacher preparation programs (Gold, 1996).

\section{Conclusion}

This study sought to gather information about the field experiences mentoring strategies of the Traditional Stem program and SKyTeach program and their impact on pre-service teachers concerns of teaching. The results of this study contributes to educational research field by noting that a pre-service teacher program that combines the presence of multiple types of mentors trained in effective methods and continuous highly engaged field experiences held many benefits in reducing concerns pre-service teachers have going into the student-teaching experiences. It also found components of pre-service teacher programs that do not lessen self-preservation concerns.

\section{Components of PST Programs Which Do Not Show Evidence of Reducing Self- Preservation Concerns}

The results of this study recognized practices that should be avoided to insure that self-preservation concerns are lessened before the student teaching experience. These include having a deficiency of physical mentoring support and depending on general observations as a sole means of field experiences.

This study found that nonexistence of an identifiable mentor may increase anxious tendencies and feelings of inadequate support. One Traditional PST in this study reported leaving the teaching program because of overwhelming anxiety. The results of this information indicate that these anxious tendencies may be an early indication of more serious future implications. Previous research (e.g. Fives et al., 2007) indicated that PSTs who have increased anxious tendencies are more likely to develop burn-out 
characteristics which lead to attrition. In addition, those PSTs who envision not having support during their pre-service training were more likely to leave the educational field before they even complete their pre-service program (e.g. Caruso, 1977; McIntyre, 1984). Mentoring should not be "on paper only", or through the use of phone calls and emails, as described by several PSTs in this study. Instead mentoring should involve a personal involvement - including mentoring conversations on non-academic themes - with the PST in an effort to warrant successful transition through the early stages of the professional teacher trajectory.

This study also found that a program that depends on general vicarious field experiences do not allow PSTs to understand the nuances of the teaching experience nor allow them to overcome content concerns of creating and implementing lesson plans before the student teaching experience. Traditional PSTs whose foundation of field experiences were centered on observational experiences were more likely to also have elevated task concerns related to being naïve about the vast array of administrative responsibilities a teacher had, in addition to the mission of teaching content material. Thus this study supports the findings of Hammerness and others (2005) which concluded that observational experiences cannot serve as a primary means of field experience to teach the complexities of the teaching profession.

\section{Necessary Components of PST Programs Which Show Evidence of Reducing Self- Preservation Concerns}

In order to assure that middle and secondary STEM PSTs begin their student-teaching experience with noticeably fewer self-preservation concerns or higher levels of self-efficacy, this study found that pre-service STEM programs need to provide 
its PSTs with a supportive mentoring team and variety of engaged field experiences. This study has also shown that this combined assistance can enable PSTs to take better advantage of their student teaching semester in order to be more strongly situated for upcoming first year of teaching.

The presence of effective mentoring is evident in reducing self-preservation subthemes. Those PSTs that received much-needed mentoring in the areas of emotional and professional guidance during their student-teaching experience were able to progress beyond primal self-preservation concerns by the end of the study. With this multi-faceted approach throughout their pre-service training, this study has shown that PSTs were able overcome primal self-preservation concerns before the student-teaching experience and reduce all self-preservation concerns by the end of the student-teaching experience.

Thus the findings of this study observed that when the expectation of STEM mentors is to provide beneficial multi-faceted mentoring strategies comprised of academic, emotional, and academic guidance in a pre-service teaching program, PSTs gain confidence to continue their training program and enter the professional teaching arena with fewer self-preservation concerns. Different mentoring procedures should include, to some extent, aspects of modeling science and mathematics lessons at a variety of grade levels; periodic reviews and prompt feedback of pre-service teachers written lesson plans; observing and/or providing critiques of fieldwork experiences; and advising pre-service teaches with regard to professional and personal growth issues. Mentoring with such a spectrum of attributes suggests that mentors need to attend professional development training to be able to provide effective support in these areas. Also by having a variety of mentors, such as having professional advisors in addition to academic 
advisors, PSTs are afforded the benefits to gather insights from an array of mentors whose main objective is to insure the success of the PST. To this end, pre-service teachers should be encouraged to establish open avenues of communication with university faculty and area in-service teachers.

In addition to having a team of effective mentors, this study found that in order to reduce subtopics of self-preservation concerns, STEM PSTs need to experience an array of sustained highly engaged field experiences prior to student teaching. The beneficial results indicate that PSTs need to experience a minimal amount of observational experiences, but those experiences should include focused objectives. This allows for the PST to center their attention on a specific aspect of the teaching profession. In addition, this study found that pre-service teachers should be slowly introduced to instructional practice opportunities by offering pre-designed mini-lessons to be taught in group settings in area schools, since young PSTs tend to doubt their initial ability to organize and implement effect lesson plans. Another finding from this study is that instructional practices should be structured to reduce self-preservation concerns by slowly transitioning from executing group teaching experiences to presenting short individual instructional practices before student teaching. Pre-service teachers should be increasingly encouraged to participate in the decision making and development of functional lesson plans as their maturity levels increase. All experiences, both observational and instructional practice, should be completed with a reflection component. Learning through reflection should not only involve evaluating the observational objective or lesson as it was presented, but it should include expanding insights to promote alternative pedagogical methods or diversity in learning techniques. 
By allowing PSTs to experience a variety of engaged instructional experiences, this study concluded that PSTs arrive at the student-teaching semester with a reserve of experiences to help eliminate primal sub-themes of self-preservation concerns.

Thus, pre-service teacher preparation programs wishing to support their PSTs to move past initial self-preservation concerns should incorporate a wide assortment of frequent high-engagement field experiences prior to the student teaching experience, and to support those experiences with a variety of experienced mentors. Mentors must offer a triad of advice and encouragement in academic, emotional, and professional arenas. Highly engaged field experiences should incorporate the practices of focused observations coupled with early and frequent instructional practice experiences. These field experiences should be coupled with reflection practices to enhance the learning experience. Having instructional practice teaching experiences within the pre-service teaching program which mimic the practices of in-service teaching appears to lessen self-preservation concerns. These findings support the findings of Charalambous, Philippou, and Kyriakides (2008), Gold (1985), and Newman and others (2000). 


\section{REFERENCES}

Ackley, B. \& Gall, M. D. (1992). Skills, strategies and outcomes of successful mentor teachers. Paper presented at the Annual Meeting of American Educational Research Association, San Francisco, CA.

Adams, R. D. \& Martray, C. (1981). Teacher development: A study of factors related to teacher concerns for pre, beginning, and experienced teachers. [Presentation Abstract]. Paper presented at the Annual Conference of the American Educational Research Association. Los Angeles, CA.

Advisors of Excellence Program. (2013). Western Kentucky University. Retrieved from www.wku.edu/advising/advisors-of-excellence.php

Ahlering, I. (1963). Reactions by student teachers. The Clearing House, 37(6), 337-340.

Allen, M. (2003). Eight questions on teacher preparation: What does the research say? Denver, CO Education Commission of the States, 6 .

Alliance for Excellent Education. (2008). What keeps good teachers in the classroom? Understanding and reducing teacher turnover. Retrieved from www.all4ed.org\\files\\TeachTurn.pdf.

Ambrosetti, A. \& Dekkers, J. (2010). The interconnectedness of the roles of mentors and mentees in pre-service teacher education mentoring relationships. Australian Journal of Teacher Education, 35(6), 42-55. 
Anderson, N. A.; Barksdale, M. A.; \& Hite, C. E. (2005). Pre-service teachers' observations of cooperating teachers and peers while participating in an early field experience. Teacher Education Quarterly, 32(4), 97-118.

Anderson, R. N., Greene, M. L., \& Loewen, P. S. (1988). Relationships among teachers' and students' thinking skills, sense of efficacy, and student achievement. Alberta Journal of Educational Research, 34(2), 148-165.

Austin-Martin, G., Bull, D., Molrine, C. (1981). A study of the effectiveness of a prestudent teaching experience in promoting positive attitudes toward teaching. Peabody Journal of Education, 58(3), 148-153.

Bandura, A. (1977). Self-efficacy: Toward a unifying theory of behavioral change. Psychological Review, 84(2), 191-215.

Bandura, A. (1986). Social foundations of thought and action: A social cognitive theory. Englewood Cliffs, N.J: Prentice-Hall.

Bandura, A. (1994). Self-efficacy. In V. S. Ramachaudran (Ed.), Encyclopedia of human behavior (Vol. 4, pp. 71-81). New York, NY: Academic Press. (Reprinted in H. Friedman [Ed.], Encyclopedia of mental health. San Diego, CA: Academic Press, 1998). Retrieved from http://des.emory.edu/mfp/BanEncy.html\#sources.

Bay-Williams, J, M.; Scott, M. B.; \& Hancock, M. (2007). Case of the mathematical team: Implementing a team model for simultaneous renewal. Journal of Educational Research, 100(4), 243-253. 
Bayer Corporation. (2004). Bayer facts of science education 2004: Are the nation's colleges adequately preparing elementary schoolteachers of tomorrow to teach science? Philadelphia, PA: Bayer Corp. Retrieved from http://www.bayerus.com/msms/news/facts.cfm? mode=detail\&id=survey04.

Beck, C. \& Kosnik, C. (2002). Professors and the practicum: Involvement of the university faculty in pre-service practicum supervision. Journal of Teacher Education, 53(1), 6-19.

Beeth, M. E. \& Adadan, E. (2006). The Influences of university-based coursework on field experience. Journal of Science Teacher Education, 17, 103-120.

Beilock, S. L., Gunderson, E. A., Ramirez G., \& Levine S. C. (2010). Female teachers' math anxiety affect girls' math achievement. Proceedings of the National Academy of Sciences of the United States of America, 107(5), 1860-1863.

Bensky, J. M., Shaw, S. F., Gouse, A. S., Bates, H., Dixon, B., \& Bean, W. E. (1980). Public Law 4-142 and stress: A problem for educators. [Abstract]. Exceptional Children, 47(1), 24-29.

Berlinger, D. C. (1988). The development of expertise in pedagogy. Paper presented at the Annual Meeting of the American Association of Colleges for Teacher Education, New Orleans, LA.

Betoret, F. D. (2006). Stressors, self-efficacy, coping resources, and burnout among secondary school teachers in Spain. Educational Psychology, 26(4), 519-539.

Billingsley, B. S. (2004). Special education teacher retention and attrition: A critical analysis of the literature. Journal of Special Education, 38(1), 39-55. 
Black-Branch, J. L. \& Lamont, W. K. (1998). Duty of care and teacher wellness: A rationale for providing support services in colleges of education, Journal of Collective Negotiations in the Public Sector, 27(3), 175-193.

Boreen, J. \& Niday, D. (2000). Breaking through the isolation: Mentoring beginning teachers. Journal of Adolescent \& Adult Literacy, 44(2), 152-163.

Borg, M., Riding, R., \& Falzon, J. (1991). Stress in teaching: a study of occupational stress and its determinants, job satisfaction and career commitment among primary schoolteachers. Educational Psychology, 11(1), 59-75.

Borich, G. D. (1988). Effective teaching methods. Columbus, OH: Merrill Publishing Company.

Borich, G. D. (1992). Effective teaching methods. (2 ${ }^{\text {nd }}$ ed.). Columbus, OH: Macmillan.

Borich, G. D. (1996). Effective teaching methods. ( ${ }^{\text {rd }}$ ed.). Columbus. OH: Merrill/MacMillan.

Borich, G. D. \& Rogan, J. M. (1988). Teacher concerns checklist. In G. Borich, Effective teaching methods. Toronto, Canada: Merrill.

Borich, G.D. \& Tombari, M. L. (1997). Educational psychology: A contemporary approach. ( $2^{\text {nd }}$ ed.). New York, NY: Longman.

Boz, Y. \& Boz, N. (2010). The nature of the relationship between teaching concerns and sense of efficacy. European Journal of Teacher Education, 33(3), 279-291.

Brahier, D. J. (2009). Teaching secondary and middle school mathematics. New York, NY: Pearson Education.

Brand, M. (1983). Stages of a teacher's career. Music Educators Journal, 69(7), 49-51. 
Brewster, C., \& Railsback, J. (2001). Supporting beginning teachers: How administrators, teachers, and policymakers can help new teachers succeed, Northwest Regional Educational Laboratory, 1-66.

Brissie, J. S., Hoover-Dempsey, K. V. \& Bassler, O. C. (1988). Individual, situational contributors to teacher burnout. Journal of Educational Research, 82(2), 106-112.

Bullough, R. V. \& Gitlin, A. D. (1994). Challenging teacher education as training: Four propositions [Abstract]. Journal of Educations for Teaching, 20(1), 67-81.

Burch, B. (2008). Replication of UTeach at Western Kentucky University. PowerPoint presentation for the Fall 2008 Renaissance Group Conference. Bowling Green, Ky. Retrieved from www.aascu.org/meetings/aa.../Friday\%201000\%20Burch.ppt

Burke, P. J., Christensen, J. C., \& Fessler, R. (1984). Teacher career stages: Implications for staff development. Bloomington, IN: Phi Delta Kappa.

Bush, W. S. (1989). Mathematics anxiety in upper elementary school teachers. School Science and Mathematics, 89(6), 499-509.

Business-Higher Education Forum (BHEF). (2006). The American competitiveness initiative: Addressing the STEM teacher shortage and improving student academic readiness. BHEF Issue Brief, Business-Higher Education Forum.

Cady, J., Meier, S. L., \& Lubinski, C. A. (2006). Developing mathematics teachers: The transition from pre-service to experience teacher. Journal of Educational Research, 99(5), 295-305.

Campbell, L. P. (1983). Teacher burnout: Description and prescription. Clearing House, 57(3), 111-113. 
Campbell, D. T. \& Stanley, J. C. (1963), Experimental and quasi-experimental designs for research. Boston, MA: Houghton Mifflin.

Campbell, L. P. \& Williamson, J. A. (1973). Dogmatism in student teachers. Education Forum, 37, 489.

Campbell, L. P. \& Williamson, J. A. (1974). Disregard those anxieties: Reassurance for student teachers. Southern Journal of Educational Research, 8(5), 222-265.

Canrinus, E. T., Helms-Lorenz, M., Beijaard, D., Buitink, J., \& Hofman, A. (2012). Selfefficacy, job satisfaction, motivation, and commitment: exploring the relationships between indicators of teachers' professional identity. European Journal of Psychology of Education, 27(1), 115-132.

Capel, S. A. ( 1997). Changes in students' anxieties and concerns after their first and second teaching practices, Educational Research, 39(2), 211 - 228.

Capel, S. (2001). Secondary students' development as teachers over the course of a PGCE year. Educational Research, 43(3), 247-261.

Capraro, M. M., Capraro, R. M., \& Helfeldt, J. (2010). Do differing types of field experiences make a difference in teacher candidates' perceived level of competence? Teacher Education Quarterly, 131-154.

Carson, R. L., Plemmons, S., Templin, T. J., \& Weiss, H. M. (2011). "You are who you are": A mixed method study of affectivity and emotional regulations in curbing teacher burnout. In G. M. Reevy \& E. Frydenberg (Eds.), Personality, Stress, and Coping: Implications for Education (pp. 239-264). Charlotte, NC, Information Age. 
Caruso, J. J. (1977). Phases in student teaching. Young Children, 33(1), 57-63.

Cavanagh, S. (2007). Grounded in content. Education Week, 27(14), 21-23.

Cedoline, A. J. (1982). Job burnout in public education: Symptoms, Causes and Survival Skills. New York, NY: Teachers College Press.

Chapman, D. W. \& Lowther, M. A. (1982). Teachers' satisfaction with teaching. The Journal for Educational Research, 75(4), 241-247.

Charalambous, C. Y. \& Philippou, G. N. (2003). Enhancing pre-service teachers' efficacy beliefs in mathematics. Proceedings of the Third conference of the European Society for Research in Mathematics Education, Bellaria, Italy.

Charalambous, C. Y. \& Philippou, G. N. (2010). Teacher's concerns and efficacy beliefs about implementing a mathematics curriculum reform: integrating two lines of inquiry. Educational Studies in Mathematics, 75(1), 1-21.

Charalambous, C. Y., Philippou, G. N., \& Kyriakides, L. (2008). Tracing the development of preservice teachers' efficacy beliefs in mathematics during fieldwork. Educational Studies in Mathematics, 67(2), 125-142.

Clement, M. (1999). Reducing the stress of student teaching. Contemporary Education, $70(4), 20-25$.

Clunies-Ross, P., Little, E., \& Kienhuis, M. (2008). Self-reported and actual use of proactive and reactive classroom management strategies and their relationship with teacher stress and student behavior. Educational Psychology, 28(6), 693 710.

Coates, T. J. \& Thoresen, C. E. (1976). Teacher anxiety: A review with recommendations. Review of Educational Research, 46(2), 159-184. 
Conway, P. F. \& Clark, C. M. (2003). The journey inward and outward: A reexamination of Fuller's concern based model of teacher development. Teaching and Teacher Education, 19, 465-482.

Cornelius-White, J. (2007). Learner-centered teacher-student relationships are effective: A meta-analysis. Review of Educational Research, 77(1), 113-143.

Cunningham, W. G. (1983). Teacher burnout-Solutions for the 1980's: A review of literature [Abstract]. The Urban Review, 15(1), 37-51.

Dadlez, S. L. (1998). A comparison of secondary professional development school and traditional teacher education graduates: Analysis of professional concerns and perceived problems. [Abstract] (Unpublished doctoral dissertation) University of California, Riverside, CA.

Dallmer, D. (2004). Collaborative relationships in teacher education: A personal narrative of conflicting roles. Curriculum Inquiry, 34(1), 29-45.

Darling-Hammond, L. (2006). Assessing teacher education the usefulness of multiple measures for assessing program outcomes. Journal of Teacher Education, 57(2), $120-138$.

Darling-Hammond, L.; Bransford, J. (2005). Preparing Teachers for a Changing World: What Teachers Should Learn and Be Able to Do. San Francisco, CA: Jossie-Bass. Darling-Hammond, L., Bullmaster, M. L., \& Cobb, V. L. (1995). Rethinking teacher leadership through professional development schools. The Elementary School Journal, 96(1), 87-106.

Darling- Hammond, L. \& McLaughlin, M. W. (1995). Polices that support professional development in an era of reform. Phi Delta Kappan, 76(8), 597-604. 
DePencier, I. (1996). The History of the University of Chicago Laboratory School.

Chicago, IL: University of Chicago. Retrieved from

http://www.ucls.uchicago.edu/about-lab/history/index.aspx

Diem, R. A. \& Schnitz, J. E. (1978). The instructional alliance in student teaching. Contemporary Education, 40(2), 72-74.

Dohrenwend, B. S., \& Dohrenwend, B. P. (1981). Life stress and illness: Formulation of the issues. In B. S. Dohrenwend \& B. P. Dohrendwend (Eds.), Stressful life events and their context, New Brunswick, NJ: Rutgers University Press, pp. 1- 27.

Dorman, J. (2003). Testing a model for teacher burnout. Australian Journal of Educational \& Developmental Psychology, 3, 35-47.

Doyal, G. T., \& Forsyth, R. A. (1973). The relationship between teacher and student anxiety levels [Abstract]. Psychology in the Schools, 10(2), 231-233.

Ducharme, L. J., Knudsen, H. K., \& Roman, P. M. (2007). Emotional exhaustion and turnover in human service occupations: The protective role of coworker support. Sociological Spectrum: Mid-South Sociological Association, 28(1), 81-104.

Dworkin, A. G. (1987). Teacher burnout in the public schools: Structural causes and consequences for children. (p. xv), Albany, New York: State University of New York Press.

Eastern Kentucky University. (2011). MODEL: Many great students, one great school. Retrieved from http://model.eku.edu/

Evans, D. E. \& Tribble, M. (1986). Perceived teaching problems, self-efficacy, and commitment to teaching among preservice teachers. Journal of Educational Research, 30(2), 31-35. 
Farber, B. A. (1984). Stress and burnout in suburban teachers. Journal of Educational Research, 77(6), 325-331.

Fimian, M. J. \& Blanton, L. P. (1987). Stress, burnout, and role problems among teacher trainees and first-year teachers. Journal of Occupational Behavior, 8(2), 157-165.

Fisher, M. H. (2011). Factors influencing stress, burnout, and retention of secondary teachers. Current Issues in Education, 14(1). Retrieved from http://cie.asu.edu.

Fitzpatrick, J. L., Sanders, J. R., and Worthen, B. R. (2011). Program evaluation: Alternate approaches and practical guidelines ( $4^{\text {th }}$ ed). Upper Saddle River, NJ: Pearson Education, Inc.

Fives, H., Hamman, D., \& Olivarez, A. (2007). Does burnout begin with studentteaching? Analyzing efficacy, burnout, and support during the student-teaching semester. Teaching \& Teacher Education, 23(6), 916-934.

Fletcher, S. H. \& Barrett, A. (2004). Developing effective beginning teachers through mentor-based induction. Mentoring and Tutoring, 12(3), 321 - 333.

Freeman, J., Simonsen, B., Briere, D. E., \& MacSuga-Gage, A. S. (2013). Preservice teacher training in classroom management: A review of state accreditation policy and teacher preparation programs. [Abstract] Teacher Education and Special Education: the Journal of the Teacher Education Division of the Council for Exceptional Children.

Friedman, I. A. (2000). Burnout in teachers: Shattered dreams of impeccable professional performance. Journal of Clinical Psychology, 56(5), 595-606.

Friedman, I. A. (1991). High and low-burnout schools: School culture aspects of teacher burnout [Abstract]. The Journal of Educational Research, 84(6), 325-333. 
Fuller, F. F. (1969). Concerns of teachers: A developmental conceptualization. American Educational Research Journal. 6(2), 207-226.

Fuller, F. F., \& Borich, G.D. (1988). Teacher concerns checklist. In G. Borich Effective teaching methods. Toronto, Canada: Merrill.

Fuller, F. F. \& Bown, O. (1975). Becoming a teacher. In K. Ryan (ed.), Teacher Education, $74^{\text {th }}$ Yearbook of the National Society for the Study of Education part 2, 25-52. Chicago, IL: University of Chicago Press.

Fuller, F. F. \& Case, C. (1972) A manual for scoring the teacher concern statement (2nd ed). [Abstract] Austin, TX: Research and Development Center for Teacher Education.

Fuller, F. F. \& Parsons, J. S. (1974). Concerns of teachers: Recent research on two assessment instruments. [Abstract]. Paper presented at the $59^{\text {th }}$ Annual Meeting of the American Research Association, Chicago, IL.

Fuller, F. F., Parsons, J. S. \& Watkins, J. E. (1974). Concerns of teachers: Research and reconceptualization [Abstract]. Paper presented at the $59^{\text {th }}$ Annual Meeting of the American Research Association, Chicago, IL.

Furlong, J. \& Maynard, T. (1995). Mentoring student teachers: The growth of professional knowledge. London, England: Routledge.

George, A. A. (1978). Measuring self, task, and impact concerns: A manual for the use of the teacher concerns questionnaire. Austin, TX: University of Texas.

Ghaith, G., \& Shaaban, K. (1999). The relationships between perceptions of teaching concerns, teaching efficacy, and selected teacher characteristics. Teaching and Teacher Education, 15, 487-496. 
Giovannetti, M. (2012). Welcome to the renaissance group: A message from the director. The Renaissance Group. Retrieve from http://www.renaissancegroup.org/about/index.shtml

Gibson, S. \& Dembo, M. H. (1984). Teacher efficacy: A construct validation. Journal of Educational Psychology, 76(4), 569-582.

Glass, D. C. \& Mcknight, J. D. (1996). Perceived control, depressive symptomatology, and professional burnout: A review of evidence [Abstract], Psychology and Health, 11(1), 23-48.

Glesne, C. (2006). Becoming qualitative researchers: An introduction (3rd edition). New York, NY: Longman.

Gold, Y. (1985a). Burnout: Causes and Solutions. The Clearing House. 58(5), 210-212.

Gold, Y. (1985b). Does teacher burnout begin with student teaching? Education, 105(3), 254-257.

Goldhaber, D. (2006). Everybody's doing it, but what does teacher testing tell us about teacher effectiveness? Paper presented at the American Education Research Association (AERA) annual meeting April 4, 2006, San Francisco, CA.

Gorsuch, R. L. (1983). Factor analysis (2nd ed.). Hillsdale, NJ: Erlbaum.

Gowie, C. J. (2010). Developing efficacy beliefs in pre-service teachers. Paper presented at the Northeastern Educational Research Association (NERA) Conference Proceedings 2010. Paper 11. Rocky Hill, Connecticut. Retrieved from http://digitalcommons.uconn.edu/nera_2010/11.

Greeno, J. (2007). Perspectival understanding of conceptions and conceptual growth in interaction. Educational Psychologist, 42(1), 9-23. 
Greer, J. G. \& Greer, B. B. (1992). Stopping burnout before it starts: Prevention Measures at the preservice level. Teacher Education and Special Education, 15(3), 168-174.

Guskey, T. R., \& Passaro, P. D. (1994). Teacher efficacy: A study of construct dimensions. American Educational Research Journal, 31(3), 627-643.

Hall, G. E. (1979). The concerns-based approach for facilitating change [Abstract]. Educational Horizons, 57(4), 202-208.

Hall, G. E., George, A. A., \& Rutherford, W. L. (1986). Measuring stages of concern about the innovation: A manual for the use of the SoC Questionnaire. Austin: Research and Development Center for Teacher Education, University of Texas at Austin.

Hall, G. E., Wallace, R. D., Jr., \& Dossett, W.A. A. (1973). Developmental conceptualization of the adoption process within educational institutions [Abstract]. Austin, TX: Research and Development Center for Teacher Education, the University of Texas.

Hall, K.M., Draper, R. J.; Smith, L.K., \& Bullough, R. V. (2008). More than a place to teach: exploring the perceptions of the roles and responsibilities of mentor teachers. Mentoring and Tutoring: Partnership in Learning, 16(3), 328-345.

Hammerness, K., Darling-Hammond, L., \& Bransford J., with others. (2005). How teachers learn and develop. In L. Darling-Hammond and J. Bransford (Eds.), Preparing Teachers for a Changing World: What Teachers Should Learn and Be Able to Do. (pp.358-389). San Francisco, CA: Jossey-Bass. 
Hargreaves, A., \& Fullan, M. (2000). Mentoring in the new millennium. Theory into Practice, 39(1), 50.

Harms, W. \& DePencier, I. (1996). Experiencing Education: 100 Years of Learning at The University of Chicago Laboratory Schools. Chicago, IL: University of Chicago. Retrieved from http://classic.ucls.uchicago.edu/about/history/education.shtml

Hart, N. I. (1987). Student teachers' anxieties: Four measured factors and their relationship to pupil disruption in class, Educational Research, 29(1), 12-18.

Hattie, J. (2003). Teachers make a difference: What is the research evidence? Paper presented at the Australian Council for Educational Research Annual Conference on Building Teacher Quality, Melbourne, Australia.

Havis, A. L. (1975). Alternatives for breaking the "discipline barrier" in our schools. Education, 96(2), 124-128.

He, Y. (2009). Strength-based mentoring in pre-service teacher education: a literature review. Mentoring \& Tutoring: Partnership in Learning, 17(3), 263-275.

Henke, R. R., Chen, X., \& Geis, S. (2000). Progress through the teacher pipeline: 199293 college graduates and elementary/secondary teaching as of 1997 (NCES No.2000152). Washington, DC: National Center for Education Statistics. Retrieved from http://nces.ed.gov/pubs2000/2000152.pdf.

History of the Jones-Jaggers Laboratory School (1971). WKU Archives. Retrieved from http://www.wku.edu/library/archive/bib38.php\#art

Hollingsworth, P. M. (1990). Reading teacher burnout and stress. Reading Improvement, 27(3), 196-199. 
Houkes, I., Janssen, P. P. M., de Jonge, J., \& Nijhuis, F. J. N. (2001). Work and individual determinants of intrinsic work motivation, emotional exhaustion, and turnover intention: A multi-sample analysis. International Journal of Stress Management, 8(4), 257-283.

Houtman, I. L. D., \& Bakker, F. C. (1987). Stress in student teachers during real and simulated standardized lectures. Journal of Human Stress, 13(4), 180-187.

Hoy, W. K. \& Woolfolk, A. E. ( 1993). Teacher efficacy scale (short form). In teachers sense of efficacy and the organizational health of schools. The Elementary School Journal, 93, 356-372.

Huling-Austin, L. (1986). Factors to consider in alternative certification programs: What can be learned from teacher induction research? Action in Teacher Education, $8(2), 51-58$.

Illinois State University (2012). University Laboratory Schools. Retrieved from http://coe.illinoisstate.edu/labschools/

Ingersoll, R. M. (2003a). The teacher shortage: Myth or reality? Educational Horizons, 81(3), 146-152.

Ingersoll, R. M. (2003b). Is there really a teacher shortage? A Research Report Cosponsored by the Consortium for Policy Research in Education and The Center for the Study of Teaching and Policy, Philadelphia, PA and Seattle, WA.

Ingersoll, R. (2003c) University of Pennsylvania. Original analysis for NCTAF of the 2000-01 Teacher Follow-up Survey. In No Dream Denied, January 2003. National Commission on Teaching and America's Future. 
Ingersoll, R. M. \& Perda, D. (2009). The mathematics and science teacher shortage: Fact and myth. Consortium for Policy Research in Education. CPRE Research Report \#RR-62, 1-41.

Ingersoll, R. M. \& Smith, T. M. (2003). The wrong solution to the teacher shortage. Educational Leadership, 60(8), 30-33.

Ingersoll, R. M. \& Strong, M. (2011). The impact of induction and mentoring programs for beginning teachers: A critical review of the research. Review of Educational Research, 81(2), 201-233.

Inman, J. (2000). Social cognitive theory: A synthesis. (Unpublished thesis). Oregon State University. Retrieved from http://www.wetherhaven.com/Documents/socialcognitivetheory.pdf

Johns, K. M. (1992). Lowering beginning teacher anxiety about parent-teacher conferences through role-playing. School Counselor, 40(2), 146-152.

Johnson, J. S. (1969). Change in student teacher dogmatism. Journal of Educational Research, 62(5), 224-226.

Johnson, S. M. \& Birkeland, S. E. (2002). Pursuing a "sense of success": new teachers explain their career decisions. American Educational Research Journal, 40(3), 581-617.

Kagan, D. M. (1992). Professional growth among pre-service and beginning teachers, Review of Educational Research, 62(2), 129 - 169. 
Kahn, J. H., Schneider, K. T., Jenkins-Heikelman, T. M., \& Moyle, L. L. (2006).

Emotional social support and job burnout among high-school teachers: Is it all due to dispositional affectivity? Journal of Organizational Behaviour, 27(6), 793 807.

Katz, L. G. (1972). The developmental stages of preschool teachers. The Elementary School Journal. 73(1), 50-54.

Kardos, S. M. (2002). New teachers' experiences of mentoring, classroom observations, and teacher meetings: Toward an understanding of professional culture. Paper presented at the American Educational Research Association: New Orleans, LA.

Kardos, S.M., Johnson, S. M., Peske, H. G., Kaffman, D. \& Liu, E. (2001). Counting on colleagues: New teachers encounter the professional cultures of their schools. Educational Administration Quarterly, 37(2), 250-290.

Kaufman, D. \& Moss, D. M. (2010). A new look at preservice teachers' conceptions of classroom management and organization: Uncovering complexity and dissonance, The Teacher Educator, 45, 118-136.

Keavney, G.\& Sinclair, K. E. (1978). Teacher concerns and teacher anxiety: A neglected topic of classroom research. Review of Educational Research, 48(2), 273-290.

Keogh, J. (2005). Who's the expert and who's the novice? Mentoring tensions in the practicum experience. Paper presented at Australian Association for Research in Education International Conference: UWS Parramatta. Retrieved from: http://www.aare.edu.au/05pap/keo05097.pdf

Kline, P. (1979). Psychometrics and psychology. London, England: Academic Press. 
Kohlberg, L. (1969). Stages and sequences: The cognitive development approach to socialization. In Goslin, D. A. (ed.) Handbook of socialization theory of research. 347-480. Chicago: Rand McNally.

Korthagen, F. A. J., \& Kessels, J. P. A. M. (1999). Linking theory and practice: Changing the pedagogy of teacher education. Educational Researcher, 28(4), 4-17.

Lai, E. (2005). Mentoring for in-service teachers in a distance teacher education programme: views of mentors, mentees and university teachers. Paper presented at the Australian Association for Research in Education International Education Research Conference: Parramatta

Lau, P. S. Y., Yuen, M. T, \& Chan, R. M. C. (2005). Do demographic characteristics make a difference to burnout among Hong Kong secondary school teachers? [Abstract] Quality-of-Life Research in Chinese, Western, and Global Contexts Social Indicators Research Series, 25, 491-516.

Lawrence, M. N., \& Butler, M. B. (2010). Becoming aware of the challenges of helping students learn: An examination of the nature of learning during a service-learning experience. Teacher Education Quarterly, 37(1), 155-176.

Lawrenson, G. M. \& McKinnon, A. J. (1982). A survey of classroom teachers of the emotionally disturbed: Attrition and burnout factors [Abstract]. Behavioral Disorders, 81(1), 41-49.

Lefever-Davis, S., Johnson, C.,\& Pearman, C. (2007). Two sides of a Partnership: Egalitarianism and Empowerment in School-University Partnerships. Journal of Educational Research, 100(4), 204-210. 
Lienert, C., Sherrill, C., \& Myers, B. (2001). Physical educators' concerns about integrating children with disabilities: A cross-cultural comparison [Abstract]. Adapted Physical Activity Quarterly, 18(1), 1-17.

Littrel, P. C., Billingsley, B. S., \& Cross, L. H. (1994). The effects of principal support on special and general educators' stress. job satisfaction, school commitment, health, and intent to stay in teaching. Remedial and Special Education, 15(5), 297-310.

Loevinger, J. (1966). The meaning and measure of ego development. American Psychologist. 21(3), 195-206.

Looney, J. (2011). Developing comprehensive induction programs at Christian schools, Journal of the International Christian Community for Teacher Education, 3(2). Retrieved from http://icctejournal.org/issues/v3i2/v3i2-looney/

Love, C. (1992). Congruence and Dissonance within the student teacher triad. (Doctoral dissertation). Retrieved from ProQuest. (303999473)

Lynn, S. K. (2002). The winding path: Understanding the career cycle of teachers. The Clearing House, 75(4), 179-182.

Lloyd C. (2010). Burnout. International Encyclopedia of Rehabilitation. Retrieved from http://cirrie.buffalo.edu/encyclopedia/en/article/2/

Malanowski, J. R. \& Wood, P. H. (1984), Burnout and self-actualization public school teachers [Abstract], The Journal of Psychology: Interdisciplinary and Applied, $117(1), 23-26$.

Maslach, C. (2003). Job burnout: New directions in research and interventions. Current Directions in Psychological Science, 12(5), 189-192. 
Marshall, P. L. (1996). Multicultural teaching concerns: New dimensions in the area of teacher concerns research? [Abstract] Journal of Educational Research, 89 (6), $371-379$.

Marso, R. N. \& Pigge, F. L. (1998). A longitudinal study of relationships between attitudes toward teaching, anxiety about teaching, self-perceived effectiveness, and attrition from teaching. Paper presented at the Annual Meeting of the Association of Teacher Educators, Dallas, TX.

Maslach, C. (2003). Job burnout: New directions in research and interventions. Current Directions in Psychological Science, 12(5), 189-192.

Mattson, K. D. (1974). Personality traits associated with effective teaching in rural and urban secondary schools [Abstract]. Journal of Educational Psychology, 66(1), $123-128$.

Maynard, T. \& Furlong, J. (1995). Learning to teach and models of mentoring. In Kerry, T., and Mayes, A. S. (eds.) Issues in Mentoring, London: Routledge, pp. 10-24.

McCann, T. M. \& Johannessen, L.R. (2004). Why do new teachers cry? Clearing House, $77(4), 138-145$.

McGuire, W. H. (1979). Teacher burnout. Today's Education, 68(4), 5.

McIntyre, D. J. (1984). A response to critics of field experience supervision. Journal of Teacher Education, 35(3), 42-45.

McIntyre, D. J. \& Killian, J. E. (1987). The influence of supervisory training for cooperative teachers on preservice teachers' development during early field experiences. Journal of Educational Research, 80(5), 277-282. 
McKinney, M., Sexton, T., \& Meyerson, M. J. (1999). Validating the efficacy-based change model. Teaching and Teacher Education, 15, 471-485.

McVey, M. K. (2004). The role of teacher education experiences in addressing the concerns of apprentice teachers. Doctoral Dissertation. Duquesne University: Pittsburgh, PA.

Metcalf-Turner P. (1999). Variable definitions of professional development schools: A desire or a dilemma? Peabody Journal of Education, 74(3/4), 33-41.

Miles, M.B., \& Huberman, A.M. (1984). Qualitative data analysis: A sourcebook of new methods. Beverly Hills, CA: Sage.

Miles, M. B., Saxl, E. R., Lieberman, A. (1988). What skills do educational "change agents" need? An empirical view. Curriculum Inquiry, 18(2), 157-193.

Miller, M. (2005). Teaching and Learning in Affective Domain. In M. Orey (Ed.), Emerging perspectives on learning, teaching, and technology. Retrieved from http://projects.coe.uga.edu/epltt

Monson, J. A. \& Bebb, A. M. (1970). New roles for the supervisor of student teaching. Educational Leadership, 28(1), 44-47.

Moody, J. (2009). Key elements in a positive practicum: Insights from Australian postprimary, Irish Educational Studies, 28(2), 155-175.

Monk, D. (1994). Subject area preparation of secondary mathematics and science teachers and student achievement. Economics of Education Review, 13(2), pp. $125-145$.

Moriarty, V., Edmonds, S., Blatchford, P. \& Martin, C. (2001). Teaching young children: Perceived satisfaction and stress. Educational Research, 43(1), 33 - 46. 
Morton, L, L,Vesco, R., Williams, N. H. \& Awender, M. A. (1997). Student teacher anxieties to class management, pedagogy, evaluation, and staff relations. British Journal of Educational Psychology, 67, 69-89.

Murnane, R., Singer, J., Willett, J., Kemple, J., \& Olsen, R. (1991). Who will teach? Policies that matter. Cambridge, MA: Harvard University Press.

Murphy, J. (2010). Causes and Solutions to Teacher Burnout. Seattle, WA: Seattle Pacific University.

Murphy, P. K.; Delli, L. A. M., \& Edwards, M. N. (2004). The good teacher and good teaching: Comparing beliefs of second-grade students, preservice teachers and inservice teachers. The Journal of Experimental Education, 72(2), 69-92.

Murray-Harvey, R., Slee, P. T., Lawson, M. J., Silins, H., Banfield, G., \& Russell, A. (2000). Under stress: The concerns and coping strategies of teacher education students. European Journal of Teacher Education, 23(1), 19-35.

Nahal, S. P. (2010). Voices from the field: Perspectives of first-year teachers on the disconnect between teacher preparation programs and the realities of the classroom. Research in Higher Education Journal, 8(1), 1-19.

National Association for Professional Development School (NAPDS). (2008). What it means to be a professional development school. Statement by the National Association for Professional Development School.

National Commission on Teaching and America's Future (NCTAF). (1996). What matters most: Teaching for America's future. Washington, DC: Author. 
National Commission on Mathematics and Science Teaching for the $21^{\text {st }}$ Century. (2000).

Before it's too late. U.S. Department of Education, Retrieved from http://www.ed.gov/americacounts/glenn.

www.cbe.wwu.edu/Krieg/Econ.\%20Documents/Teacher\%20Quality\%20Attrition \%20EER\%20Final.pdf

National Council of Accreditation of Teacher Education (NCATE). (2008). Unit Standards. Retrieved from http://www.ncate.org/Standards/NCATEUnitStandards/UnitStandardsinEffect200 8/tabid/476/Default.aspx\#concept.

National Council for Accreditation of Teacher Education (NCATE). (2001). Standards for Professional development schools. Retrieved from: http://www.ncate.org/documents/pdsStandards.pdf

National Council for Accreditation of Teacher Education (NCATE). (2013). What makes a teacher effective? What research says about teacher preparation. Retrieved from:

http://www.ncate.org/LinkClick.aspx?fileticket=JFRrmWqa1jU\%3d\&tabid=361

National Council of Teachers of Mathematics (NCTM), (2000). Principles and standards for school mathematics. Reston, VA.

National Education Health Association Health Information Network (NEAHIN). (2001). Violence in the communities and schools: A stress reduction guide for teachers and other school staff, National Education Association Health Information Network and Center for Mental Health Services Retrieved from http://crisisguide.neahin.org/resources/docs/Stress-Guide-pdf. 
National Science Board (2008). Science and engineering indicators 2008. Washington, DC: National Science Foundation. Retrieved from http://www.nsf.gov/statistics/seind08/c1/c1h.htm\#c1sxl5.

Newhouse, P. C. (2001). Applying the concerns-based adoption model to research on computers in classrooms. Journal of Research on Technology in Education, 33(5), $1-21$.

Newman, C., Lenhart, L., Moss, B., Newman, D. ( 2000). A four-year cross sectional study of changes in self-efficacy and stages of concern among pre-service teachers. Paper presented at the Annual Meeting of the Mid-Western Educational Research Association: Chicago, IL.

New Teacher Center at the University of California, Santa Cruz (NCT). (2007).New teacher support pays off: A return on investment for educators and kids, $N C T$ Policy Brief, 1 - 4.

Nguyen, H. T. (2009). An inquiry-based practicum model: What knowledge, practices, and relationships typify empowering teaching and learning experiences for student teachers, cooperating teachers and college supervisors? Teaching and Teacher Education, 25, 655-662.

Noble, K. (1970). Communities of practice: Innovation in early childhood education and care teacher and practitioner preparation. The International Journal of Learning, 14(9), 133-138.

Parsons, J. S. (1973). Assessment of anxiety about teaching using the teaching anxiety scale: Manual and research report [Abstract]. Research and Development Center for Teacher Education, University of Texas at Austin. 
Petrusich, M. M. (1966). Some relationships between anxiety and the classroom behavior of student teachers. Journal of Teacher Education, 18(2), 243-245.

Phi Delta Kappa. (1980). Why do some urban schools succeed? [Abstract] (p. 133-134), Bloomington, IN: Phi Delta Kappa.

Piaget, J. (1971). Biology and Knowledge. Chicago. IL: University of Chicago Press.

Pigge, F. L. \& Marso, R. N. (1995). A seven-year longitudinal multi-factor assessment of teaching concerns development through preparation and early years of teaching. Paper presented at the Annual Conference of the American Educational Research Association, San Francisco, CA.

Preece, P.F.W. (1979). Student teacher anxiety and class-control problems on teaching practice: A cross-lagged panel analysis. British Educational Research Journal, 5(1), 13-19.

Pyper, J. (2009). Pre-service mathematics teacher efficacy trajectories. Paper presented at the Canadian Society for the Study of Education Annual Conference: Ottawa, Ontario.

Rajeswari, S. M., Santhanam, T., Babu, B. P., \& Rao, D. B. (2008) Stress and attitudes of women teachers. Darya Ganj, New Delhi: Discovery Publishing House PVT. LTD.

Reeves, C. K., \& Kazelskis, R. (1985). Concerns of preservice and in-service teachers. Journal of Educational Research, 78(5), 267-271.

Reyes, P. \& Hoyle, D. (1992). Teachers' satisfaction with principals' communication. Journal of Educational Research, 85(3), 163-168. 
Rising Above the Gathering Storm. (2006, January 24). [Editorial] New York Times, Retrieved from Academic Search Premier database.

Roberts, C. M. (2004). The dissertation journey: A practical and comprehensive guide to planning, writing, and defending your dissertation. Thousand Oaks, CA.

Rodriguez B. \& Gerrow, R. (2003) Tackling the Texas teacher shortage: UTeach turns liberal arts and natural science students into educator. Feature article. University of Texas at Austin. Retrieved from http://www.utexas.edu/feature/archive/2003/uteach.html

Rogan, J. M., Borich, G. D., \& Taylor, H. P. (1992). Validation of the stages of concern questionnaire. Action in Teacher Education, 2, 43-49.

Rogusky, M. (2003). No dream denied: A pledge to America's children. Washington, DC: National Commission on Teaching and America's Future (NCTAF).

Rokeach, M. (1960). The open and closed mind: investigations into the nature of belief systems and personality systems. New York, NY: Basic Books.

Rorrison, D. (2005, November). Turning a critical lens on the practicum in secondary preservice teacher education programs. In Proceedings of the AARE International Education Research Conference. Parramatta.

Rossman. G. B. \& Rallis, S. F. (2003). Learning in the field: An introduction to qualitative research ( $2^{\text {nd }}$ ed). Thousand Oaks, CA: Sage.

Roth, W. M. \& Tobin, K. (2001). Learning to teach science as practice. Teacher and Teacher Education, 17, 771-784.

Russell, A. (2006). Teacher induction programs: Trends and Opportunities. American Association of State Colleges and Universities, 3(10). 
Rust, F. (1988). How supervisors think about teaching. Journal of Teacher Education, 39(2), 56-64.

Sadowski, C., Blackwell, M., \& Willard, J. (1986). Assessing locus of control, perceived stress, and performance of student teachers. Education, 106(3), 352-353.

Salkind, N. J. (Ed.). (2010). Encyclopedia of research design. Thousand Oaks, CA:

SAGE Publications, Inc. doi: http://dx.doi.org/10.4135/9781412961288

Sanders, T. (2004). No time to waste: The vital role of college and university leaders in improving science and mathematics education. Adapted from Presentation at the Invitational Conference on Teacher Preparation and Institutions of Higher Education: Mathematics and Science Content Knowledge, United States Department of Education. [Brochure]. Austin, TX: Education Commission of the States Retrieved from http://www.ecs.org/clearinghouse/54/80/5480.htm

Sass, D. A., Seal, A. K., \& Martin, N. K. (2011). Predicting teacher retention using stress and support variables. Journal of Educational Administration, 49(2), 200-215.

Schaie, K. W. (1979). Cognitive development in aging, Paper Presented at the Conference of Language and Communication in the Elderly. Boston, Mass.

Scherer, C. (1979). Effects of early field experience on student teachers' self-concepts and performance. The Journal of Experimental Education, 47(3), 208-214.

Schmidt, W., Burroughs, N., \& Cogan, L. (2013). World class standards for preparing teachers of mathematics. (Working Paper) Center for the Study of Curriculum and The Education Policy Center. Retrieved from http://education.msu.edu/csc/pdf/World-Class-Standards-for-PreparingTeachers-of-Mathematics.pdf 
Schonfeld, I. S. (1990). Psychological distress in a sample of teachers. Journal of Psychology, 124(3), 321-338.

Schwab, R. L. \& Iwanicki, E. F. (1982). Perceived role conflict, role ambiguity, and teacher burnout. Educational Administration Quarterly, 18(1) 60-74.

Schwab, R. L. (1986). Educational burnout: Sources and consequences. Educational Research Quarterly, 10(3) 14-30.

Seidman, S. A. \& Zager, J. (1991). A study of coping behaviors and teacher burnout [Abstract], Work and Stress: An International Journal of Work, Health, \& Organizations, 5(3), 205-216.

Sellinger, S. (1972). An investigation of the effects of organizational climate and teacher anxiety on test anxiety of elementary school students. Dissertation Abstract International, 32, 5515A.

Selman, R. L. (1980). The growth of interpersonal understanding: Developmental and clinical analyses. New York, NY: Academic Press.

Selye, H. (1950), Stress and the general adaptive syndrome, British Medical Journal, 1(4667), 1384-1392.

Serpell, Z. (2000). Beginning teacher induction: A Review of the literature [Abstract]. American Association of Colleges for Teacher Education, Washington, DC.

Shadish, W. R., Cook, T. D., \& Campbell, D. T. (2002). Experimental and quasiexperimental designs for generalized casual inference. New York, NY: Houghton Mufflin.

Shoffner, M. (2008). Informal reflection in pre-service teacher education. Reflective Practice, 9(2), 123-134. 
Shuff, M., \& Shuff, R. (1972). Designed for excellence: A program for laboratory experience. Journal of Teacher Education, 23(2), 215-19.

SKyTeach. (2010). SKyTeach graduate survey [Survey-under Draft] Unpublished document. Western Kentucky University, Bowling Green, KY.

SKyTeach Overview. (2012). SKyTeach: Preparing the next generation of math and science teachers. Retrieved from wkunews.files.wordpress.com/2012/06/skyteach-2012overview.docx

Soderber, P. A. (1964). Dogmatism and the public school teacher. Journal of Teacher Education, 15(3), 245-251.

Smith, T. M. \& Ingersoll, R. M. (2004). What are the effects of induction and mentoring on beginning teacher turnover? American Educational Research Journal, 41(3), $681-714$.

Smithers, A., Robinson, P., \& Great Britain. (2003). Factors affecting teachers decisions to leave the profession. Research Report RR430, University of Liverpool. Retrieve from http:/dera.ioe.ac.uk/4759/1/RR430.pdf

Smylie, M. A. (1996). Teacher stress in time of reform. In R. Vandenberghe \& A. M. Huberman (Eds.), Understanding and preventing teacher burnout: A sourcebook of international research and practice (pp. 59-84). New York, NY: Cambridge University Press.

Spooner, M., Flowers, C., Lambert, R., \& Algozzine, B. (2008). Is more really better? Examining perceived benefits of an extended student teaching experience. Clearing House, 81(6), 263-269. 
Steele, N. A. (2010). Three characteristics of effective teachers. Applications of Research in Music Education, 28(2), 71-78.

Steffy, B. E. \& Wolfe, M. P. (2001). A life-cycle model for Career Teachers. Kappa Delta Pi Record, 38(1), 16 - 19.

Stevens, J. P. (2009). Applied multivariate statistics for the social sciences ( $5^{\text {th }}$ ed.). New York, NY: Routledge.

Strawitz, B. M. (1975). Dogmatism and the beliefs of pre-service and inservice elementary science teachers [Abstract]. Paper presented at the Annual Meeting of the National Association for Research in Science Teaching, Los Angeles, CA.

Sumsion, J. \& Thomas, P. (2006). Managing student teacher stress associated with the practicum. Journal of Early Childhood Teacher Education, 20(3), 237-336.

Sutter County Superintendent of Schools. (2012). Tri-county BTSA induction program participating teacher cost FAQ's. Retrieved from www.sutter.k12.ca.us/departments/BTSA\%20FAQ\%20Document.pdf

Teddlie, C. \& Tashakkori, A. (2009). Foundations of mixed methods research, integrating quantitative and qualitative approaches in the social and behavioral sciences. Thousand Oaks, CA: Sage.

Thompson, M. L. (1963). Identifying anxieties experienced by student teachers. Journal of Teacher Education, 14, 435-439.

Trachtman, R. (2007). Inquiry and accountability in professional development schools. Journal of Educational Research, 100(4), 197-203. 
Traister, C. A. (2005). The perceptions of student teachers, cooperating teachers, and university supervisors regarding the assessments of student teacher performance. (Doctoral dissertation). Retrieved from ProQuest. (UMI Number: 3202529)

Troman, G. \& Woods, P. (2000). Careers under stress: Teacher adaptations at a time of intensive reform. Journal of Educational Change, 1, 253-275.

Tschannen-Moran, M. \& Hoy, A. W. (2001). Teacher efficacy: Capturing and elusive construct. Teaching and Teacher Education, 17, 783-805.

Tschannen-Moran, M., Hoy, A. W., \& Hoy, W. K. (1998). Teacher efficacy: Its meaning and measure. Review of Educational Research, 68(2), 202-248.

Tunks, J. \& Weller, K. (2009). Changing practice, changing minds, from arithmetical to algebraic thinking: An application of the concerns-based adoption model (CBAM). Educational Studies in Mathematics, 72(2), 161-183.University of Chicago Laboratory Schools. (2011). Mission statement. Retrieved from http://www.ucls.uchicago.edu/about-lab/mission-statement/index.aspx University of Texas College of Education. (2007). UTeach expands nationally. Adapted from University of Texas at Austin College of natural Sciences press release [Brochure]. Austin, Tx: Kay Randall. Retrieved fromhttp://www.edb.utexas.edu/education/news/2007/uteachInst/

UTeach Curriculum. (2009). Retrieved from www.uteachinstitute.org/.../UTeach_curriculum-degree_plans.pdf

UTeach Institute. (2011). UTeach Elements of Success. University of Texas at Austin. Retrieved from http://www.uteachinstitute.org/files/uploads/uteach_institute_EOS.pdf 
UTeach Institute. (2012). UTeach National Replication. University of Texas at Austin. Retrieved from http://www.uteachinstitute.org/files/uploads/uteach_snapshot_natl.pdf

UTeach Institute. (2013). UTeach Replicating Success. University of Texas at Austin. Retrieved from http://www.uteach-institute.org/replication/detail/replication/

Van den Berg, R., Sleegers, P., and Geijsel, F. (2001). Teachers' Concerns about Adaptive Teaching: Evaluation of a Support Program. Journal of Curriculum and Supervision, 16(3), 245-258.

Veal, M. \& Rikard, L. (1998). Cooperating teachers' perspectives on the student teaching triad. Journal of Teacher Education, 49(2), 108-120.

Veenman, S. (1984). Perceived problems of beginning teachers. Review of Educational Research, 54(2), 143-178.

Villar, A. \& Strong, M. (2007). Is mentoring work the money? A benefit-cost analysis and five-year rate of return of a comprehensive mentoring program for beginning teachers, Unpublished Manuscript. Retrieved from www.maine.gov/education/teacherinduction/forms/Mentoring\%20Article.pdf Wadlington, E. M., Slaton, E., \& Partridge, M. E. (1998). Alleviating stress in the pre-service teachers during field experiences. Education, 119(2), 335.

Warnath, C. F. \& Shelton, J. L. (1976). The ultimate disappointment: The burned-out counselor. Personnel and Guidance Journal, 55(4), 172-175.

Watson, D. \& Clark, L. A. (1988). Positive and negative affectivity and their relation to anxiety and depressive disorders. Journal of Abnormal Psychology, 97(3), 346353. 
Watzke, J. L. (2007). Longitudinal study of stages of beginning teacher development in a field-based teacher education program. The Teacher Educator, 38(3), 209-229.

Weisbord, M. R. (1989). Productive Workplaces. San Francisco, CA: Jossey-Bass.

Western Kentucky University. (2005). 2005-2007 Catalog. Retrieved from http://www.collegesource.org/displayinfo/catalink.asp?pid=\{8CA0C9DC-83034CB3-AB0E-0AE73F7319A5 $\} \&$ oig $=\{$ D13770BF-69BA-4867-8C8DC936989FB5EC $\} \& v t=5$

Western Kentucky University. (2011). 2011-2012 Catalog. Retrieved from http://www.collegesource.org/displayinfo/catalink.asp?pid=\{A855C194-AFE84483-A1ED-52E35A5E858D $\} \& o i g=\{D 13770 B F-69 B A-4867-8 C 8 D-$ C936989FB5EC $\} \& v t=5$

Wideen, M., Mayer-Smith, J., \& Moon, B. (1998). A critical analysis of the research on learning to teach: Making the case for an ecological perspective on inquiry [Abstract]. Review of Education Research, 68(2), 130-178.

Wine, J. (1971). Test anxiety and direction of attention. Psychological Bulletin, 76(2), 92-104.

Yee, A. H. (1969). Do cooperating teachers influence the attitudes of student teachers? Journal of Educational Psychology, 60(4), 327-332 


\section{APPENDICES}

APPENDIX A

Initial Interview Questions

\section{Consent and Permission to Record:}

Before we begin I would like to reiterate that your participation is voluntary and that you may withdraw from the study whenever you choose. Previously, you signed an informed consent form that permits me to record today's interview; however, I would like to verbally reaffirm your permission to do so. Do you give your permission to record today's interview? Would you kindly respond with YES or NO, please?

\section{Confidentiality:}

To ensure the confidentiality of your responses, no names will be used in any publications or presentations. All data collected will omit the names of the participants and instructors. Any audio taped interviews will be anonymous, and the tapes will be destroyed one year after the study is completed. Prior to their destruction, they will be kept in locked file cabinets in the Department of Mathematics when not in use. Any concerns about anonymity are minor, especially when compared to the benefits from this research to the students and instructors of WKU STEM Teachers.

\section{Background Information:}

1. What is your name? (strictly to assist me with aligning these answers to the survey you did in class! Your name will NOT appear in any written document!)

2. What is your major?

3. What influenced your decision to become a math/science middle/secondary teacher?

4. Why did you choose to teach at the middle/secondary level?

\section{Confidence in Teaching Courses}

5. How confident are you in teaching (low level) secondary Math/Science course?

6. How confident are you in teaching (medium level) secondary Math/Science course? 


\section{Confidence in Teaching Courses (continued)}

7. How confident are you in teaching (high level) secondary Math/Science course?

8. Initially, what were your concerns about student teaching? Please be specific.

\section{Concerns surrounding teaching have been found to cluster around three different areas: Personal Concerns, Task-Related Concerns, and Impact on Student Learning Concerns. Answer the following questions to relay your level of concern on each category:}

\section{Personal Concerns}

9. What level of concern (low-medium-high) do you have in the following areas? Give a brief explanation of your answer:

Student respect, Peer respect, Professional Teachers/Principal respect, Parent respect

Performance Evaluation: Doing well when being observed, receiving favorable evaluation

Doing well when another teacher is in the room

Content Concerns: Ability to prepare adequate lesson plans

\section{Task-Related Concerns}

10. What level of concern (low-medium-high) do you have in the following areas? Give a brief explanation of your answer:

Being assigned extra duties or extra responsibilities, Administrative
disruptions
Insufficient time for planning or rest. Insufficient time for grading or
testing,
Too many students, Behavioral Disruptions, Class Management Issues
Not enough time with supervising teacher, time management issues

\section{Student Achievement Concerns}

11. What level of concern (low-medium-high) do you have in the following areas? Give a brief explanation of your answer:

Helping students value learning. Increasing student sense of accomplishment, Helping student reach their educational potential. Knowing alternative learning methods/styles Diagnosing student learning, physical, and emotional problems 


\section{Evaluation of the SKyTeach/Traditional Program}

\section{Content Areas (Math/Science Classes)}

12. How have the classes you have been attending affected your content knowledge?

13. Describe the class you liked the best and why? In which class did you learn the most? [Why?] Which class do you feel was a "waste of time"? [Why?]

14. How have the classes that you have attended prepared you to become a classroom teacher?

\section{Mentoring Areas}

15. Before this semester, who was your primary mentor in your development as a pre-service teacher? How did your mentor prepare you to assume the role of a classroom teacher?

16. How much time in a semester did you visit or come in contact your advisor/mentor? (e.g. hours, days, sessions, ...)

17. Have you discussed something with your mentor that made you reflect on a teaching incident? [Expand.]

18. How has your mentor helped you be more analytical in your observations/teaching experiences in the classroom? [Expand.]

19. Describe your mentor/induction program. (e.g. required/not required, informal/formal).

20. Do you have suggestions for improving the mentoring experience?

\section{Field Work Areas}

21. How much time have you spent in the classroom field experience before your student-teaching experience?

22. What percent of your field experience was for the purpose of

Observation, Administrative (grading papers, surveys,...)

Instructional practice (leading discussion or lesson, substitute teaching,...

Other: [Can you expand?] 
23. How have the field prepared you to assume the role of a classroom teacher? Has something happened to you or to another teacher that you would have handled differently now that you have reflected on the incident? [Expand.]

24. Has (your program) helped you be more analytical in your observations/teaching experiences? If so, how?[Expand]

25. Do you have suggestions for improving the field experiences?

26. How have preparing field lessons equipped you to assume the role of a classroom teacher?

27. Briefly describe an instance that you would change something about the lesson you presented. [How did this program help you critic your work?]

\section{Overview of Program}

28. What aspects of your educational program best prepared you for your career?

29. What improvements do you feel your educational program needs to better prepare you for your career?

\section{Concluding Questions}

30. List adjectives to describe how you feel about your (upcoming) student-teaching assignment (teaching career)? [Why did you pick these words?]

31. Can you think of anything else you would like to share?

Thank You!!!!!! 


\section{APPENDIX B}

Final Interview Questions

\section{Consent and Permission to Record:}

Before we begin I would like to reiterate that your participation is voluntary and that you may withdraw from the study whenever you choose. Previously, you signed a passive informed consent form that permits me to record today's interview; however, I would like to verbally reaffirm your permission to do so. Do you give your permission to record today's interview? Would you kindly respond with YES or NO, please?

\section{Confidentiality:}

To ensure the confidentiality of your responses etc., no names will be used in any publications or presentations. All data collected will omit the names of the participants and instructors. Any audio taped interviews will be anonymous, and the tapes will be destroyed one year after the study is completed. Prior to their destruction, they will be kept in locked file cabinets in the Department of Mathematics when not in use. Any concerns about anonymity are minor, especially when compared to the benefits from this research to the students and instructors of WKU STEM Teachers.

\section{Confidence in Teaching}

In the first round of interviews there were certain topics of concern that seemed to appear over and over again. Can you tell me on a scale of one to five (five being most concerned) how do now you feel about these topics.

\section{Self-Preservation Concerns}

1. What level of concern (low-medium-high) do you have in the following areas?

Respect of Others: Student respect, Peer respect,

Professional Teachers/Principal respect, Parent respect

Performance Evaluation: Doing well when being observed,

Receiving favorable evaluation

Doing well when another teacher is in the room

Content Concerns: Ability to prepare adequate lesson plans;

Ability to self-reflect noting beneficial aspects and

\section{Task-Related Concerns} ways to improve lesson

2. What level of concern (low-medium-high) do you have in the following areas?

Extra duties, extra responsibilities,

Administrative disruptions: Distracting from learning,

Interrupting Learning, Interrupting Assessments 
Insufficient time: for planning or rest, for grading or testing,

Management Issues: Too many students, Behavioral Disruptions, Class

Management Issues

Time issues: Not enough time with supervising teacher,

Time management issues

\section{Student Achievement Concerns}

3. What level of concern (low-medium-high) do you have in the following areas?

Helping students value learning, increasing student sense of accomplishment, Helping student reach their educational potential.

Knowing alternative learning methods/styles

Diagnosing student learning, physical, and emotional problems

[Can you expand on any of these? Most concerned /least concerned]

\section{Mentoring:}

4. Did you have opportunities to engage in dialogue with anyone regarding your concerns?(e.g. advisor, mentor, professional colleague, student blogging ...) [If so, please describe briefly.]

5. Describe how having an advisor/ mentor aiding in preparing during your student-teaching experience ( e.g. insight on classes to take, personal or academic issues resolved, overall helpful/not-helpful).

\section{Field Experience}

6. Describe what aspects of Field Experience aiding in preparing for your student-teaching experience ( e.g. insight on teaching styles, ways to address content issues, administrative aspects clarified, discipline issues explored, overall helpful/not-helpful).

7. Looking at the different types of field experience (observation, administrative, instructional practice) which would you like to have less of before student teaching? [Why?]

8. Looking at the different types of field experience (observation, administrative, instructional practice) which would you like to have more of before student teaching? [Why?]

9. Did you do any administrative field work (i.e. grading papers)while student teaching? Was it helpful? [How so/why not?] 


\section{Final Remarks}

10. What other aspects or experiences from your Teacher Education program most prepared you to deal or identify with your concerns about your student-teaching experience? Did these help during the student-teaching experience?

11. Have you secured a teaching position or do you plan to continue looking for a position in the education field? What aspect(s) of your educational program that we have discussed have encouraged (prepared) you to continue?

12. Anything else you would like to share about your teacher training experience/curriculum at this university? 


\section{APPENDIX C}

\section{Qualitative Coding}

The following is the codes for the study of STEM seniors in two pre-service programs. These are the traditional program and the SKyTeach program.

There were a total of 10 candidates used in the creation of the coding:

Focus Group: Six Participants (4 traditional and 2 SKyTeach)

Interviewees: 4 Participants (2 traditional and 2 SKyTeach)

There were two meetings of each group.

The Code (B) represents a response before the student-teaching experience

The Code (A) represents a response after the student-teaching experience.

The students 1-6 are traditional students and 7-10 are replication. 
Teacher Concerns (Example of Coding Page)

Teachers concerns have been found to follow a certain developmental pattern. These can be separated into three categories: Self-preservation concerns, Task-related concerns; and Concerns for Student Needs and Effect of Teaching- Fuller, F. F. (1969).

Concerns of teachers: A developmental conceptualization. American Educational Research Journal 6(2), $207-26$.

\begin{tabular}{|c|c|c|c|c|c|c|c|c|c|c|c|c|c|}
\hline & & & \multicolumn{8}{|c|}{ Traditional PSTs } & \multicolumn{3}{|c|}{ SKyTeach PST } \\
\hline Code & Level & Descriptor & 1 & 2 & 3 & 4 & 5 & 6 & 7 & 8 & 9 & 10 & $\mathrm{~T}$ \\
\hline SP & & $\begin{array}{l}\text { Self -Preservation concerns are manifested as personal } \\
\text { concerns like mastering subject matter knowledge, } \\
\text { classroom management, concerned about how others view } \\
\text { their teaching. }\end{array}$ & & & & & & & & & & & \\
\hline & $\mathrm{L}$ & (Low)-I am not concerned about these issues & & & & & & & & & & & \\
\hline & $\mathrm{H}$ & (High)-I am very concerned about these issues & & & & & & & & & & & \\
\hline TR & & $\begin{array}{l}\text { Task-Related Concerns are manifested in concerns of time } \\
\text { constraints, concern of class number, extra duties, behavioral } \\
\text { control issues }\end{array}$ & & & & & & & & & & & \\
\hline & $\mathrm{L}$ & (Low)-I am not concerned about these issues & & & & & & & & & & & \\
\hline & $\mathrm{H}$ & (High)-I am very concerned about these issues & & & & & & & & & & & \\
\hline SNTE & $\mathrm{L}$ & $\begin{array}{l}\text { Student Needs and Teaching Effect Concerns are } \\
\text { manifested as concerns in increasing student learning and } \\
\text { promoting emotional growth. }\end{array}$ & & & & & & & & & & & \\
\hline & $\mathrm{L}$ & (Low)-I am not concerned about these issues & & & & & & & & & & & \\
\hline & $\mathrm{H}$ & (High)-I am very concerned about these issues & & & & & & & & & & & \\
\hline
\end{tabular}


Mentoring (Example of Coding Page)- The presence of a mentor to assist in academic, professional, and emotional aspects of the pre-service teacher helps alleviate concerns in teaching assignments

\begin{tabular}{|c|c|c|c|c|c|c|c|c|c|c|c|c|c|}
\hline Code & Level & Descriptor & 1 & 2 & 3 & 4 & 5 & 6 & 7 & 8 & 9 & 10 & $\mathrm{~T}$ \\
\hline $\mathrm{M} / \mathrm{A}$ & & $\begin{array}{l}\text { Mentoring/Academic: Person(s) in mentoring capacity } \\
\text { helped pre/service teacher select course work that would } \\
\text { benefit their growth in the education field }\end{array}$ & & & & & & & & & & & \\
\hline & $\varnothing$ & Non-existent & & & & & & & & & & & \\
\hline & $\mathrm{H}$ & (Very Helpful) My mentor was very helpful in this aspect & & & & & & & & & & & \\
\hline $\mathrm{M} / \mathrm{P}$ & & $\begin{array}{c}\text { Mentoring/Professional: Person(s) in mentoring capacity } \\
\text { helped pre/service teacher with lesson plans, suggestions } \\
\text { about presentations or behavioral issues, or suggestions about } \\
\text { activities }\end{array}$ & & & & & & & & & & & \\
\hline & $\varnothing$ & Non-existent & & & & & & & & & & & \\
\hline & $\mathrm{H}$ & (Very Helpful) My mentor was very helpful in this aspect & & & & & & & & & & & \\
\hline $\mathrm{M} / \mathrm{E}$ & & $\begin{array}{l}\text { Mentoring/Emotional: Person(s) in mentoring capacity } \\
\text { helped pre/service teacher with personal/emotional concerns }\end{array}$ & & & & & & & & & & & \\
\hline & $\varnothing$ & Non-existent & & & & & & & & & & & \\
\hline & $\mathrm{H}$ & (Very Helpful) My mentor was very helpful in this aspect & & & & & & & & & & & \\
\hline & & Orher & & & & & & & & & & & \\
\hline
\end{tabular}


Field Experiences (Example of Coding Page) - the existence of field experience situations in the classroom can alleviate concern. There are three types of field experience: Observation, Administrative, Instructional practice.

\begin{tabular}{|c|c|c|c|c|c|c|c|c|c|c|c|c|c|}
\hline Code & Level & Descriptor & 1 & 2 & 3 & 4 & 5 & 6 & 7 & 8 & 9 & 10 & $\mathrm{~T}$ \\
\hline \multirow[t]{3}{*}{ FE/O } & & $\begin{array}{l}\text { Field Experience-Observation: Consisting of going into a } \\
\text { classroom for the sole purpose of observing the actions of the } \\
\text { classroom and teacher. }\end{array}$ & & & & & & & & & & & \\
\hline & $\mathrm{M}$ & $\begin{array}{l}\text { (Moderately Helpful)-This experience was moderately helpful } \\
\text { in alleviating concerns about student teaching }\end{array}$ & & & & & & & & & & & \\
\hline & $\mathrm{H}$ & $\begin{array}{l}\text { (Very Helpful) This experience was very helpful in alleviating } \\
\text { concerns about student teaching }\end{array}$ & & & & & & & & & & & \\
\hline \multirow[t]{3}{*}{$\begin{array}{l}\text { FE/A } \\
d\end{array}$} & & $\begin{array}{l}\text { Field Experience-Administration: Consisting of going into } \\
\text { a school environment to do administrative tasks like grading } \\
\text { papers, collecting money, taking roll,... }\end{array}$ & & & & & & & & & & & \\
\hline & $\mathrm{M}$ & $\begin{array}{l}\text { (Moderately Helpful)-This experience was moderately helpful } \\
\text { in alleviating concerns about student teaching }\end{array}$ & & & & & & & & & & & \\
\hline & $\mathrm{H}$ & $\begin{array}{l}\text { (Very Helpful) This experience was very helpful in alleviating } \\
\text { concerns about student teaching }\end{array}$ & & & & & & & & & & & \\
\hline \multirow[t]{3}{*}{$\mathrm{FE} / \mathrm{In}$} & & $\begin{array}{l}\text { Field Experience-Instructional Practice: Consisting of } \\
\text { going into a classroom to instruct a portion of a class, a class } \\
\text { period, or an entire day. }\end{array}$ & & & & & & & & & & & \\
\hline & $\mathrm{M}$ & $\begin{array}{l}\text { (Moderately Helpful)-This experience was moderately helpful } \\
\text { in alleviating concerns about student teaching }\end{array}$ & & & & & & & & & & & \\
\hline & $\mathrm{H}$ & $\begin{array}{l}\text { (Very Helpful) This experience was very helpful in alleviating } \\
\text { concerns }\end{array}$ & & & & & & & & & & & \\
\hline
\end{tabular}


APPENDIX D

Teacher Concerns Checklist

\section{Demographics:}

Name:

Phone:

(Your name will only be used to match up these responses to other answers.

IT WILL NOT BE USED IN THE STUDY!!!)

1. What is your age? years old

2. What is your gender?

3. Specify your race.
Male

African American/Black

Native American/ Alaska Native

Asian

Hispanic/Latino

Native Hawaiian/Pacific Islander

Caucasian Female

4. What is your major? Math

Science [Specify Area:

$\ldots$ African American/Black
Native American/ Alaska Native
Asian
H_ Hispanic/Latino
Native Hawaiian/Pacific Islander
Caucasian

Science [Specify Area:

5. What is your certification level? Middle School Secondary

6. What Teacher Preparation Program did you graduate under?

SKyTeach

Traditional 


\section{Instructions}

Please answer each of the 45 questions below. Each question has two parts, one that examines your level of concern with a particular issue, and one that examines how well your Teacher Education Program prepared you to deal with this issue.

For Part A of each question, please fill in the box that corresponds to the answer that best describes your level of concern towards the RIGHT of the question (use one of the circles in the right-hand column for each question).

For Part B, please put a checkmark in the box next to the statement that best describes how your teacher education program prepared you to deal with this challenge towards the BOTTOM of the question. Please answer every question honestly; there is no right or wrong answer.

\begin{tabular}{|c|c|}
\hline Education Program & Personal Concern \\
\hline $\begin{array}{l}\text { 1. } \begin{array}{l}\text { a. Insufficient clerical help for teachers. } \\
\text { b. Teacher Education Program prepared me to } \\
\text { address (deal with, handle) this concern ... } \\
0 \text { did not prepare me at all O prepared me a little } \\
\text { prepared me } \quad \text { prepared me well } \\
0 \text { prepared me extremely well }\end{array}\end{array}$ & $\begin{array}{l}\text { How Concerned are you } \\
\text { about this topic? } \\
\text { Not Concerned [ ] } \\
\text { A Little Concerned [ ] } \\
\text { Moderately Concerned [ ] } \\
\text { Very Concerned [ ] } \\
\text { Totally Preoccupied [ ] }\end{array}$ \\
\hline $\begin{array}{l}\text { 2. a.Whether the students respect me. } \\
\text { b. Teacher Education Program prepared me to address } \\
\text { (deal with, handle) this concern ... } \\
\text { did not prepare me at all } \bigcirc \text { prepared me a little } \\
0 \text { prepared me } \\
0 \text { prepared me extremely well }\end{array}$ & $\begin{array}{l}\text { How Concerned are you } \\
\text { about this topic? } \\
\text { Not Concerned [ ] } \\
\text { A Little Concerned [ ] } \\
\text { Moderately Concerned [ ] } \\
\text { Very Concerned [ ] } \\
\text { Totally Preoccupied }\end{array}$ \\
\hline $\begin{array}{l}\text { 3. Too many extra duties and responsibilities. } \\
\text { b. Teacher Education Program prepared me to address } \\
\text { (deal with, handle) this concern ... } \\
0 \text { did not prepare me at all } 0 \text { prepared me a little } \\
0 \text { prepared me } \\
\text { prepared me extremely well }\end{array}$ & $\begin{array}{l}\text { How Concerned are you } \\
\text { about this topic? } \\
\text { Not Concerned [ ] } \\
\text { A Little Concerned [ ] } \\
\text { Moderately Concerned [ ] } \\
\text { Very Concerned [ ] } \\
\text { Totally Preoccupied }\end{array}$ \\
\hline 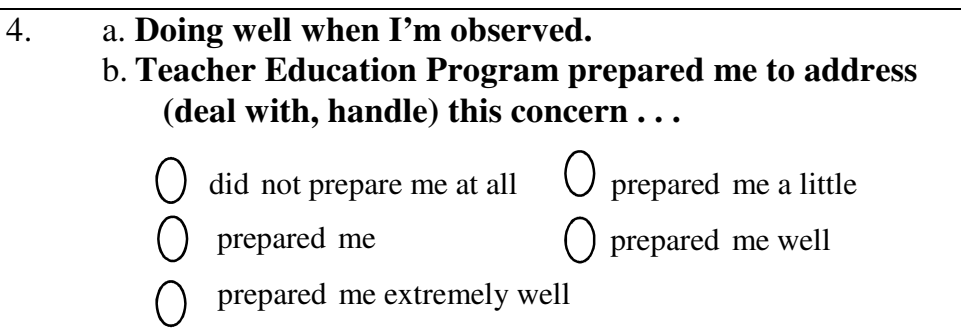 & $\begin{array}{l}\text { How Concerned are you } \\
\text { about this topic? } \\
\text { Not Concerned [ ] } \\
\text { A Little Concerned [ ] } \\
\text { Moderately Concerned [ ] } \\
\text { Very Concerned [ ] } \\
\text { Totally Preoccupied }\end{array}$ \\
\hline
\end{tabular}




\begin{tabular}{|c|c|}
\hline Education Program & Personal Concern \\
\hline $\begin{array}{l}\text { a. Helping students to value learning. } \longrightarrow \\
\text { b. Teacher Education Program prepared me to address } \\
\text { (deal with, handle) this concern ... } \\
\text { did not prepare me at all } \bigcirc \text { prepared me a little } \\
0 \text { prepared me } \quad \bigcirc \text { prepared me well } \\
0 \text { prepared me extremely well }\end{array}$ & $\begin{array}{l}\text { How Concerned are you } \\
\text { about this topic? } \\
\text { Not Concerned [ ] } \\
\text { A Little Concerned [ ] } \\
\text { Moderately Concerned [ ] } \\
\text { Very Concerned [ ] } \\
\text { Totally Preoccupied }\end{array}$ \\
\hline $\begin{array}{l}\text { 6. a. Insufficient time for rest and class preparation. } \\
\text { b. Teacher Education Program prepared me to address } \\
\text { (deal with, handle) this concern ... } \\
\text { did not prepare me at all } \bigcirc \text { prepared me a little } \\
0 \text { prepared me } \quad 0 \text { prepared me well } \\
0 \text { prepared me extremely well }\end{array}$ & $\begin{array}{l}\text { How Concerned are you } \\
\text { about this topic? } \\
\text { Not Concerned [ ] } \\
\text { A Little Concerned [ ] } \\
\text { Moderately Concerned [ ] } \\
\text { Very Concerned [ ] } \\
\text { Totally Preoccupied }\end{array}$ \\
\hline $\begin{array}{l}\text { 7. a. Not enough assistance from specialized teachers. } \\
\text { b. Teacher Education Program prepared me to address } \\
\text { (deal with, handle) this concern ... } \\
\text { did not prepare me at all } 0 \text { prepared me a little } \\
0 \text { prepared me } \\
0 \text { prepared me extremely well }\end{array}$ & $\begin{array}{l}\text { How Concerned are you } \\
\text { about this topic? } \\
\text { Not Concerned [ ] } \\
\text { A Little Concerned [ ] } \\
\text { Moderately Concerned [ ] } \\
\text { Very Concerned [ ] } \\
\text { Totally Preoccupied }\end{array}$ \\
\hline $\begin{array}{l}\text { 8. a. Managing my time efficiently. } \\
\text { b. Teacher Education Program prepared me to address } \\
\text { (deal with, handle) this concern ... } \\
0 \text { did not prepare me at all } \bigcirc \text { prepared me a little } \\
0 \text { prepared me } \quad \bigcirc \text { prepared me well } \\
0 \text { prepared me extremely well }\end{array}$ & $\begin{array}{l}\text { How Concerned are you } \\
\text { about this topic? } \\
\text { Not Concerned [ ] } \\
\text { A Little Concerned [ ] } \\
\text { Moderately Concerned [ ] } \\
\text { Very Concerned [ ] } \\
\text { Totally Preoccupied }\end{array}$ \\
\hline 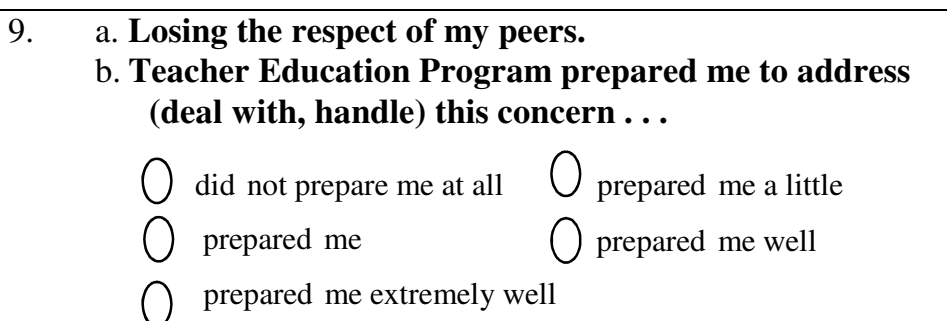 & $\begin{array}{l}\text { How Concerned are you } \\
\text { about this topic? } \\
\text { Not Concerned [ ] } \\
\text { A Little Concerned [ ] } \\
\text { Moderately Concerned [ ] } \\
\text { Very Concerned [ ] } \\
\text { Totally Preoccupied }\end{array}$ \\
\hline 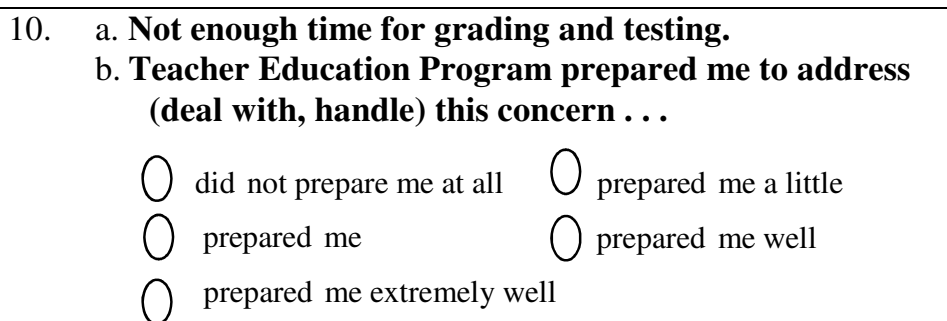 & $\begin{array}{l}\text { How Concerned are you } \\
\text { about this topic? } \\
\text { Not Concerned [ ] } \\
\text { A Little Concerned [ ] } \\
\text { Moderately Concerned [ ] } \\
\text { Very Concerned [ ] } \\
\text { Totally Preoccupied }\end{array}$ \\
\hline
\end{tabular}




\begin{tabular}{|c|c|}
\hline Education Program & Personal Concern \\
\hline $\begin{array}{l}\text { 11. The inflexibility of the curriculum. } \longrightarrow \\
\text { b. Teacher Education Program prepared me to address } \\
\text { (deal with, handle) this concern ... } \\
0 \text { did not prepare me at all } 0 \text { prepared me a little } \\
0 \text { prepared me } \quad 0 \text { prepared me well } \\
0 \text { prepared me extremely well }\end{array}$ & $\begin{array}{l}\text { How Concerned are you } \\
\text { about this topic? } \\
\text { Not Concerned [ ] } \\
\text { A Little Concerned [ ] } \\
\text { Moderately Concerned [ ] } \\
\text { Very Concerned [ ] } \\
\text { Totally Preoccupied }\end{array}$ \\
\hline $\begin{array}{l}\text { 12. a. Too many standards and regulations set for teachers. } \\
\text { b. Teacher Education Program prepared me to address } \\
\text { (deal with, handle) this concern ... } \\
0 \text { did not prepare me at all } \bigcirc \text { prepared me a little } \\
0 \text { prepared me } \\
0 \text { prepared me extremely well }\end{array}$ & $\begin{array}{l}\text { How Concerned are you } \\
\text { about this topic? } \\
\text { Not Concerned [ ] } \\
\text { A Little Concerned [ ] } \\
\text { Moderately Concerned [ ] } \\
\text { Very Concerned [ ] } \\
\text { Totally Preoccupied }\end{array}$ \\
\hline $\begin{array}{l}\text { 13. a. My ability to prepare adequate lesson plans. } \\
\text { b. Teacher Education Program prepared me to address } \\
\text { (deal with, handle) this concern ... } \\
\text { did not prepare me at all } \bigcirc \text { prepared me a little } \\
0 \text { prepared me } \\
\text { prepared me extremely well }\end{array}$ & $\begin{array}{l}\text { How Concerned are you } \\
\text { about this topic? } \\
\text { Not Concerned [ ] } \\
\text { A Little Concerned [ ] } \\
\text { Moderately Concerned [ ] } \\
\text { Very Concerned [ ] } \\
\text { Totally Preoccupied }\end{array}$ \\
\hline 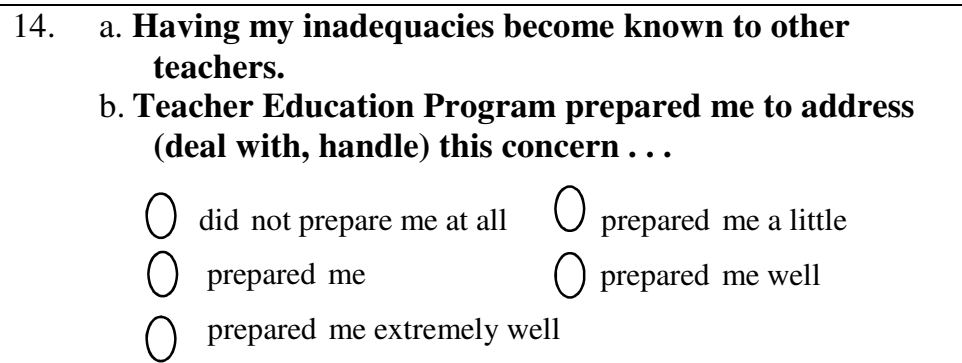 & $\begin{array}{l}\text { How Concerned are you } \\
\text { about this topic? } \\
\text { Not Concerned [ ] } \\
\text { A Little Concerned [ ] } \\
\text { Moderately Concerned [ ] } \\
\text { Very Concerned [ ] } \\
\text { Totally Preoccupied }\end{array}$ \\
\hline $\begin{array}{l}\text { 15. a. Increasing students' feelings of accomplishment. } \\
\text { b. Teacher Education Program prepared me to address } \\
\text { (deal with, handle) this concern ... } \\
\text { did not prepare me at all } 0 \text { prepared me a little } \\
0 \text { prepared me } \quad \text { prepared me well } \\
0 \text { prepared me extremely well }\end{array}$ & $\begin{array}{l}\text { How Concerned are you } \\
\text { about this topic? } \\
\text { Not Concerned [ ] } \\
\text { A Little Concerned [ ] } \\
\text { Moderately Concerned [ ] } \\
\text { Very Concerned [ ] } \\
\text { Totally Preoccupied }\end{array}$ \\
\hline 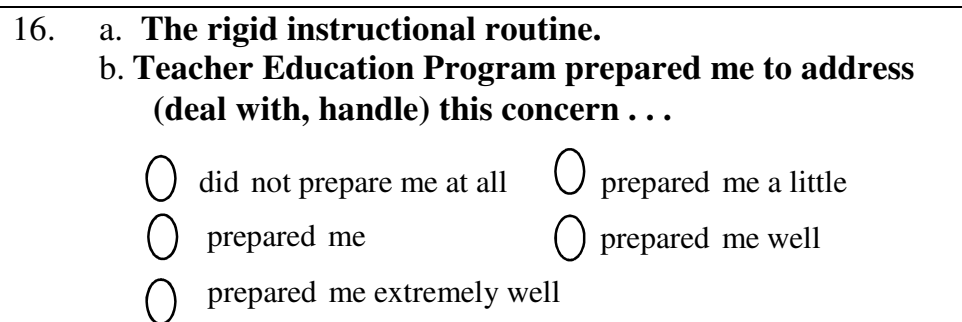 & $\begin{array}{l}\text { How Concerned are you } \\
\text { about this topic? } \\
\text { Not Concerned [ ] } \\
\text { A Little Concerned [ ] } \\
\text { Moderately Concerned [ ] } \\
\text { Very Concerned [ ] } \\
\text { Totally Preoccupied }\end{array}$ \\
\hline
\end{tabular}




\begin{tabular}{|c|c|}
\hline Education Program & Personal Concern \\
\hline $\begin{array}{l}\text { a. Diagnosing student learning problems. } \longrightarrow \\
\text { b. Teacher Education Program prepared me to address } \\
\text { (deal with, handle) this concern ... } \\
\begin{array}{l}\text { did not prepare me at all } \quad \text { prepared me a little } \\
\text { prepared me } \\
0 \text { prepared me extremely well }\end{array}\end{array}$ & $\begin{array}{l}\text { How Concerned are you } \\
\text { about this topic? } \\
\text { Not Concerned [ ] } \\
\text { A Little Concerned [ ] } \\
\text { Moderately Concerned [ ] } \\
\text { Very Concerned [ ] } \\
\text { Totally Preoccupied }\end{array}$ \\
\hline $\begin{array}{l}\text { 18. What the principal may think if there is too much } \\
\text { noise in my classroom. } \\
\text { b. Teacher Education Program prepared me to address } \\
\text { (deal with, handle) this concern ... } \\
0 \text { did not prepare me at all } 0 \text { prepared me a little } \\
0 \text { prepared me } \\
0 \text { prepared me extremely well }\end{array}$ & $\begin{array}{l}\text { How Concerned are you } \\
\text { about this topic? } \\
\text { Not Concerned [ ] } \\
\text { A Little Concerned [ ] } \\
\text { Moderately Concerned [ ] } \\
\text { Very Concerned [ ] } \\
\text { Totally Preoccupied }\end{array}$ \\
\hline $\begin{array}{l}\text { 19. a. Whether each student is reaching his or her potential. } \\
\text { b. Teacher Education Program prepared me to address } \\
\text { (deal with, handle) this concern ... } \\
\text { did not prepare me at all } 0 \text { prepared me a little } \\
0 \text { prepared me } \\
0 \text { prepared me extremely well }\end{array}$ & $\begin{array}{l}\text { How Concerned are you } \\
\text { about this topic? } \\
\text { Not Concerned [ ] } \\
\text { A Little Concerned [ ] } \\
\text { Moderately Concerned [ ] } \\
\text { Very Concerned [ ] } \\
\text { Totally Preoccupied }\end{array}$ \\
\hline $\begin{array}{l}20 \text { a. Obtaining a favorable evaluation of my teaching. } \\
\text { b. Teacher Education Program prepared me to address } \\
\text { (deal with, handle) this concern ... } \\
\text {. } \\
\text { did not prepare me at all } 0 \text { prepared me a little } \\
0 \text { prepared me } \quad 0 \text { prepared me well } \\
0 \text { prepared me extremely well }\end{array}$ & $\begin{array}{l}\text { How Concerned are you } \\
\text { about this topic? } \\
\text { Not Concerned [ ] } \\
\text { A Little Concerned [ ] } \\
\text { Moderately Concerned [ ] } \\
\text { Very Concerned [ ] } \\
\text { Totally Preoccupied }\end{array}$ \\
\hline $\begin{array}{l}\text { 21. a. Having too many students in a class. } \\
\text { b. Teacher Education Program prepared me to address } \\
\text { (deal with, handle) this concern ... } \\
\text { did not prepare me at all } 0 \text { prepared me a little } \\
0 \text { prepared me } \quad 0 \text { prepared me well } \\
0 \text { prepared me extremely well }\end{array}$ & $\begin{array}{l}\text { How Concerned are you } \\
\text { about this topic? } \\
\text { Not Concerned [ ] } \\
\text { A Little Concerned [ ] } \\
\text { Moderately Concerned [ ] } \\
\text { Very Concerned [ ] } \\
\text { Totally Preoccupied }\end{array}$ \\
\hline $\begin{array}{l}22 \text { a. Recognizing the social and emotional needs of the } \\
\text { students. } \\
\text { b. Teacher Education Program prepared me to address } \\
\text { (deal with, handle) this concern ... } \\
\text { did not prepare me at all } \bigcirc \text { prepared me a little } \\
\text { prepared me } \\
0 \text { prepared me extremely well }\end{array}$ & $\begin{array}{l}\text { How Concerned are you } \\
\text { about this topic? } \\
\text { Not Concerned [ ] } \\
\text { A Little Concerned [ ] } \\
\text { Moderately Concerned [ ] } \\
\text { Very Concerned [ ] } \\
\text { Totally Preoccupied }\end{array}$ \\
\hline
\end{tabular}




\begin{tabular}{|c|c|}
\hline Education Program & Personal Concern \\
\hline $\begin{array}{l}\text { 23. a. Challenging unmotivated students. } \longrightarrow \\
\text { b. Teacher Education Program prepared me to address } \\
\text { (deal with, handle) this concern ... } \\
\text {. did not prepare me at all } \bigcirc \text { prepared me a little } \\
0 \text { prepared me } \quad 0 \text { prepared me well } \\
0 \text { prepared me extremely well }\end{array}$ & $\begin{array}{l}\text { How Concerned are you } \\
\text { about this topic? } \\
\text { Not Concerned [ ] } \\
\text { A Little Concerned [ ] } \\
\text { Moderately Concerned [ ] } \\
\text { Very Concerned [ ] } \\
\text { Totally Preoccupied }\end{array}$ \\
\hline $\begin{array}{l}24 \text { a. Losing the respect of my students. } \\
\text { b. Teacher Education Program prepared me to address } \\
\text { (deal with, handle) this concern ... } \\
\text { did not prepare me at all } 0 \text { prepared me a little } \\
0 \text { prepared me } \quad 0 \text { prepared me well } \\
0 \text { prepared me extremely well }\end{array}$ & $\begin{array}{l}\text { How Concerned are you } \\
\text { about this topic? } \\
\text { Not Concerned [ ] } \\
\text { A Little Concerned [ ] } \\
\text { Moderately Concerned [ ] } \\
\text { Very Concerned [ ] } \\
\text { Totally Preoccupied }\end{array}$ \\
\hline $\begin{array}{l}\text { 25. a. Lack of public support for schools. } \\
\text { b. Teacher Education Program prepared me to address } \\
\text { (deal with, handle) this concern ... } \\
\text { did not prepare me at all } \bigcirc \text { prepared me a little } \\
0 \text { prepared me } \quad 0 \text { prepared me well } \\
0 \text { prepared me extremely well }\end{array}$ & $\begin{array}{l}\text { How Concerned are you } \\
\text { about this topic? } \\
\text { Not Concerned [ ] } \\
\text { A Little Concerned [ ] } \\
\text { Moderately Concerned [ ] } \\
\text { Very Concerned [ ] } \\
\text { Totally Preoccupied }\end{array}$ \\
\hline $\begin{array}{l}\text { 26. My ability to maintain the appropriate degree of class } \\
\text { control. } \\
\text { b. Teacher Education Program prepared me to address } \\
\text { (deal with, handle) this concern ... } \\
\text { did not prepare me at all } \bigcirc \text { prepared me a little } \\
0 \text { prepared me } \\
0 \text { prepared me extremely well }\end{array}$ & $\begin{array}{l}\text { How Concerned are you } \\
\text { about this topic? } \\
\text { Not Concerned [ ] } \\
\text { A Little Concerned [ ] } \\
\text { Moderately Concerned [ ] } \\
\text { Very Concerned [ ] } \\
\text { Totally Preoccupied }\end{array}$ \\
\hline $\begin{array}{l}27 \text { a. Not having sufficient time to plan. } \\
\text { b. Teacher Education Program prepared me to address } \\
\text { (deal with, handle) this concern ... } \\
\text { did not prepare me at all } \bigcirc \text { prepared me a little } \\
0 \text { prepared me } \quad 0 \text { prepared me well } \\
0 \text { prepared me extremely well }\end{array}$ & $\begin{array}{l}\text { How Concerned are you } \\
\text { about this topic? } \\
\text { Not Concerned [ ] } \\
\text { A Little Concerned [ ] } \\
\text { Moderately Concerned [ ] } \\
\text { Very Concerned [ ] } \\
\text { Totally Preoccupied }\end{array}$ \\
\hline $\begin{array}{l}\text { 28. a. Getting students to behave. } \\
\text { b. Teacher Education Program prepared me to address } \\
\text { (deal with, handle) this concern ... } \\
\text { did not prepare me at all } O \text { prepared me a little } \\
0 \text { prepared me } \quad 0 \text { prepared me well } \\
0 \text { prepared me extremely well }\end{array}$ & $\begin{array}{l}\text { How Concerned are you } \\
\text { about this topic? } \\
\text { Not Concerned [ ] } \\
\text { A Little Concerned [ ] } \\
\text { Moderately Concerned [ ] } \\
\text { Very Concerned [ ] } \\
\text { Totally Preoccupied }\end{array}$ \\
\hline
\end{tabular}




\begin{tabular}{|c|c|}
\hline Education Program & Personal Concern \\
\hline $\begin{array}{l}\text { 29. a. Understanding why certain students make slow } \\
\text { progress. } \\
\text { b. Teacher Education Program prepared me to address } \\
\text { (deal with, handle) this concern ... } \\
0 \text { did not prepare me at all } \bigcirc \text { prepared me a little } \\
0 \text { prepared me } \quad \bigcirc \text { prepared me well } \\
0 \text { prepared me extremely well }\end{array}$ & $\begin{array}{l}\text { How Concerned are you } \\
\text { about this topic? } \\
\text { Not Concerned [ ] } \\
\text { A Little Concerned [ ] } \\
\text { Moderately Concerned [ ] } \\
\text { Very Concerned [ ] } \\
\text { Totally Preoccupied }\end{array}$ \\
\hline $\begin{array}{l}\text { 30. a. Having an embarrassing incident occur in my } \\
\text { classroom for which I might be judged responsible. } \\
\text { b. Teacher Education Program prepared me to address } \\
\text { (deal with, handle) this concern ... } \\
\text { did not prepare me at all } \bigcirc \text { prepared me a little } \\
0 \text { prepared me } \quad \bigcirc \text { prepared me well } \\
0 \text { prepared me extremely well }\end{array}$ & $\begin{array}{l}\text { How Concerned are you } \\
\text { about this topic? } \\
\text { Not Concerned [ ] } \\
\text { A Little Concerned [ ] } \\
\text { Moderately Concerned [ ] } \\
\text { Very Concerned [ ] } \\
\text { Totally Preoccupied }\end{array}$ \\
\hline $\begin{array}{l}\text { 31. a. Not being able to cope with trouble-makers in } \\
\text { my classes. } \\
\text { b. Teacher Education Program prepared me to address } \\
\text { (deal with, handle) this concern ... } \\
0 \text { did not prepare me at all } 0 \text { prepared me a little } \\
0 \text { prepared me } \\
0 \text { prepared me extremely well }\end{array}$ & $\begin{array}{l}\text { How Concerned are you } \\
\text { about this topic? } \\
\text { Not Concerned [ ] } \\
\text { A Little Concerned [ ] } \\
\text { Moderately Concerned [ ] } \\
\text { Very Concerned [ ] } \\
\text { Totally Preoccupied }\end{array}$ \\
\hline $\begin{array}{l}32 \text { a. That my peers may think I'm not doing an } \\
\text { adequate job. } \\
\text { b. Teacher Education Program prepared me to address } \\
\text { (deal with, handle) this concern ... } \\
\text { did not prepare me at all } 0 \text { prepared me a little } \\
0 \text { prepared me } \\
0 \text { prepared me extremely well }\end{array}$ & $\begin{array}{l}\text { How Concerned are you } \\
\text { about this topic? } \\
\text { Not Concerned [ ] } \\
\text { A Little Concerned [ ] } \\
\text { Moderately Concerned [ ] } \\
\text { Very Concerned [ ] } \\
\text { Totally Preoccupied }\end{array}$ \\
\hline $\begin{array}{l}\text { 33. a. My ability to work with disruptive students. } \\
\text { b. Teacher Education Program prepared me to address } \\
\text { (deal with, handle) this concern ... } \\
\text {. } \\
\text { did not prepare me at all } 0 \text { prepared me a little } \\
\text { prepared me prepared me extremely well }\end{array}$ & $\begin{array}{l}\text { How Concerned are you } \\
\text { about this topic? } \\
\text { Not Concerned [ ] } \\
\text { A Little Concerned [ ] } \\
\text { Moderately Concerned [ ] } \\
\text { Very Concerned [ ] } \\
\text { Totally Preoccupied }\end{array}$ \\
\hline
\end{tabular}




\begin{tabular}{|c|c|c|}
\hline \multicolumn{2}{|r|}{ Education Program } & Personal Concern \\
\hline & $\begin{array}{l}\text { a. Understanding ways in which student health and } \\
\text { nutrition problems can affect learning. } \\
\text { b. Teacher Education Program prepared me to address } \\
\text { (deal with, handle) this concern... } \\
\text { did not prepare me at all } \quad \text { prepared me a little } \\
\text { prepared me } \\
\text { prepared me extremely well }\end{array}$ & $\begin{array}{l}\text { How Concerned are you } \\
\text { about this topic? } \\
\text { Not Concerned [ ] } \\
\text { A Little Concerned [ ] } \\
\text { Moderately Concerned [ ] } \\
\text { Very Concerned [ ] } \\
\text { Totally Preoccupied }\end{array}$ \\
\hline & $\begin{array}{l}\text { a. Appearing competent to parents. } \\
\text { b. Teacher Education Program prepared me to address } \\
\text { (deal with, handle) this concern ... } \\
\text { did not prepare me at all } \bigcirc \text { prepared me a little } \\
\text { prepared me } \quad \bigcirc \text { prepared me well } \\
0 \text { prepared me extremely well }\end{array}$ & $\begin{array}{l}\text { How Concerned are you } \\
\text { about this topic? } \\
\text { Not Concerned [ ] } \\
\text { A Little Concerned [ ] } \\
\text { Moderately Concerned [ ] } \\
\text { Very Concerned [ ] } \\
\text { Totally Preoccupied }\end{array}$ \\
\hline & $\begin{array}{l}\text { a. Meeting the needs of different kinds of students. } \\
\text { b. Teacher Education Program prepared me to address } \\
\text { (deal with, handle) this concern... } \\
\begin{array}{l}\text { did not prepare me at all } \\
\text { prepared me a little } \\
\text { prepared me }\end{array} \text { prepared me well } \\
0 \text { prepared me extremely }\end{array}$ & $\begin{array}{l}\text { How Concerned are you } \\
\text { about this topic? } \\
\text { Not Concerned [ ] } \\
\text { A Little Concerned [ ] } \\
\text { Moderately Concerned [ ] } \\
\text { Very Concerned [ ] } \\
\text { Totally Preoccupied }\end{array}$ \\
\hline & $\begin{array}{l}\text { a. Seeking alternative ways to ensure that students learn } \\
\text { the subject matter. } \\
\text { b. Teacher Education Program prepared me to address } \\
\text { (deal with, handle) this concern ... } \\
\text { did not prepare me at all } \bigcirc \text { prepared me a little } \\
0 \text { prepared me } \\
\text { prepared me extremely well }\end{array}$ & $\begin{array}{l}\text { How Concerned are you } \\
\text { about this topic? } \\
\text { Not Concerned [ ] } \\
\text { A Little Concerned [ ] } \\
\text { Moderately Concerned [ ] } \\
\text { Very Concerned [ ] } \\
\text { Totally Preoccupied }\end{array}$ \\
\hline & $\begin{array}{l}\text { a. Understanding the psychological and cultural } \\
\text { differences, } \\
\text { b. Teacher Education Program prepared me to address } \\
\text { (deal with, handle) this concern ... } \\
\text { did not prepare me at all } \bigcirc \text { prepared me a little } \\
\text { prepared me } \\
\text { prepared me extremely well }\end{array}$ & $\begin{array}{l}\text { How Concerned are you } \\
\text { about this topic? } \\
\text { Not Concerned [ ] } \\
\text { A Little Concerned [ ] } \\
\text { Moderately Concerned [ ] } \\
\text { Very Concerned [ ] } \\
\text { Totally Preoccupied }\end{array}$ \\
\hline 39 & $\begin{array}{l}\text { a. Adapting myself to the needs of different students. } \\
\text { b. Teacher Education Program prepared me to address } \\
\text { (deal with, handle) this concern ... } \\
\text { did not prepare me at all } \quad \text { prepared me a little } \\
\text { prepared me } \\
\text { prepared me extremely well }\end{array}$ & $\begin{array}{l}\text { How Concerned are you } \\
\text { about this topic? } \\
\text { Not Concerned [ ] } \\
\text { A Little Concerned [ ] } \\
\text { Moderately Concerned [ ] } \\
\text { Very Concerned [ ] } \\
\text { Totally Preoccupied }\end{array}$ \\
\hline
\end{tabular}




\begin{tabular}{|c|c|}
\hline Education Program & Personal Concern \\
\hline 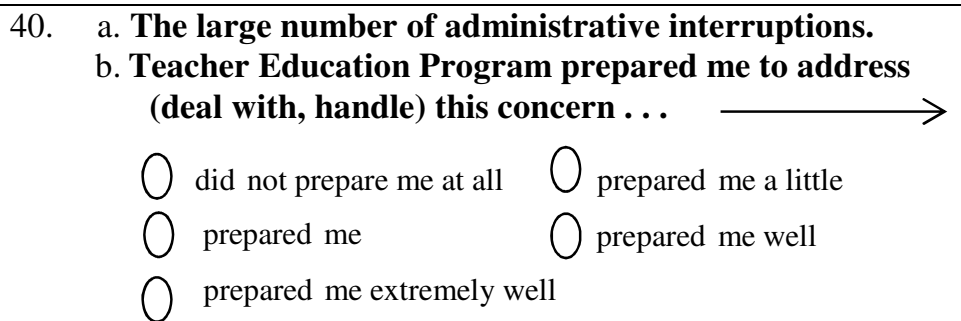 & $\begin{array}{l}\text { How Concerned are you } \\
\text { about this topic? } \\
\text { Not Concerned [ ] } \\
\text { A Little Concerned [ ] } \\
\text { Moderately Concerned [ ] } \\
\text { Very Concerned [ ] } \\
\text { Totally Preoccupied }\end{array}$ \\
\hline $\begin{array}{l}\text { 41. a. Guiding students toward intellectual and emotional } \\
\text { growth. } \\
\text { b. Teacher Education Program prepared me to address } \\
\text { (deal with, handle) this concern ... } \\
0 \text { did not prepare me at all } \bigcirc \text { prepared me a little } \\
0 \text { prepared me } \\
0 \text { prepared me extremely well }\end{array}$ & $\begin{array}{l}\text { How Concerned are you } \\
\text { about this topic? } \\
\text { Not Concerned [ ] } \\
\text { A Little Concerned [ ] } \\
\text { Moderately Concerned [ ] } \\
\text { Very Concerned [ ] } \\
\text { Totally Preoccupied }\end{array}$ \\
\hline 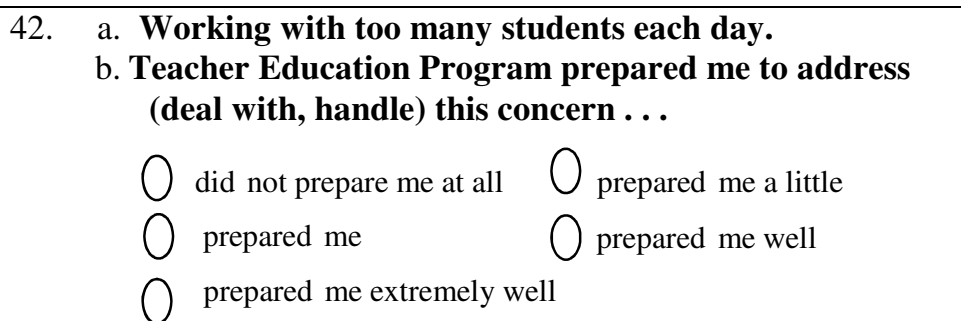 & $\begin{array}{l}\text { How Concerned are you } \\
\text { about this topic? } \\
\text { Not Concerned [ ] } \\
\text { A Little Concerned [ ] } \\
\text { Moderately Concerned [ ] } \\
\text { Very Concerned [ ] } \\
\text { Totally Preoccupied }\end{array}$ \\
\hline 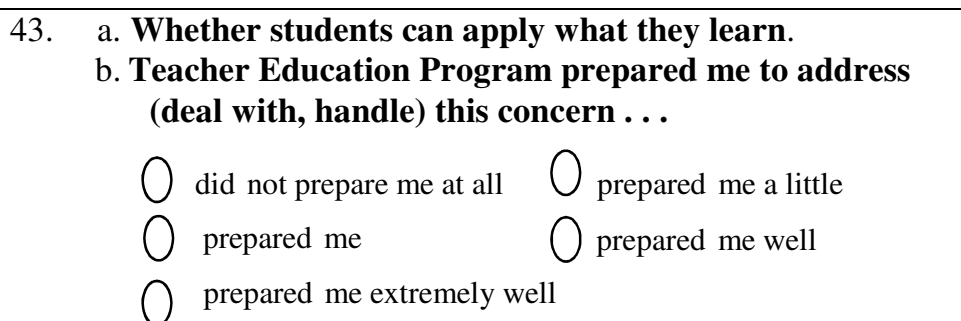 & $\begin{array}{l}\text { How Concerned are you } \\
\text { about this topic? } \\
\text { Not Concerned [ ] } \\
\text { A Little Concerned [ ] } \\
\text { Moderately Concerned [ ] } \\
\text { Very Concerned [ ] } \\
\text { Totally Preoccupied }\end{array}$ \\
\hline $\begin{array}{l}\text { 44. a. Teaching effectively when another teacher is present. } \\
\text { b. Teacher Education Program prepared me to address } \\
\text { (deal with, handle) this concern ... } \\
\text {. } \\
\text { did not prepare me at all } 0 \text { prepared me a little } \\
\text { prepared me } \quad 0 \text { prepared me well } \\
\text { prepared me extremely well }\end{array}$ & $\begin{array}{l}\text { How Concerned are you } \\
\text { about this topic? } \\
\text { Not Concerned [ ] } \\
\text { A Little Concerned [ ] } \\
\text { Moderately Concerned [ ] } \\
\text { Very Concerned [ ] } \\
\text { Totally Preoccupied }\end{array}$ \\
\hline $\begin{array}{l}\text { 45. a. Understanding what factors motivate students to learn. } \\
\text { b. Teacher Education Program prepared me to address } \\
\text { (deal with, handle) this concern ... } \\
\text {. } \\
\text { did not prepare me at all } 0 \text { prepared me a little } \\
\text { prepared me } \quad 0 \text { prepared me well } \\
0 \text { prepared me extremely well }\end{array}$ & $\begin{array}{l}\text { How Concerned are you } \\
\text { about this topic? } \\
\text { Not Concerned [ ] } \\
\text { A Little Concerned [ ] } \\
\text { Moderately Concerned [ ] } \\
\text { Very Concerned [ ] } \\
\text { Totally Preoccupied }\end{array}$ \\
\hline
\end{tabular}




\section{Answer honestly, please:}

\section{Mentoring:}

46. Do you have opportunities to engage in dialogue with anyone regarding your concerns?(e.g. advisor, mentor, professional colleague, ...) If so, please describe briefly.

47. How much time in a semester did you visit or contact your advisor/mentor? (e.g. hours, days, sessions, ...)

48. Describe your mentor/induction program. (e.g. required/not required, informal/formal).

49. Describe how having an advisor/ mentor aiding in preparing for your student-teaching experience (e.g. insight on classes to take, personal or academic issues resolved, overall helpful/not-helpful). 


\section{Field Experience}

50. How much time have you spent in the classroom field experience Before your student-teaching experience?

51. What percent of your field experience was for the purpose of

\% Observation, $\quad \ldots \begin{array}{r}\% \text { Administrative (grading papers, } \\ \text { surveys,...) }\end{array}$
\% Instructional practice (leading discussion or lesson, substitute
teaching,...
$\%$ Other:

52. Describe what aspects of Field Experience aiding in preparing for your student-teaching experience (e.g. insight on teaching styles, ways to address content issues , administrative aspects clarified, discipline issues explored, overall helpful/not-helpful).

\section{Final Remarks}

53. What other aspects or experiences from your Teacher Education program most prepared you to deal or identify with your concerns about your student-teaching experience?

54. Anything else you would like to share about your teacher training experience/curriculum at this university?

\section{Thank you for being a part of this study.}




\author{
APPENDIX E \\ Assorted Tables of Concern \\ Containing Open-Ended Responses
}

Table 7B

Ratio of Responses related to Self-Preservation Concerns throughout the Study (includes open-ended responses)

\begin{tabular}{cccc}
\hline & Before & After & During \\
\hline & \multicolumn{3}{c}{ High Concerns } \\
\cline { 2 - 4 } Traditional $(\mathrm{n}=21)$ & 0.9 & .67 & 0.67 \\
& $(T=21)$ & $(T=21)$ & $(T=9)$ \\
SKyTeach $(\mathrm{n}=38)$ & 0.82 & 0.41 & 0.83 \\
& $(S=17)$ & $(S=17)$ & $(S=6)$ \\
\cline { 2 - 4 } & & Confident (not Concerned) \\
Traditional $(\mathrm{n}=21)$ & 0.43 & 0.19 & 0.78 \\
& $(T=21)$ & $(T=21)$ & $(T=9)$ \\
SKyTeach $(\mathrm{n}=38)$ & 0.94 & 0.76 & 0.17 \\
& $(S=17)$ & $(S=17)$ & $(S=6)$ \\
\hline
\end{tabular}

Notes. Values in the table cells are ratio of responses-per-person.

$\mathrm{T}$ designates the number of possible contributing Traditional PST participants. S designates the number of possible contributing SKyTeach PST participants. Groups within a program are not independent. 
Table 10B

Ratio of Responses related to Task-Related Concerns throughout the Study (includes open-ended responses)

\begin{tabular}{cccc}
\hline & Before & After & During \\
\hline & \multicolumn{3}{c}{ High Concerns } \\
& \multicolumn{3}{c}{0.48} \\
Traditional $(\mathrm{n}=21)$ & 0.24 & $(T=21)$ & 1.22 \\
& $(T=21)$ & 0.41 & $(T=9)$ \\
SKyTeach $(\mathrm{n}=38)$ & 0.53 & $(S=17)$ & 1.0 \\
& $(S=17)$ & Confident (not Concerned) \\
\cline { 2 - 4 } & \multicolumn{3}{c}{0.14} \\
Traditional $(\mathrm{n}=21)$ & 0.095 & $(T=21)$ & 0.11 \\
& $(T=21)$ & 0.24 & $(T=9)$ \\
SKyTeach $(\mathrm{n}=38)$ & 0.24 & $(S=17)$ & 0.17 \\
& $(S=17)$ & $S=6)$
\end{tabular}

Notes. Values in the table cells are ratio of responses-per-person.

$\mathrm{T}$ designates the number of possible Traditional PSTs in that data category. S designates the number of possible SKyTeach PSTs in that data category. Groups within a program are not independent.

Table 13B

Ratio of Responses related to Student-Impact Related Concerns throughout the Study (includes open-ended responses)

Before $\quad$ After $\quad$ During

High Concern for Student Well-Being

\begin{tabular}{lccc} 
& 0.38 & 0.62 & 1.7 \\
Traditional $(\mathrm{n}=21)$ & $(T=21)$ & $(T=21)$ & $(T=9)$ \\
& 1.12 & 1.29 & 2.3 \\
SKyTeach $(\mathrm{n}=38)$ & $(S=17)$ & $(S=17)$ & $(S=6)$ \\
\cline { 2 - 4 }
\end{tabular}

Lack of Concern for Student Well-Being

$\begin{array}{lccc}\text { Traditional }(\mathrm{n}=21) & 0.0 & 0.0 & 0.8 \\ & (T=21) & (T=21) & (T=9) \\ \text { SKyTeach }(\mathrm{n}=38) & 0.12 & 0.06 & 0.7 \\ & (S=17) & (S=17) & (S=6)\end{array}$

Notes. Values in the table cells are ratio of responses-per-person.

$\mathrm{T}$ designates the number of possible Traditional PSTs in that data category. S designates the number of possible SKyTeach PSTs in that data category. Groups within a program are not independent. 


\section{CURRICULUM VITA}

NAME:

ADDRESS:

DOB:

EDUCATION

\& TRAINING
Twyla Diane Harris

Department of Mathematics

1906 College Heights Boulevard

College Heights Hall 3115

Western Kentucky University

Bowling Green, KY 42101

Knoxville, Tennessee - June 22, 1959

B.S., Mathematics

Belmont College

May, 1983

M. A. Mathematics Education

Western Kentucky University

May, 1983

Ed. S. Secondary Mathematics Education

Western Kentucky University

May, 2008

Ph. D. Middle and Secondary Mathematics Education University of Louisville

May, 2015

Williamson County Teacher of the Month

Franklin, Tennessee

1988

Kappa Delta Pi's Outstanding Student Teacher Award Belmont College

Nashville, Tennessee

1983 
PROFESSIONAL SOCIETIES:

Western Kentucky Council of Teachers of Mathematics Acting President 2015

$2013-2015$

National Council of Teachers of Mathematics $2009-2015$

Pi Mu Epsilon

$2000-2015$

Association of Mathematics Teacher Educators $2011-2012$

PUBLICATIONS: The Effects of Two Homework Assessment Schemes and At Risk Student Performance in College Algebra Education Specialist's Thesis

May, 2008

Peanut Butter Sandwiches

Mathematical Moments

Center of Excellence for the Enrichment of Science and Mathematics Education University of Tennessee at Martin

May, 1988

\section{INVITED PRESENTATIONS:}

"An Interactive Approach to Solving Basic Absolute Value Equations"

Western Kentucky Council of Teachers of Mathematics Bowling Green, KY

April 24, 2014

"A Conceptual Construct of Integers" - Co-speaker Kentucky Center for Mathematics Conference Lexington, $\mathrm{KY}$

February 25, 2011

"Financial Mathematics with TI-83 or TI-84"-Co-speaker Western Kentucky Council of Teachers of Mathematics Bowling Green, KY

November 9, 2006 
"The Use of Manipulatives and Evaluation Procedures in the Elementary Mathematics Classroom"

Bowling Green, KY

August 2, 2002 